\title{
Economic consequences of public oversight of the auditing profession
}

Citation for published version (APA):

Zou, L. (2017). Economic consequences of public oversight of the auditing profession: insights from the capital and audit market. [Doctoral Thesis, Maastricht University]. Datawyse / Universitaire Pers Maastricht. https://doi.org/10.26481/dis.20171220lz

Document status and date:

Published: 01/01/2017

DOI:

10.26481/dis.20171220lz

Document Version:

Publisher's PDF, also known as Version of record

\section{Please check the document version of this publication:}

- A submitted manuscript is the version of the article upon submission and before peer-review. There can be important differences between the submitted version and the official published version of record.

People interested in the research are advised to contact the author for the final version of the publication, or visit the DOI to the publisher's website.

- The final author version and the galley proof are versions of the publication after peer review.

- The final published version features the final layout of the paper including the volume, issue and page numbers.

Link to publication

\footnotetext{
General rights rights.

- You may freely distribute the URL identifying the publication in the public portal. please follow below link for the End User Agreement:

www.umlib.nl/taverne-license

Take down policy

If you believe that this document breaches copyright please contact us at:

repository@maastrichtuniversity.nl

providing details and we will investigate your claim.
}

Copyright and moral rights for the publications made accessible in the public portal are retained by the authors and/or other copyright owners and it is a condition of accessing publications that users recognise and abide by the legal requirements associated with these

- Users may download and print one copy of any publication from the public portal for the purpose of private study or research.

- You may not further distribute the material or use it for any profit-making activity or commercial gain

If the publication is distributed under the terms of Article $25 \mathrm{fa}$ of the Dutch Copyright Act, indicated by the "Taverne" license above, 
Economic Consequences of Public Oversight

of the Auditing Profession:

Insights from the Capital and Audit Market 


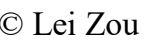

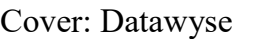

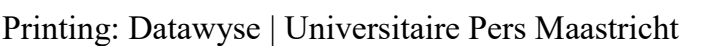

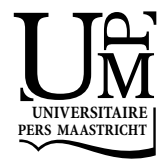

ISBN: 9789461597885 


\title{
ECONOMIC CONSEQUENCES OF PUBLIC OVERSIGHT OF THE AUDITING PROFESSION:
}

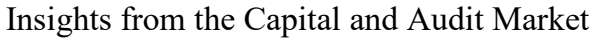

\section{DISSERTATION}

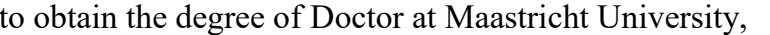

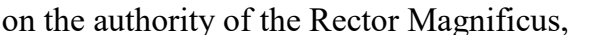

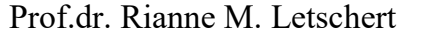

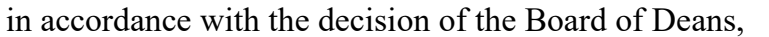

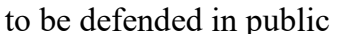

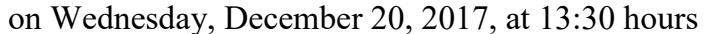

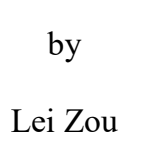




\section{Supervisor:}

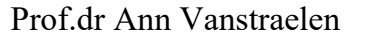

\section{Co-Supervisor:}

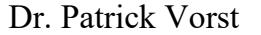

Assessment Committee:

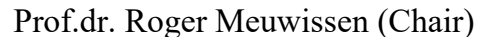

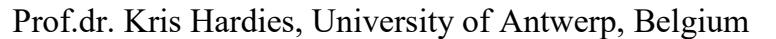

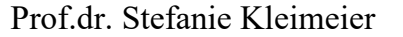

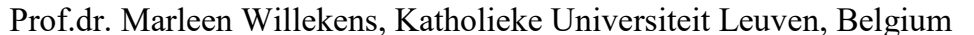




\section{Acknowledgements}

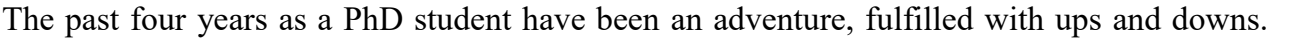

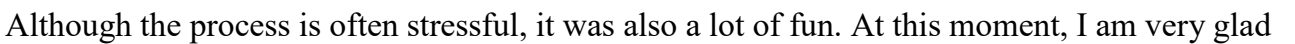

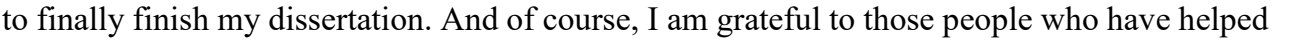

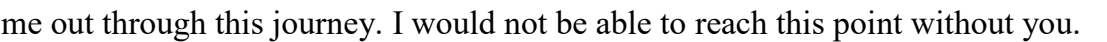

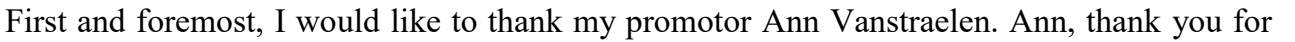

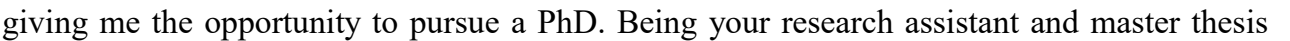

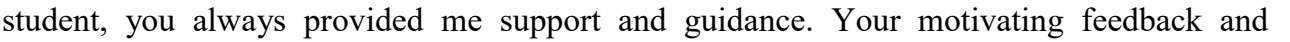

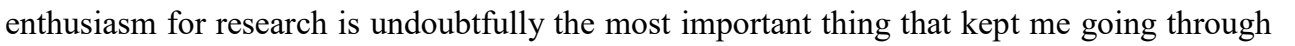

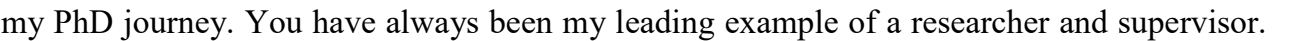

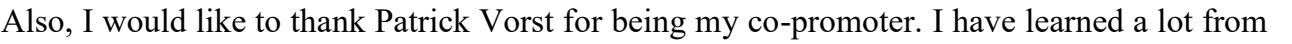

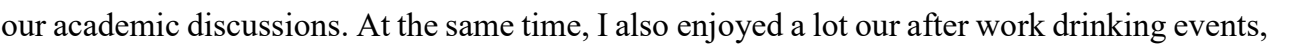

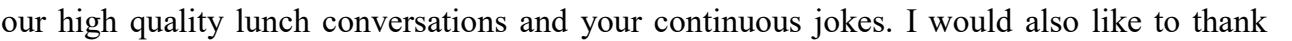

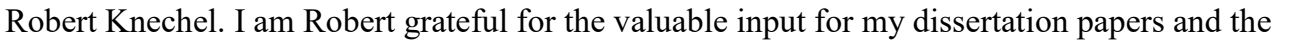

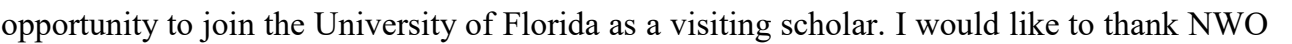

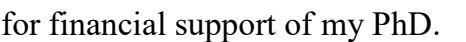

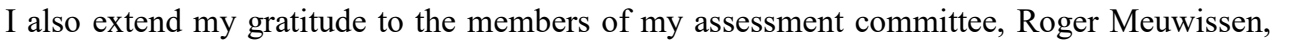

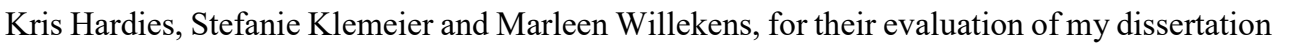

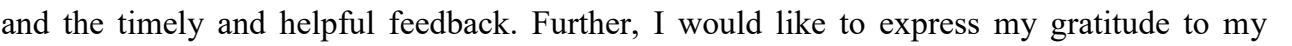

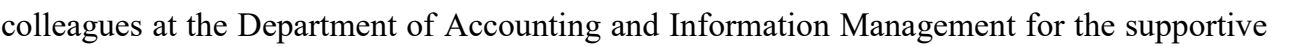

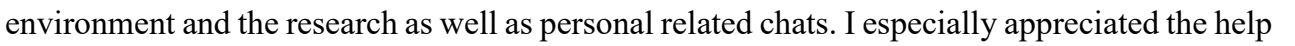

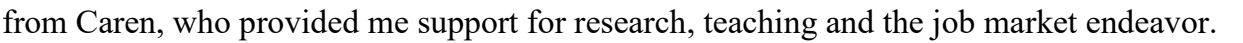

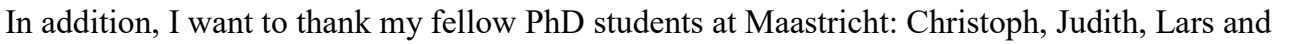

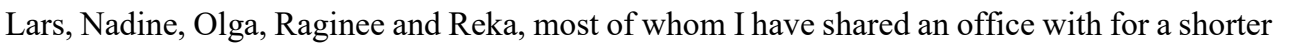

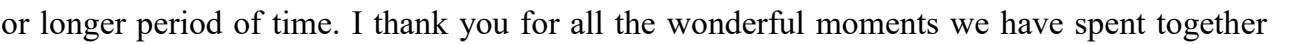

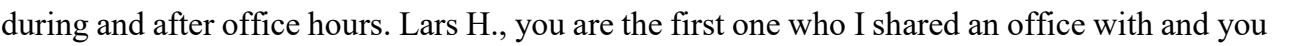

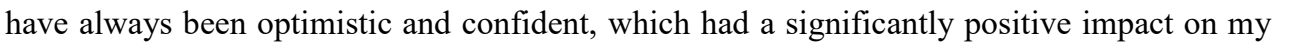

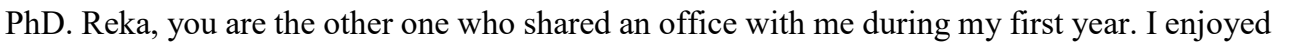

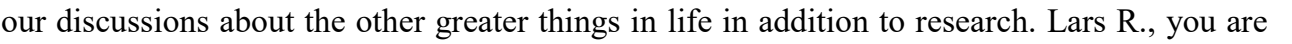

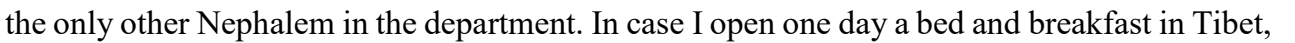

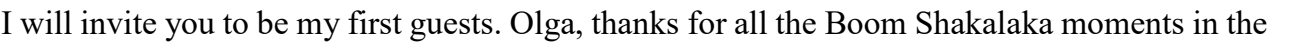

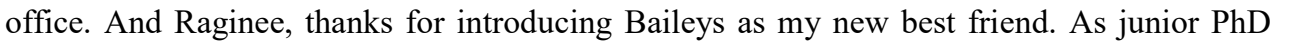

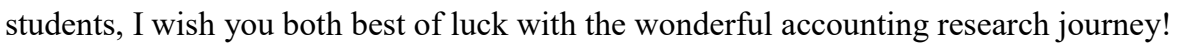

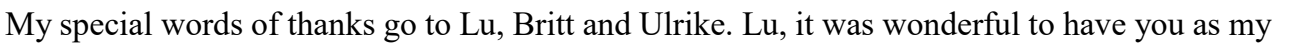

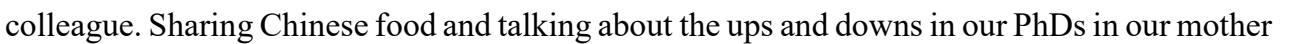

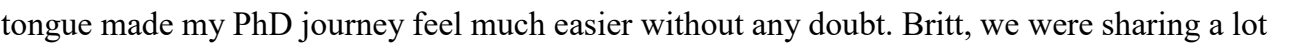

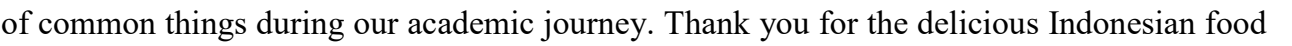

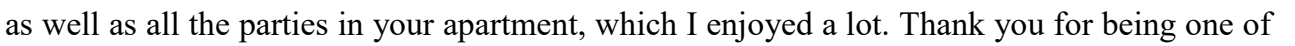

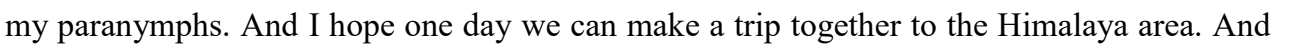

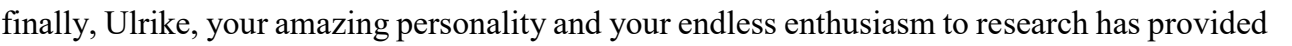




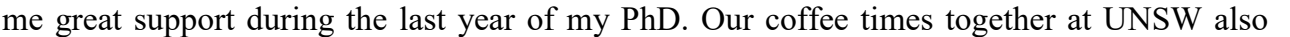

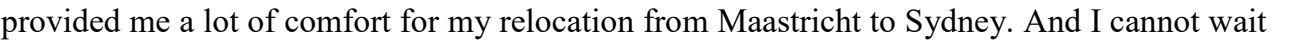

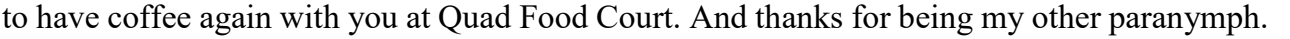

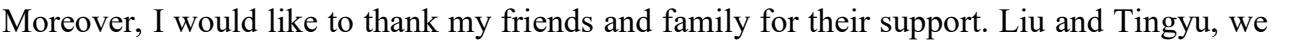

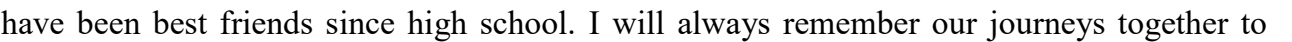

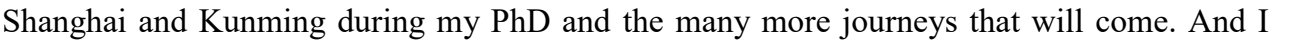

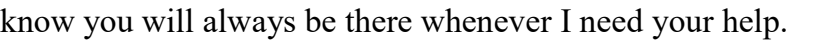

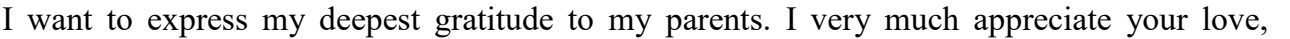

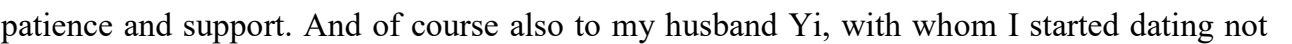

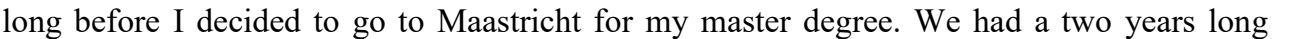

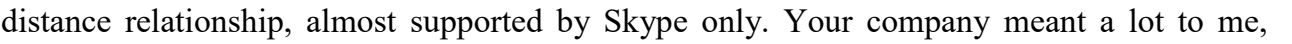

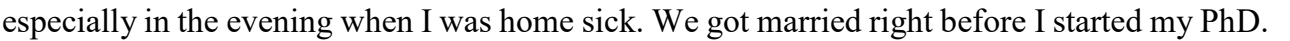

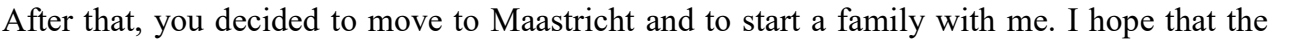

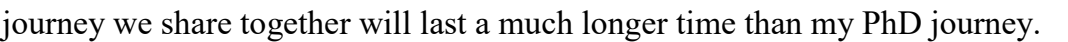

$\square \square \square$

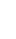




\section{Table of Contents}

Chapter 1: Introduction

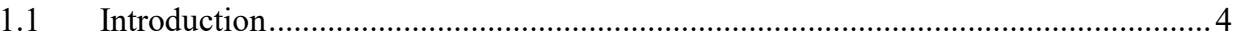

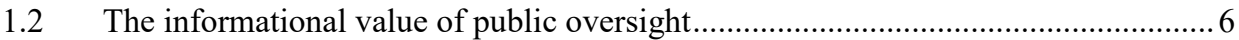

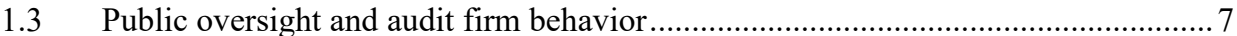

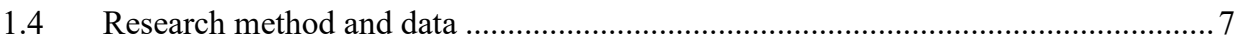

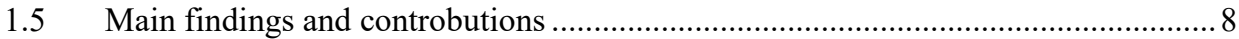

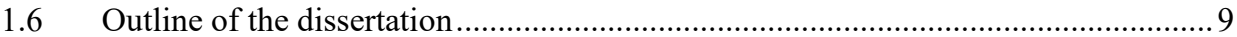

Chapter 2: The Impact of PCAOB Inspections on Stock Market Liquidity over Time .11

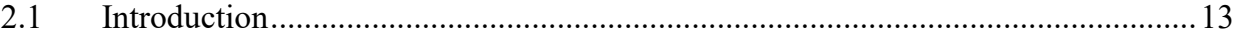

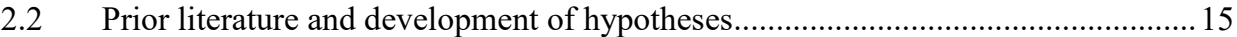

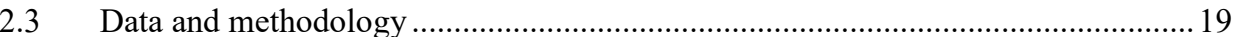

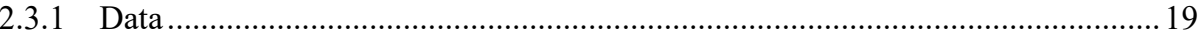

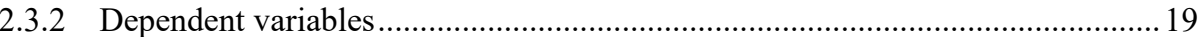

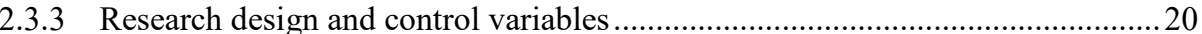

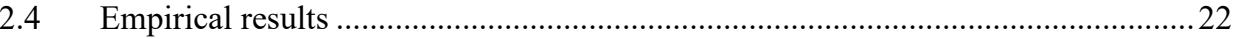

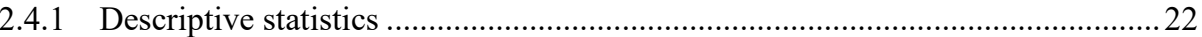

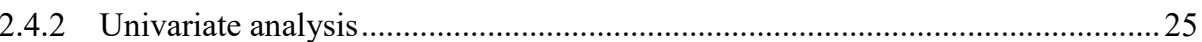

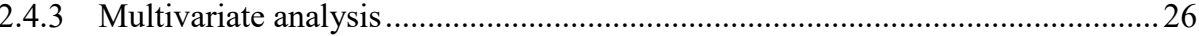

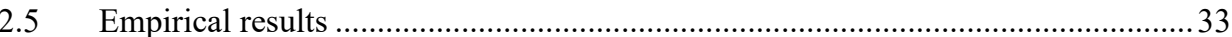

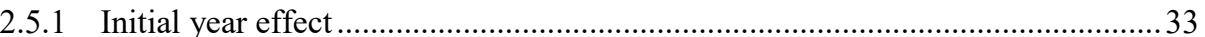

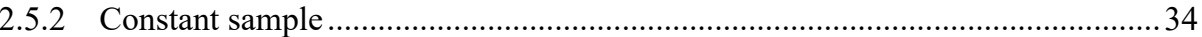

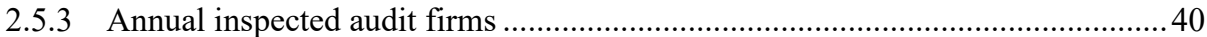

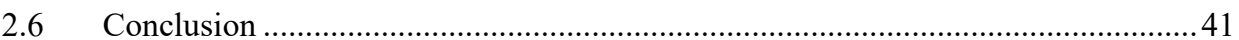

Chapter 3: PCAOB Inspections and Audit Firm Behavior: An Analysis of the First Three Inspection Rounds of Small Audit Firms ................................................................45

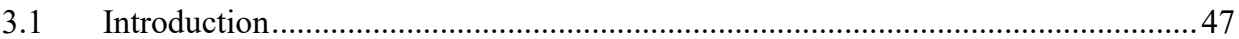

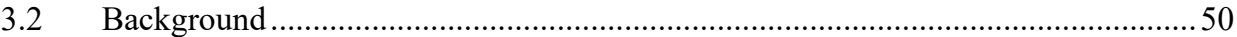

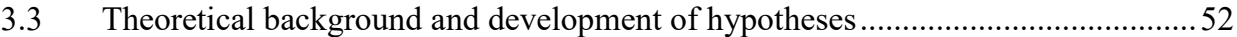

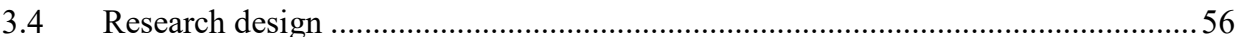

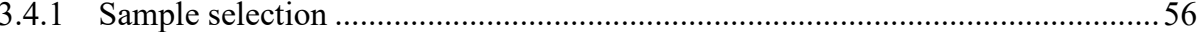




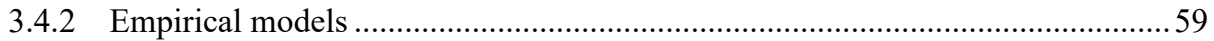

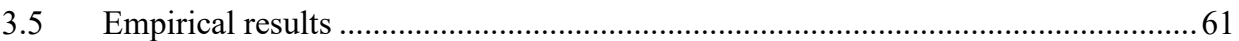

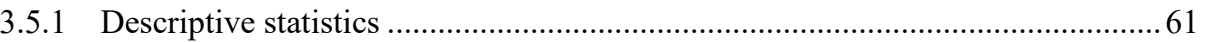

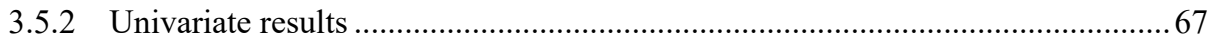

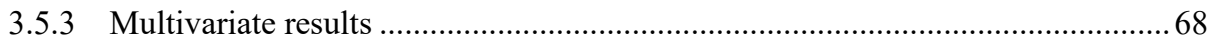

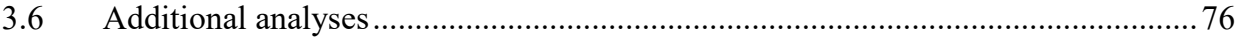

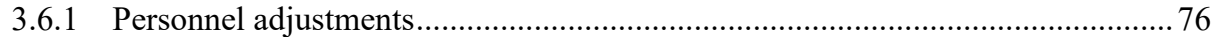

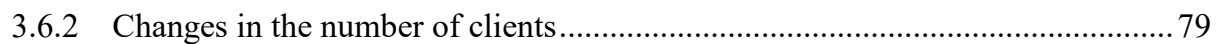

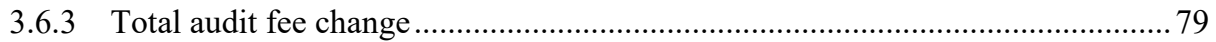

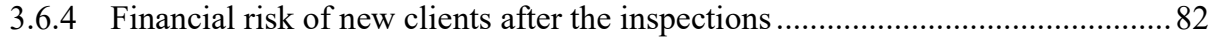

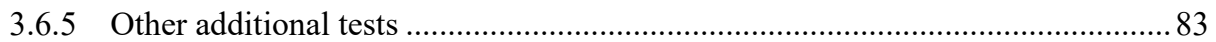

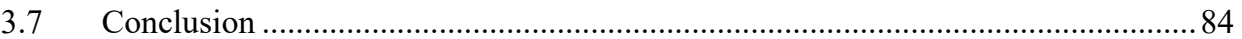

Chapter 4: Market Reactions to Public Oversight: Evidence from the Netherlands......85

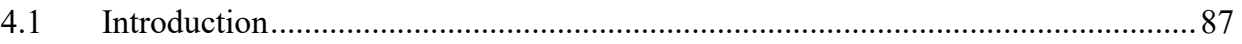

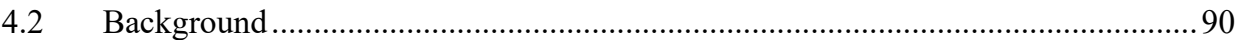

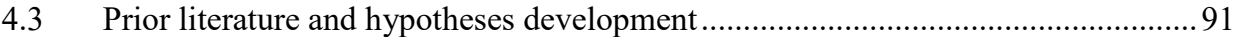

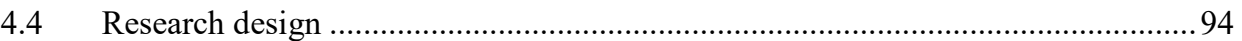

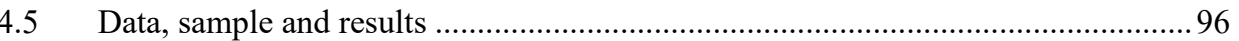

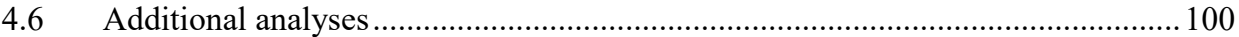

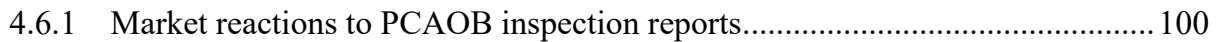

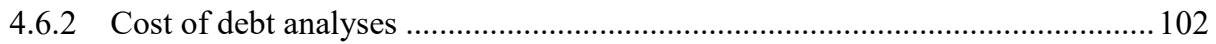

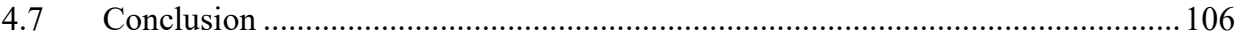

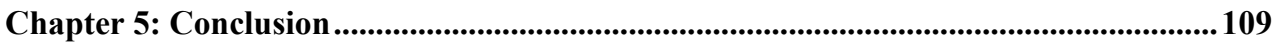

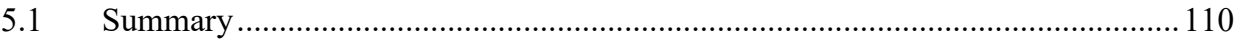

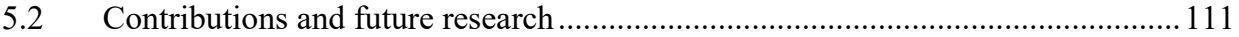

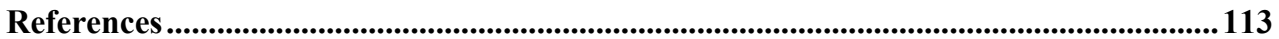

Appendix 1: Variable definitions for Chapter2 ….................................................................. 120

Appendix 2: Variable definitions for Chapter3 ........................................................................... 122

Appendix 3: Variable definitions for Chapter4 ........................................................................... 124

Appendix 4: Valorization-addendum............................................................................................. 125 
Chapter 1: Introduction 


\subsection{Introduction}

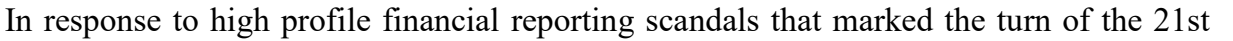

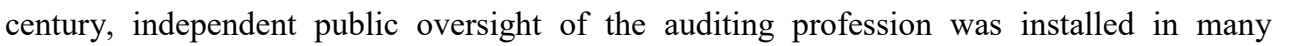

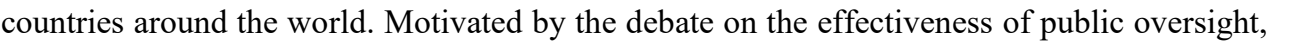

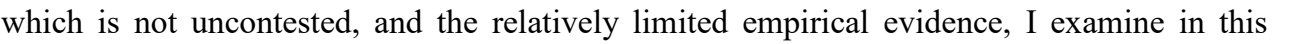

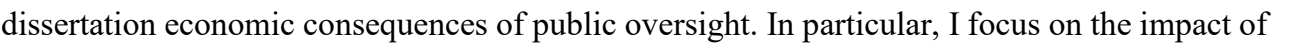

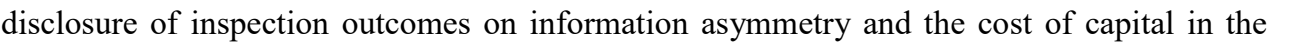

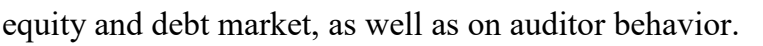

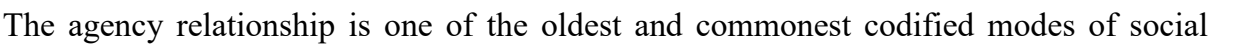

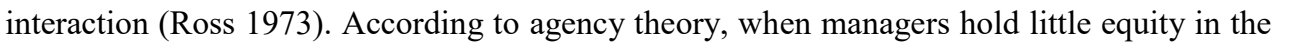

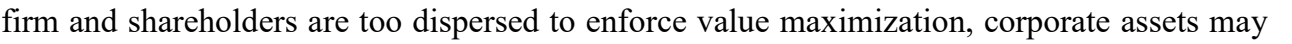

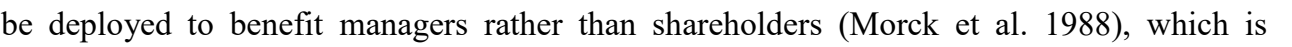

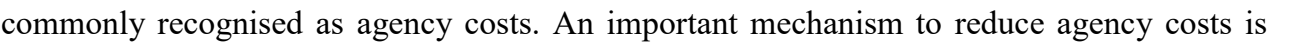

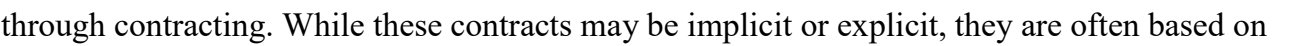

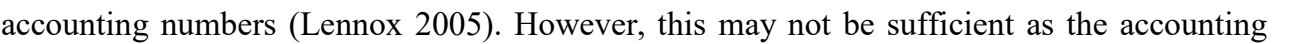

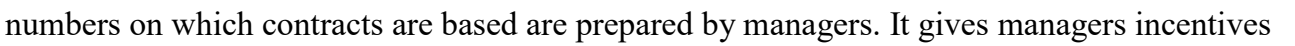

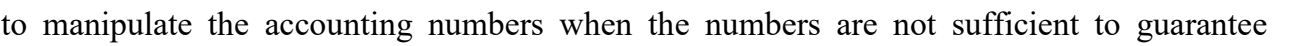
manager's compensation. As a result, auditing conducted by independent auditors are

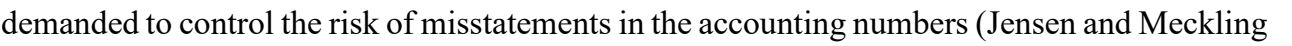

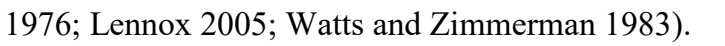

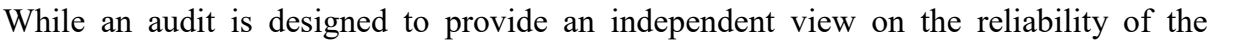

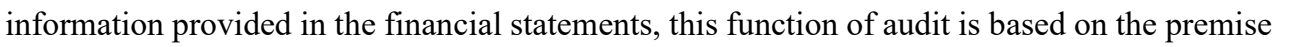

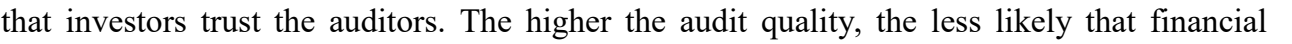

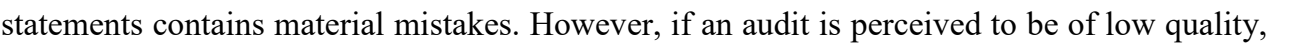
ए ए

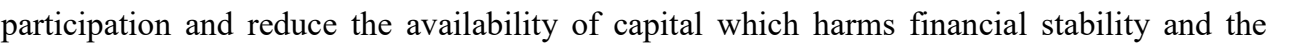

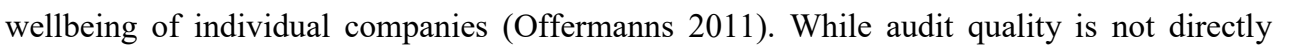

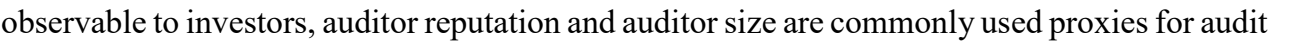

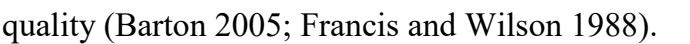

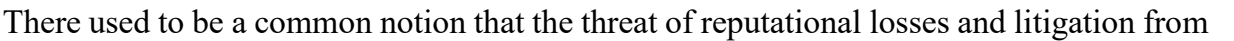

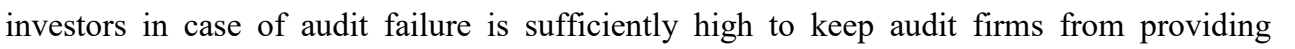

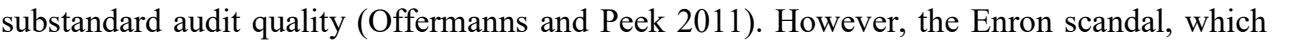

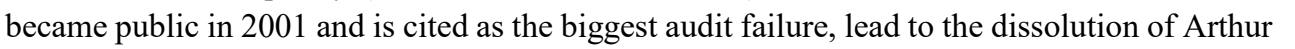

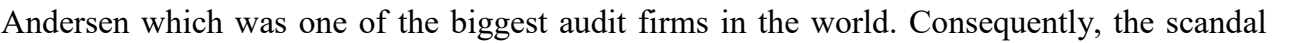

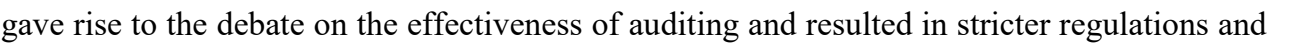

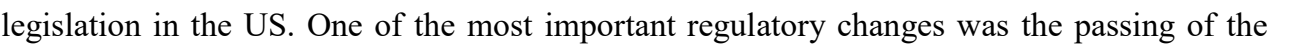

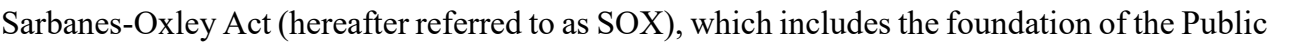

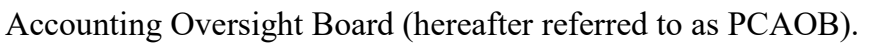

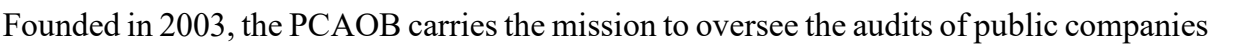

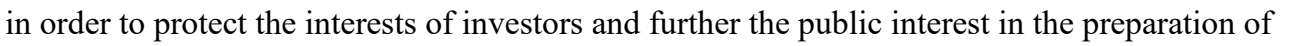




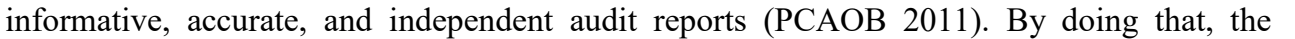

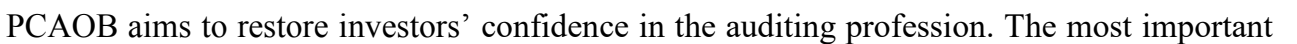

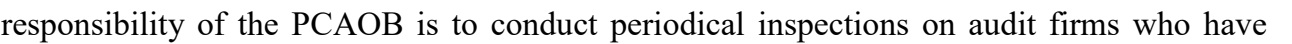

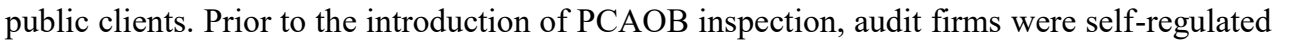

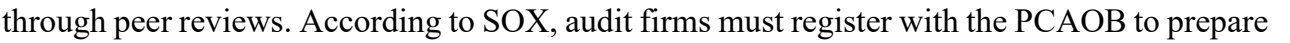

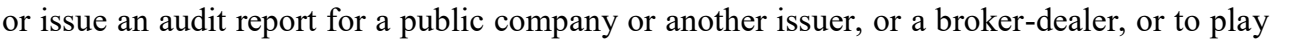

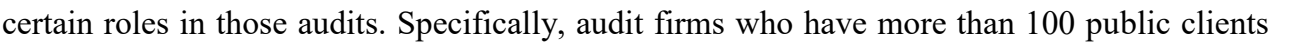

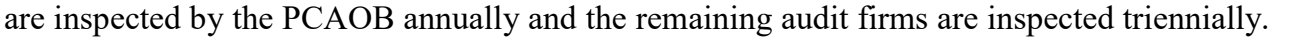
The inspectors evaluate audit firms' quality control policies and procedures as well as review

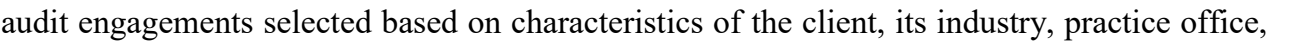

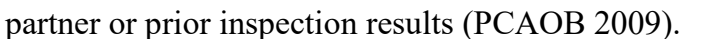

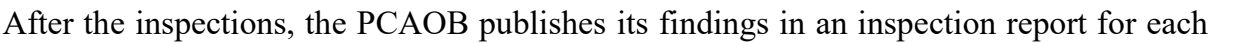

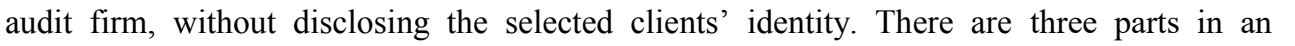

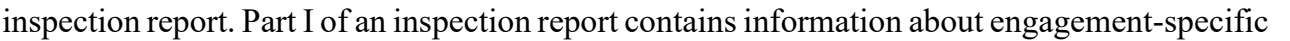

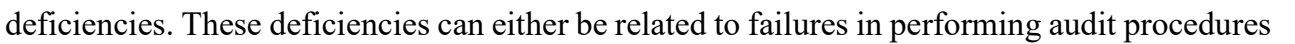

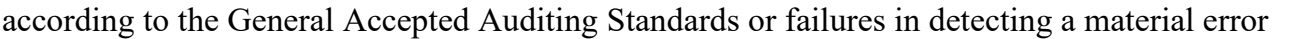

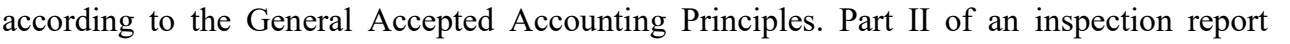
indicates whether deficiencies are identified in audit firm's quality control system. However, प

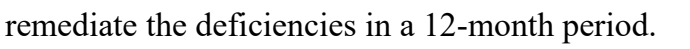

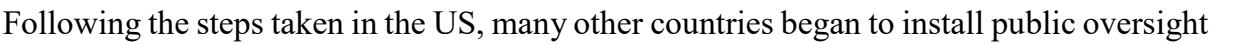

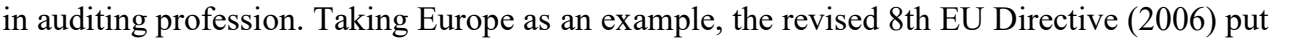

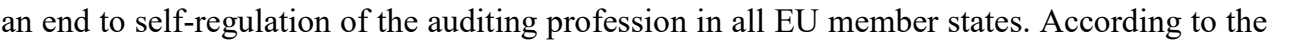

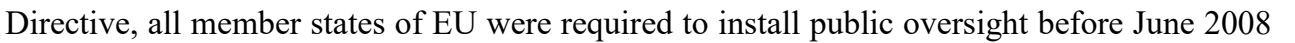

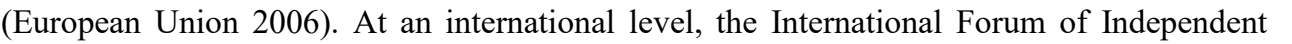

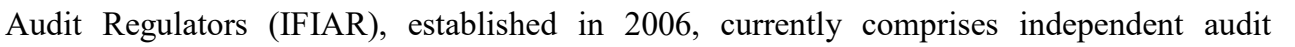

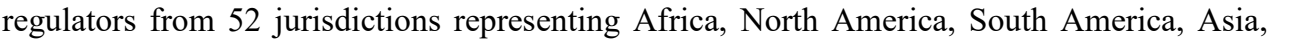

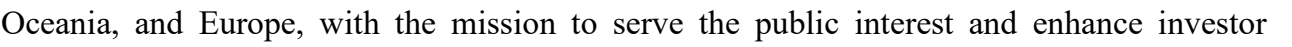

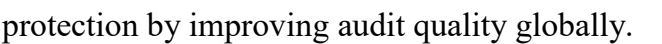

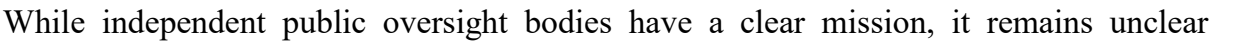

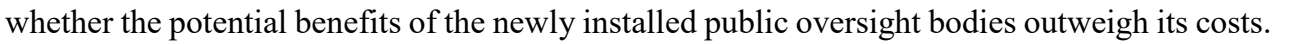

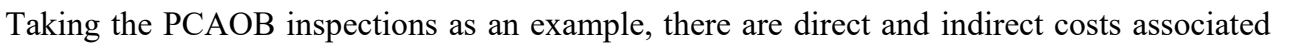
with it. The direct costs are reflected in the PCAOB's budget. Under Section 109 of the

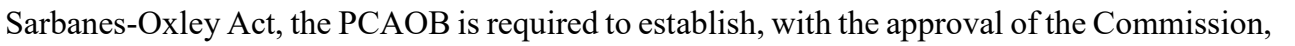

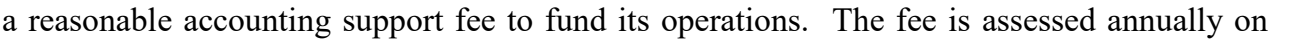

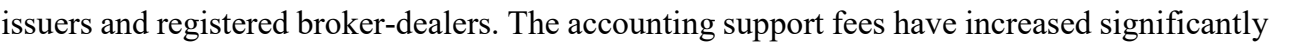

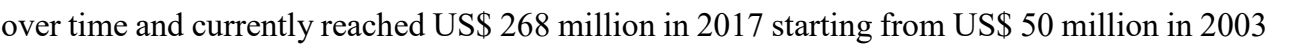

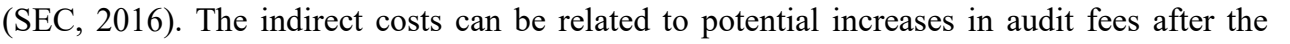

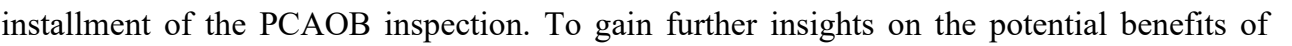

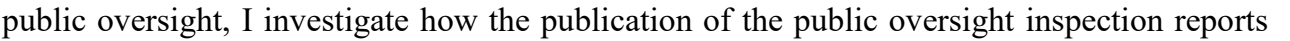

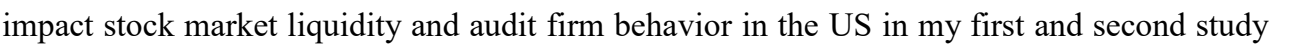

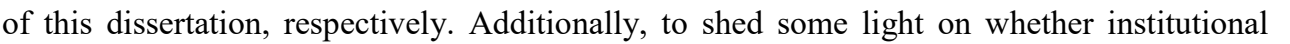




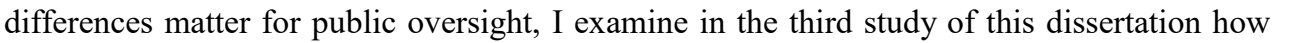

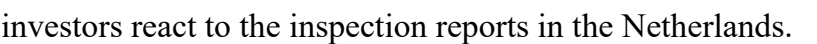

$\square$

\subsection{The informational value of public oversight}

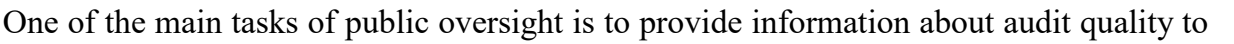
ए ए ए एव

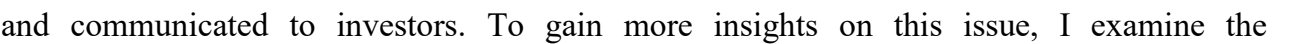

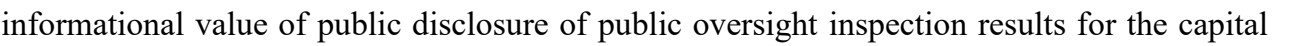

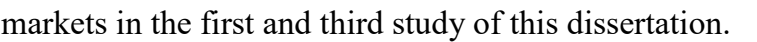

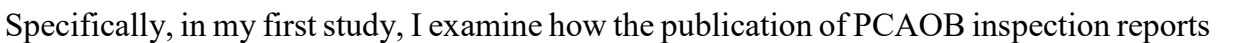

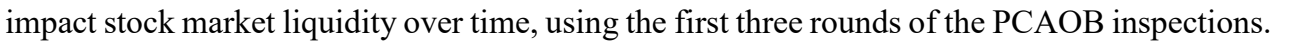

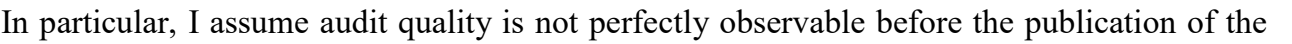

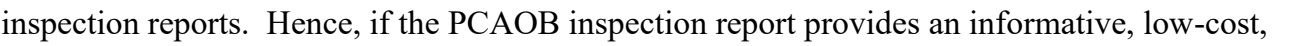

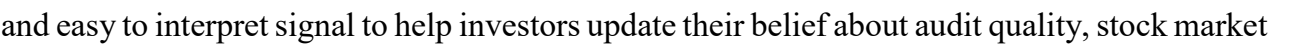

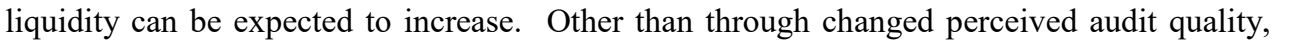

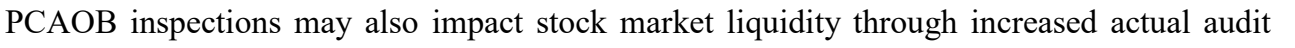

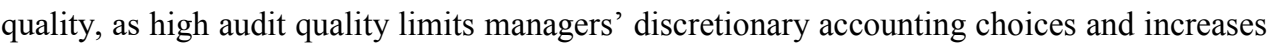

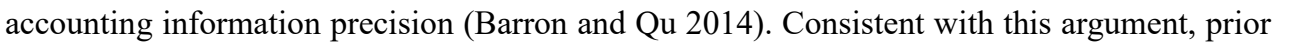

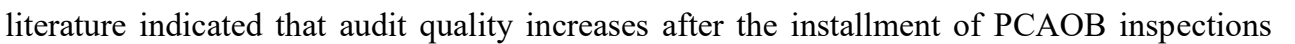

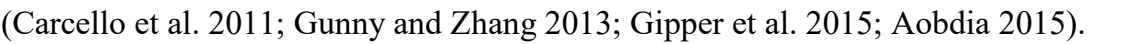

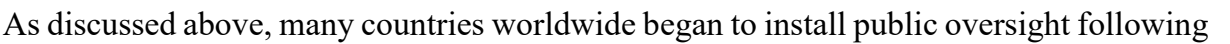
पा

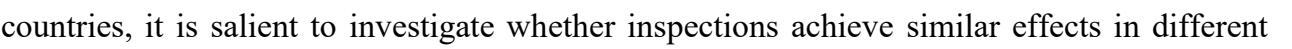

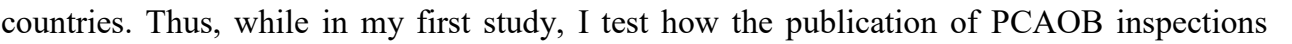

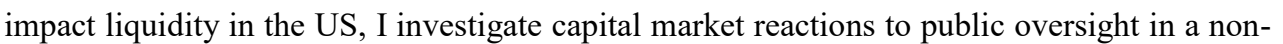

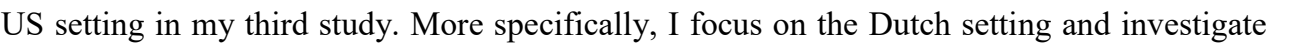

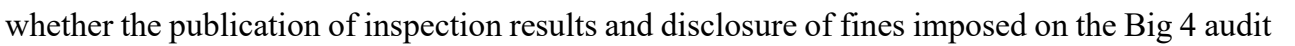

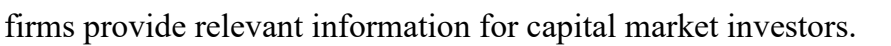

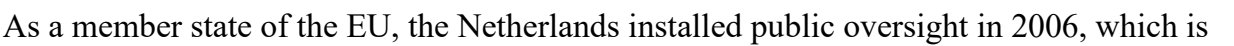

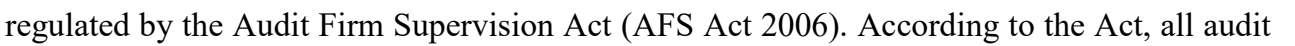

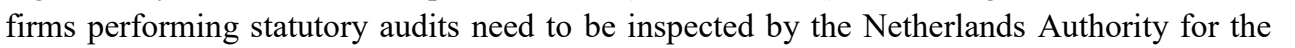

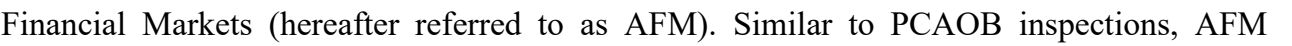
ए

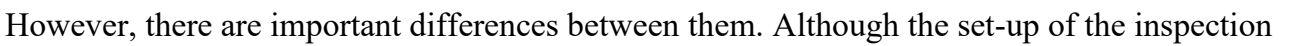

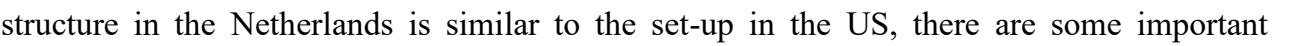

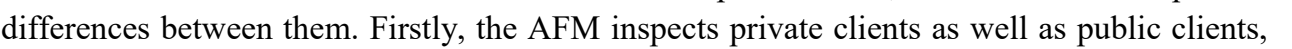

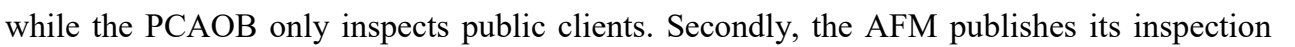

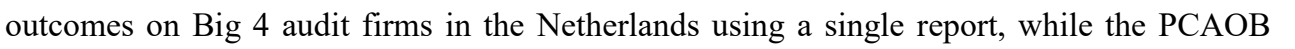




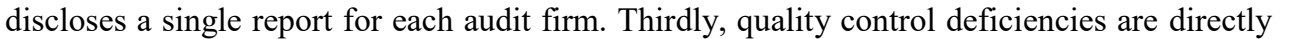

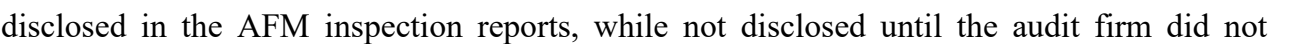

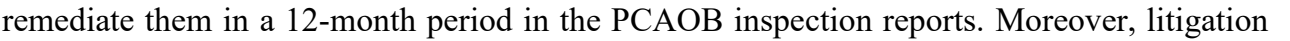

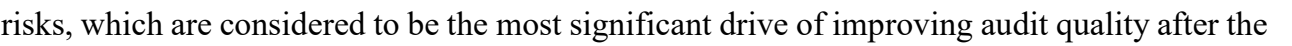
ए

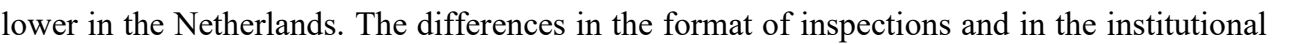

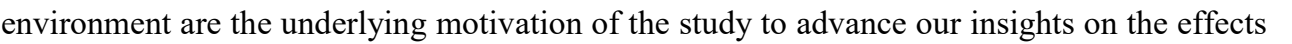

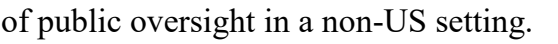

$\square$

\subsection{Public oversight and audit firm behavior}

Other than its intention to restore investors' confidence in the auditing profession, in

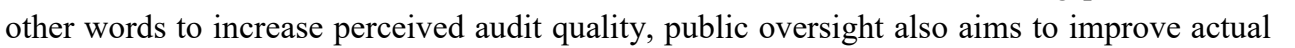

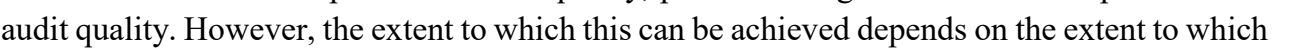
ए एव ए ए।

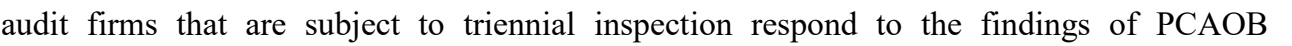

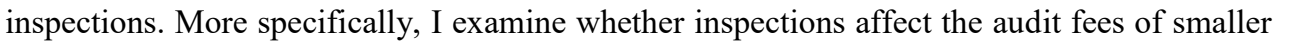

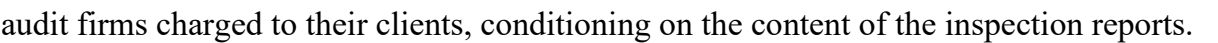

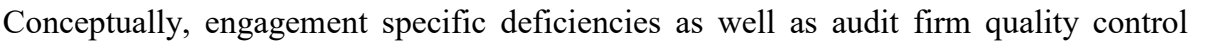

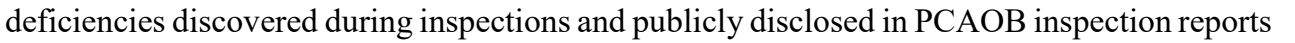
can lead to changes in the auditor's incentive structure and behavior, in response to the

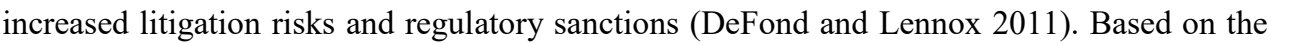

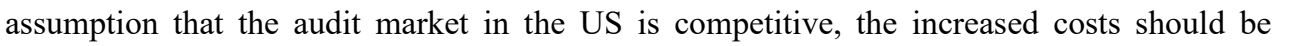

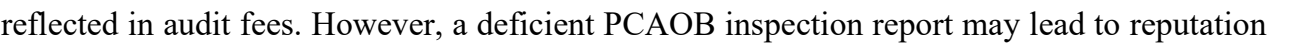
damage for audit firms, which may have an adverse effect on clients' valuations (Dee et al.

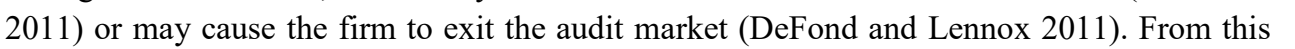

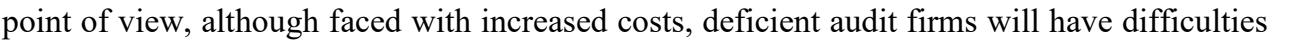
ए

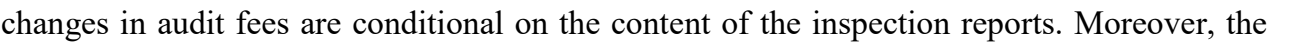

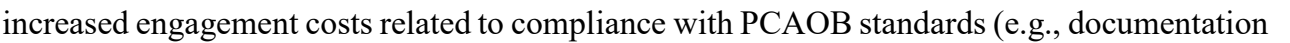

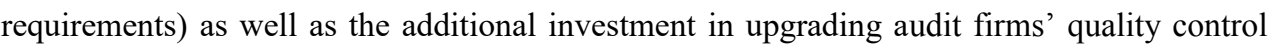

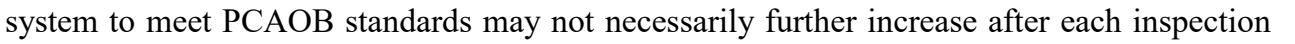

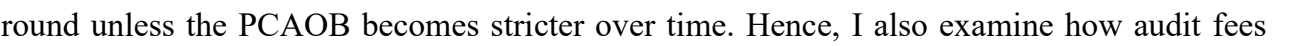

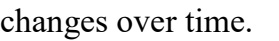

\subsection{Research method and data}

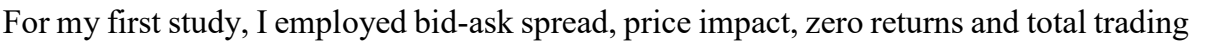

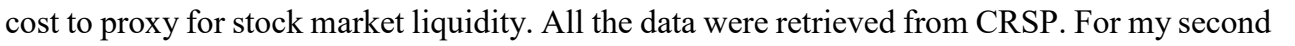

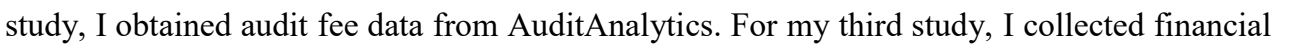




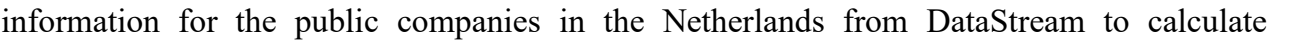

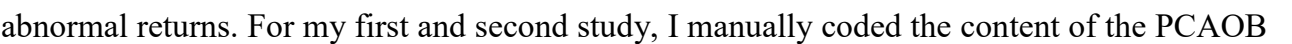

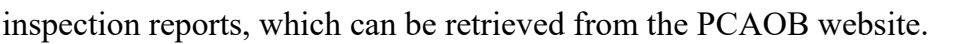

$\square$

\subsection{Main findings and controbutions}

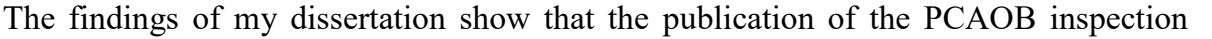
प

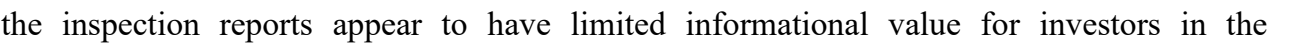

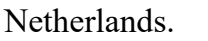

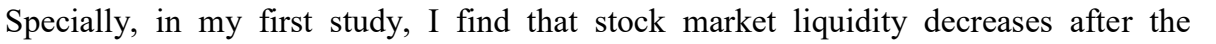

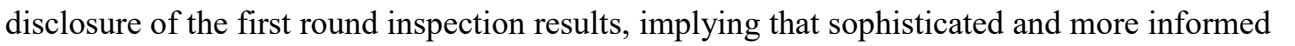

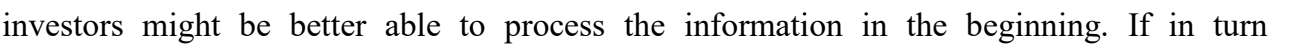

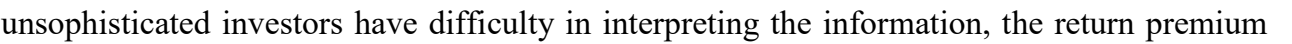

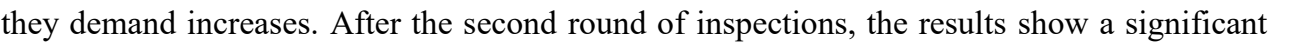
ए एव प

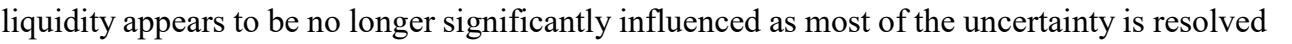

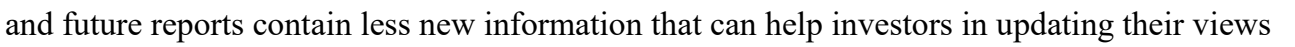

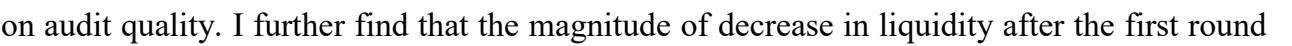

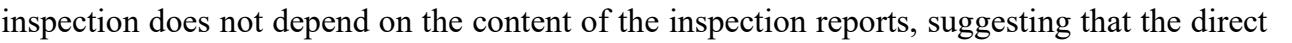

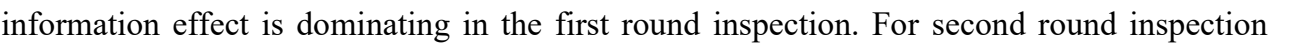

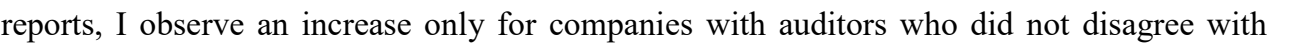

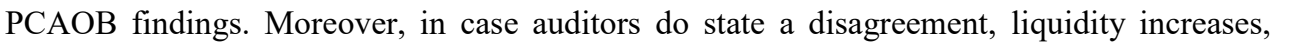

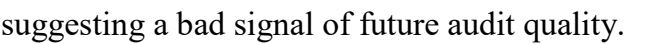

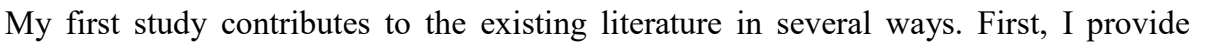

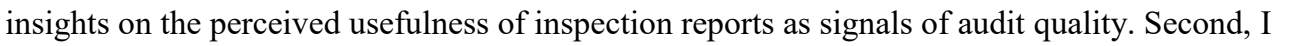

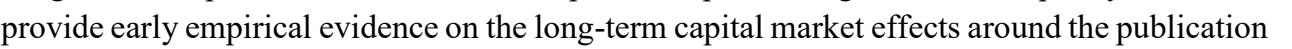

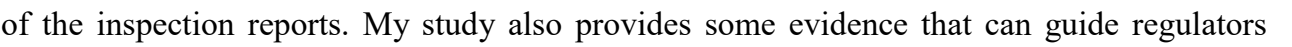

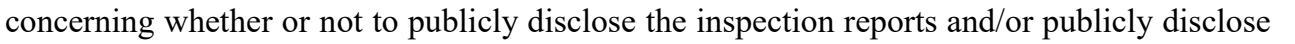

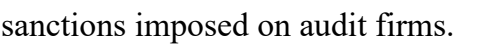

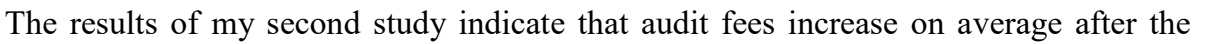

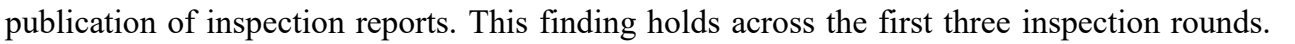

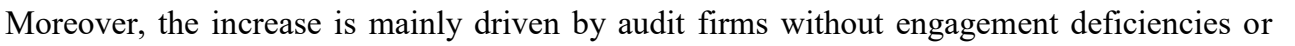

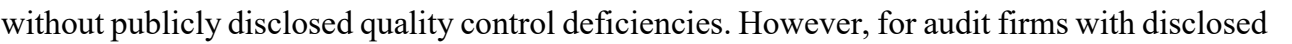

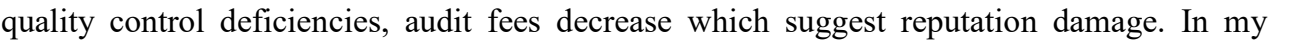

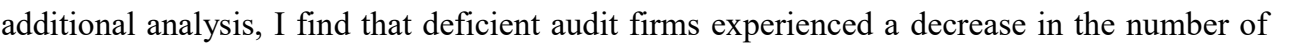

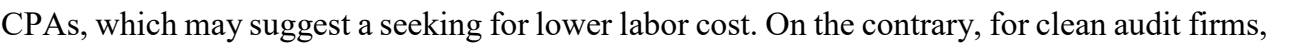

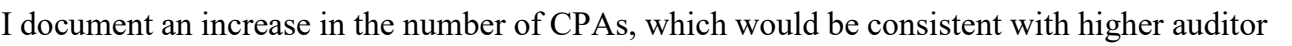

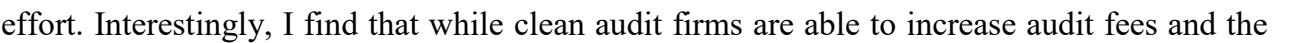

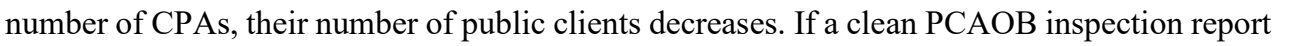




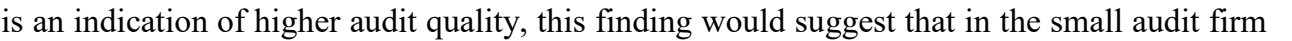

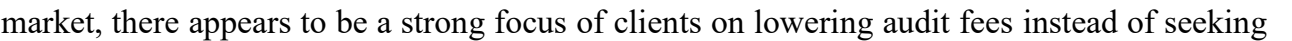

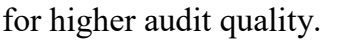

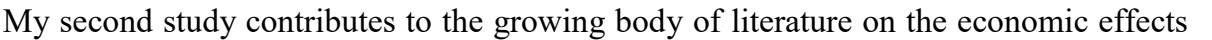

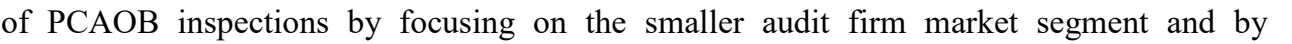

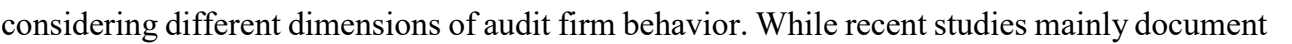

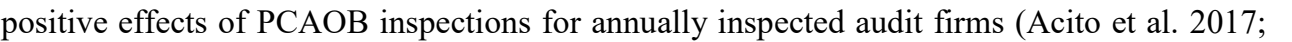

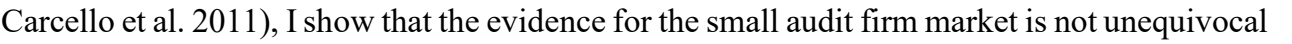

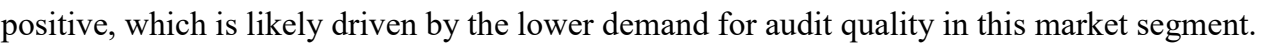

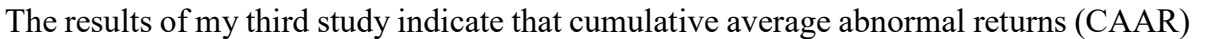

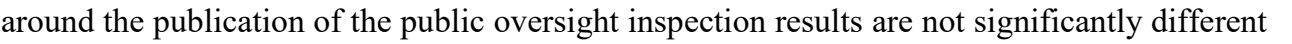

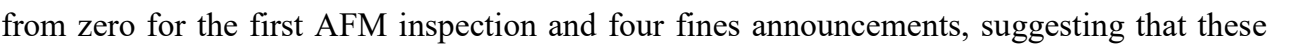
ए

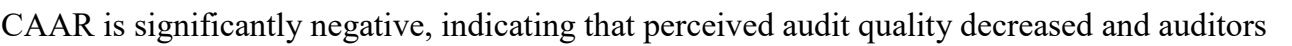

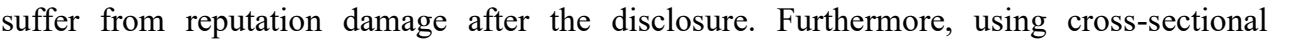

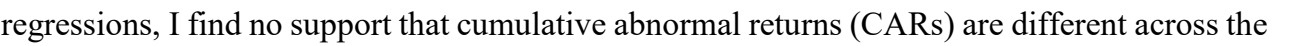

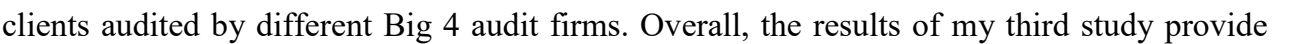
limited support that AFM inspection reports change capital market investors' perceived audit $\square|\Pi \|| \Pi \mid \square$

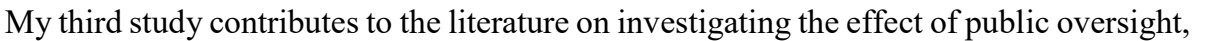

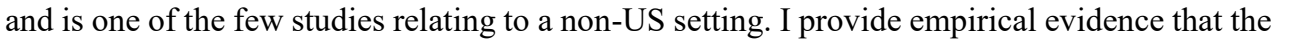

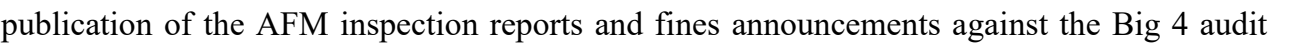

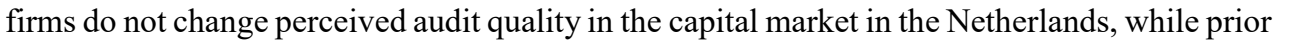

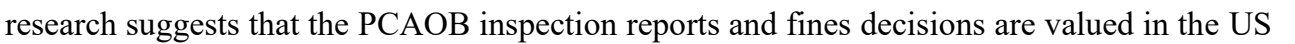

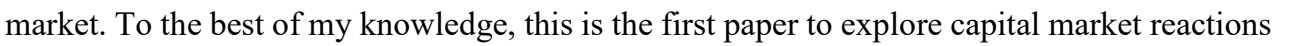

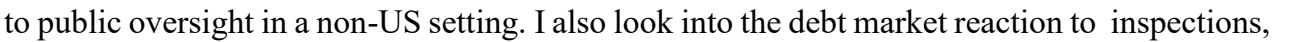
which is important for practice since debt plays a key role in companies' financing activities

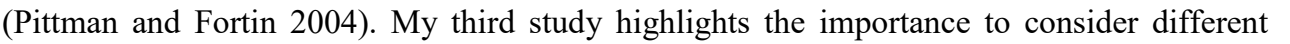

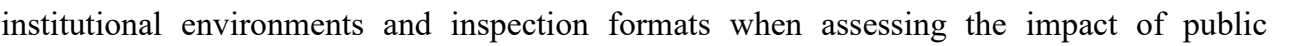

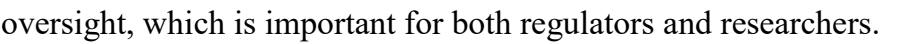

$\square$

\subsection{Outline of the dissertation}

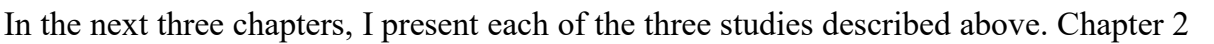

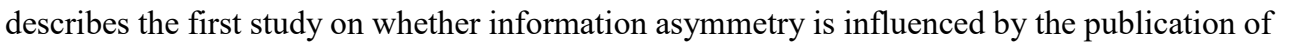

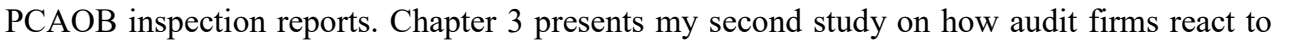

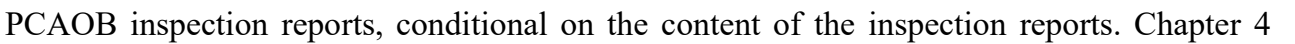

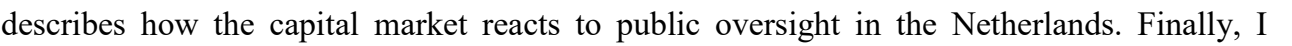

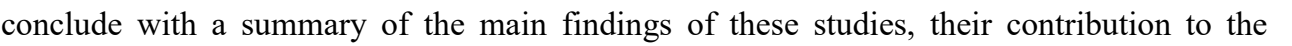

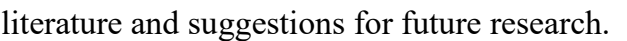



Chapter 2: The Impact of PCAOB Inspections on Stock Market Liquidity over Time 


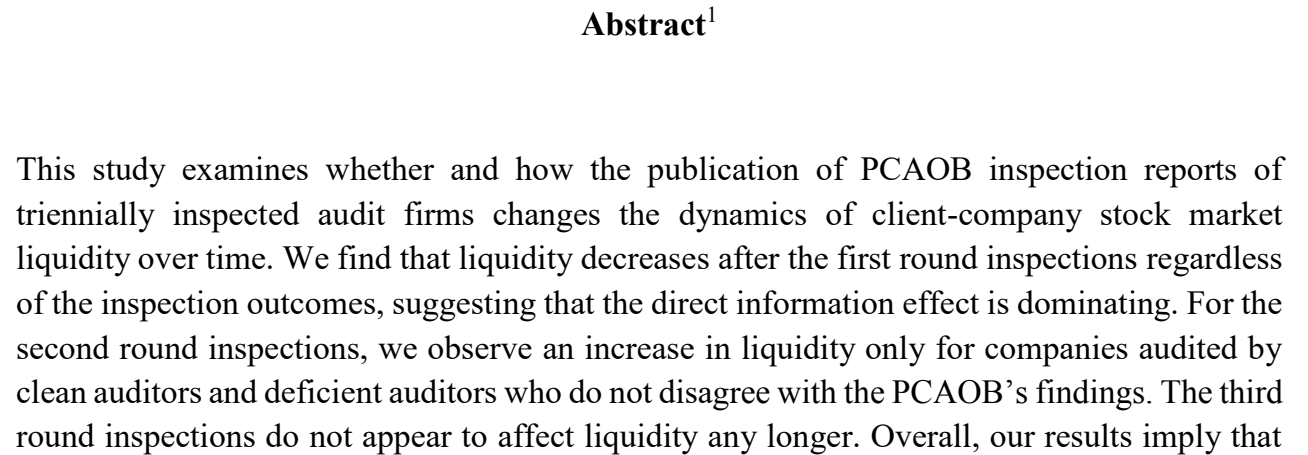

PCAOB inspection reports change investors' perceptions of future audit quality. Moreover,

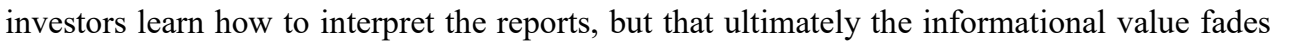

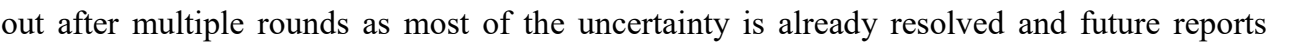

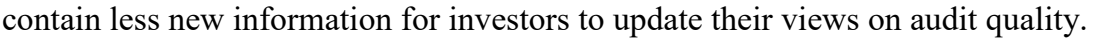




\subsection{Introduction}

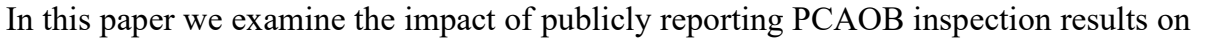

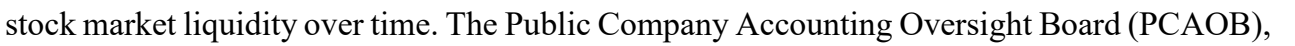

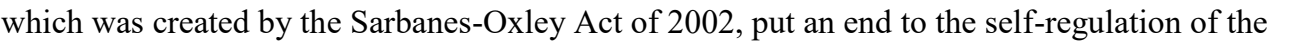

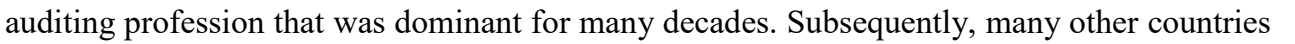

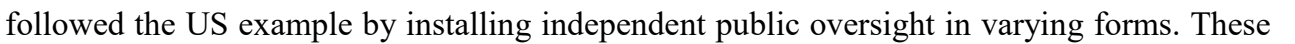

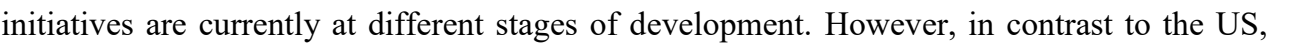

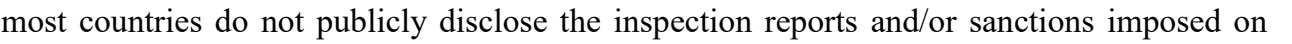

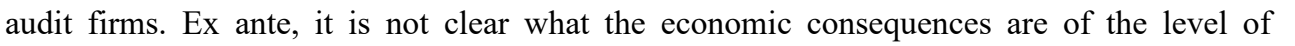

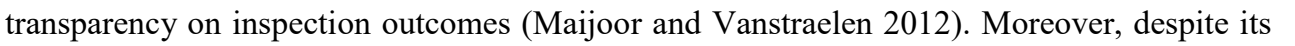

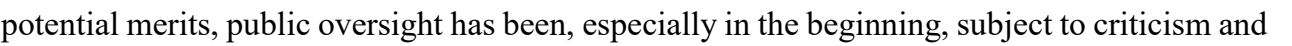

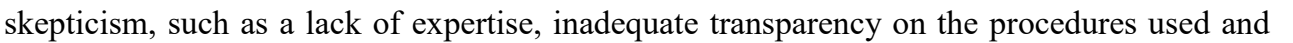

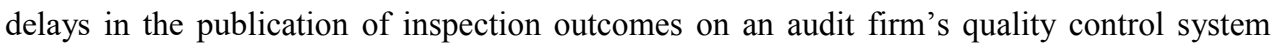

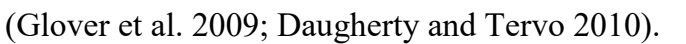

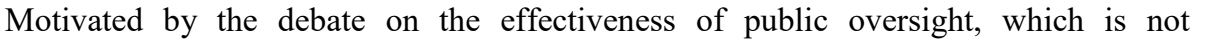

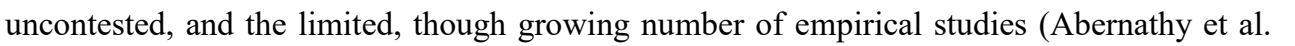

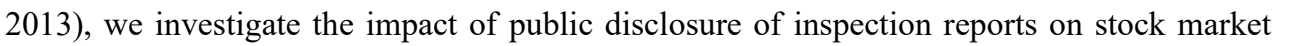

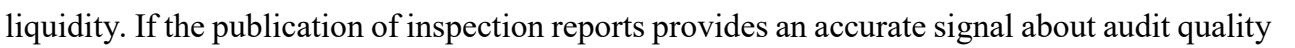
and changes investors' percep

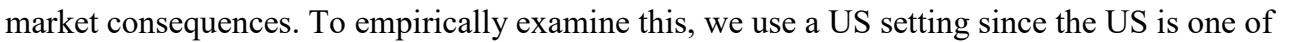

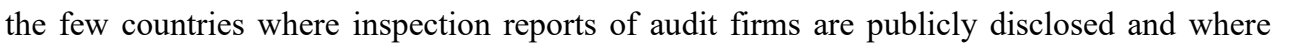

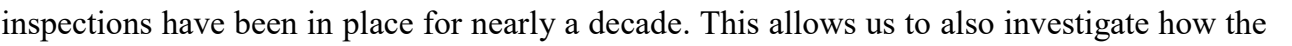

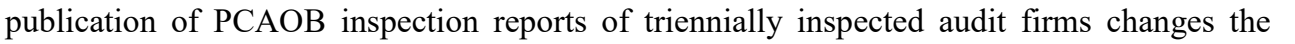

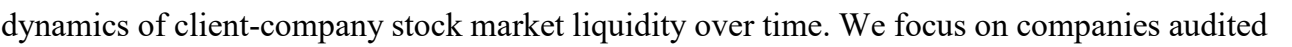

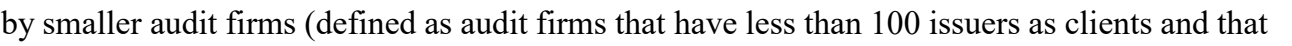

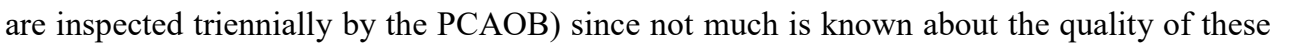

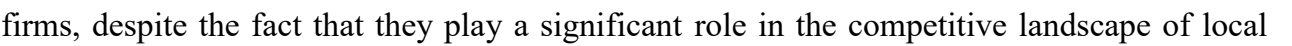

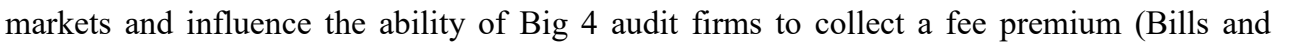

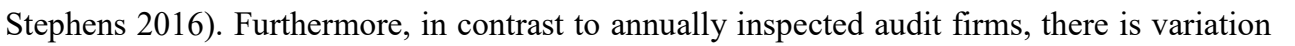

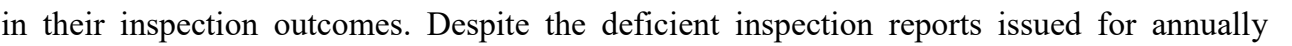

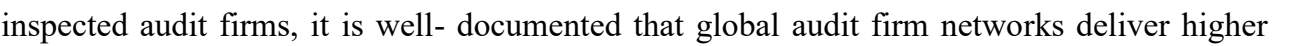

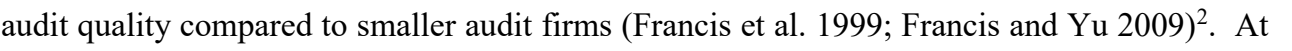

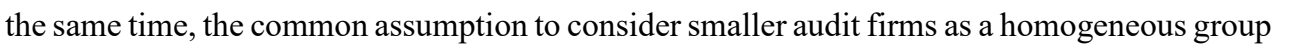

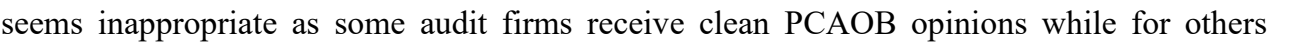

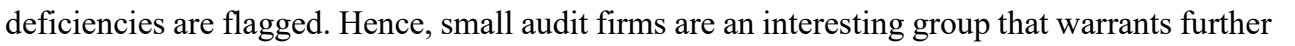

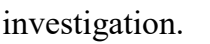

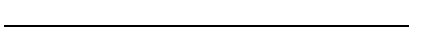

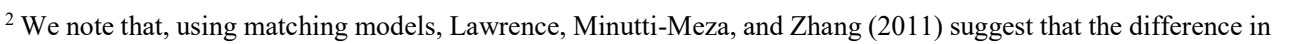

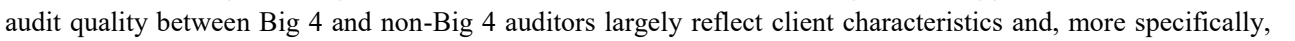

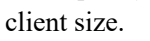




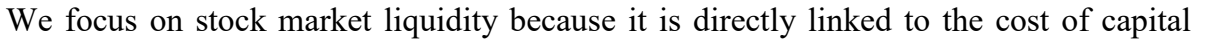

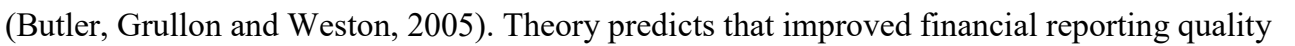

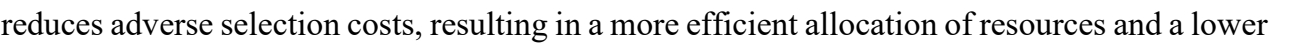

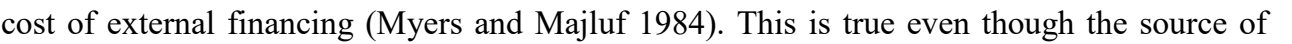

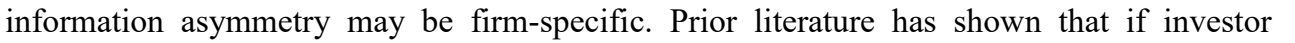

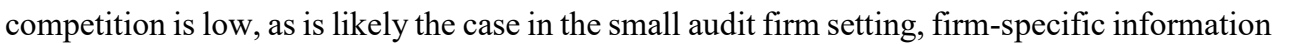

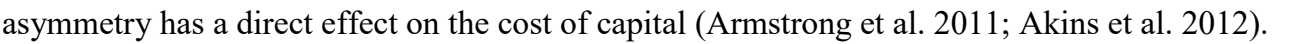

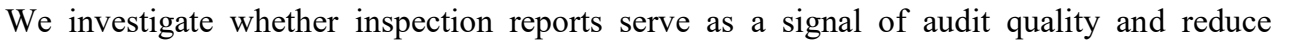

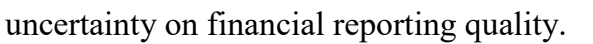

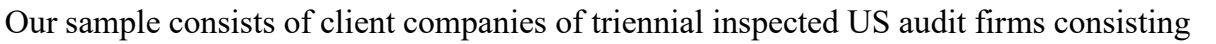

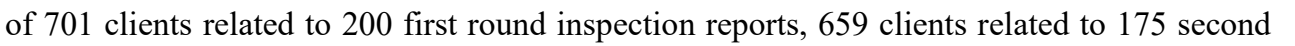

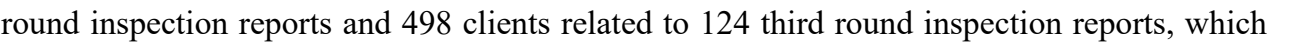

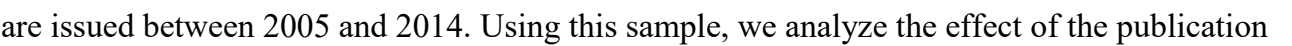

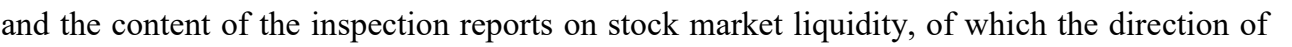

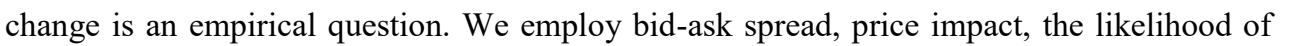

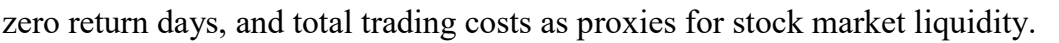

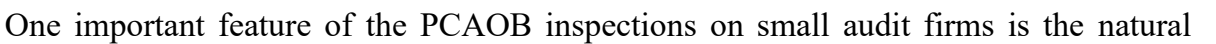

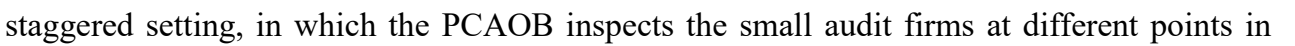

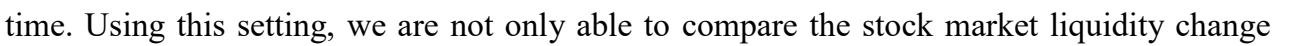

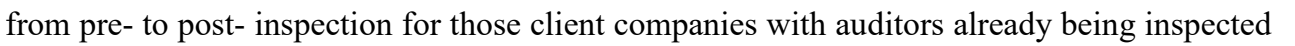

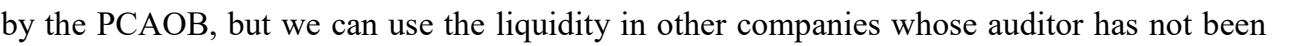

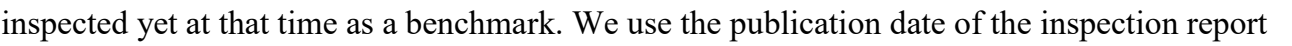

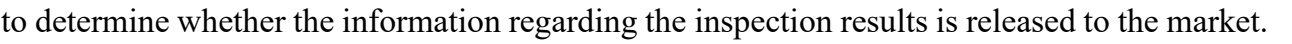

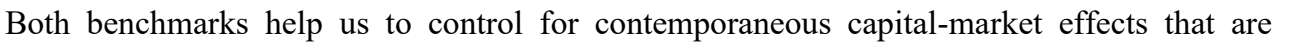

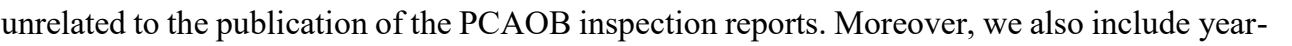

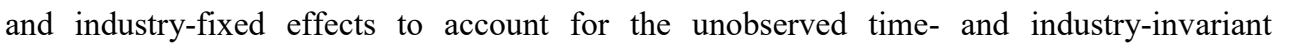

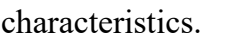

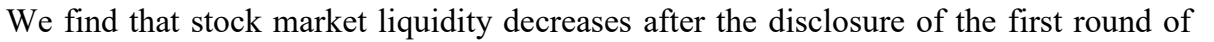

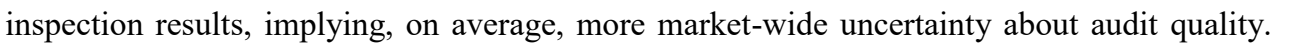

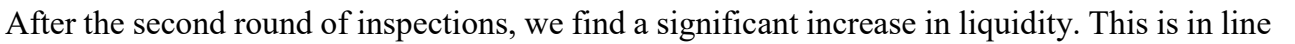

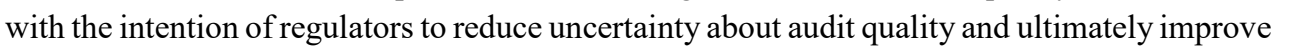

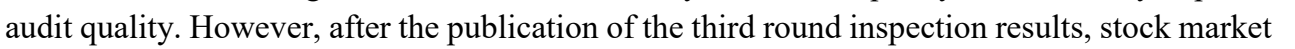

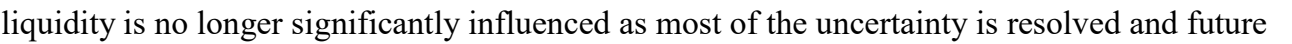

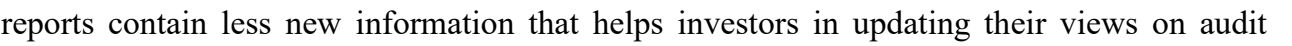

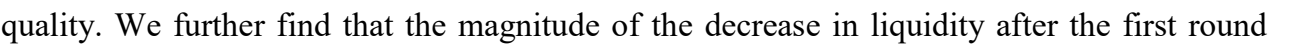

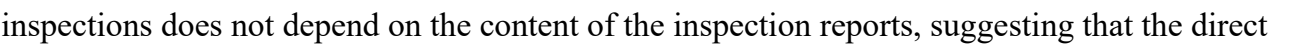

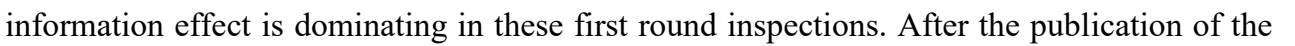

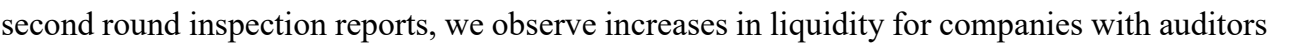

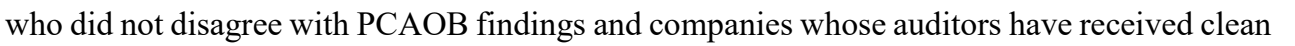

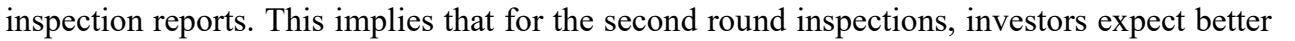

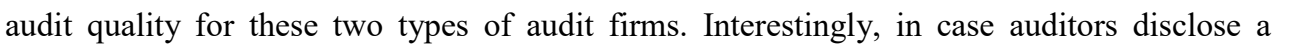

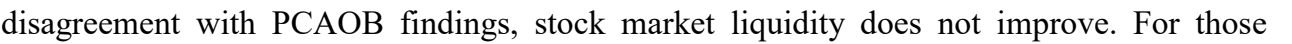




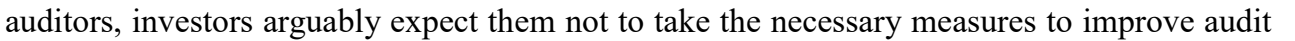

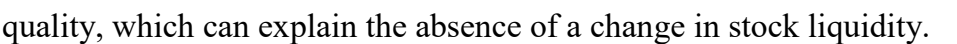

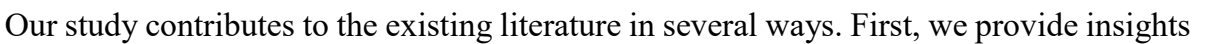

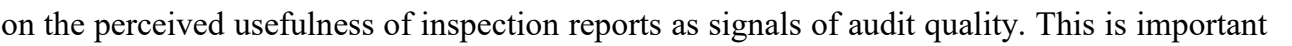

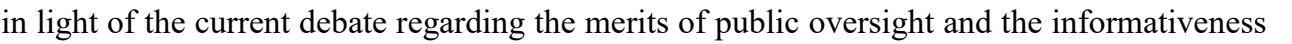

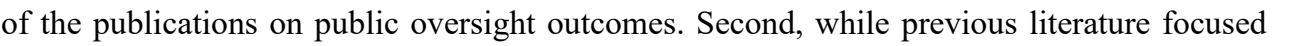

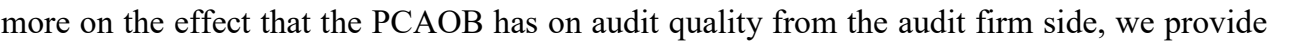

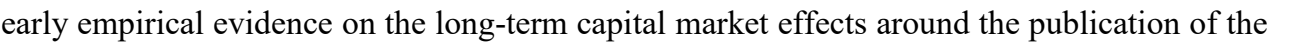

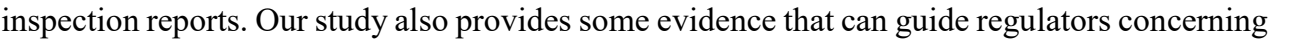

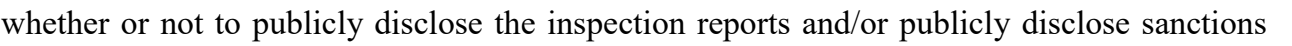

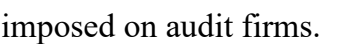

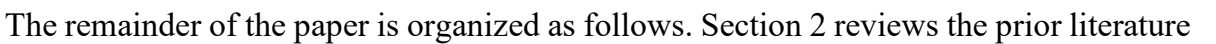

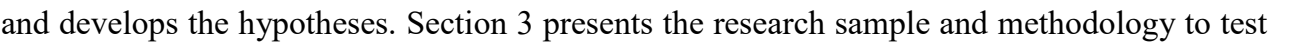

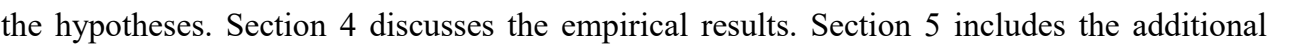

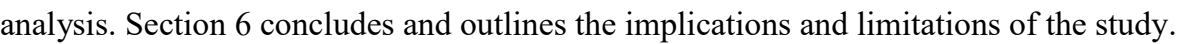

\subsection{Prior literature and development of hypotheses}

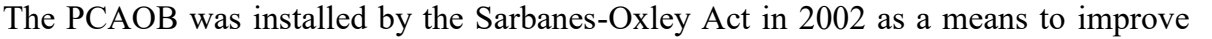
audit quality and protect investors' interests. However, opinions on the effectiveness of

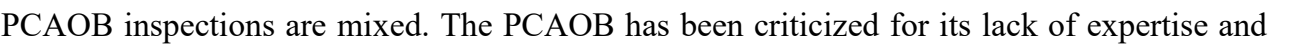

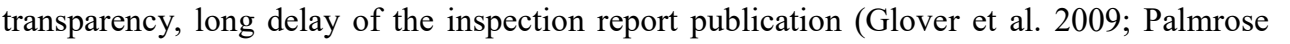

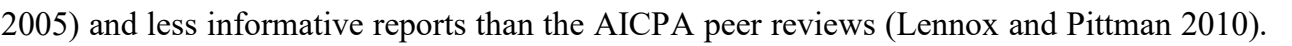
प

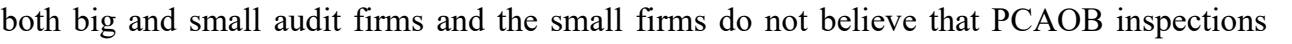

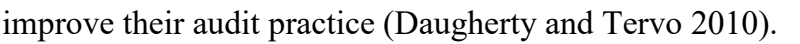

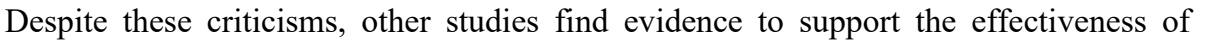

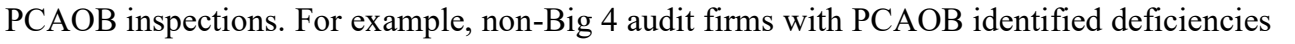

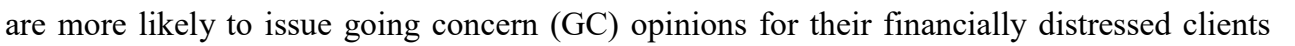

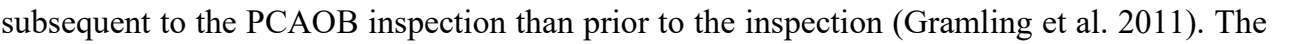

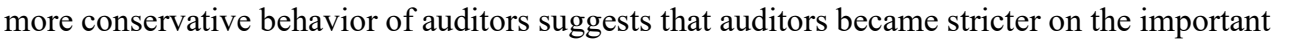
reporting issues in clients' financial statements. The finding that over 600 small auditors exit

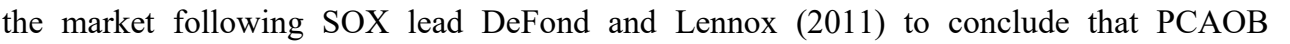
ए

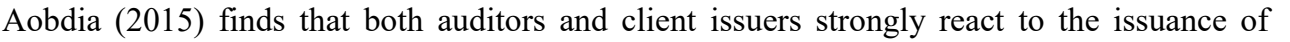

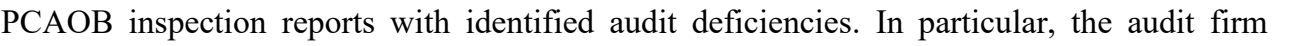

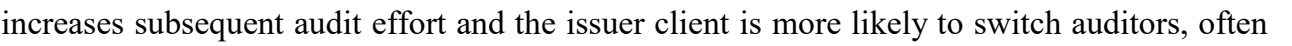

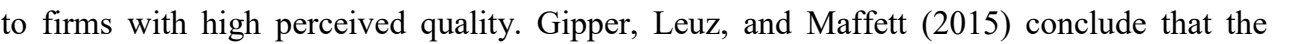

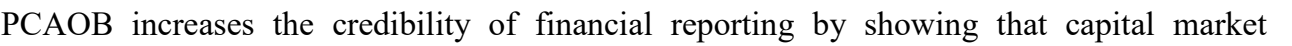

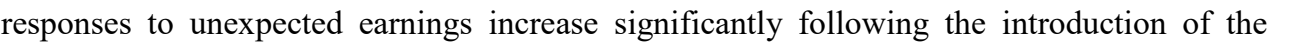

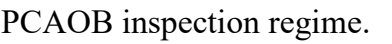




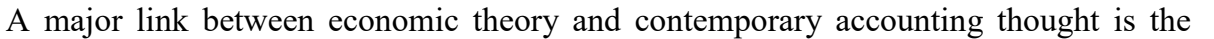

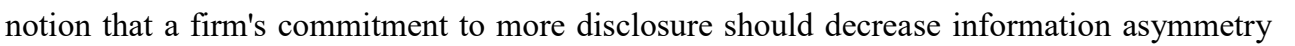

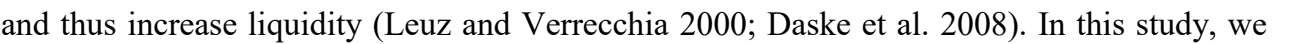

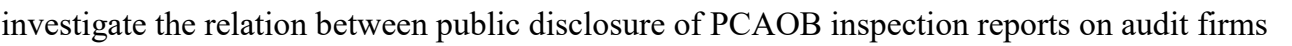

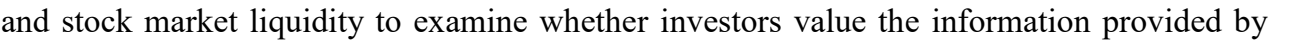

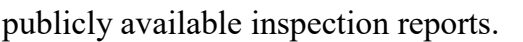

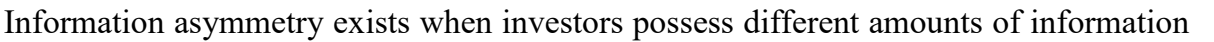
about a firm's value (Akerlof 1970). It allows investors with superior information to $\square \square \square$

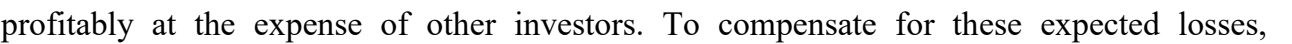

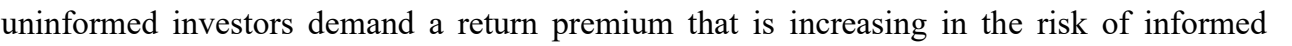

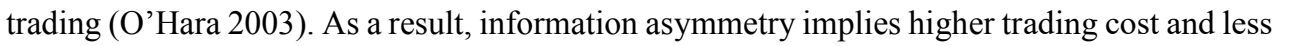

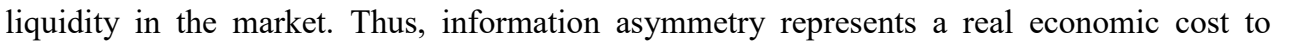

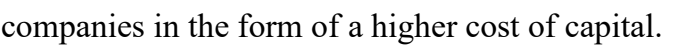

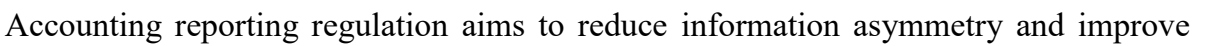

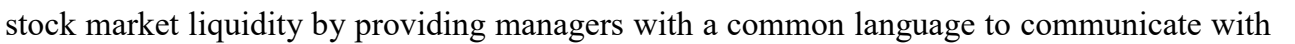
ए

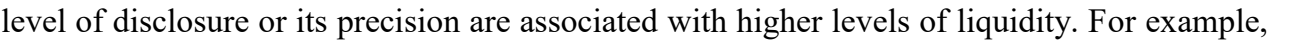

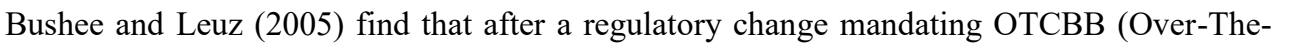

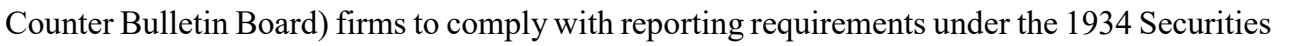

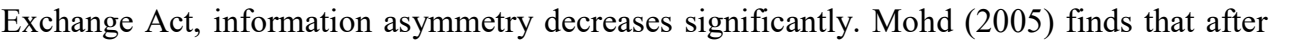

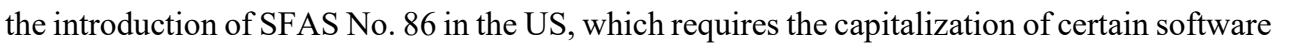

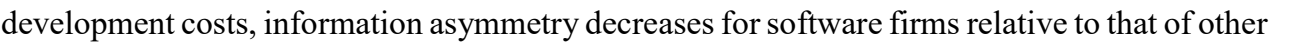

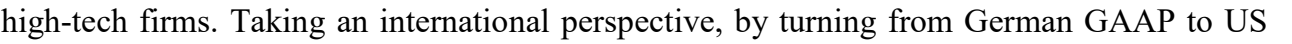

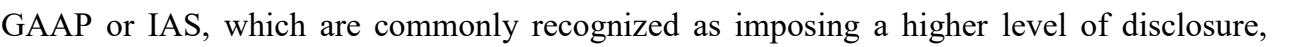
एயா

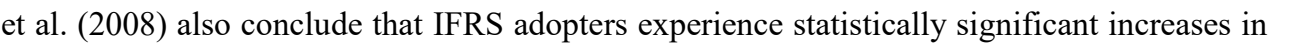

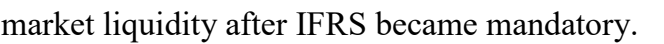

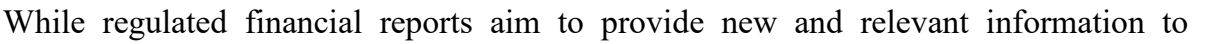

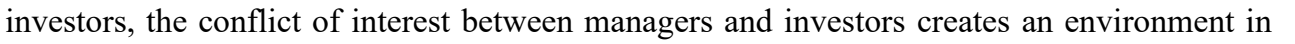

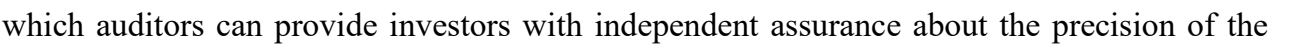

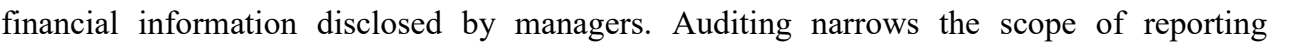

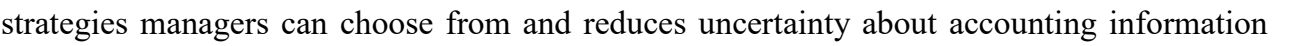

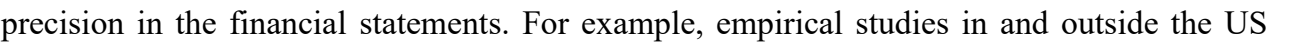

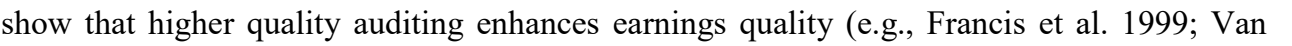

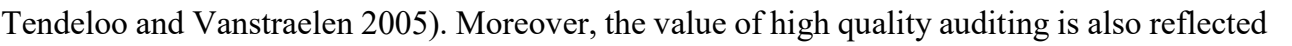

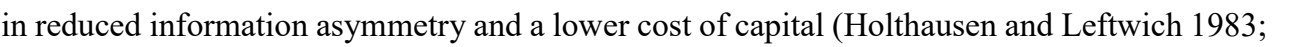

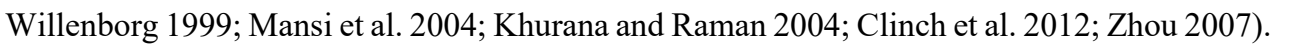

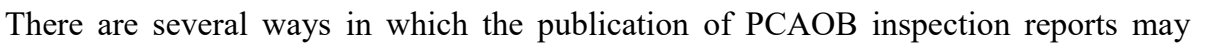

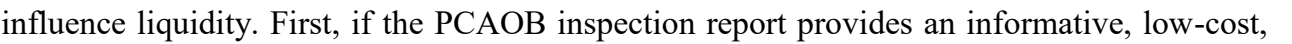

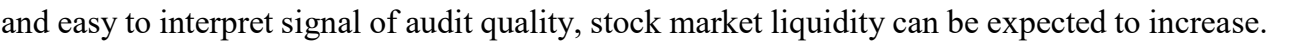

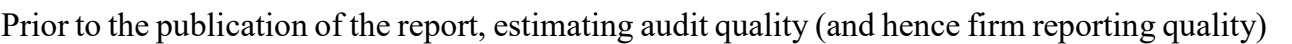




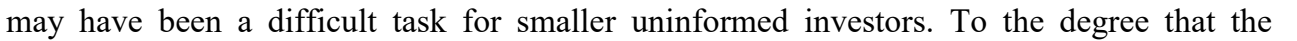

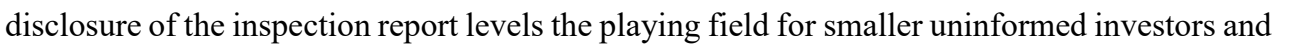

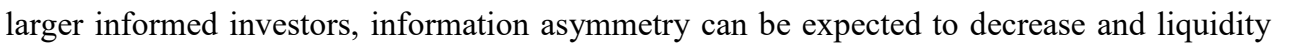

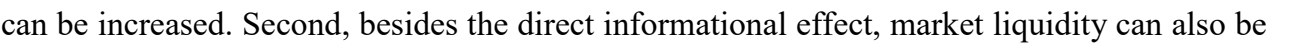

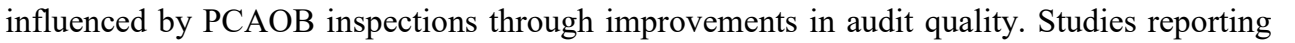

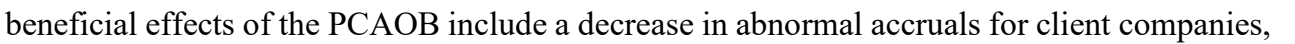

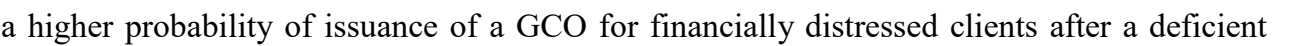

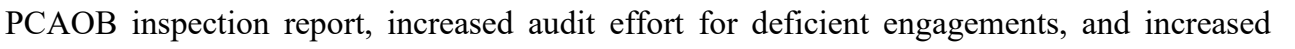

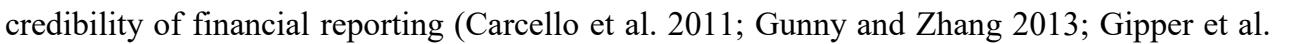

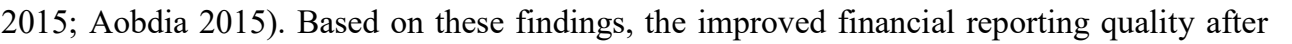

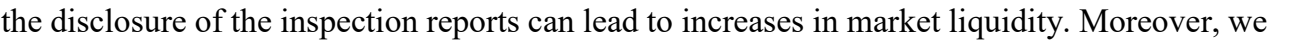

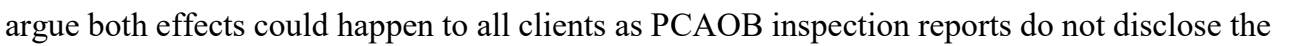

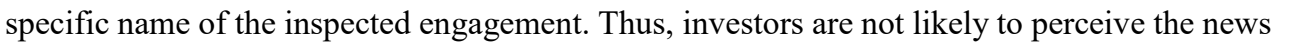

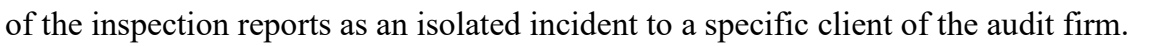

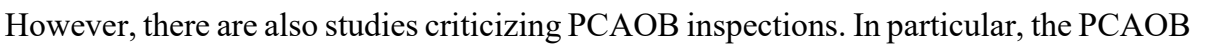

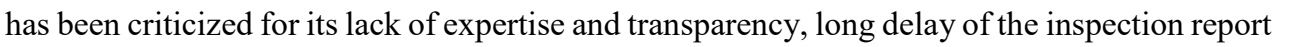

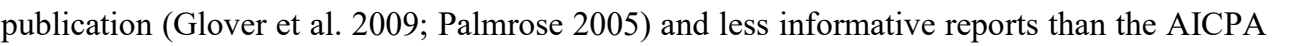

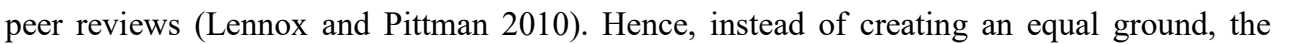

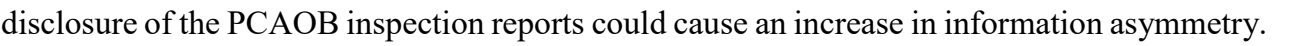

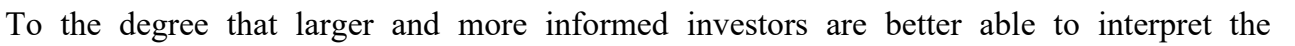

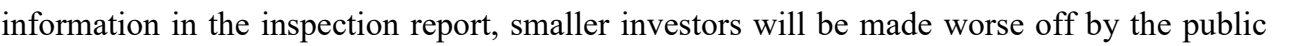

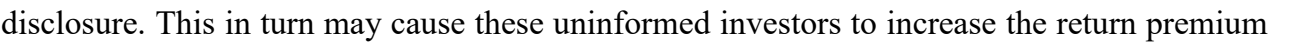

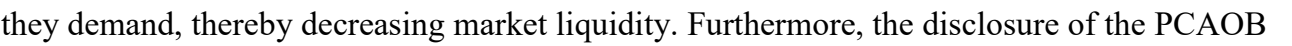

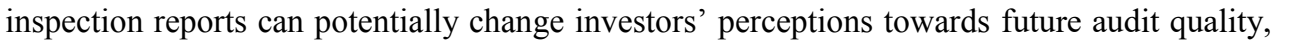

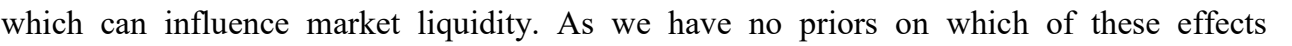

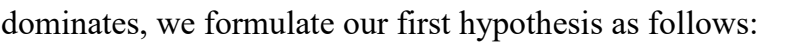

\section{$\square \square$ The publication of PCAOB inspection reports changes stock market liquidity. $\square$}

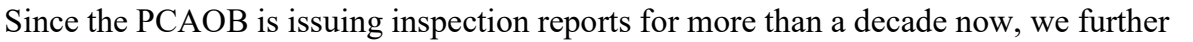

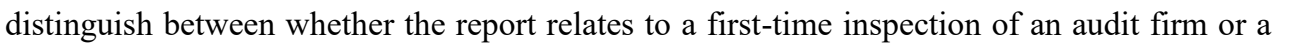

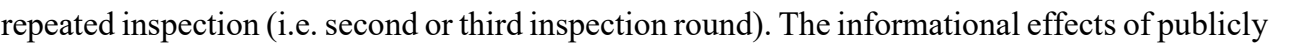

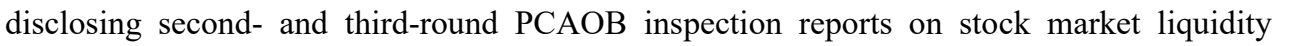

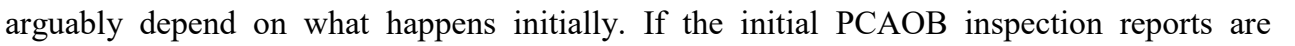
ए

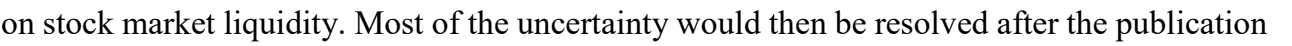

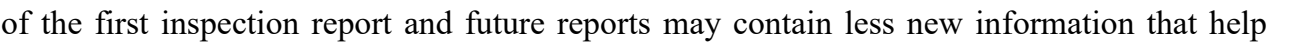

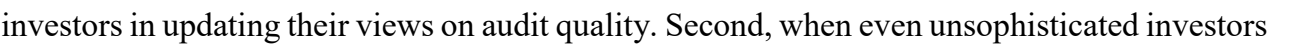

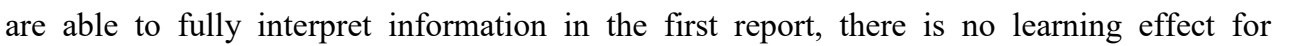

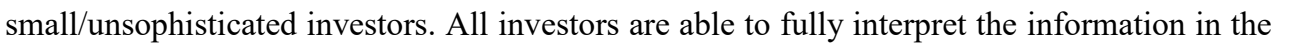

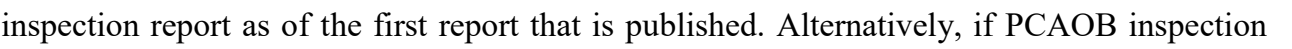
ए

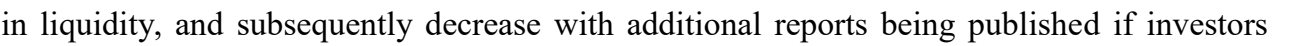
एण 


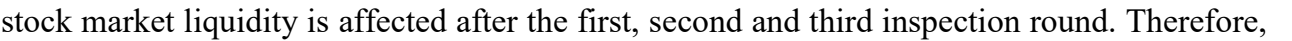

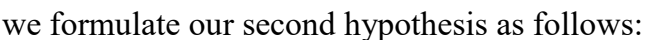

\section{$\square \square$ The effect of PCAOB inspection reports on stock market liquidity changes over time. $\square$}

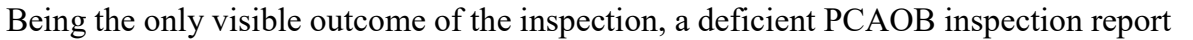
प प

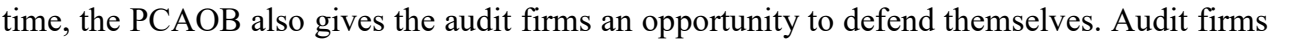

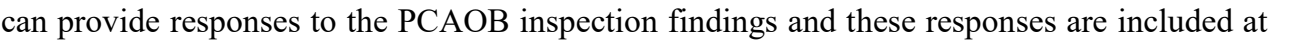

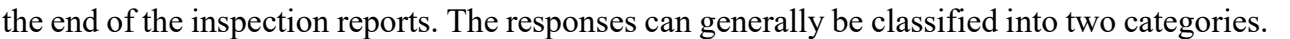

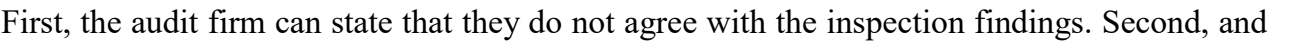

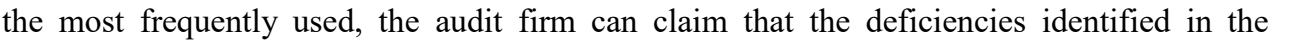

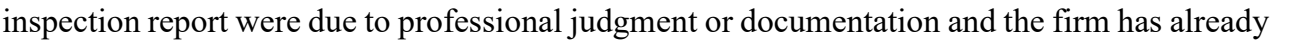

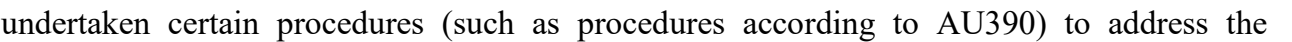
पणमाणा

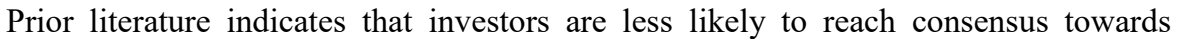

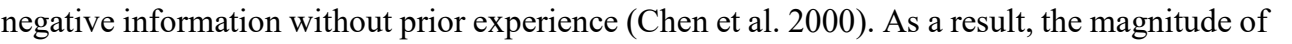

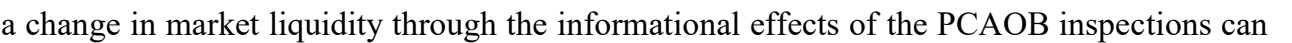

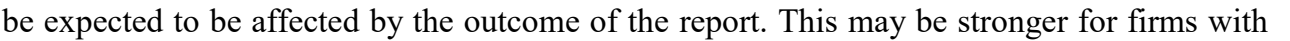

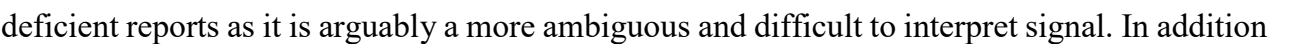

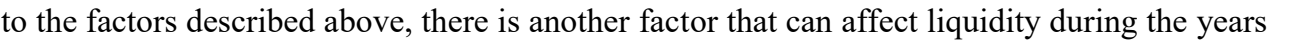

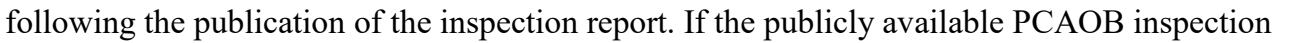

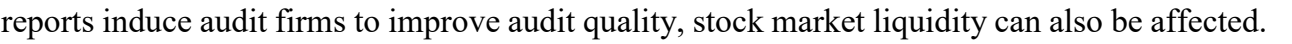

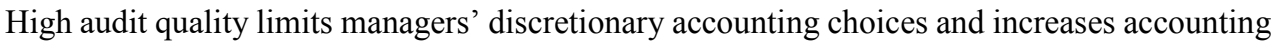

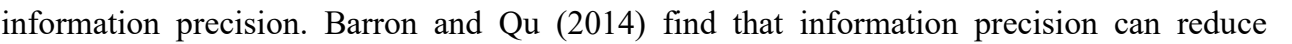

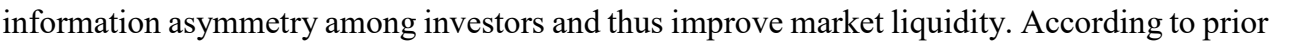

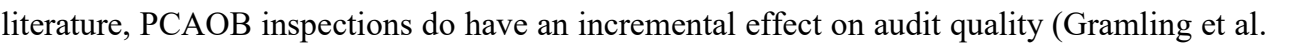

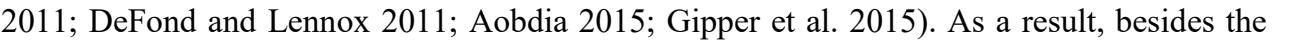

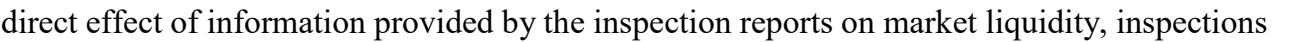

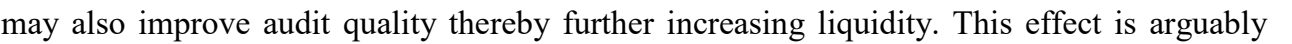

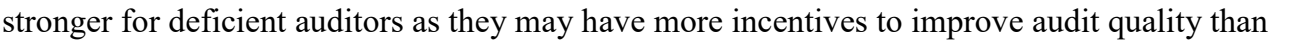

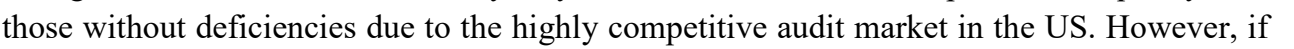

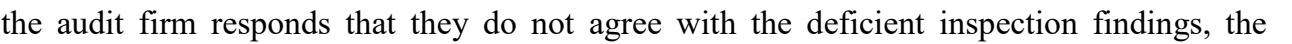

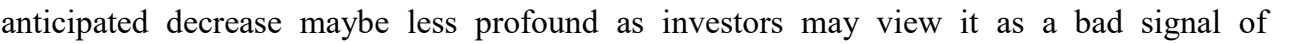

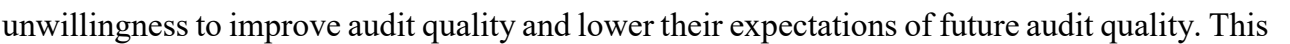

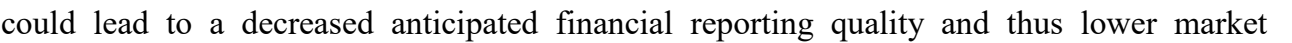
एणाणाणाए

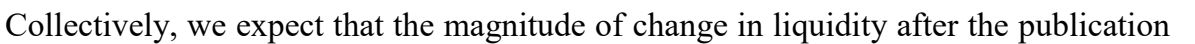

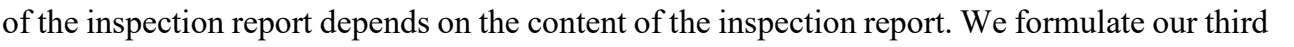

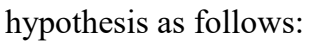


$\square \square$ The stock market liquidity change after the publication of the inspection report is different across clients of deficient audit firms stating disagreement with the $P C A O B$ 's findings, clients of deficient audit firms not stating disagreement with $P C A O B$ 's findings and clients of clean audit firms.

\subsection{Data and methodology}

\subsubsection{Data}

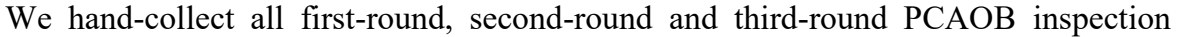

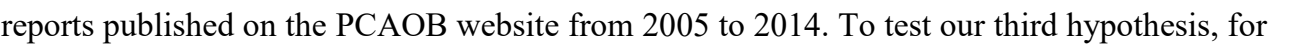
each inspection report, we further manually code the type of the report as "Deficient" or not,

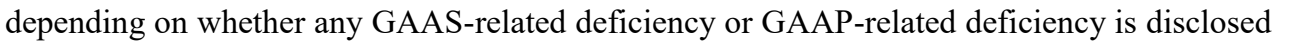

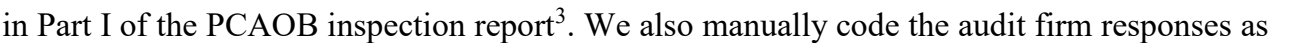
"Disagree" or not. If the audit firms state that they disagree or if they state that they do not fully agree with the PCAOB's findings, we code the responses as 1 for "Disagree". All other responses are labeled as 0 for "Disagree". We then match the reports with client information

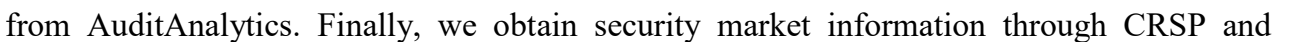

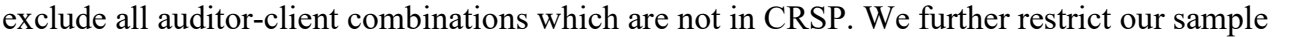

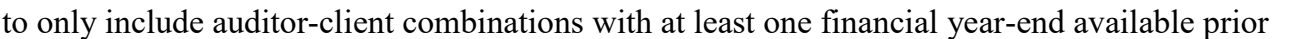

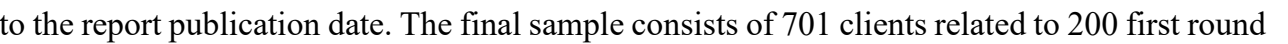
ए

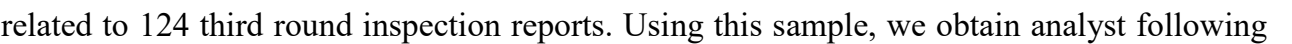

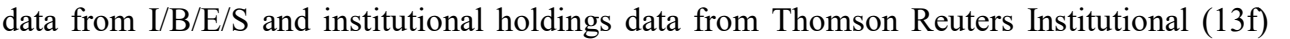

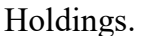

\subsubsection{Dependent variables}

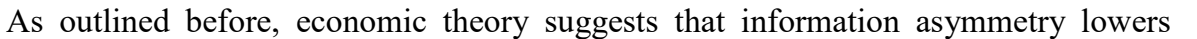

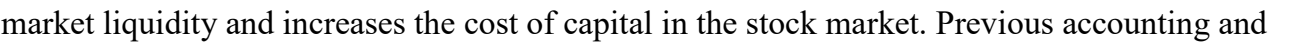

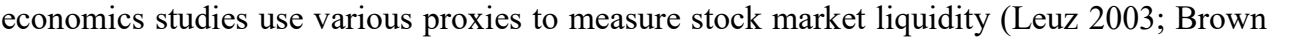

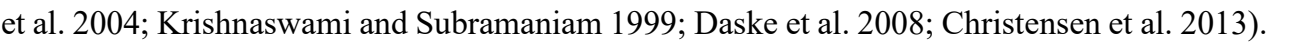

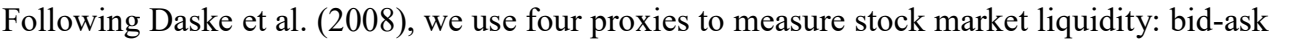

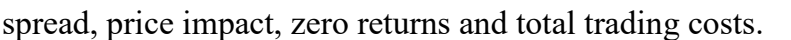

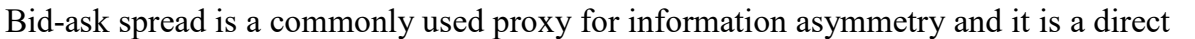

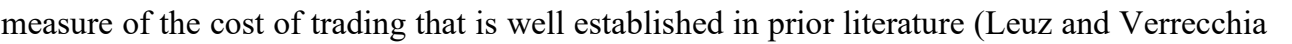

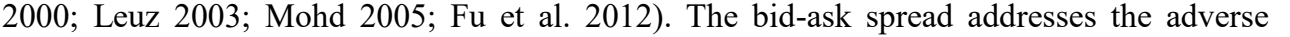
selection problem that arises from transactions in a firm's shares in the presence of

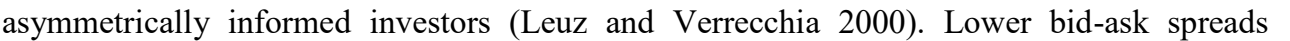

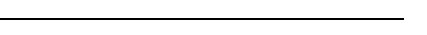

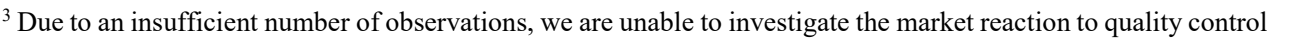

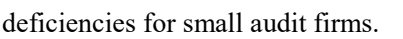




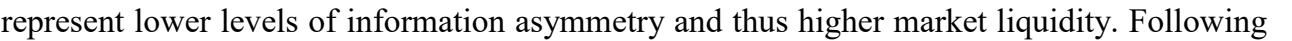

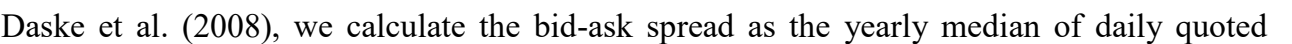

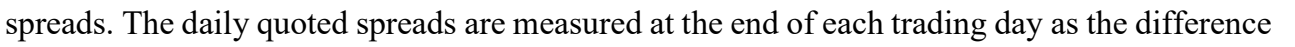

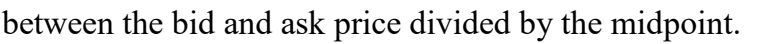

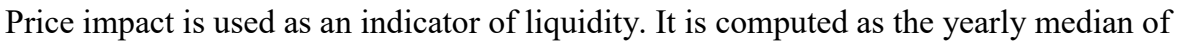

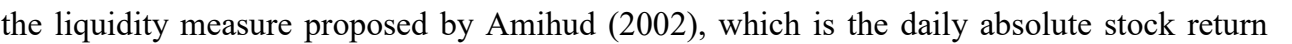

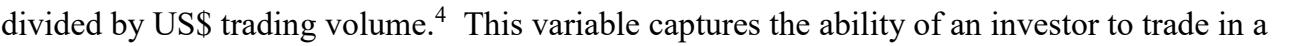

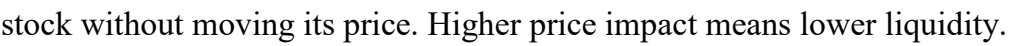

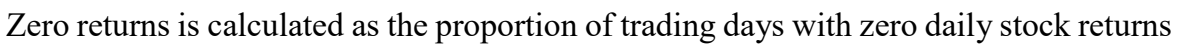

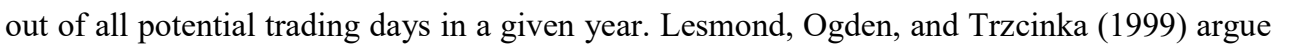

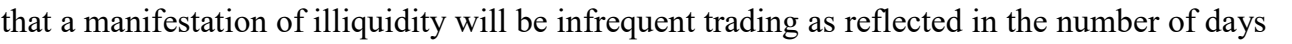

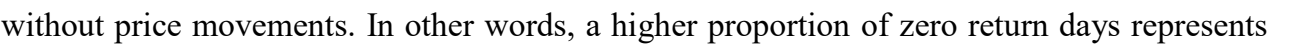

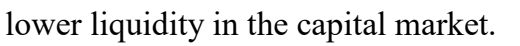

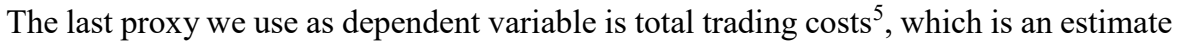

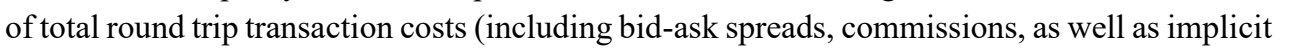

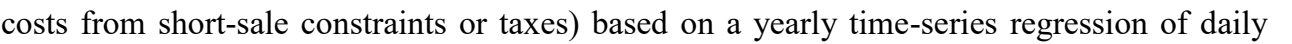

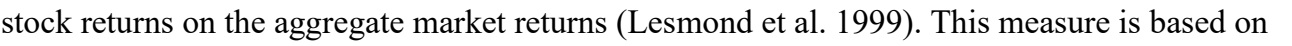

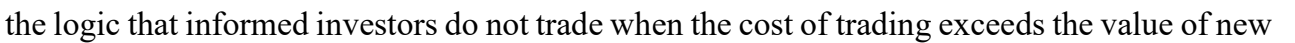

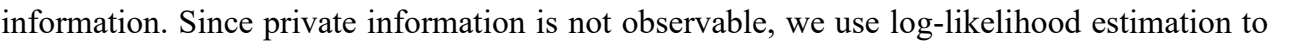
derive a proxy of total trading costs using a panel of firms' daily stock returns and equal $\square$

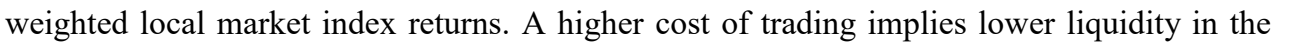

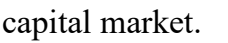

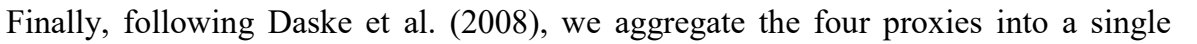

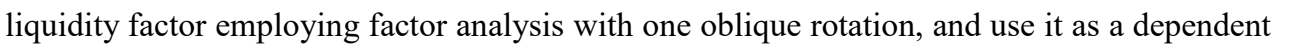

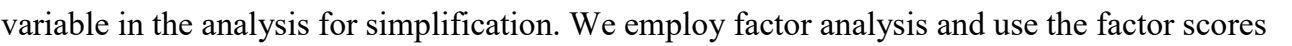

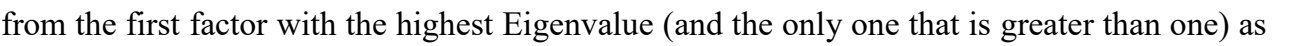

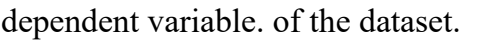

$\square$

\subsubsection{Research design and control variables}

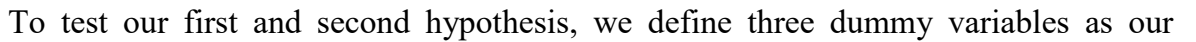

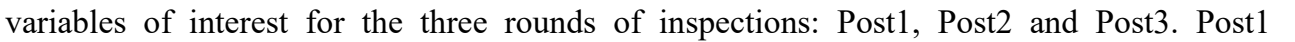

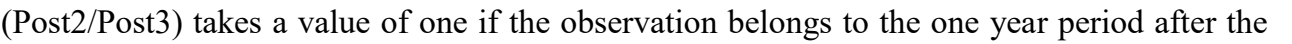

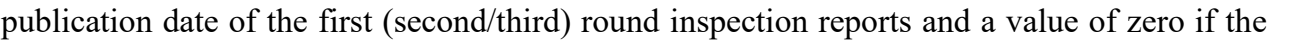

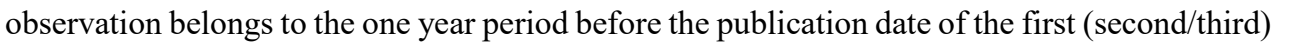

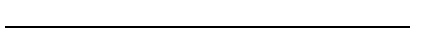

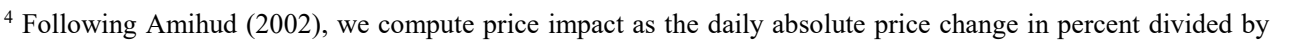

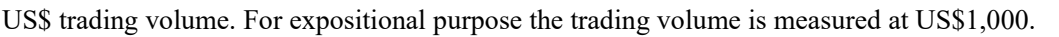

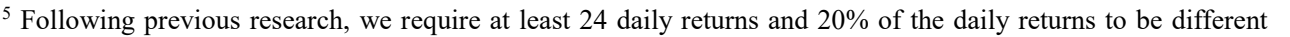

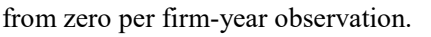




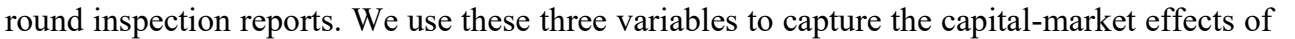

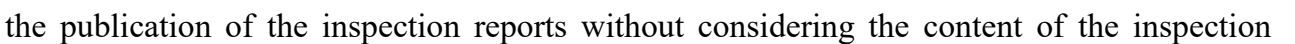
reports. For our third hypothesis, we combine our manually coded variable, "Deficient", with

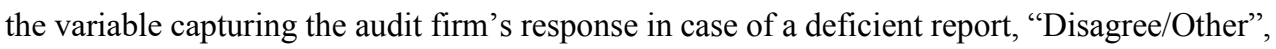

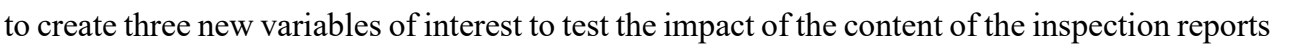

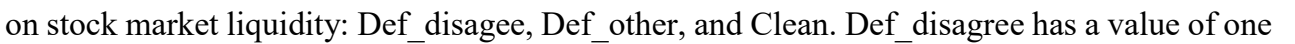

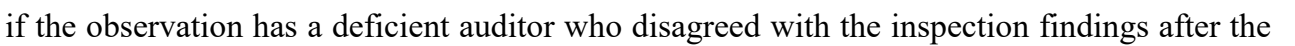

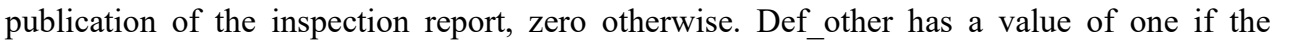

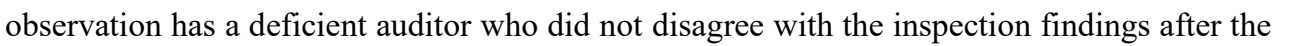

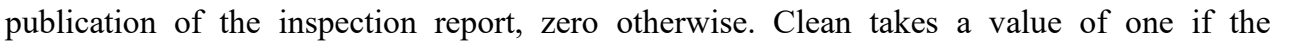
observation has a clean auditor after the publication of each round's inspection report, zero

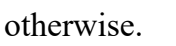

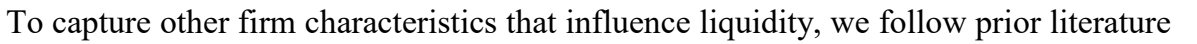

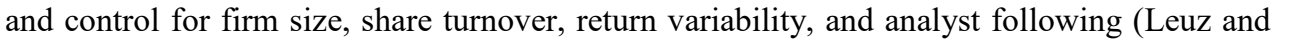

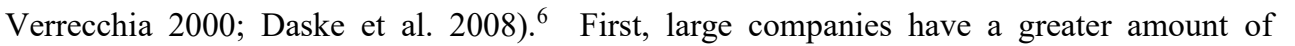

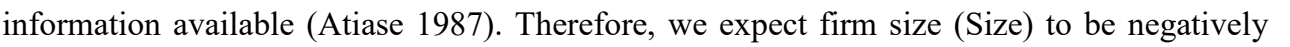

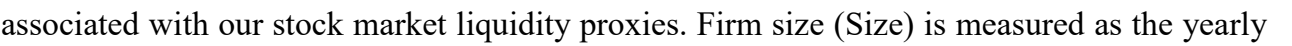

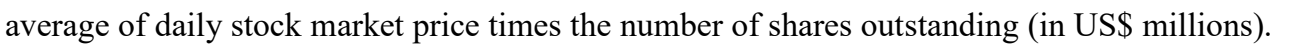

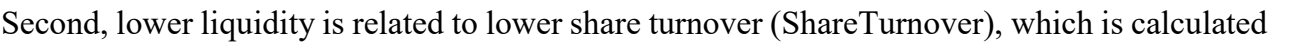

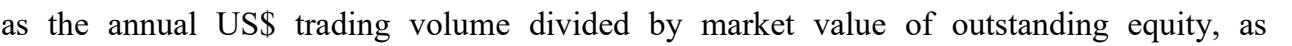

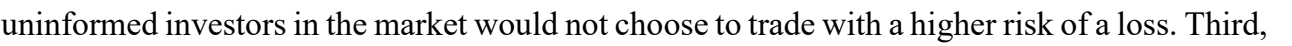

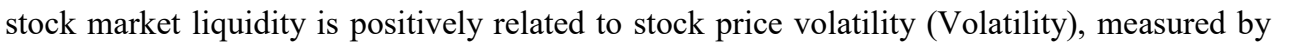

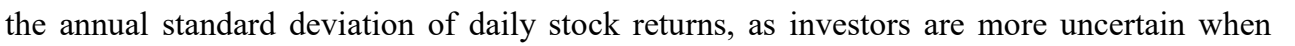

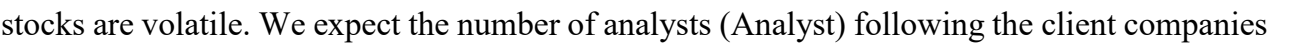
एण

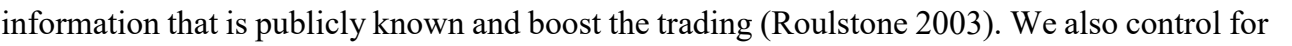

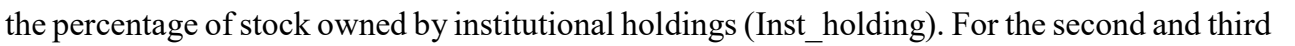
ए

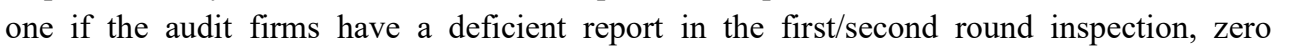

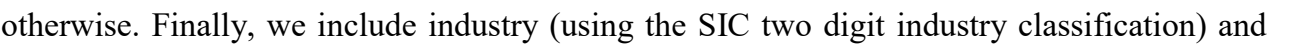

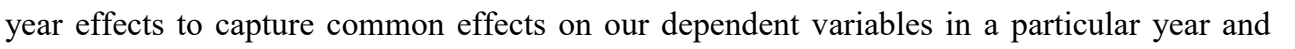
पापाणाणाए

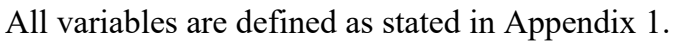

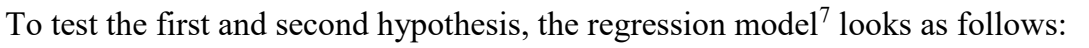
$\square$

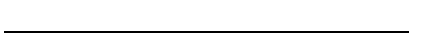

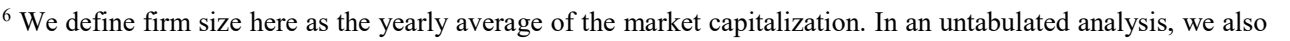

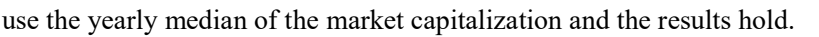

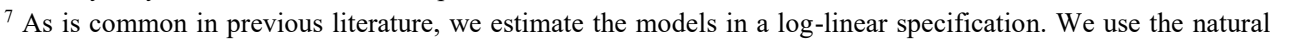

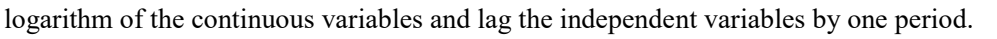




$$
\begin{gathered}
\text { IA Proxy }_{\mathrm{i}, \mathrm{t}}=\alpha_{0}+\alpha_{1} \text { Post }_{i, \mathrm{t}} 1 / 2 / 3+\alpha_{2} \text { Size }_{\mathrm{i}, \mathrm{t}-1}+\alpha_{3} \text { ShareTurnover }_{\mathrm{i}, \mathrm{t}-1} \\
+\alpha_{4} \text { Volatility }_{\mathrm{i}, \mathrm{t}-1}+\alpha_{5} \text { Analyst }_{\mathrm{i}, \mathrm{t}-1}+\alpha_{5} \text { Inst_holding }_{\mathrm{i}, \mathrm{t}-1}+\text { Year fixed effects }_{+}+ \\
\text {Industry fixed effects }+\delta
\end{gathered}
$$

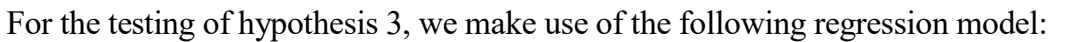

IA Proxy ${ }_{i, \mathrm{t}}=\alpha_{0}+\alpha_{1}$ Def_disagree $_{i}+\alpha_{2}$ Def_other $_{i}+\alpha_{3}$ Clean $_{\mathrm{i}}+\alpha_{4}$ Size $_{\mathrm{i}, \mathrm{t}-1}+$ $\alpha_{5}$ ShareTurnover $_{\mathrm{i}, \mathrm{t}-1}+\alpha_{6}$ Volatility $_{\mathrm{i}, \mathrm{t}-1}+\alpha_{7}$ Analyst $_{\mathrm{i}, \mathrm{t}-1}+\alpha_{8}$ Inst_holding $_{\mathrm{i}, \mathrm{t}-1}+$ Year fixed effects + Industry fixed effects $+\delta$

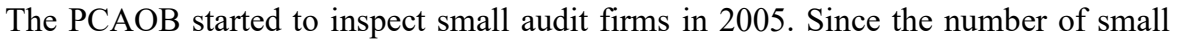

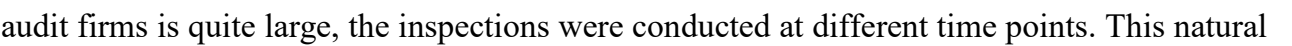

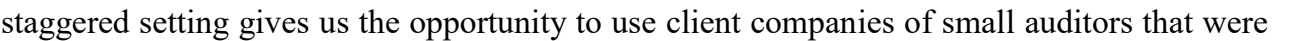

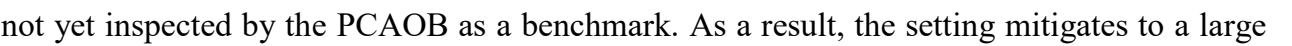

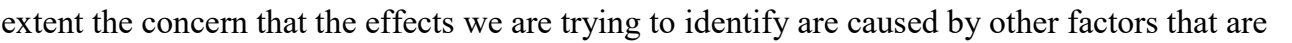

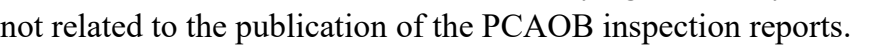

\subsection{Empirical results}

\subsubsection{Descriptive statistics}

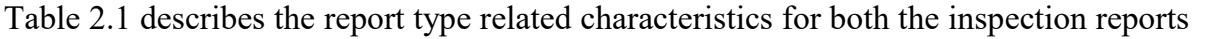

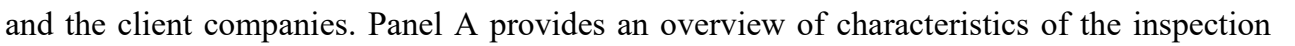

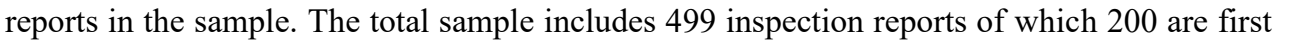

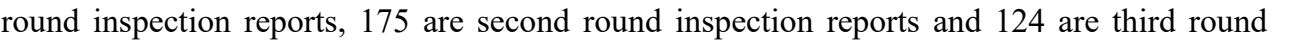

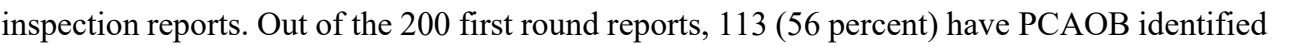

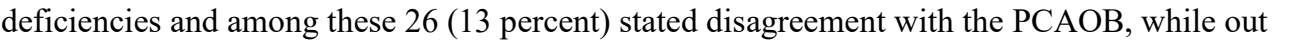

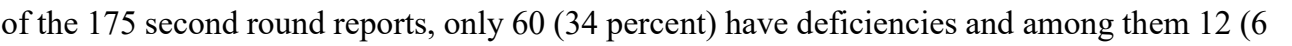

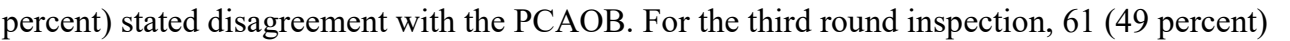

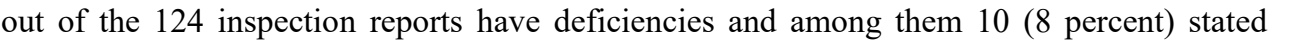

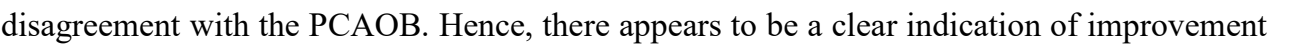

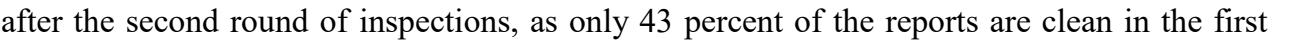

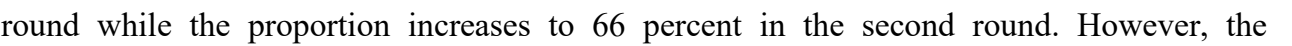

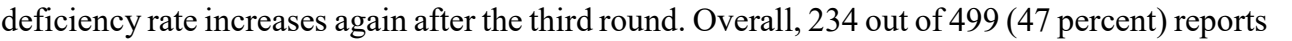

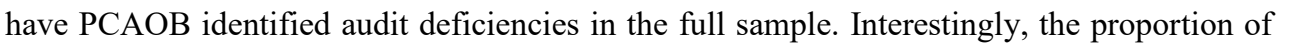

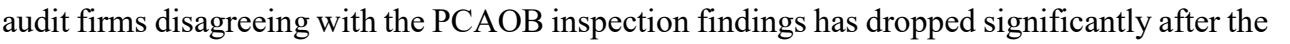
एव

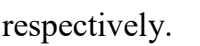

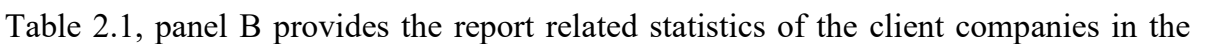

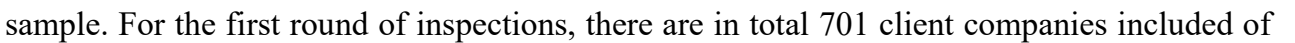

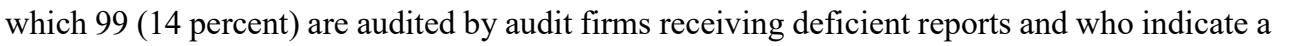




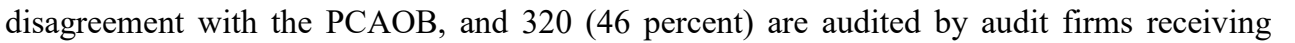

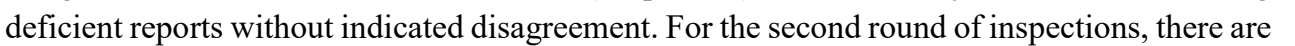

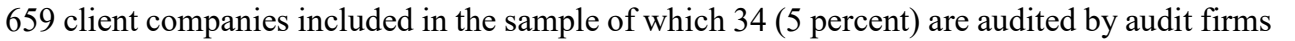

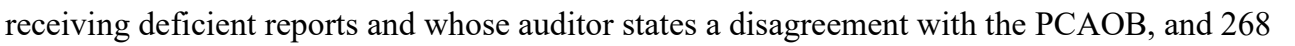

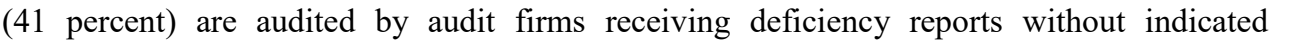

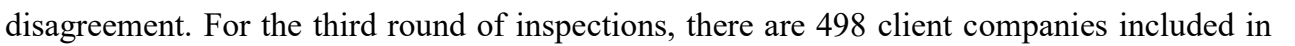

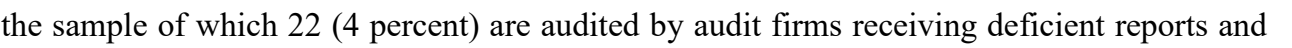

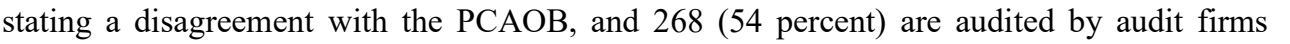

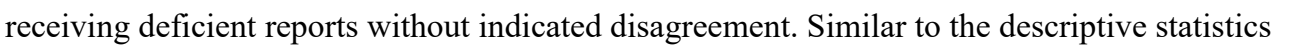

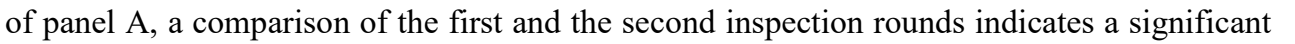
प

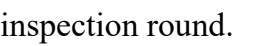

Table 2.1: Descriptives for PCAOB inspection results

Panel A: Inspection reports

\begin{tabular}{|c|c|c|c|c|c|c|c|c|}
\hline \multirow{2}{*}{$\frac{\square}{\text { Inspection results } \square}$} & \multicolumn{2}{|c|}{ First-round $\square$} & \multicolumn{2}{|c|}{ Second-round $\square$} & \multicolumn{2}{|c|}{ Third-round $\square$} & \multicolumn{2}{|r|}{ Total $\square$} \\
\hline & $\mathrm{N} \square$ & Percentage $\sqsubset$ & $\mathrm{N} \square$ & Percentage \lceil & $\mathrm{N} \square$ & Percentage [ & $\mathrm{N} \square$ & Percentage $\sqsubset$ \\
\hline Def_disagree $\square$ & $27 \square$ & $13.50 \square$ & $12 \square$ & $6.86 \square$ & $10 \square$ & $8.06 \square$ & $49 \square$ & $9.82 \square$ \\
\hline Def_other $\square$ & $86 \square$ & $43.00 \square$ & $48 \square$ & $27.43 \square$ & $51 \square$ & $41.13 \square$ & $185 \square$ & $37.07 \square$ \\
\hline Clean $\square$ & $87 \square$ & $43.50 \square$ & $115 \sqsubset$ & $65.71 \square$ & $63 \square$ & $50.81 \square$ & $265 \square$ & $53.11 \square$ \\
\hline Total $\square$ & $200 \square$ & $100.00 \square$ & $175 \sqsubset$ & $100.00 \square$ & $124 \sqsubset$ & $100.00 \square$ & $499 \square$ & $100.00 \square$ \\
\hline
\end{tabular}

Panel B: Report related characteristics of client companies $\square$

\begin{tabular}{|c|c|c|c|c|c|c|c|c|}
\hline$\square$ & \multicolumn{2}{|c|}{ First-round $\square$} & \multicolumn{2}{|c|}{ Second-round $\square$} & \multicolumn{2}{|c|}{ Third-round $\square$} & \multicolumn{2}{|r|}{ Total $\square$} \\
\hline Inspection results $\square$ & $\mathrm{N} \square$ & Percentage $\sqsubset$ & $\mathrm{N} \square$ & Percentage [ & $\mathrm{N} \square$ & Percentage [ & $\mathrm{N} \square$ & Percentage \\
\hline Def_disagree $\square$ & $99 \square$ & $14.12 \square$ & $34 \square$ & $5.16 \square$ & $22 \square$ & $4.42 \square$ & $155 \square$ & $8.34 \square$ \\
\hline Def_other $\square$ & $320 \square$ & $45.65 \square$ & $268 \sqsubset$ & $40.67 \square$ & $268 \sqsubset$ & $53.81 \square$ & $856 \square$ & $46.07 \square$ \\
\hline Clean $\square$ & $282 \square$ & $40.23 \square$ & $357 \sqsubset$ & $54.17 \square$ & $208 \sqsubset$ & $41.77 \square$ & $847 \square$ & $45.59 \square$ \\
\hline Total $\square$ & $701 \square$ & $100.00 \square$ & $659 \sqsubset$ & $100.00 \square$ & $498 \sqsubset$ & $100.00 \square$ & $1858 \sqsubset$ & $100.00 \square$ \\
\hline
\end{tabular}

All variables definitions are included in Appendix 1. 


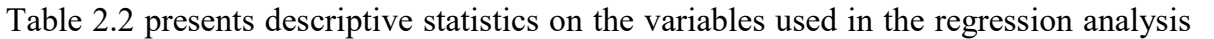

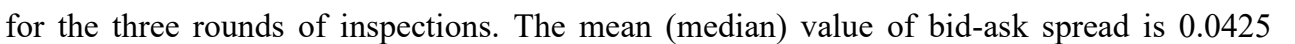

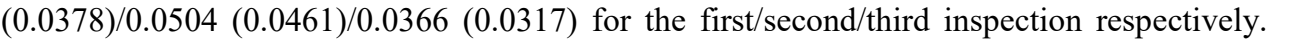

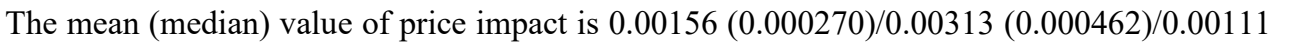

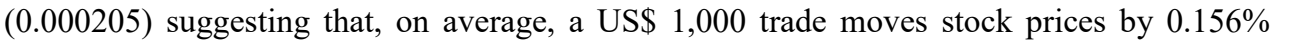

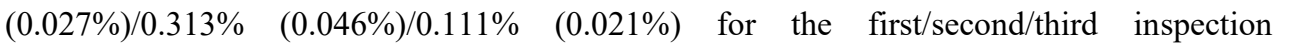

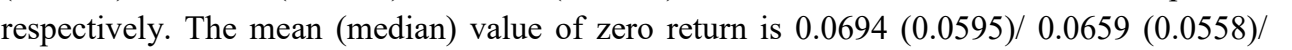

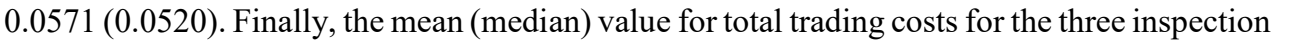

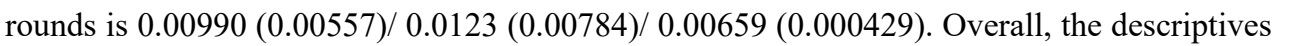

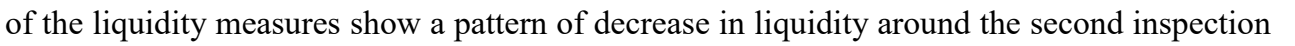

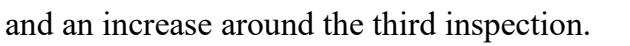

\begin{tabular}{lcccccc}
\hline \multicolumn{7}{c}{ Table 2.2: Descriptive Statistics $\square$} \\
\hline VARIABLES $\square$ & N $\square$ & mean $\square$ & p50 $\square$ & sd $\square$ & min $\square$ & $\max \square$ \\
\hline Panel A: First inspection $\square$ & & & & & & \\
\hline Bid_ask_spread $\square$ & $1,402 \square$ & $0.0425 \square$ & $0.0378 \square$ & $0.0272 \square$ & $0.00604 \square$ & $0.145 \square$ \\
Price Impact $\square$ & $1,402 \square$ & $0.00156 \square$ & $0.000270 \square$ & $0.00413 \square$ & $1.74 \mathrm{e}-06 \square$ & $0.0303 \square$ \\
Zero Return $\square$ & $1,402 \square$ & $0.0694 \square$ & $0.0595 \square$ & $0.0518 \square$ & $0.00395 \square$ & $0.250 \square$ \\
Total Trading Costs $\square$ & $1,402 \square$ & $0.00990 \square$ & $0.00557 \square$ & $0.0122 \square$ & $0.000174 \square$ & $0.0695 \square$ \\
\hline Size $\square$ & $1,402 \square$ & $130.9 \square$ & $73.57 \square$ & $178.9 \square$ & $5.772 \square$ & $1,123 \square$ \\
Share Turnover $\square$ & $1,402 \square$ & $1.250 \square$ & $0.474 \square$ & $2.274 \square$ & $0.0375 \square$ & $15.21 \square$ \\
Volatility $\square$ & $1,402 \square$ & $0.0338 \square$ & $0.0287 \square$ & $0.0203 \square$ & $0.00707 \square$ & $0.107 \square$ \\
Analyst $\square$ & $1,402 \square$ & $0.998 \square$ & $0.000 \square$ & $1.870 \square$ & $0.000 \square$ & $10.000 \square$ \\
Inst_holding $\square$ & $1,402 \square$ & $0.154 \square$ & $0.0860 \square$ & $0.192 \square$ & $0.000 \square$ & $0.875 \square$ \\
\hline Panel B: Second inspection $\square$ & & & & & & \\
\hline Bid_ask_spread $\square$ & $1,318 \square$ & $0.0504 \square$ & $0.0461 \square$ & $0.0257 \square$ & $0.0117 \square$ & $0.141 \square$ \\
Price Impact $\square$ & $1,318 \square$ & $0.00313 \square$ & $0.000462 \square$ & $0.00786 \square$ & $1.53 \mathrm{e}-06 \square$ & $0.0513 \square$ \\
Zero Return $\square$ & $1,318 \square$ & $0.0659 \square$ & $0.0558 \square$ & $0.0469 \square$ & $0.000 \square$ & $0.234 \square$ \\
Total Trading Costs $\square$ & $1,318 \square$ & $0.0123 \square$ & $0.00784 \square$ & $0.0141 \square$ & $0.000444 \square$ & $0.0799 \square$ \\
\hline Size $\square$ & $1,318 \square$ & $113.1 \square$ & $53.20 \square$ & $153.1 \square$ & $3.111 \square$ & $866.0 \square$ \\
Share Turnover $\square$ & $1,318 \square$ & $1.180 \square$ & $0.454 \square$ & $2.218 \square$ & $0.0413 \square$ & $15.49 \square$ \\
Volatility $\square$ & $1,318 \square$ & $0.0495 \square$ & $0.0436 \square$ & $0.0272 \square$ & $0.0117 \square$ & $0.162 \square$ \\
Analyst $\square$ & $1,318 \square$ & $1.256 \square$ & $0.000 \square$ & $2.091 \square$ & $0.000 \square$ & $10.000 \square$ \\
Inst_holding $\square$ & $1,318 \square$ & $0.192 \square$ & $0.121 \square$ & $0.209 \square$ & $0.000 \square$ & $0.877 \square$ \\
\hline & & & & & & \\
\hline
\end{tabular}


Table 2.2 Continued

\section{Panel C: Third inspection}

\begin{tabular}{|c|c|c|c|c|c|c|}
\hline Bid_ask_spread $\square$ & $996 \square$ & $0.0366 \square$ & $0.0317 \square$ & $0.0201 \square$ & $0.00809 \square$ & $0.104 \square$ \\
\hline Price Impact $\square$ & $996 \square$ & $0.00111 \square$ & $0.000205 \square$ & $0.00258 \square$ & $7.95 \mathrm{e}-07 \square$ & $0.0178 \square$ \\
\hline Zero Return $\square$ & $996 \square$ & $0.0571 \square$ & $0.0520 \square$ & $0.0377 \square$ & $0.000 \square$ & $0.190 \square$ \\
\hline Total Trading Costs $\square$ & $996 \square$ & $0.00659 \square$ & $0.00429 \square$ & $0.00681 \square$ & $2.02 \mathrm{e}-07 \square$ & $0.0356 \square$ \\
\hline Size $\square$ & $996 \square$ & $144.8 \square$ & $55.68 \square$ & $256.9 \square$ & $3.623 \square$ & $1,577 \square$ \\
\hline Share Turnover $\square$ & $996 \square$ & $1.287 \square$ & $0.544 \square$ & $2.421 \square$ & $0.0468 \square$ & $16.04 \square$ \\
\hline Volatility $\square$ & $996 \square$ & $0.0367 \square$ & $0.0323 \square$ & $0.0197 \square$ & $0.0103 \square$ & $0.112 \square$ \\
\hline Analyst $\square$ & $996 \square$ & $1.666 \square$ & $1.000 \square$ & $2.546 \square$ & 0.000 & $12.000 \square$ \\
\hline Inst_holding $\square$ & $996 \square$ & $0.228 \square$ & $0.152 \square$ & $0.224 \square$ & 0.000 & $0.903 \square$ \\
\hline
\end{tabular}

All continuous variables winsorized at the $1 \%$ and $99 \%$ level. $\square$

All variables definitions can be found in Appendix 1.

\subsubsection{Univariate analysis}

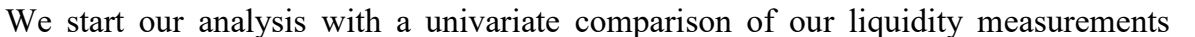

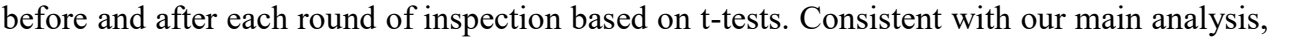

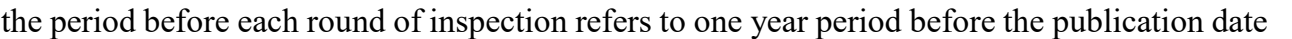

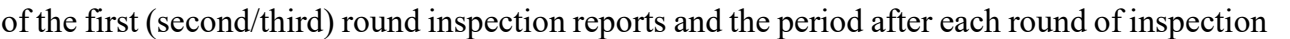

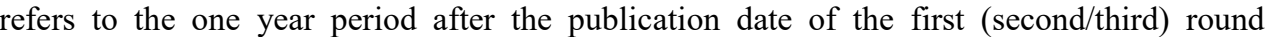

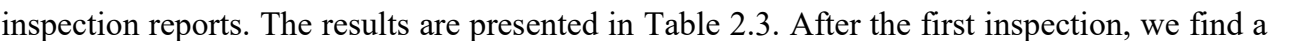

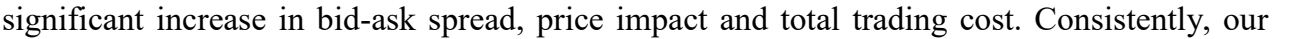

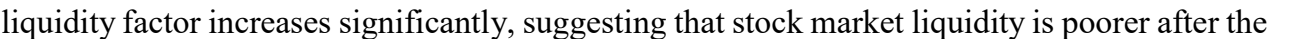
ए

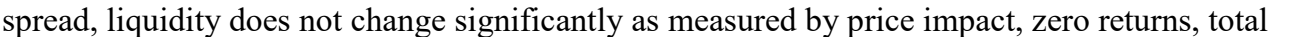

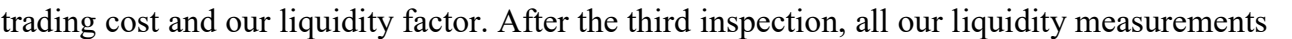

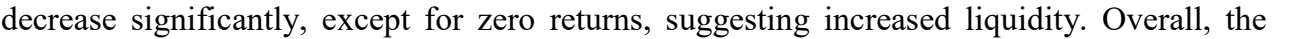

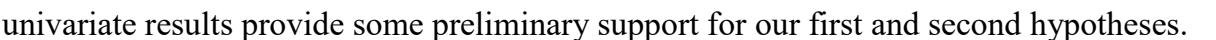


Table 2.3 Univariate Analysis

\begin{tabular}{|c|c|c|c|c|c|c|c|c|c|}
\hline \multirow{2}{*}{$\frac{\square}{\square}$} & \multicolumn{3}{|c|}{ First Inspection $\square$} & \multicolumn{3}{|c|}{ Second Inspection $\square$} & \multicolumn{3}{|c|}{ Third Inspection $\square$} \\
\hline & Pre $\square$ & Post $\square$ & $\operatorname{Diff} \square$ & Pre $\square$ & Post $\square$ & Diff $\square$ & Pre $\square$ & Post $\square$ & Diff $\square$ \\
\hline $\begin{array}{l}\text { Log_Bid-ask } \\
\text { spread } \square\end{array}$ & -3.493[ & $-3.250 \square$ & $0.243 * * * \square$ & -3.094 & $-3.135 \square$ & $-0.041 * \square$ & -3.431[ & $-3.480 \square$ & $-0.049 *$ \\
\hline Log_Price impact $\square$ & -8.590[ & $-8.088 \square$ & $0.502 * * * \square$ & -7.847 & $-7.812 \square$ & $-0.035 \square$ & -8.592[ & $-8.868 \square$ & $\begin{array}{c}- \\
0.276^{* *}\end{array}$ \\
\hline Zero return $\square$ & $0.070 \sqsubset$ & $0.069 \square$ & $\square-0.001 \square$ & 0.065 & $0.067 \square$ & $-0.002 \square$ & $0.059 \sqsubset$ & $0.055 \square$ & $-0.004 *[$ \\
\hline Log_Trading cost $\square$ & -5.357 & $-5.102 \square$ & $0.255 * * * \square$ & -4.932 & $-4.934 \square$ & $-0.002 \square$ & -5.633 & $-5.712 \square$ & -0.079 \\
\hline Liquidity factor $\square$ & -0.088[ & $0.088 \square$ & $0.176^{* * *} \square$ & -0.001 & $0.006 \square$ & $0.007 \square$ & 0.048[ & $-0.044 \square$ & $-0.092 *$ \\
\hline
\end{tabular}

All continuous variables winsorized at the $1 \%$ and $99 \%$ level.

All variables definitions can be found in Appendix 1.

$\square$

\subsubsection{Multivariate analysis}

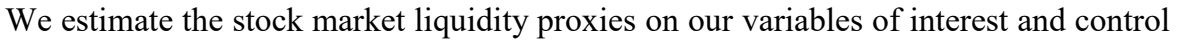

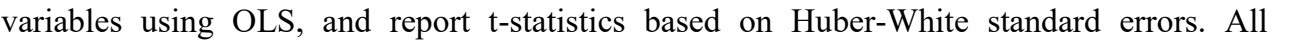

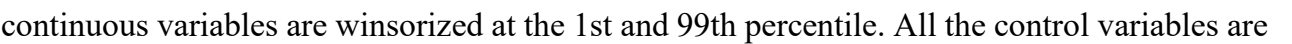

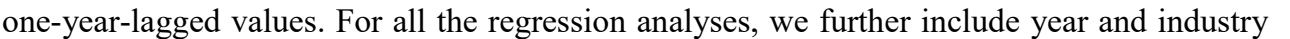

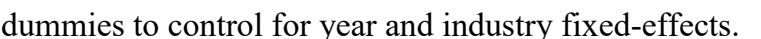

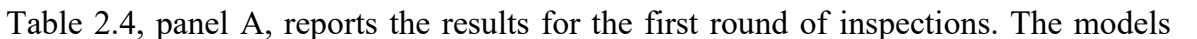

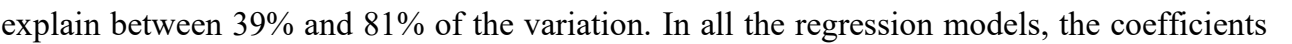

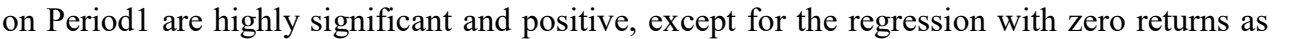

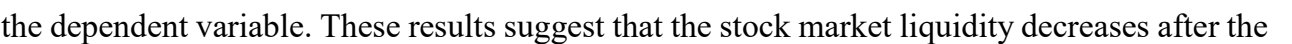

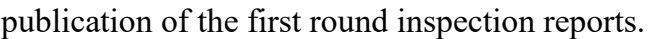

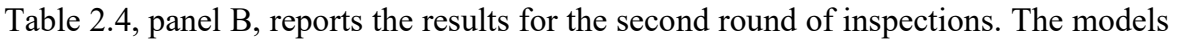

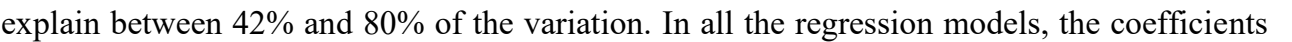

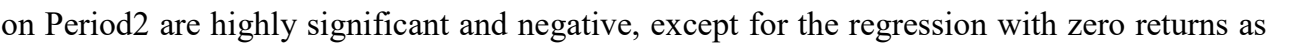
प

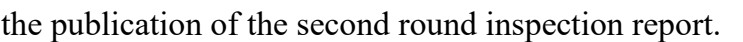

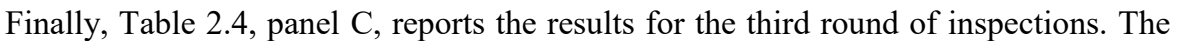

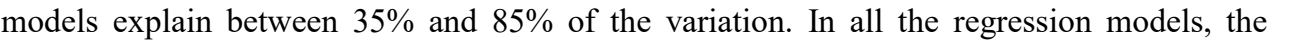

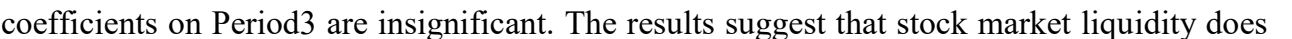

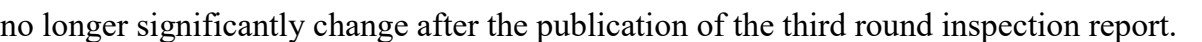

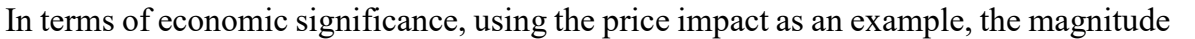

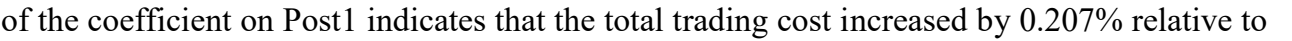

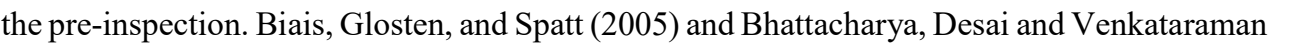

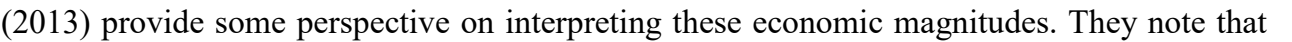

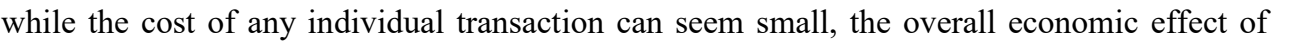

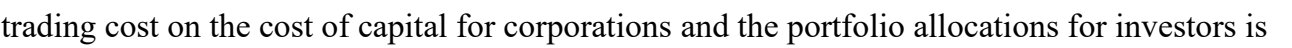

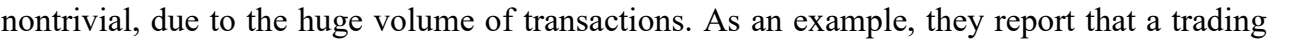




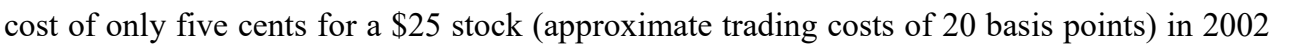

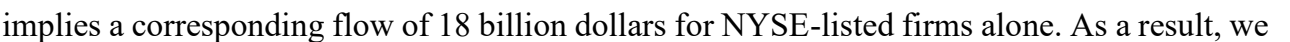

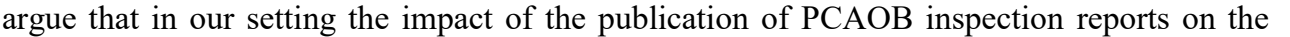

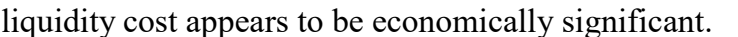

\begin{tabular}{|c|c|c|c|c|c|}
\hline \multicolumn{6}{|c|}{ Table 2.4: Pooled regression results } \\
\hline 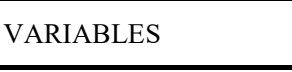 & 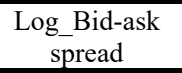 & 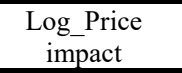 & पणणाणाण & 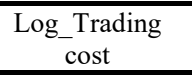 & 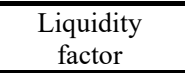 \\
\hline \multicolumn{6}{|l|}{ Panel A: First inspection $\square$} \\
\hline 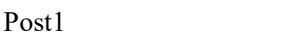 & $0.158 * * * \square$ & $0.464 * * * \square$ & $-0.00107 \square$ & $0.207 * * * \square$ & $0.150 * * * \square$ \\
\hline$\square$ & $(4.436) \square$ & $(8.478) \square$ & $(-0.813) \square$ & $(3.519) \square$ & $(3.956) \square$ \\
\hline 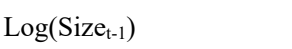 & $0.0459 * \square$ & $-1.179 * * * \square$ & $-0.0205 * * * \square$ & $-0.481 * * * \square$ & $-0.442 * * * \square$ \\
\hline$\square$ & $(1.749) \square$ & $(-20.72) \square$ & $(-6.523) \square$ & $(-7.101) \square$ & $(-8.048) \square$ \\
\hline 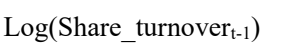 & $-0.00425 \square$ & $-0.809 * * * \square$ & $-0.0136 * * * \square$ & $-0.286 * * * \square$ & $-0.272 * * * \square$ \\
\hline$\square$ & $(-0.193) \square$ & $(-27.67) \square$ & $(-13.95) \square$ & $(-8.659) \square$ & $(-12.18) \square$ \\
\hline 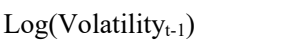 & $0.791 * * * \square$ & $0.770 * * * \square$ & $0.00347 \square$ & $0.665^{* * * *} \square$ & $0.430 * * * \square$ \\
\hline$\square$ & $(23.75) \square$ & $(11.53) \square$ & $(0.537) \square$ & $(5.197) \square$ & $(4.384) \square$ \\
\hline 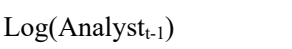 & $0.0668 * * * \square$ & $-0.0508 \square$ & $-0.00288 \square$ & $-0.0278 \square$ & $-0.0329 \square$ \\
\hline$\square$ & $(3.007) \square$ & $(-1.135) \square$ & $(-1.256) \square$ & $(-0.483) \square$ & $(-0.802) \square$ \\
\hline 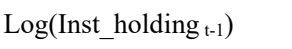 & $-0.165^{*} \square$ & $-0.234 \square$ & $-0.0117 \square$ & $-0.537 * * \square$ & $-0.373 * * \square$ \\
\hline$\square$ & $(-1.781) \square$ & $(-1.007) \square$ & $(-1.103) \square$ & $(-2.348) \square$ & $(-2.121) \square$ \\
\hline 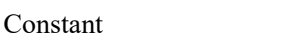 & $-1.304 * * * \square$ & $-1.907 * * * \square$ & $0.214 * * * \square$ & $-1.326 * * * \square$ & $3.154 * * * \square$ \\
\hline$\square$ & $(-5.765) \square$ & $(-3.204) \square$ & $(10.34) \square$ & $(-2.857) \square$ & $(9.166) \square$ \\
\hline 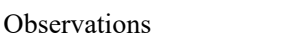 & $1,402 \square$ & $1,402 \square$ & $1,402 \square$ & $1,402 \square$ & $1,402 \square$ \\
\hline पणणाणम & $0.712 \square$ & $0.814 \square$ & $0.420 \square$ & $0.599 \square$ & $0.640 \square$ \\
\hline 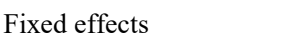 & Year/industry [ & Year/industry $\square$ & Year/industry [ & Year/industry $\square$ & Year/industry $\square$ \\
\hline पणापणाणाप & $0.698 \square$ & $0.805 \square$ & $0.393 \square$ & $0.580 \square$ & $0.623 \square$ \\
\hline
\end{tabular}


Table 2.4 continued

\begin{tabular}{|c|c|c|c|c|c|}
\hline \multicolumn{6}{|c|}{ Panel B: Second inspection $\square$} \\
\hline 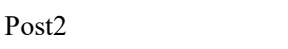 & $-0.0985 * * * \square$ & $-0.232 * * * \square$ & $-0.00154 \square$ & $-0.139 * * * \square$ & $-0.110 * * * \square$ \\
\hline$\square$ & $(-4.742) \square$ & $(-3.904) \square$ & $(-0.770) \square$ & $(-3.379) \square$ & $(-3.180) \square$ \\
\hline$\square \square \square$ & $0.0339 \square$ & $0.148 * * \square$ & $-0.000920 \square$ & $0.101 * * \square$ & $0.0763 * * \square$ \\
\hline$\square$ & $(1.457) \square$ & $(2.219) \square$ & $(-0.411) \square$ & $(2.201) \square$ & $(1.970) \square$ \\
\hline 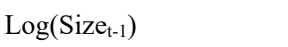 & $-0.00582 \square$ & $-1.215 * * * \square$ & $-0.0167 * * * \square$ & $-0.397 * * * \square$ & $-0.387 * * * \square$ \\
\hline$\square$ & $(-0.428) \square$ & $(-31.21) \square$ & $(-12.77) \square$ & $(-14.81) \square$ & $(-17.11) \square$ \\
\hline 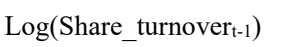 & $0.0348 * * * \square$ & $-0.697 * * * \square$ & $-0.0112 * * * \square$ & $-0.174 * * * \square$ & $-0.189 * * * \square$ \\
\hline$\square$ & $(3.134) \square$ & $(-21.93) \square$ & $(-10.46) \square$ & $(-7.961) \square$ & $(-10.24) \square$ \\
\hline 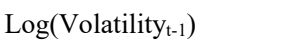 & $0.527 * * * \square$ & $0.409 * * * \square$ & $0.00417 * \square$ & $0.593 * * * \square$ & $0.432 * * * \square$ \\
\hline$\square$ & $(20.64) \square$ & $(5.601) \square$ & $(1.703) \square$ & $(11.78) \square$ & $(10.18) \square$ \\
\hline 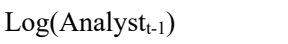 & $0.00741 \square$ & $-0.169 * * * \square$ & $-0.00254 \square$ & $-0.0828 * \square$ & $-0.0749 * * \square$ \\
\hline$\square$ & $(0.342) \square$ & $(-2.720) \square$ & $(-1.221) \square$ & $(-1.935) \square$ & $(-2.079) \square$ \\
\hline 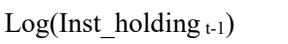 & $-0.188 * * \square$ & $-0.293 \square$ & $-0.00876 \square$ & $-0.397 * * \square$ & $-0.314 * * \square$ \\
\hline$\square$ & $(-2.121) \square$ & $(-1.152) \square$ & $(-1.028) \square$ & $(-2.266) \square$ & $(-2.132) \square$ \\
\hline पएणता & $-1.273 * * * \square$ & $-3.152 * * * \square$ & $0.0976 * * * \square$ & $-2.132 * * * \square$ & $2.232 * * * \square$ \\
\hline$\square$ & $(-4.270) \square$ & $(-3.692) \square$ & $(3.409) \square$ & $(-3.623) \square$ & $(4.505) \square$ \\
\hline 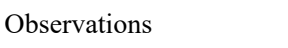 & $1,318 \square$ & $1,318 \square$ & $1,318 \square$ & $1,318 \square$ & $1,318 \square$ \\
\hline 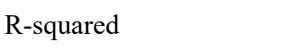 & $0.505 \square$ & $0.805 \square$ & $0.446 \square$ & $0.567 \square$ & $0.605 \square$ \\
\hline 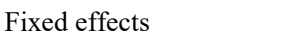 & Year/industry [ & Year/industry $\square$ & Year/industry [ & Year/industry $\square$ & Year/industry \\
\hline 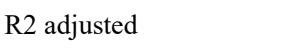 & $0.480 \square$ & $0.795 \square$ & $0.419 \square$ & $0.545 \square$ & $0.585 \square$ \\
\hline \multicolumn{6}{|c|}{ Panel C: Third inspection $\square$} \\
\hline 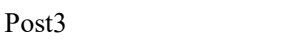 & $0.0307 \square$ & $-0.0593 \square$ & $-0.00158 \square$ & $0.0686 \square$ & $0.000405 \square$ \\
\hline$\square$ & $(1.479) \square$ & $(-1.035) \square$ & $(-0.815) \square$ & $(0.868) \square$ & $(0.0119) \square$ \\
\hline पवाण & $-0.0152 \square$ & $-0.0531 \square$ & $0.000785 \square$ & $-0.0361 \square$ & $-0.0109 \square$ \\
\hline$\square$ & $(-0.663) \square$ & $(-0.841) \square$ & $(0.366) \square$ & $(-0.413) \square$ & $(-0.290) \square$ \\
\hline 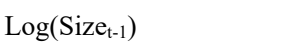 & $-0.0177 \square$ & $-1.038 * * * \square$ & $-0.0110 * * * \square$ & $-0.388 * * * \square$ & $-0.316^{* * *} \square$ \\
\hline$\square$ & $(-1.326) \square$ & $(-28.17) \square$ & $(-8.770) \square$ & $(-7.617) \square$ & $(-14.42) \square$ \\
\hline 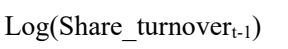 & $-0.0134 \square$ & $-0.757 * * * \square$ & $-0.009 * * * \square$ & $-0.313 * * * \square$ & $-0.251 * * * \square$ \\
\hline$\square$ & $(-1.127) \square$ & $(-23.06) \square$ & $(-8.639) \square$ & $(-6.914) \square$ & $(-12.89) \square$ \\
\hline 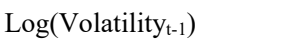 & $0.683 * * * \square$ & $0.751 * * * \square$ & $0.00487^{*} \square$ & $0.736^{* * *} \square$ & $0.419 * * * \square$ \\
\hline$\square$ & $(24.80) \square$ & $(9.901) \square$ & $(1.890) \square$ & $(7.024) \square$ & $(9.300) \square$ \\
\hline
\end{tabular}




\begin{tabular}{|c|c|c|c|c|c|}
\hline \multicolumn{6}{|c|}{ Table 2.4 continued } \\
\hline 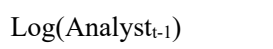 & $0.0911 * * * \square$ & $-0.262 * * * \square$ & $0.000747 \square$ & $0.126 \square$ & $0.0185 \square$ \\
\hline$\square$ & $(4.471) \square$ & $(-4.658) \square$ & $(0.392) \square$ & $(1.619) \square$ & $(0.554) \square$ \\
\hline 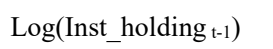 & $-0.0151 \square$ & $-0.421 * \square$ & $-0.0172 * * \square$ & $-1.338 * * * \square$ & $-0.516 * * * \square$ \\
\hline$\square$ & $(-0.165) \square$ & $(-1.666) \square$ & $(-2.008) \square$ & $(-3.831) \square$ & $(-3.434) \square$ \\
\hline 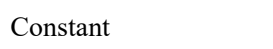 & $-0.399 \square$ & $-2.121 * * * \square$ & $0.116 * * * \square$ & $-0.624 \square$ & $3.010 * * * \square$ \\
\hline$\square$ & $(-1.367) \square$ & $(-2.635) \square$ & $(4.251) \square$ & $(-0.561) \square$ & $(6.294) \square$ \\
\hline 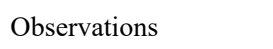 & $996 \square$ & $996 \square$ & $996 \square$ & $996 \square$ & $996 \square$ \\
\hline पाणायाए & $0.682 \square$ & $0.858 \square$ & $0.390 \square$ & $0.463 \square$ & $0.667 \square$ \\
\hline 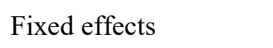 & Year/industry [ & Year/industry $\square$ & Year/industry [ & Year/industry $\square$ & Year/industry $\square$ \\
\hline पणमाणाणा & $0.663 \square$ & $0.850 \square$ & $0.352 \square$ & $0.430 \square$ & $0.646 \square$ \\
\hline 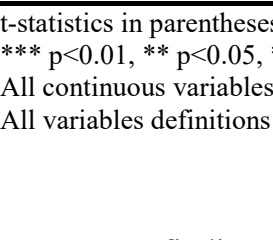 & 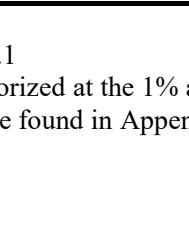 & 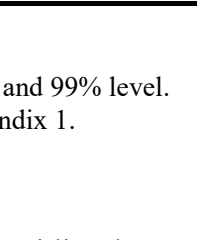 & & & \\
\hline
\end{tabular}

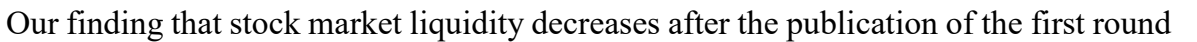

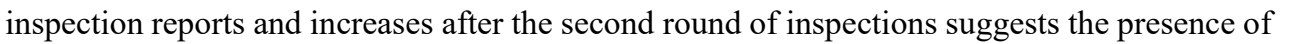

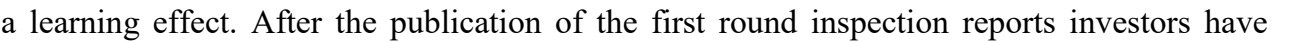

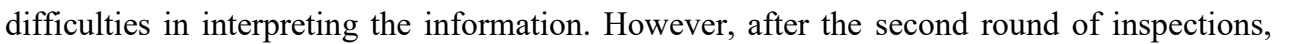

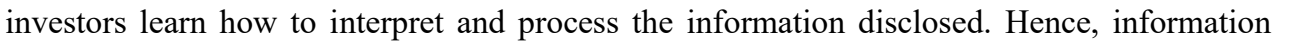

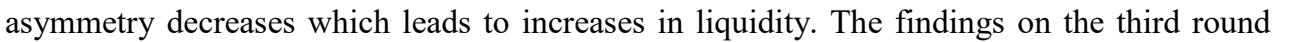

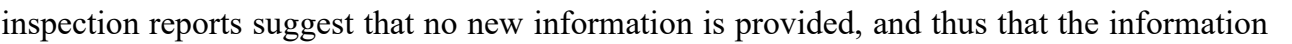

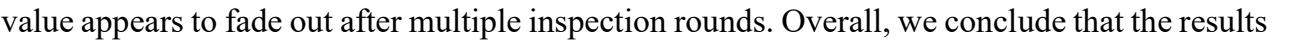

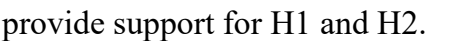

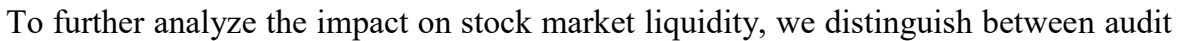

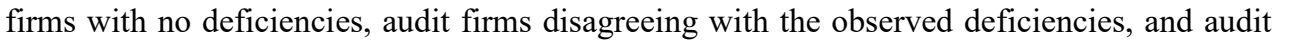
ए

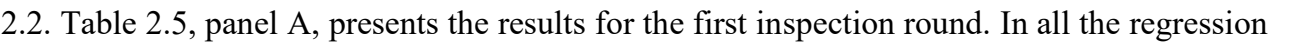

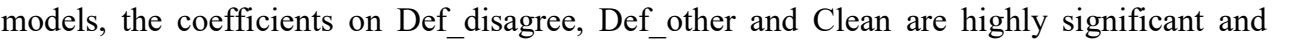

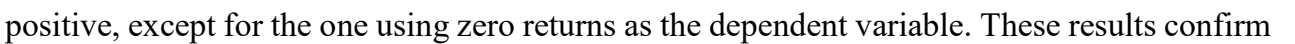

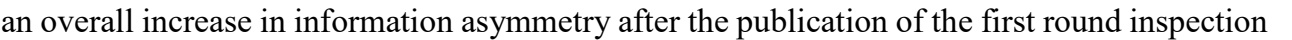

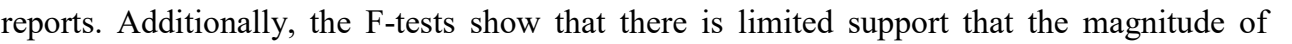

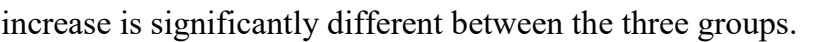

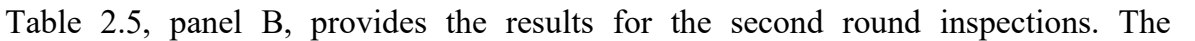

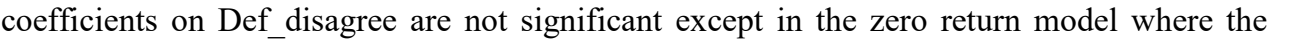

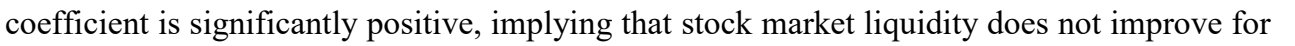

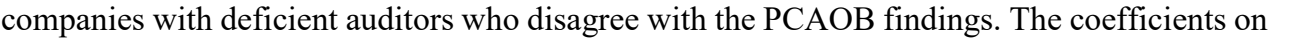

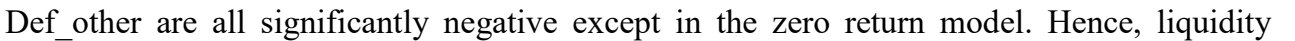




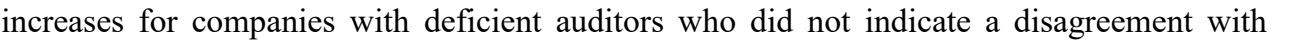

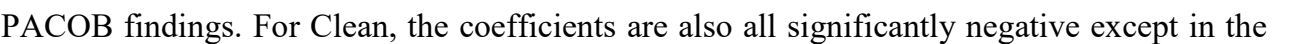

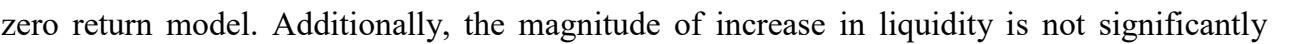

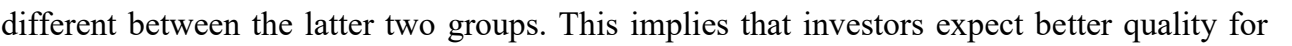

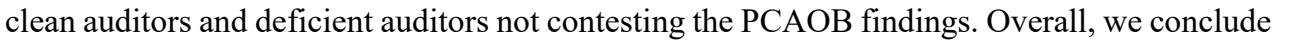

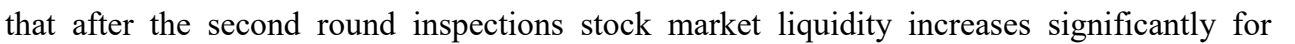

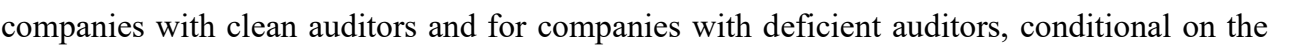

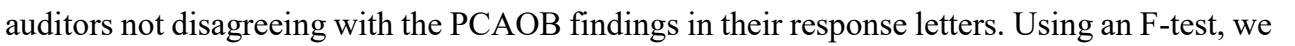

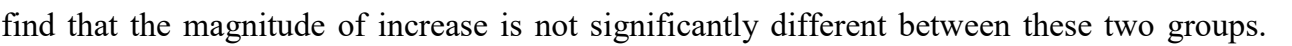

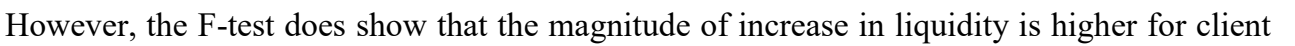

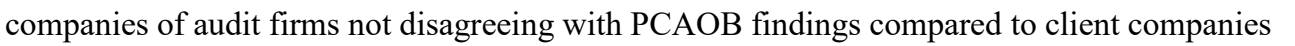

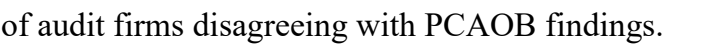

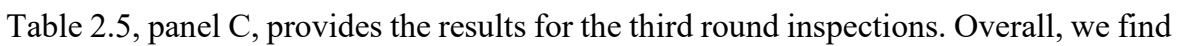

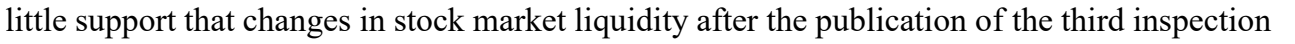

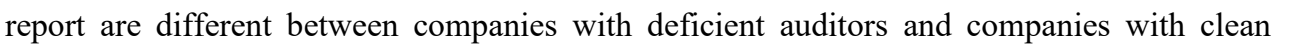

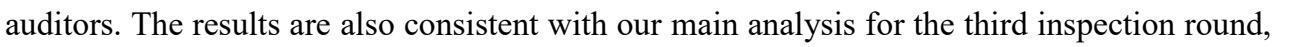

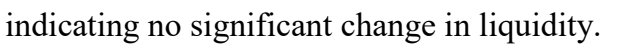

Table 2.5: Regression with inspection reports content

\begin{tabular}{|c|c|c|c|c|c|}
\hline \multicolumn{6}{|l|}{ Panel A: First inspection } \\
\hline 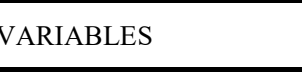 & 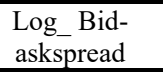 & 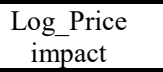 & 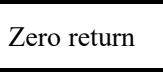 & 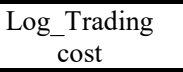 & 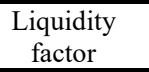 \\
\hline 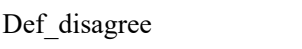 & $0.221 * * * \square$ & $0.704 * * * \square$ & $-0.00132 \square$ & $0.252 * * \square$ & $0.190 * * * \square$ \\
\hline$\square$ & $(3.805) \square$ & $(7.158) \square$ & $(-0.391) \square$ & $(2.681) \square$ & $(2.946) \square$ \\
\hline 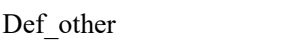 & $0.167 * * * \square$ & $0.433 * * * \square$ & $-0.000333 \square$ & $0.217 * * * \square$ & $0.155^{* * *} \square$ \\
\hline$\square$ & $(6.018) \square$ & $(6.579) \square$ & $(-0.180) \square$ & $(3.563) \square$ & $(3.996) \square$ \\
\hline 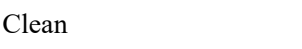 & $0.127 * * \square$ & $0.413 * * * \square$ & $-0.00179 \square$ & $0.180 * * \square$ & $0.129 * * \square$ \\
\hline$\square$ & $(2.126) \square$ & $(4.910) \square$ & $(-1.288) \square$ & $(2.437) \square$ & $(2.567) \square$ \\
\hline 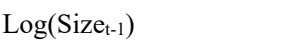 & $0.0468 * \square$ & $-1.177 * * * \square$ & $-0.0204 * * * \square$ & $-0.481 * * * \square$ & $-0.442 * * * \square$ \\
\hline$\square$ & $(1.816) \square$ & $(-19.82) \square$ & $(-6.545) \square$ & $(-7.046) \square$ & $(-7.983) \square$ \\
\hline 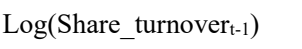 & $-0.00432 \square$ & $-0.809 * * * \square$ & $-0.0136 * * * \square$ & $-0.286^{* * *} \square$ & $-0.272 * * * \square$ \\
\hline$\square$ & $(-0.195) \square$ & $(-27.41) \square$ & $(-13.99) \square$ & $(-8.646) \square$ & $(-12.15) \square$ \\
\hline 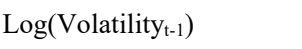 & $0.790 * * * \square$ & $0.777 * * * \square$ & $0.00336 \square$ & $0.664 * * * \square$ & $0.430 * * * \square$ \\
\hline$\square$ & $(23.76) \square$ & $(11.53) \square$ & $(0.519) \square$ & $(5.182) \square$ & $(4.387) \square$ \\
\hline 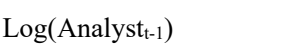 & $0.0639 * * * \square$ & $-0.0625 \square$ & $-0.00286 \square$ & $-0.0298 \square$ & $-0.0348 \square$ \\
\hline$\square$ & $(2.887) \square$ & $(-1.304) \square$ & $(-1.229) \square$ & $(-0.508) \square$ & $(-0.829) \square$ \\
\hline 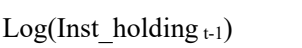 & $-0.162 * \square$ & $-0.226 \square$ & $-0.0117 \square$ & $-0.535 * * \square$ & $-0.372 * * \square$ \\
\hline$\square$ & $(-1.744) \square$ & $(-0.984) \square$ & $(-1.105) \square$ & $(-2.344) \square$ & $(-2.121) \square$ \\
\hline
\end{tabular}




\begin{tabular}{|c|c|c|c|c|c|}
\hline \multicolumn{6}{|c|}{ Table 2.5 continued } \\
\hline पणापापा & $-1.275 * * * \square$ & $-1.855 * * * \square$ & $0.215 * * * \square$ & $-1.301 * * * \square$ & $3.173 * * * \square$ \\
\hline$\square$ & $(-5.399) \square$ & $(-3.169) \square$ & $(10.42) \square$ & $(-2.823) \square$ & $(9.237) \square$ \\
\hline 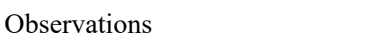 & $1,402 \square$ & $1,402 \square$ & $1,402 \square$ & $1,402 \square$ & $1,402 \square$ \\
\hline 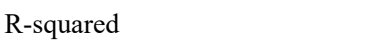 & $0.712 \square$ & $0.815 \square$ & $0.420 \square$ & $0.599 \square$ & $0.640 \square$ \\
\hline 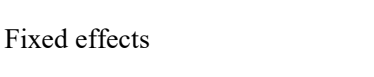 & $\begin{array}{c}\text { Year/industr } \\
\mathrm{y} \square\end{array}$ & Year/industry [ & Year/industry $\sqsubset$ & Year/industry $\square$ & Year/industry $\square$ \\
\hline 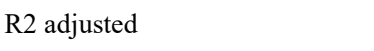 & $0.699 \square$ & $0.806 \square$ & $0.392 \square$ & $0.580 \square$ & $0.623 \square$ \\
\hline 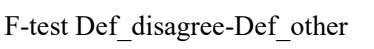 & $0.054 \square$ & $0.271 * * * \square$ & $0.0001 \square$ & $0.035 \square$ & $0.035 \square$ \\
\hline 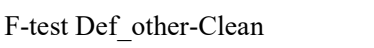 & $0.040 \square$ & $0.020 \square$ & $0.0015 \square$ & $0.037 \square$ & $0.026 \square$ \\
\hline \multicolumn{6}{|l|}{ Panel B: Second inspection $\square$} \\
\hline पாயாणாण & $-0.0554 \square$ & $0.0985 \square$ & $0.0179 * * * \square$ & $0.220 \square$ & $0.214 \square$ \\
\hline$\square$ & $(-1.013) \square$ & $(0.442) \square$ & $(2.934) \square$ & $(1.391) \square$ & $(1.660) \square$ \\
\hline पणापापाप & $-0.127 * * * \square$ & $-0.344 * * * \square$ & $-0.00301 \square$ & $-0.207 * * * \square$ & $-0.167 * * * \square$ \\
\hline$\square$ & $(-3.769) \square$ & $(-4.196) \square$ & $(-1.053) \square$ & $(-5.606) \square$ & $(-5.387) \square$ \\
\hline$\square \square ा \square$ & $-0.0804 * * * \square$ & $-0.178 * \square$ & $-0.00227 \square$ & $-0.120^{*} \square$ & $-0.0969 \square$ \\
\hline$\square$ & $(-3.385) \square$ & $(-1.790) \square$ & $(-0.965) \square$ & $(-1.718) \square$ & $(-1.612) \square$ \\
\hline पवाम & $0.0361 \square$ & $0.159 * * \square$ & $-0.000589 \square$ & $0.110 * * \square$ & $0.0836^{* *} \square$ \\
\hline$\square$ & $(1.383) \square$ & $(2.228) \square$ & $(-0.277) \square$ & $(2.284) \square$ & $(2.066) \square$ \\
\hline 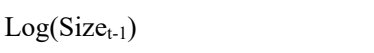 & $-0.00666 \square$ & $-1.218 * * * \square$ & $-0.0167 * * * \square$ & $-0.400 * * * \square$ & $-0.389 * * * \square$ \\
\hline$\square$ & $(-0.501) \square$ & $(-31.29) \square$ & $(-8.849) \square$ & $(-9.442) \square$ & $(-10.45) \square$ \\
\hline 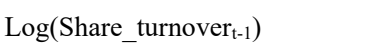 & $0.0349 * * \square$ & $-0.697 * * * \square$ & $-0.0112 * * * \square$ & $-0.175^{* * * *} \square$ & $-0.189 * * * \square$ \\
\hline$\square$ & $(2.197) \square$ & $(-20.85) \square$ & $(-8.486) \square$ & $(-6.159) \square$ & $(-7.926) \square$ \\
\hline 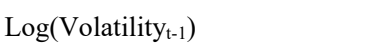 & $0.522 * * * \square$ & $0.392 * * * \square$ & $0.00396 * * \square$ & $0.583 * * * \square$ & $0.423 * * * \square$ \\
\hline$\square$ & $(9.146) \square$ & $(4.393) \square$ & $(2.064) \square$ & $(13.51) \square$ & $(12.93) \square$ \\
\hline 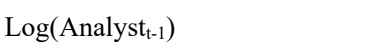 & $0.00944 \square$ & $-0.159 * * * \square$ & $-0.00224 \square$ & $-0.0750 \square$ & $-0.0682 * \square$ \\
\hline$\square$ & $(0.531) \square$ & $(-3.056) \square$ & $(-1.119) \square$ & $(-1.630) \square$ & $(-1.893) \square$ \\
\hline 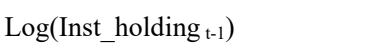 & $-0.195 * * \square$ & $-0.326 \square$ & $-0.00975 \square$ & $-0.423 * \square$ & $-0.337 * \square$ \\
\hline$\square$ & $(-2.659) \square$ & $(-1.491) \square$ & $(-1.194) \square$ & $(-1.886) \square$ & $(-1.873) \square$ \\
\hline 口पषणाए & $-1.287 * * * \square$ & $-3.197 * * * \square$ & $0.0982 * * * \square$ & $-2.147 * * * \square$ & $2.221 * * * \square$ \\
\hline$\square$ & $(-6.174) \square$ & $(-6.828) \square$ & $(6.277) \square$ & $(-6.464) \square$ & $(7.708) \square$ \\
\hline 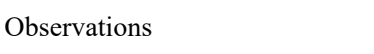 & $1,318 \square$ & $1,318 \square$ & $1,318 \square$ & $1,318 \square$ & $1,318 \square$ \\
\hline 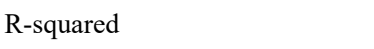 & $0.506 \square$ & $0.806 \square$ & $0.451 \square$ & $0.570 \square$ & $0.608 \square$ \\
\hline 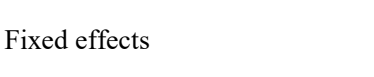 & $\begin{array}{c}\text { Year/industr } \\
\mathrm{y} \square\end{array}$ & Year/industry [ & Year/industry $\sqsubset$ & Year/industry $\square$ & Year/industry $\square$ \\
\hline पणाणाणाए & $0.481 \square$ & $0.796 \square$ & $0.422 \square$ & $0.548 \square$ & $0.588 \square$ \\
\hline 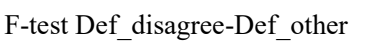 & $0.072 \square$ & $0.443 * * \square$ & $0.021 * * * \square$ & $0.427 * * \square$ & $0.381 * * * \square$ \\
\hline 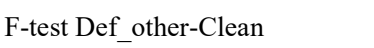 & $-0.047 \square$ & $-0.166 \square$ & $-0.001 \square$ & $-0.087 \square$ & $-0.070 \square$ \\
\hline
\end{tabular}


Table 2.5 continued

\begin{tabular}{|c|c|c|c|c|c|}
\hline \multicolumn{6}{|l|}{ Panel C: Third inspection $\square$} \\
\hline 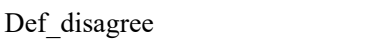 & $0.177 * * \square$ & $0.104 \square$ & $0.00145 \square$ & $0.0262 \square$ & $0.0604 \square$ \\
\hline$\square$ & $(2.448) \square$ & $(0.521) \square$ & $(0.213) \square$ & $(0.0946) \square$ & $(0.508) \square$ \\
\hline$\square \square \mathbb{ा प ा प ् र ~}$ & $-0.0458 \square$ & $-0.0986 \square$ & $0.00100 \square$ & $-0.0251 \square$ & $-0.0171 \square$ \\
\hline$\square$ & $(-1.308) \square$ & $(-1.018) \square$ & $(0.305) \square$ & $(-0.188) \square$ & $(-0.297) \square$ \\
\hline 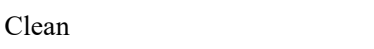 & $-0.00471 \square$ & $0.00248 \square$ & $-0.000436 \square$ & $0.0635 \square$ & $0.0108 \square$ \\
\hline$\square$ & $(-0.175) \square$ & $(0.0333) \square$ & $(-0.173) \square$ & $(0.617) \square$ & $(0.244) \square$ \\
\hline पणाए & $-0.0197 \square$ & $-0.0536 \square$ & $0.000705 \square$ & $-0.0375 \square$ & $-0.0127 \square$ \\
\hline$\square$ & $(-0.854) \square$ & $(-0.840) \square$ & $(0.325) \square$ & $(-0.426) \square$ & $(-0.335) \square$ \\
\hline 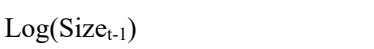 & $-0.0180 \square$ & $-1.036 * * * \square$ & $-0.0109 * * * \square$ & $-0.389 * * * \square$ & $-0.315 * * * \square$ \\
\hline$\square$ & $(-1.354) \square$ & $(-28.11) \square$ & $(-8.733) \square$ & $(-7.641) \square$ & $(-14.41) \square$ \\
\hline 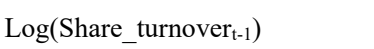 & $-0.0138 \square$ & $-0.759 * * * \square$ & $-0.00967 * * * \sqsubset$ & $-0.312 * * * \square$ & $-0.252 * * * \square$ \\
\hline$\square$ & $(-1.159) \square$ & $(-23.10) \square$ & $(-8.670) \square$ & $(-6.878) \square$ & $(-12.90) \square$ \\
\hline 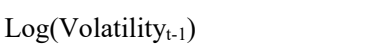 & $0.676 * * * \square$ & $0.762 * * * \square$ & $0.00507 * \square$ & $0.734 * * * \square$ & $0.421 * * * \square$ \\
\hline$\square$ & $(24.55) \square$ & $(10.01) \square$ & $(1.961) \square$ & $(6.977) \square$ & $(9.301) \square$ \\
\hline 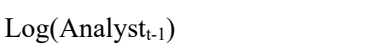 & $0.0937 * * * \square$ & $-0.258 * * * \square$ & $0.000744 \square$ & $0.127 \square$ & $0.0197 \square$ \\
\hline$\square$ & $(4.599) \square$ & $(-4.577) \square$ & $(0.389) \square$ & $(1.633) \square$ & $(0.589) \square$ \\
\hline 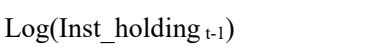 & $-0.0128 \square$ & $-0.422 * \square$ & $-0.0175 * * \square$ & $-1.325 * * * \square$ & $-0.515 * * * \square$ \\
\hline$\square$ & $(-0.140) \square$ & $(-1.666) \square$ & $(-2.034) \square$ & $(-3.789) \square$ & $(-3.423) \square$ \\
\hline पणाणाण & $-0.398 \square$ & $-2.140 * * * \square$ & $0.116 * * * \square$ & $-0.650 \square$ & $3.003 * * * \square$ \\
\hline$\square$ & $(-1.367) \square$ & $(-2.655) \square$ & $(4.250) \square$ & $(-0.583) \square$ & $(6.270) \square$ \\
\hline पणाणाणाणा & $996 \square$ & $996 \square$ & $996 \square$ & $996 \square$ & $996 \square$ \\
\hline पामाणाए & $0.684 \square$ & $0.858 \square$ & $0.390 \square$ & $0.463 \square$ & $0.667 \square$ \\
\hline 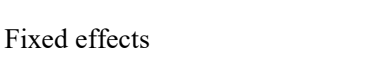 & $\begin{array}{c}\text { Year/industr } \\
\mathrm{y} \square\end{array}$ & Year/industry [ & Year/industry $\sqsubset$ & Year/industry $\square$ & Year/industry $\square$ \\
\hline पणापणतणा & $0.664 \square$ & $0.849 \square$ & $0.351 \square$ & $0.429 \square$ & $0.646 \square$ \\
\hline 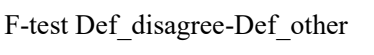 & $0.223 * * \square$ & $0.203 \square$ & $0.0005 \square$ & $0.051 \square$ & $0.078 \square$ \\
\hline 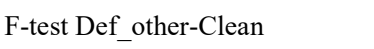 & $-0.041 \square$ & $-0.101 \square$ & $0.0014 \square$ & $-0.089 \square$ & $-0.028 \square$ \\
\hline
\end{tabular}

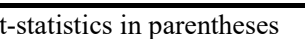

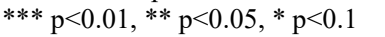

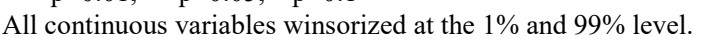

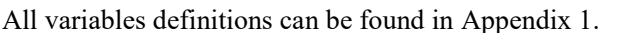




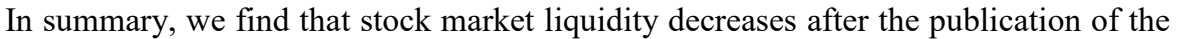

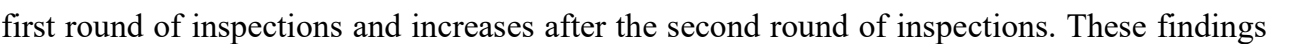

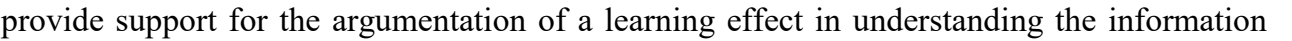

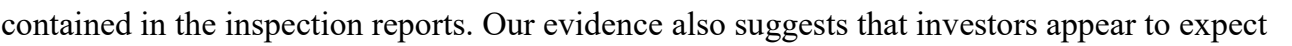

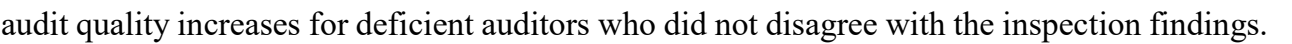

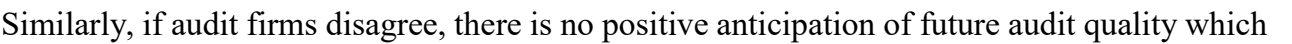

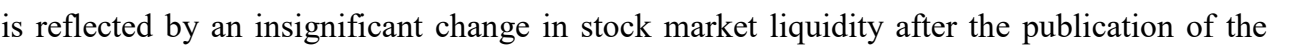

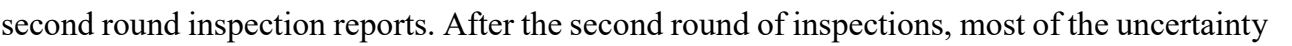

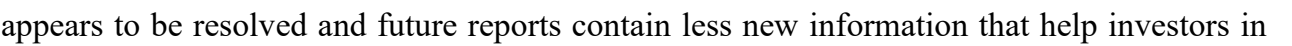

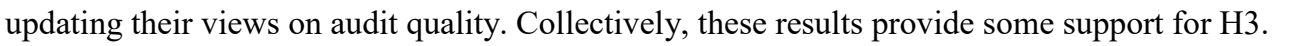

\subsection{Empirical results}

\subsubsection{Initial year effect}

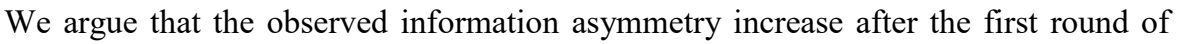

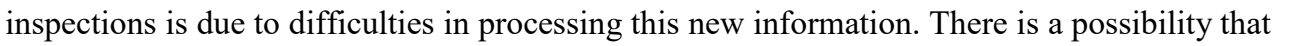

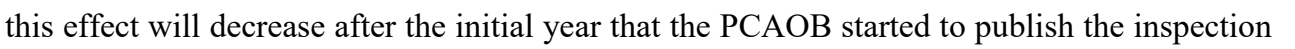

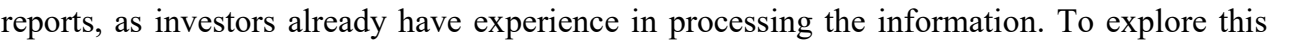

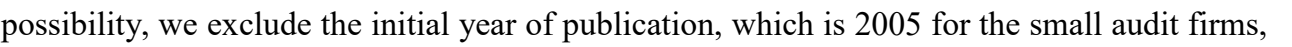

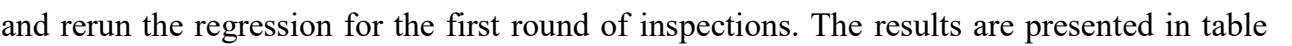

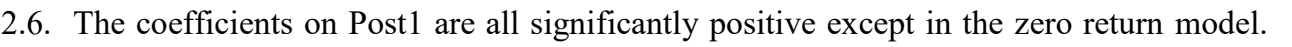

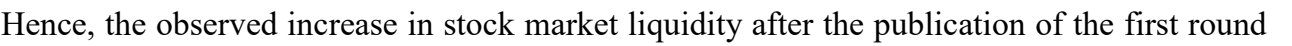

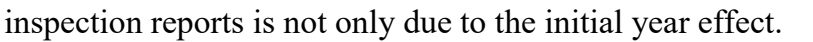

\section{$\square$ \\ $\square$ \\ $\square$ \\ $\square$ \\ $\square$ \\ $\square$ \\ $\square$ \\ $\square$ \\ $\square$ \\ $\square$ \\ $\square$}




\begin{tabular}{|c|c|c|c|c|c|}
\hline 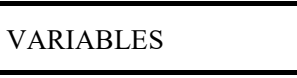 & 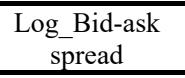 & 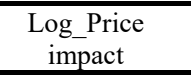 & 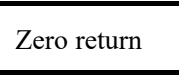 & 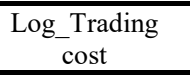 & 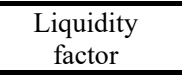 \\
\hline$\square \square \square \square$ & $0.194 * * * \square$ & $0.494 * * * \square$ & $-0.00215 \square$ & $0.238 * * * \square$ & $0.166^{* * * *} \square$ \\
\hline$\square$ & $(6.074) \square$ & $(8.958) \square$ & $(-1.465) \square$ & $(4.302) \square$ & $(4.568) \square$ \\
\hline 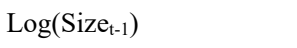 & $0.0504 * \square$ & $-1.182 * * * \square$ & $-0.0208 * * * \square$ & $-0.473 * * * \square$ & $-0.439 * * * \square$ \\
\hline$\square$ & $(1.918) \square$ & $(-19.33) \square$ & $(-6.271) \square$ & $(-6.256) \square$ & $(-7.224) \square$ \\
\hline 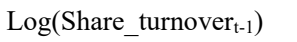 & $0.00429 \square$ & $-0.819 * * * \square$ & $-0.0147 * * * \square$ & $-0.305 * * * \square$ & $-0.288 * * * \square$ \\
\hline$\square$ & $(0.167) \square$ & $(-26.17) \square$ & $(-11.12) \square$ & $(-7.397) \square$ & $(-10.08) \square$ \\
\hline 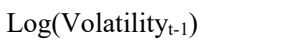 & $0.771 * * * \square$ & $0.770 * * * \square$ & $0.00183 \square$ & $0.644 * * * \square$ & $0.414 * * * \square$ \\
\hline$\square$ & $(21.53) \square$ & $(9.815) \square$ & $(0.265) \square$ & $(4.595) \square$ & $(3.851) \square$ \\
\hline 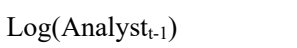 & $0.0656^{* *} \square$ & $-0.0518 \square$ & $-0.00220 \square$ & $-0.00874 \square$ & $-0.0192 \square$ \\
\hline$\square$ & $(2.655) \square$ & $(-1.226) \square$ & $(-0.964) \square$ & $(-0.148) \square$ & $(-0.459) \square$ \\
\hline 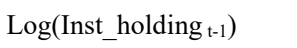 & $-0.185^{*} \square$ & $-0.199 \square$ & $-0.0121 \square$ & $-0.571 * * \square$ & $-0.392 * * \square$ \\
\hline$\square$ & $(-2.010) \square$ & $(-0.814) \square$ & $(-1.057) \square$ & $(-2.321) \square$ & $(-2.056) \square$ \\
\hline पणाणाण & $-1.475^{* * *} \square$ & $-1.866 * * \square$ & $0.215 * * * \square$ & $-1.511 * * * \square$ & $3.054 * * * \square$ \\
\hline$\square$ & $(-6.150) \square$ & $(-2.497) \square$ & $(9.744) \square$ & $(-3.161) \square$ & $(8.421) \square$ \\
\hline 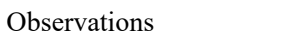 & $1,254 \square$ & $1,254 \square$ & $1,254 \square$ & $1,254 \square$ & $1,254 \square$ \\
\hline पमणणण & $0.723 \square$ & $0.815 \square$ & $0.436 \square$ & $0.593 \square$ & $0.635 \square$ \\
\hline पणாயாயாயய & Year/industry [ & Year/industry $\square$ & Year/industry [ & Year/industry $\square$ & Year/industry $\square$ \\
\hline 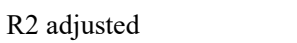 & $0.710 \square$ & $0.806 \square$ & $0.409 \square$ & $0.573 \square$ & $0.618 \square$ \\
\hline
\end{tabular}

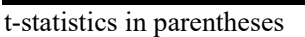

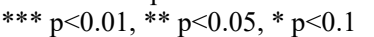

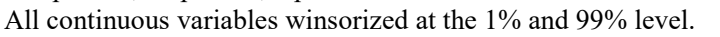

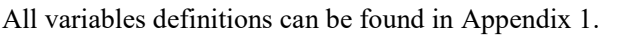

$\square$

\subsubsection{Constant sample}

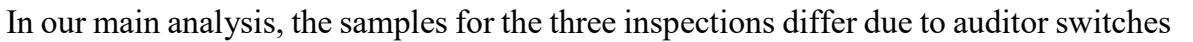

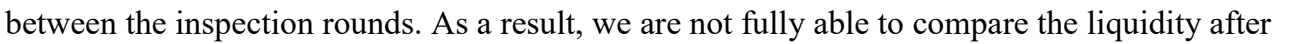
ए ए।

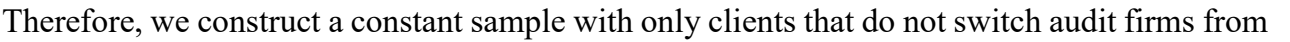

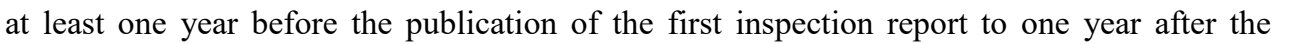

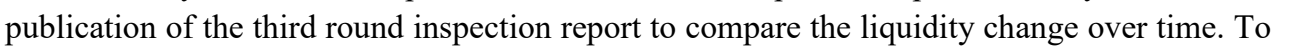

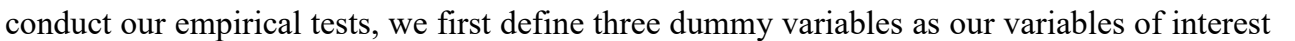

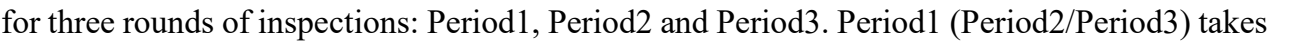

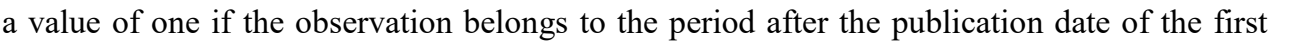

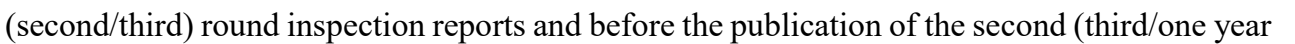

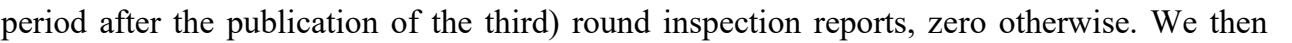
combine our manually coded variables "Deficient", "Disagree" and the period dummies to

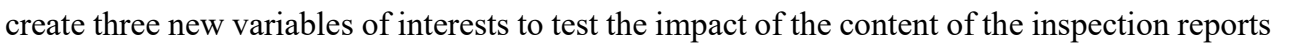




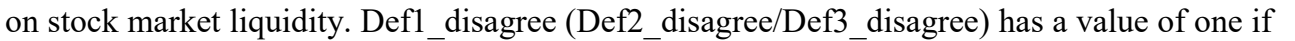
ए ए।

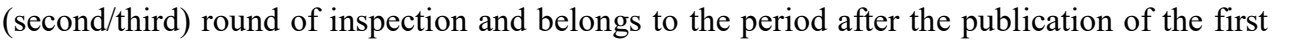

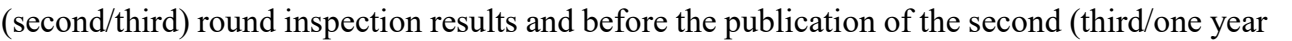

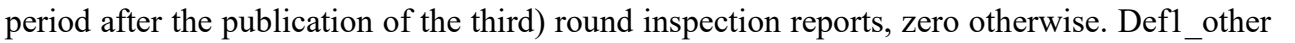

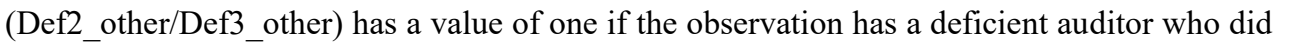

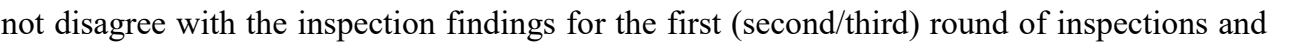

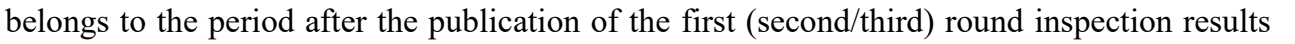

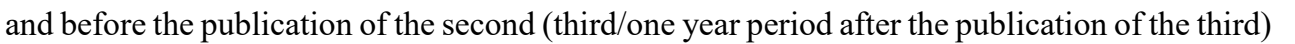

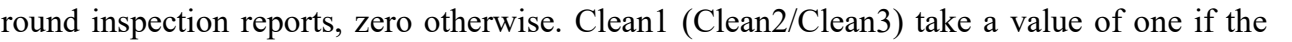

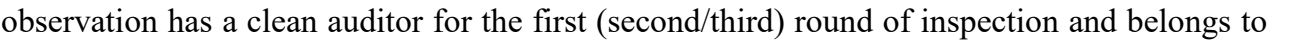

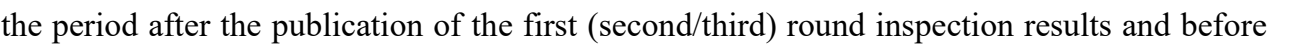
ए ए।

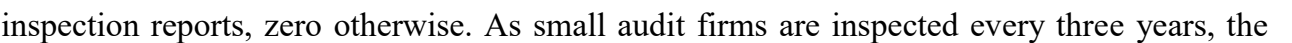

period between the inspections are quite long. We include an additional variable "Days" to

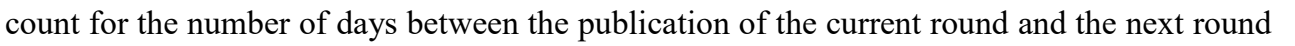

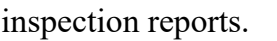

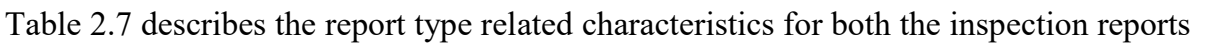

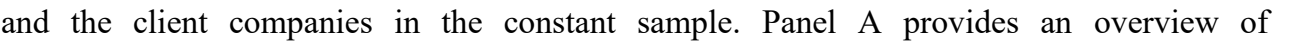

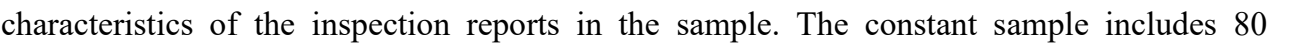
ए

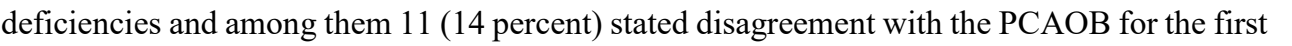

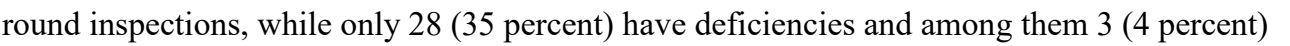

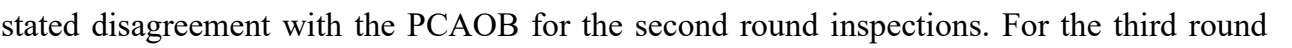

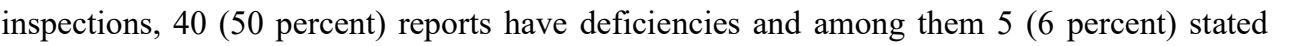

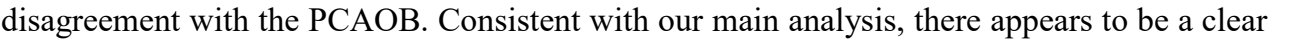

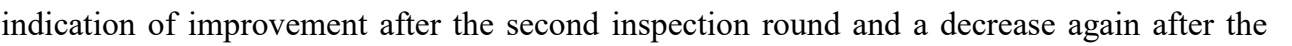

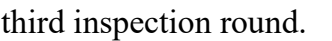

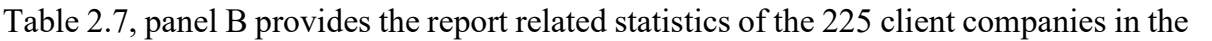

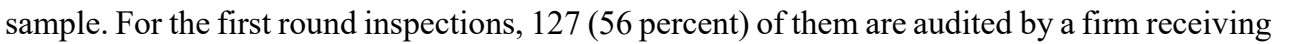

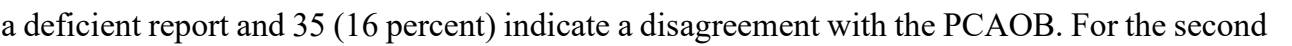

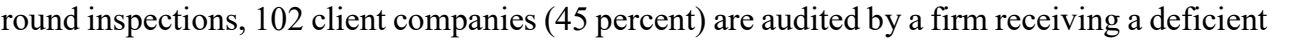

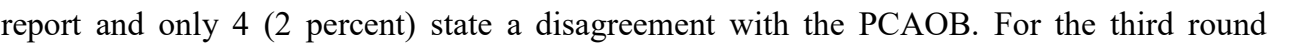
ए

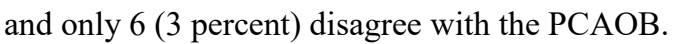


Table 2.7: PCAOB inspection for constant sample

\begin{tabular}{|c|c|c|c|c|c|c|}
\hline \multicolumn{7}{|c|}{ Panel A: Inspection reports } \\
\hline & \multicolumn{2}{|c|}{ First-round } & \multicolumn{2}{|c|}{ Second-round } & \multicolumn{2}{|c|}{ Third-round } \\
\hline 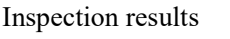 & $\square \square$ & पएणापाए & $\square \square$ & 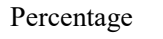 & $\square \square$ & 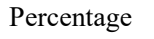 \\
\hline 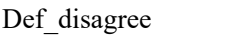 & $\square \square$ & $\square ण \square$ & $\square$ & 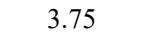 & $\square$ & $\square ण 1$ \\
\hline$\square \square[|ण| \mathbb{~}$ & $\square$ & $\square \mid \square \square$ & $\square \square$ & $\square|\square|$ & $\square$ & $\square \mid \square \square$ \\
\hline पणाए & $\square$ & पण口 & $\square \square$ & पाए & $\square$ & पण口 \\
\hline 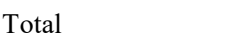 & $\square$ & $\square|| ⿴ \mid \square$ & $\square \square$ & 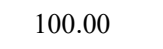 & $\square$ & $\square \mid \| \square$ \\
\hline \multicolumn{7}{|c|}{ Panel B: Report related characteristics of client companies $\square$} \\
\hline & \multicolumn{2}{|c|}{ First-round } & \multicolumn{2}{|c|}{ Second-round } & \multicolumn{2}{|c|}{ Third-round } \\
\hline 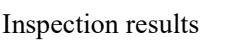 & $\square \square$ & 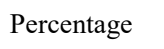 & $\square \square$ & 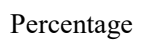 & $\square \square$ & 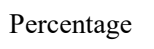 \\
\hline பாயாயாயம & $\square$ & पाणम & $\square$ & $\square \square$ & $\square$ & $\square \square \square$ \\
\hline पणापणाण & $\square \square$ & पाणा & $\square$ & पाणा & $\square \square$ & 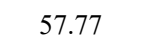 \\
\hline पखणा & $\square \square$ & पाणा & $\square \square$ & पाणा & $\square$ & $\square ण \square$ \\
\hline 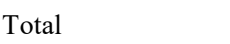 & $\square \square$ & पाणा & $\square \square$ & पाला & $\square \square$ & पाणा \\
\hline
\end{tabular}

Table 2.8: Descriptive Statistics for constant sample small audit firms

\begin{tabular}{|c|c|c|c|c|c|c|}
\hline 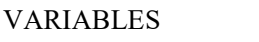 & $\square \square$ & $\square \Pi \square$ & $\square \square$ & $\square$ & $\square \square \square$ & $\square \square \square$ \\
\hline पणमापापाणमा & $900 \square$ & $0.0356 \square$ & $0.0317 \square$ & $0.0182 \square$ & $0.00777 \square$ & $0.0940 \square$ \\
\hline 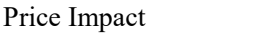 & $900 \square$ & $0.000942 \square$ & $0.000223 \square$ & $0.00213 \square$ & $1.06 \mathrm{e}-06 \square$ & $0.0149 \square$ \\
\hline पणापणताप & $900 \square$ & $0.0541 \square$ & $0.0479 \square$ & $0.0390 \square$ & $0.00103 \square$ & $0.191 \square$ \\
\hline 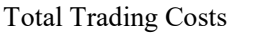 & $900 \square$ & $0.00704 \square$ & $0.00568 \square$ & $0.00527 \square$ & $0.000806 \square$ & $0.0304 \square$ \\
\hline पाएा & $900 \square$ & $159.8 \square$ & $77.57 \square$ & $244.9 \square$ & $6.261 \square$ & $1,481 \square$ \\
\hline 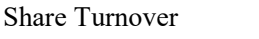 & $900 \square$ & $1.760 \square$ & $0.764 \square$ & $2.716 \square$ & $0.0376 \square$ & $16.14 \square$ \\
\hline 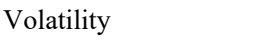 & $900 \square$ & $0.0353 \square$ & $0.0309 \square$ & $0.0191 \square$ & $0.00923 \square$ & $0.111 \square$ \\
\hline पणाणाप & $900 \square$ & $1.651 \square$ & $1 \square$ & $2.450 \square$ & $0 \square$ & $11 \square$ \\
\hline 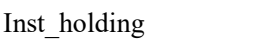 & $900 \square$ & $0.211 \square$ & $0.143 \square$ & $0.220 \square$ & $0 \square$ & $0.890 \square$ \\
\hline
\end{tabular}

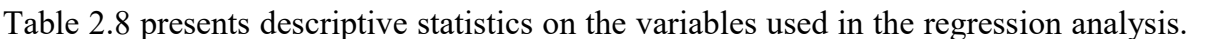

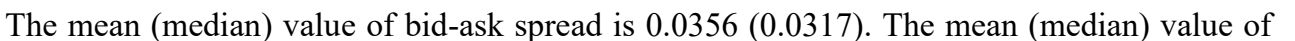

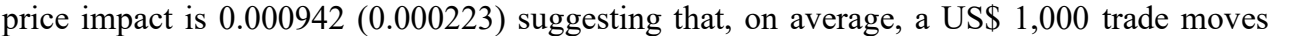




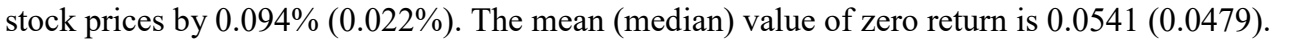

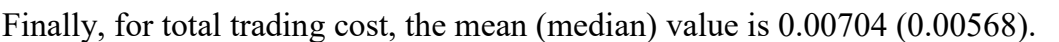

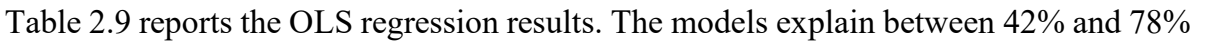

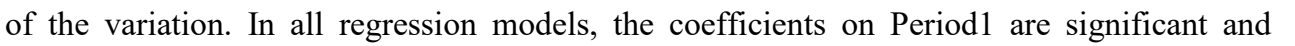

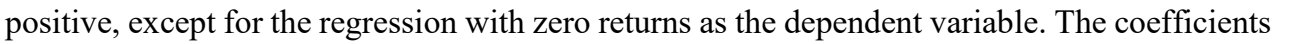

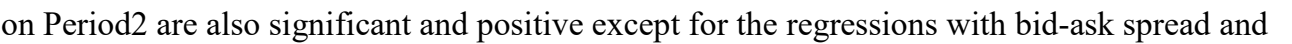

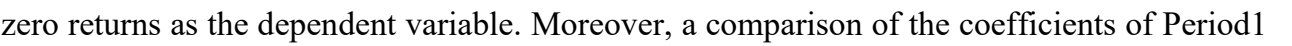

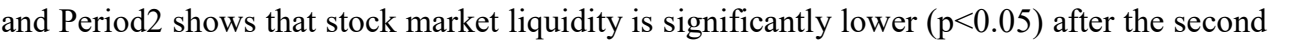

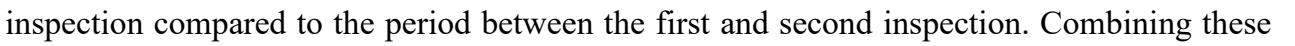

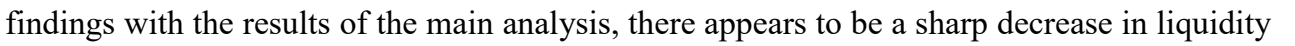

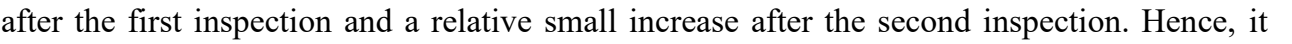

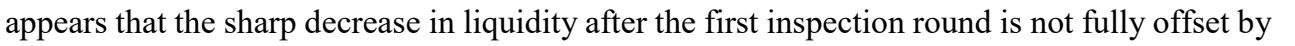

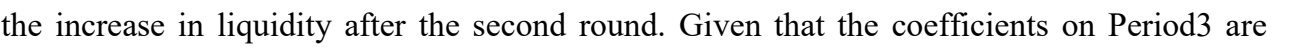

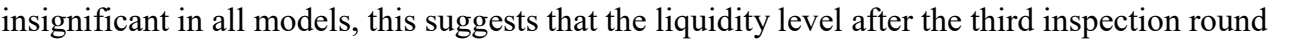

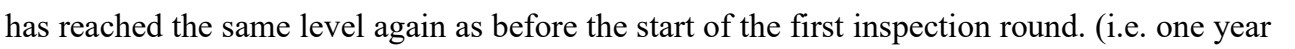

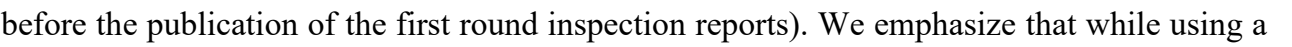

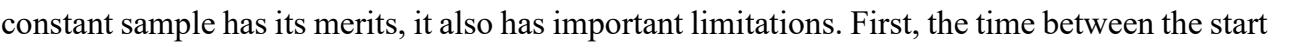

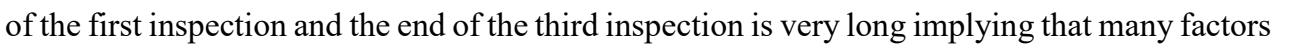

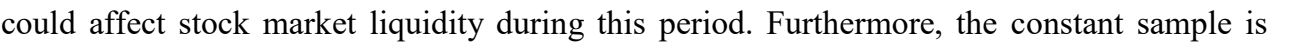

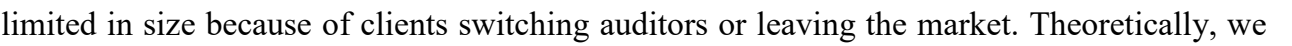

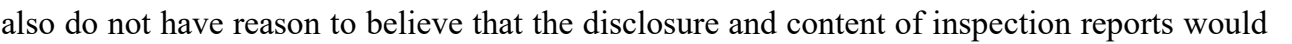

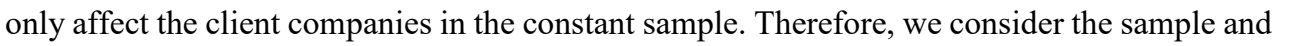

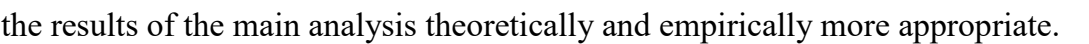

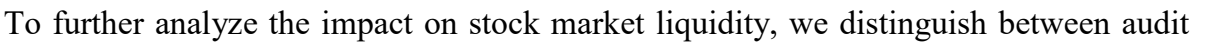

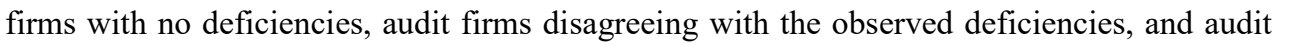

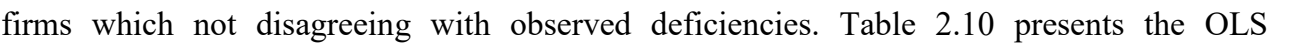

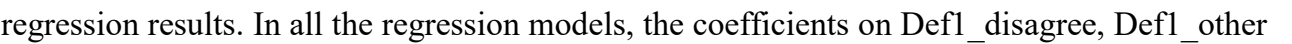

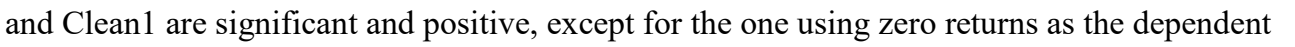

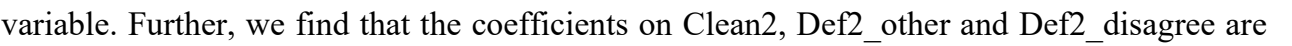

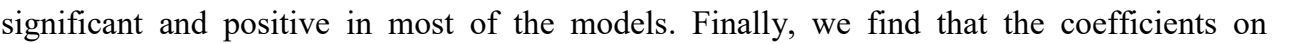

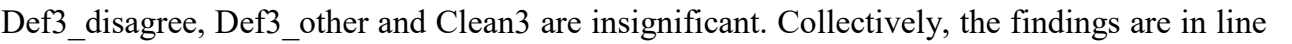

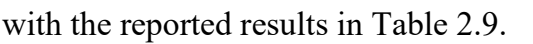

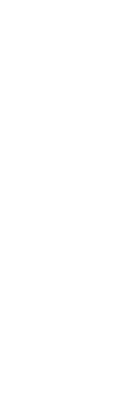


Table 2.9: Regression with for constant sample small audit firms

\begin{tabular}{|c|c|c|c|c|c|}
\hline 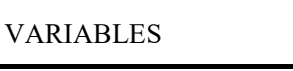 & 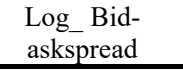 & 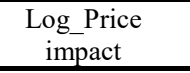 & 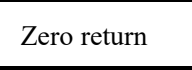 & 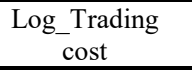 & 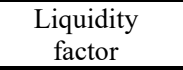 \\
\hline$\square \square \| ा \mid \square$ & $0.293 * * * \square$ & $0.669 * * * \square$ & $0.000867 \square$ & $0.280 * * * \square$ & $0.253 * * * \square$ \\
\hline$\square$ & $(3.837) \square$ & $(4.550) \square$ & $(0.190) \square$ & $(3.286) \square$ & $(3.354) \square$ \\
\hline 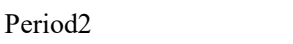 & $0.141 \square$ & $1.123 * * * \square$ & $0.00882 \square$ & $0.299 * \square$ & $0.393 * * * \square$ \\
\hline$\square$ & $(1.523) \square$ & $(5.197) \square$ & $(1.178) \square$ & $(1.847) \square$ & $(3.458) \square$ \\
\hline 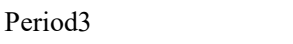 & $0.100 \square$ & $0.416 \square$ & $0.00449 \square$ & $0.149 \square$ & $0.178 \square$ \\
\hline$\square$ & $(0.555) \square$ & $(0.985) \square$ & $(0.664) \square$ & $(0.571) \square$ & $(0.829) \square$ \\
\hline 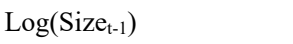 & $0.0414 \square$ & $-1.269 * * * \square$ & $-0.0166 * * * \square$ & $-0.252 * * * \square$ & $-0.454 * * * \square$ \\
\hline$\square$ & $(1.215) \square$ & $(-25.67) \square$ & $(-5.204) \square$ & $(-6.658) \square$ & $(-9.611) \square$ \\
\hline 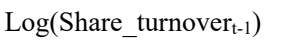 & $0.0239 \square$ & $-0.573 * * * \square$ & $-0.00845 * * * \square$ & $-0.0816^{* *} \square$ & $-0.201 * * * \square$ \\
\hline$\square$ & $(1.083) \square$ & $(-11.04) \square$ & $(-7.489) \square$ & $(-2.245) \square$ & $(-7.972) \square$ \\
\hline 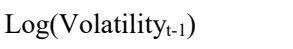 & $0.514 * * * \square$ & $0.282 * * \square$ & $0.00256 \square$ & $0.415 * * * \square$ & $0.289 * * * \square$ \\
\hline$\square$ & $(21.93) \square$ & $(2.681) \square$ & $(0.877) \square$ & $(7.146) \square$ & $(5.190) \square$ \\
\hline 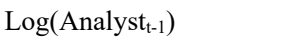 & $0.0160 \square$ & $-0.102 * \square$ & $0.000942 \square$ & $-0.0316 \square$ & $-0.0179 \square$ \\
\hline$\square$ & $(0.483) \square$ & $(-1.943) \square$ & $(0.738) \square$ & $(-0.671) \square$ & $(-0.544) \square$ \\
\hline 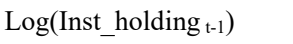 & $-0.344 * * * \square$ & $-0.581 * * * \square$ & $-0.00822 \square$ & $-0.531 * \square$ & $-0.423 * * \square$ \\
\hline$\square$ & $(-3.347) \square$ & $(-3.098) \square$ & $(-0.944) \square$ & $(-1.853) \square$ & $(-2.064) \square$ \\
\hline 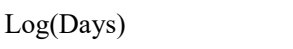 & $-0.108 \square$ & $-0.331 * * \square$ & $0.000248 \square$ & $-0.182 * * \square$ & $-0.134 \square$ \\
\hline$\square$ & $(-1.614) \square$ & $(-2.220) \square$ & $(0.0483) \square$ & $(-2.379) \square$ & $(-1.370) \square$ \\
\hline 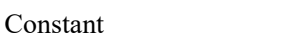 & $-1.222 * * * \square$ & $-0.0961 \square$ & $0.141^{* * * *} \square$ & $-1.026 * \square$ & $4.113 * * * \square$ \\
\hline$\square$ & $(-2.767) \square$ & $(-0.102) \square$ & $(7.142) \square$ & $(-1.961) \square$ & $(8.363) \square$ \\
\hline 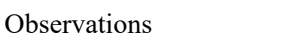 & $900 \square$ & $900 \square$ & $900 \square$ & $900 \square$ & $900 \square$ \\
\hline पषणायमा & $0.615 \square$ & $0.788 \square$ & $0.460 \square$ & $0.455 \square$ & $0.646 \square$ \\
\hline 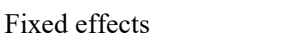 & Year/industry $\sqsubset$ & Year/industry $\square$ & Year/industry $\square$ & Year/industry $\square$ & Year/industry $\square$ \\
\hline पणतापाणाए & $0.590 \square$ & $0.774 \square$ & $0.424 \square$ & $0.419 \square$ & $0.622 \square$ \\
\hline 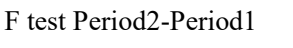 & $-0.152 * * * \square$ & $0.454 * * * \square$ & $0.0079 * * \square$ & $0.019 \square$ & $0.140 * * \square$ \\
\hline 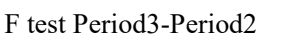 & $-0.041 \square$ & $-0.707 * \square$ & $-0.0043 \square$ & $-0.150 \square$ & $-0.215 \square$ \\
\hline
\end{tabular}

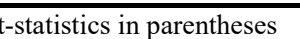

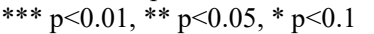

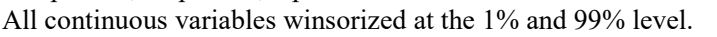

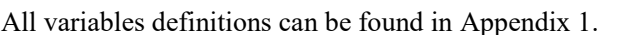




\begin{tabular}{|c|c|c|c|c|c|}
\hline 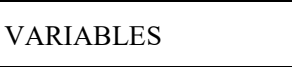 & 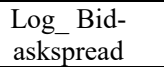 & 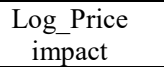 & पणमाणाणम & 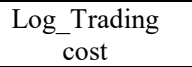 & 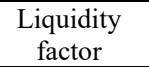 \\
\hline def1_disagree $\square$ & $0.187 * * * \square$ & $0.640 * * \square$ & $-0.00110 \square$ & $0.333 * * * \square$ & $0.243 * * \square$ \\
\hline$\square$ & $(3.346) \square$ & $(2.701) \square$ & $(-0.246) \square$ & $(3.459) \square$ & $(2.418) \square$ \\
\hline def1_other $\square$ & $0.317 * * * \square$ & $0.701 * * * \square$ & $-0.000433 \square$ & $0.258 * * * \square$ & $0.238 * * * \square$ \\
\hline$\square$ & $(3.745) \square$ & $(4.646) \square$ & $(-0.0749) \square$ & $(2.750) \square$ & $(2.853) \square$ \\
\hline clean1 $\square$ & $0.433 * * * \square$ & $0.683 * * * \square$ & $0.000560 \square$ & $0.315^{* *} \square$ & $0.280 * * \square$ \\
\hline$\square$ & $(4.977) \square$ & $(3.838) \square$ & $(0.0738) \square$ & $(2.683) \square$ & $(2.217) \square$ \\
\hline def2_disagree $\square$ & $0.198 \square$ & $1.441 * * \square$ & $0.0492 * * * \square$ & $0.932 * \square$ & $1.109^{* * *} \square$ \\
\hline$\square$ & $(1.132) \square$ & $(2.303) \square$ & $(5.306) \square$ & $(1.952) \square$ & $(3.066) \square$ \\
\hline def2_other $\square$ & $0.156 \square$ & $1.082 * * * \square$ & $0.0102 * \square$ & $0.230 \square$ & $0.373 * * * \square$ \\
\hline$\square$ & $(1.328) \square$ & $(4.904) \square$ & $(1.732) \square$ & $(1.106) \square$ & $(3.297) \square$ \\
\hline clean $2 \square$ & $0.235 * * \square$ & $1.154 * * * \square$ & $0.00696 \square$ & $0.317 * * \square$ & $0.396 * * * \square$ \\
\hline$\square$ & $(2.525) \square$ & $(5.111) \square$ & $(0.689) \square$ & $(2.054) \square$ & $(2.792) \square$ \\
\hline def3_disagree $\square$ & $0.246 \square$ & $0.559 \square$ & $0.01000 \square$ & $0.347 \square$ & $0.350 \square$ \\
\hline$\square$ & $(0.973) \square$ & $(0.524) \square$ & $(0.661) \square$ & $(0.907) \square$ & $(0.897) \square$ \\
\hline def3_other $\square$ & $0.101 \square$ & $0.435 \square$ & $0.00982 \square$ & $0.114 \square$ & $0.218 \square$ \\
\hline$\square$ & $(0.570) \square$ & $(0.951) \square$ & $(1.139) \square$ & $(0.338) \square$ & $(0.768) \square$ \\
\hline clean3 $\square$ & $0.0973 \square$ & $0.365 \square$ & $0.00461 \square$ & $0.0802 \square$ & $0.142 \square$ \\
\hline$\square$ & $(0.450) \square$ & $(0.855) \square$ & $(0.620) \square$ & $(0.259) \square$ & $(0.580) \square$ \\
\hline 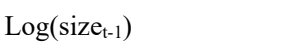 & $0.0422 \square$ & $-1.271 * * * \square$ & $-0.0167 * * * \square$ & $-0.258 * * * \square$ & $-0.458 * * * \square$ \\
\hline$\square$ & $(1.216) \square$ & $(-25.89) \square$ & $(-5.281) \square$ & $(-7.099) \square$ & $(-9.892) \square$ \\
\hline 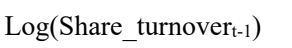 & $0.0244 \square$ & $-0.573 * * * \square$ & $-0.00843 * * * \square$ & $-0.0782 * * \square$ & $-0.199 * * * \square$ \\
\hline$\square$ & $(1.072) \square$ & $(-10.99) \square$ & $(-7.837) \square$ & $(-2.301) \square$ & $(-8.521) \square$ \\
\hline 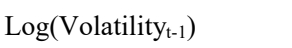 & $0.526 * * * \square$ & $0.286 * * \square$ & $0.00229 \square$ & $0.418 * * * \square$ & $0.290 * * * \square$ \\
\hline$\square$ & $(20.49) \square$ & $(2.563) \square$ & $(0.692) \square$ & $(6.645) \square$ & $(4.569) \square$ \\
\hline 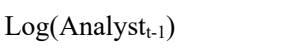 & $0.0166 \square$ & $-0.105 * * \square$ & $0.000799 \square$ & $-0.0372 \square$ & $-0.0222 \square$ \\
\hline$\square$ & $(0.497) \square$ & $(-2.027) \square$ & $(0.598) \square$ & $(-0.822) \square$ & $(-0.685) \square$ \\
\hline 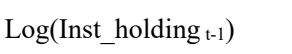 & $-0.334 * * * \square$ & $-0.562 * * * \square$ & $-0.00845 \square$ & $-0.500 * \square$ & $-0.409 * * \square$ \\
\hline$\square$ & $(-3.253) \square$ & $(-2.843) \square$ & $(-0.971) \square$ & $(-1.792) \square$ & $(-2.032) \square$ \\
\hline पणापणाण & $-0.164 * * \square$ & $-0.344 * * \square$ & $0.00120 \square$ & $-0.202 * \square$ & $-0.140 \square$ \\
\hline$\square$ & $(-2.516) \square$ & $(-2.110) \square$ & $(0.181) \square$ & $(-1.902) \square$ & $(-1.097) \square$ \\
\hline पणापापा & $-0.806 * \square$ & $0.0353 \square$ & $0.137 * * * \square$ & $-0.850 \square$ & $4.198 * * * \square$ \\
\hline$\square$ & $(-1.857) \square$ & $(0.0325) \square$ & $(5.017) \square$ & $(-1.320) \square$ & $(6.459) \square$ \\
\hline 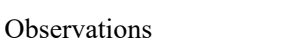 & $900 \square$ & $900 \square$ & $900 \square$ & $900 \square$ & $900 \square$ \\
\hline पणापामा & $0.622 \square$ & $0.789 \square$ & $0.465 \square$ & $0.460 \square$ & $0.649 \square$ \\
\hline
\end{tabular}


Table 2.10 continued

\begin{tabular}{|c|c|c|c|c|c|}
\hline 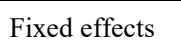 & Year/industry [ & Year/industry $\square$ & Year/industry $\square$ & Year/industry $\square$ & Year/industry $\square$ \\
\hline 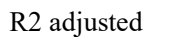 & $0.594 \square$ & $0.773 \square$ & $0.426 \square$ & $0.420 \square$ & $0.623 \square$ \\
\hline \multicolumn{6}{|c|}{ 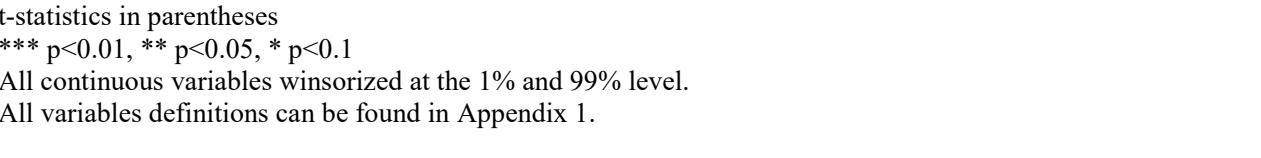 } \\
\hline
\end{tabular}

\subsubsection{Annual inspected audit firms}

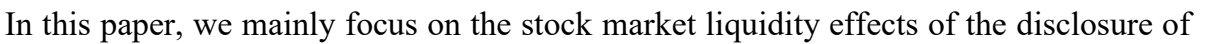
ए

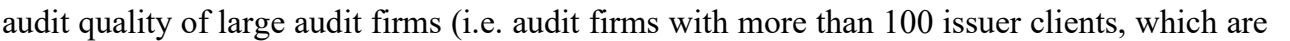

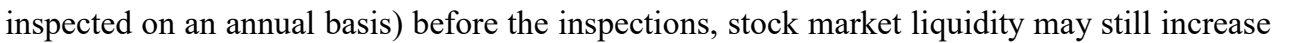

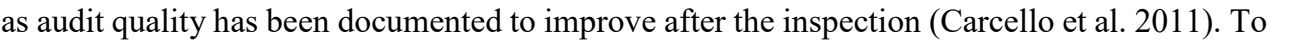

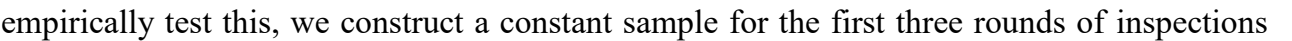

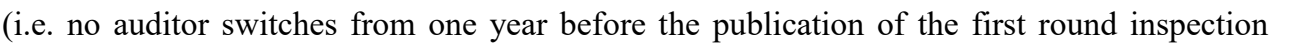

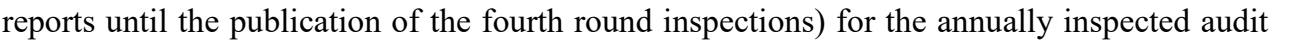

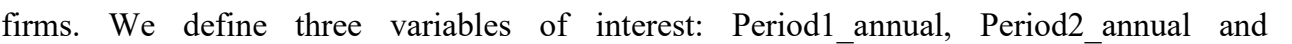

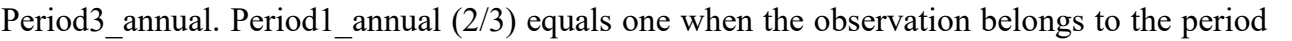

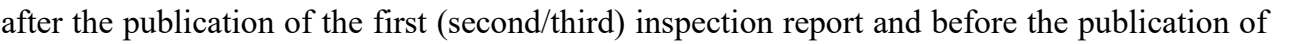

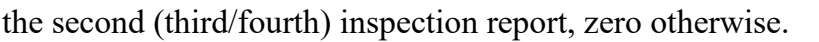

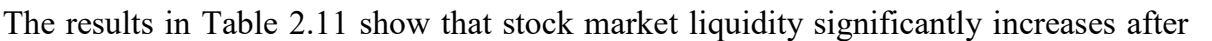
the publication of the first inspection report, suggesting an increase in the investors' perception

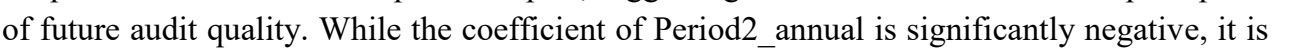

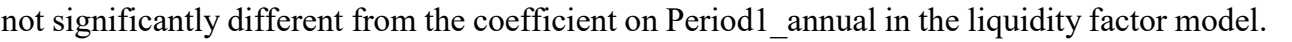

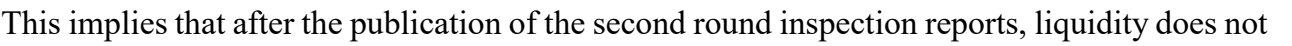

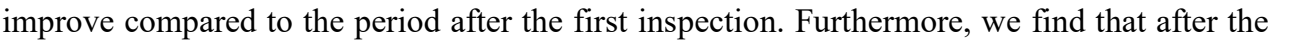

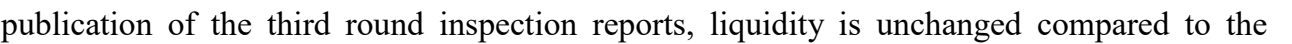

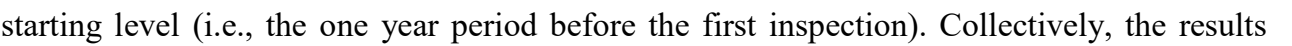

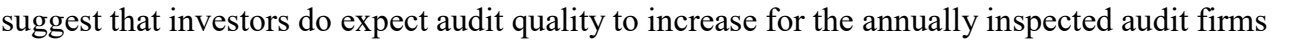

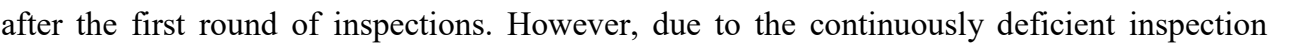
एம

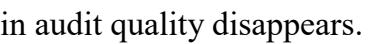

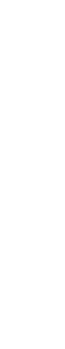


Table 2.11: Regression with constant sample for annual inspected firms

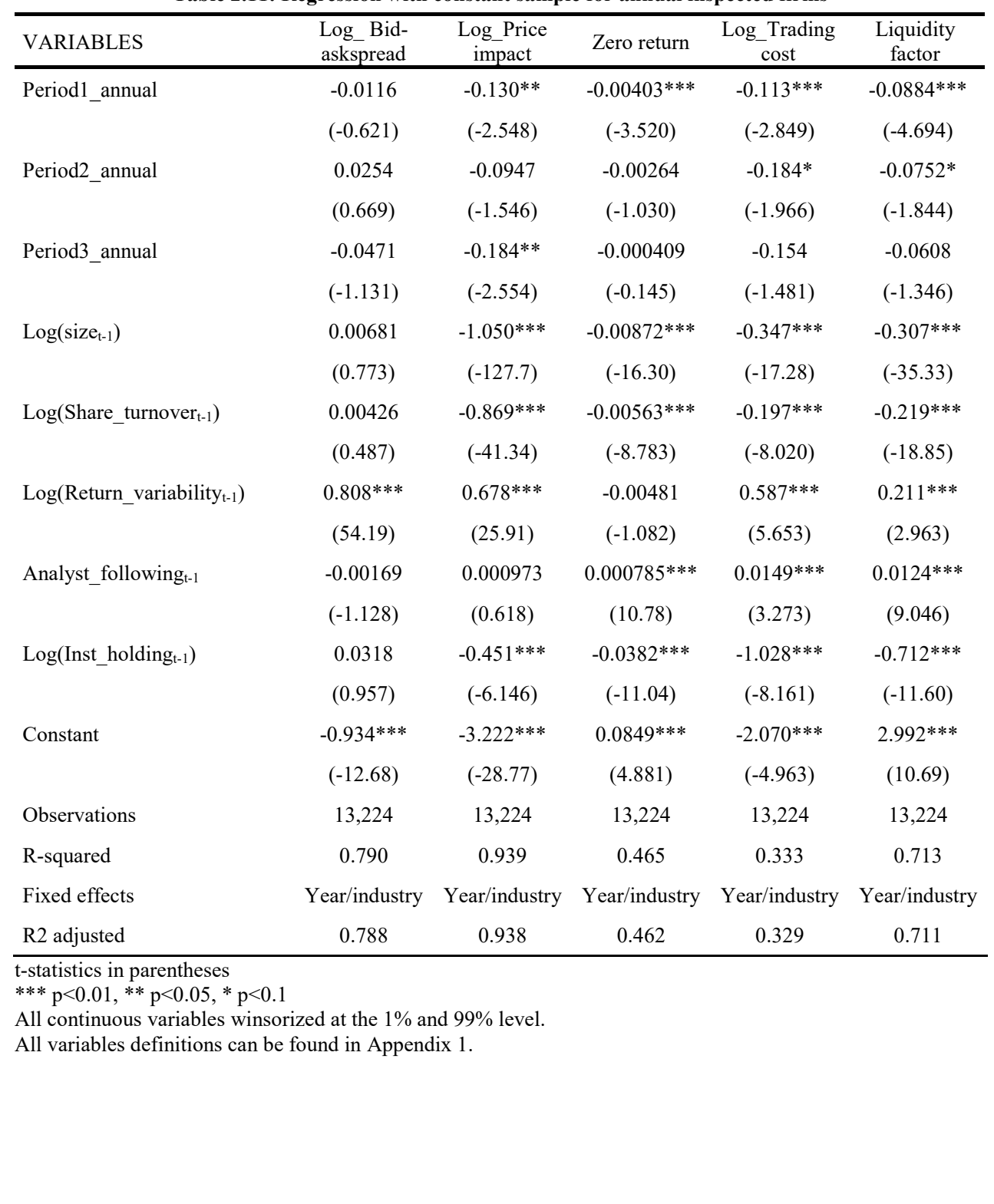

\subsection{Conclusion}

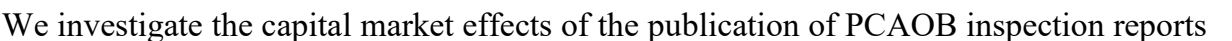

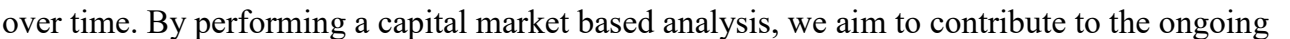

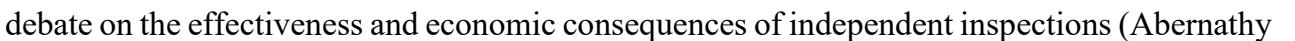

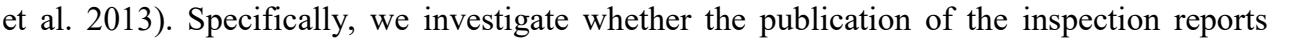

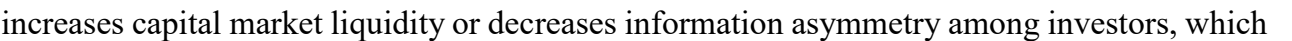




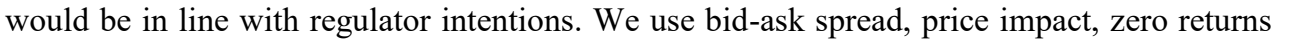

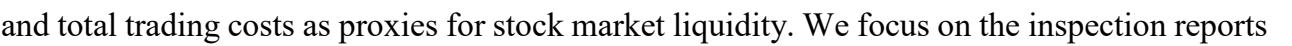

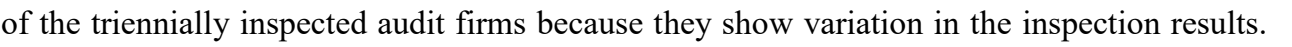

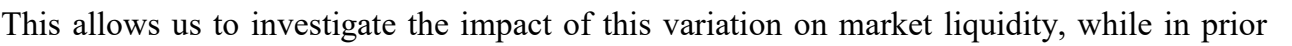

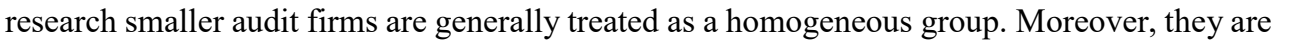

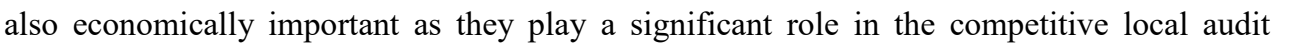

\section{markets and significantly influence Big4 audit firms' ability to collect a fee premium (Bills and}

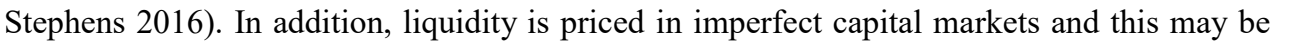

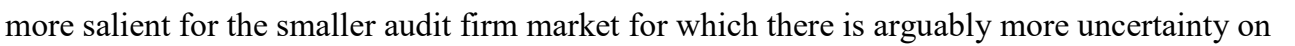

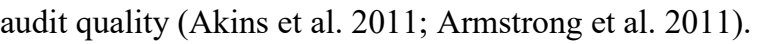

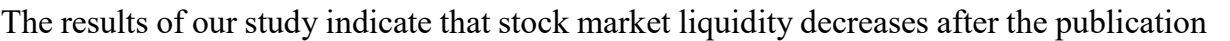

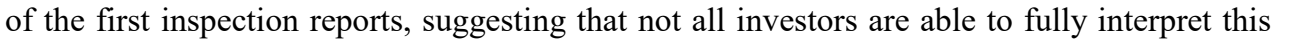

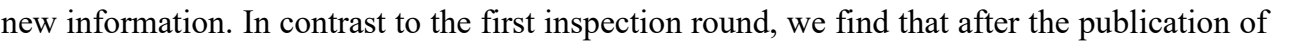
प

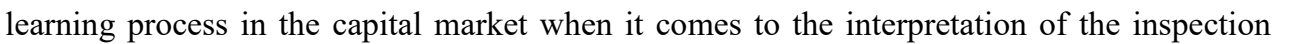

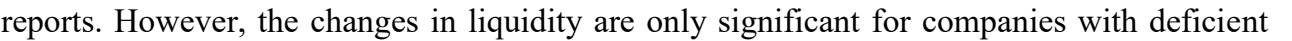

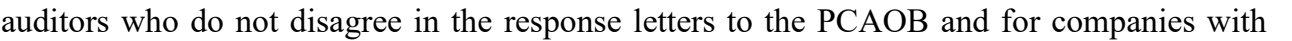

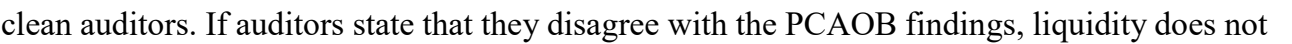

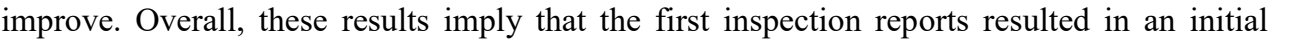

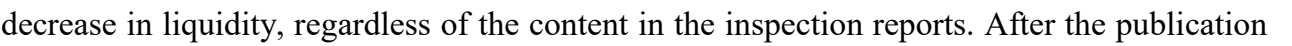

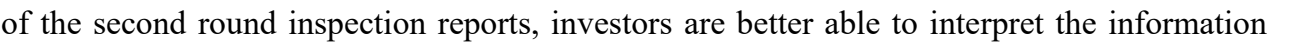

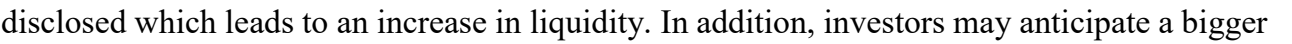

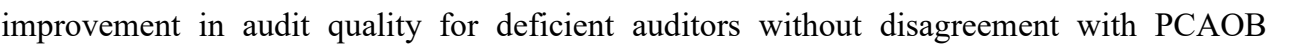

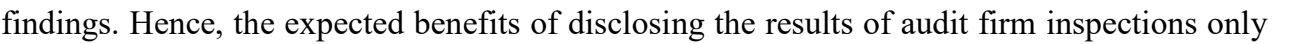

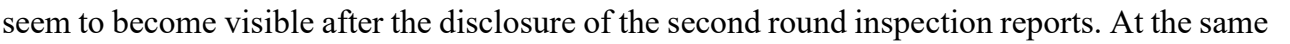

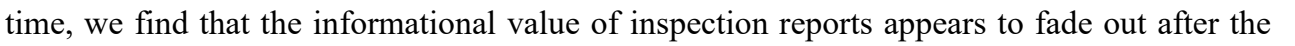

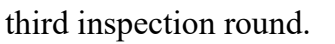

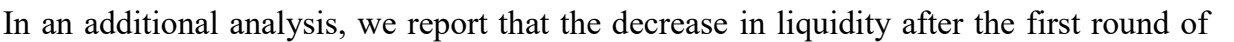

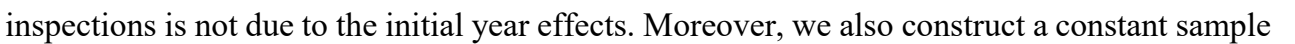

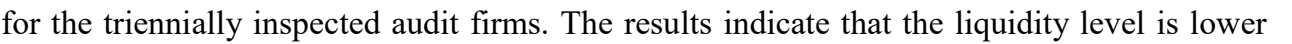

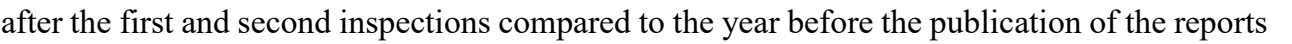

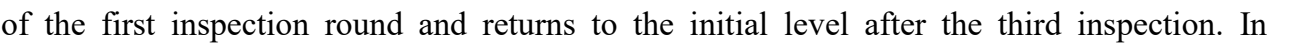

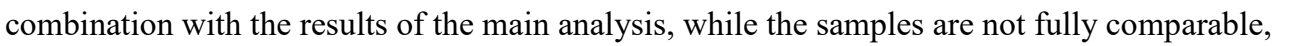
प

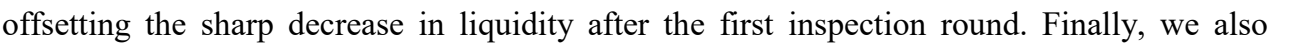

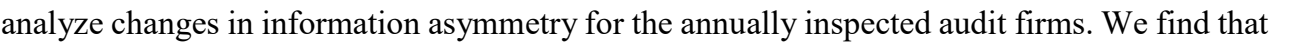

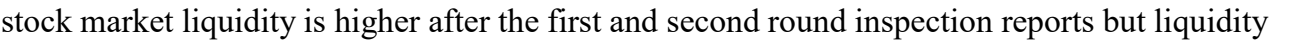

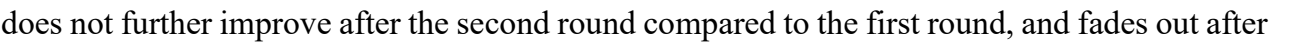

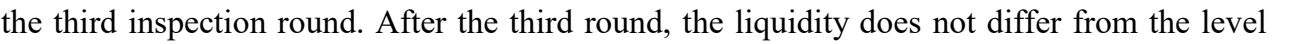

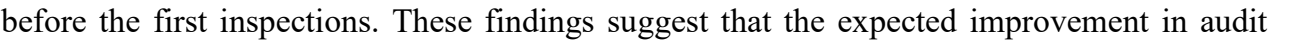

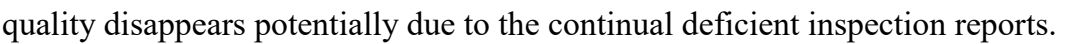




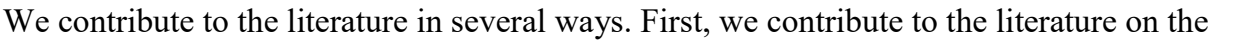

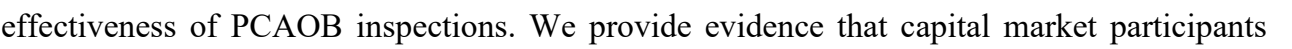

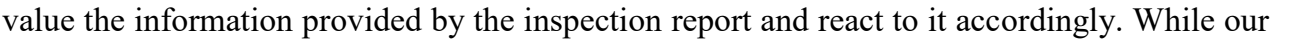

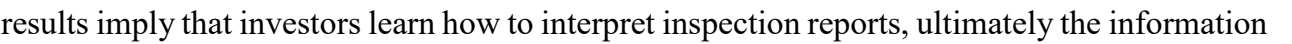

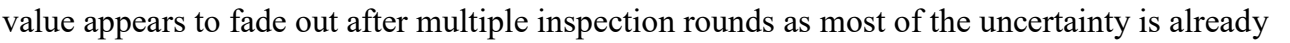
ए

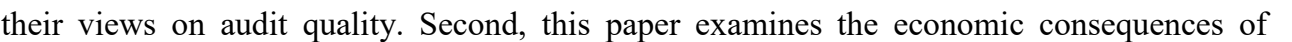
disclosures on audit firm performance from the stock market investors' perspective, which to

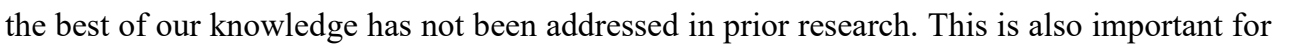

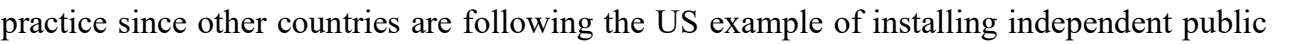

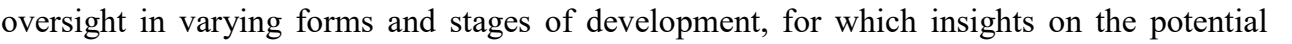

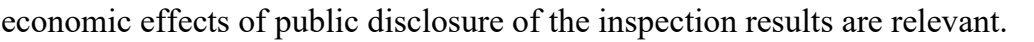

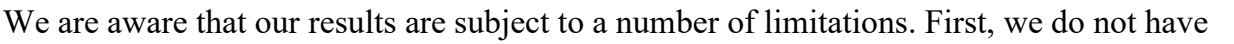

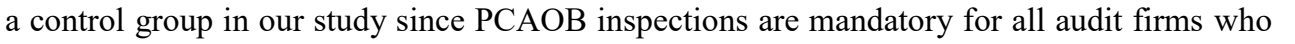

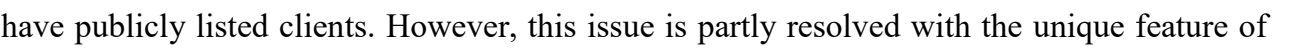

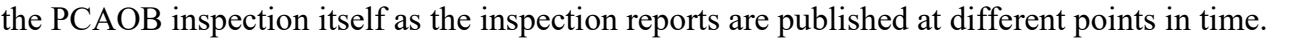

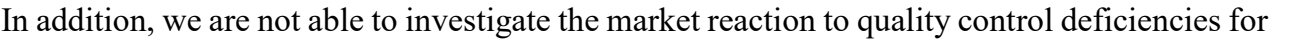

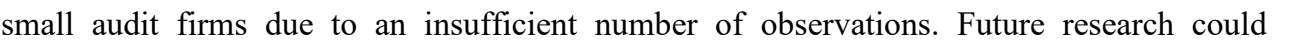

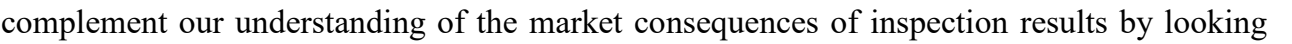

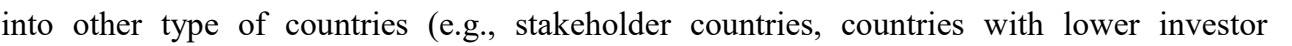

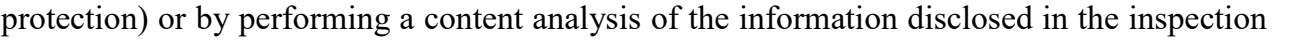
पामापापा 

Chapter 3: PCAOB Inspections and Audit Firm Behavior: An Analysis of the First Three Inspection Rounds of Small Audit Firms 


\begin{abstract}
$^{8}$

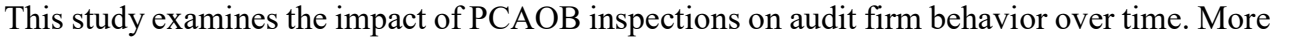

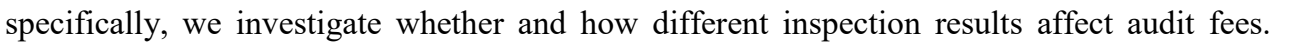

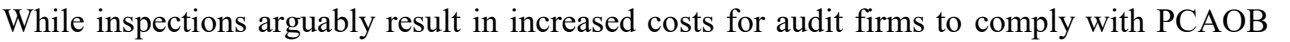

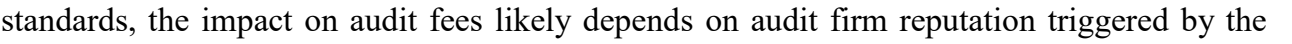
ए

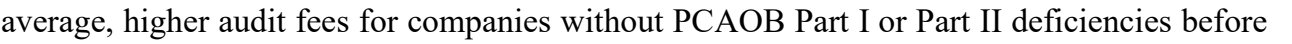

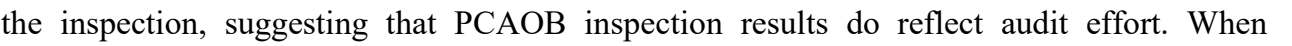

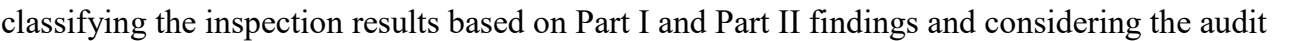

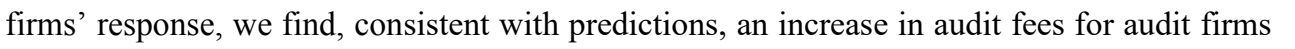

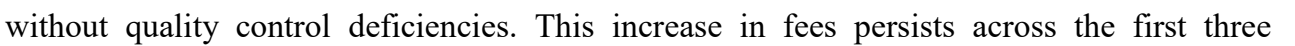

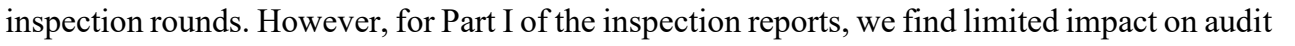

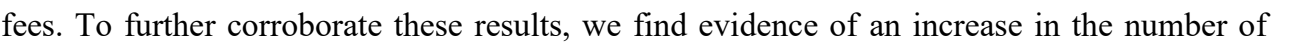

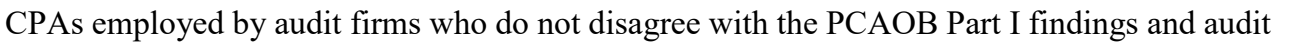

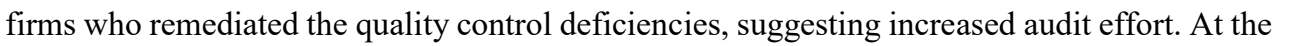

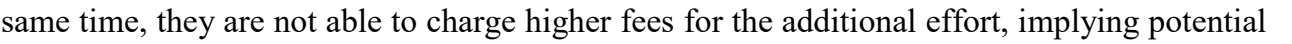

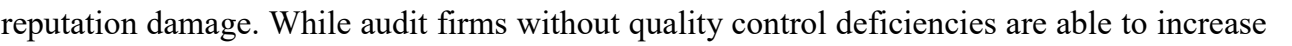

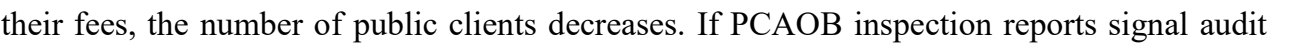

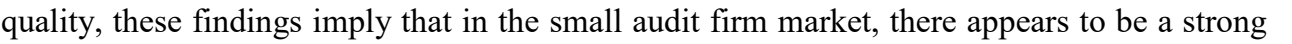

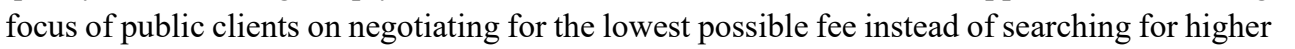

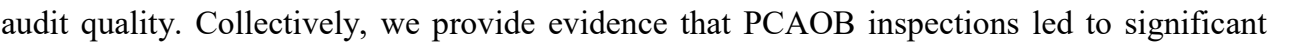

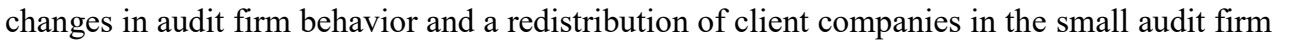

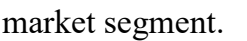

एा

$\square$

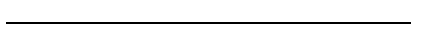

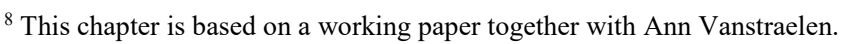




\subsection{Introduction}

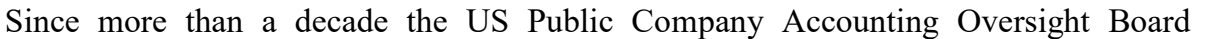

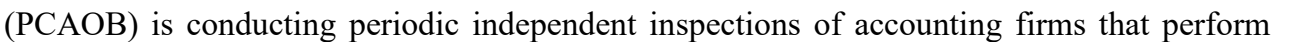

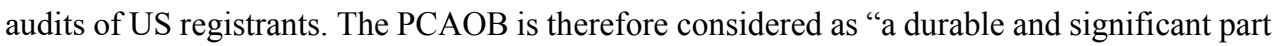
of the regulatory landscape" (Coates and

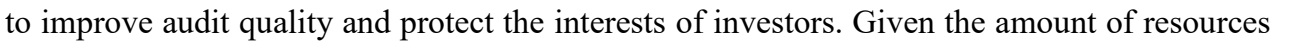

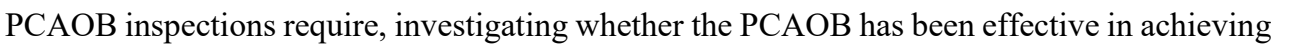

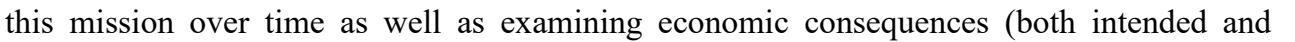
பाயா

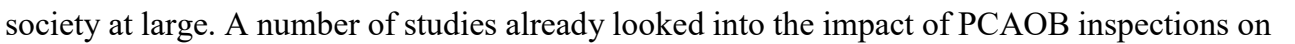

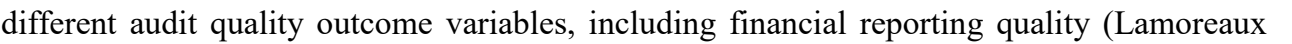

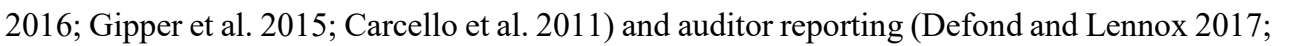

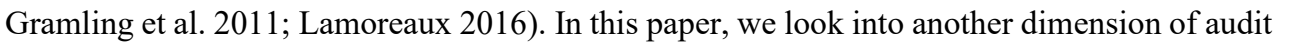

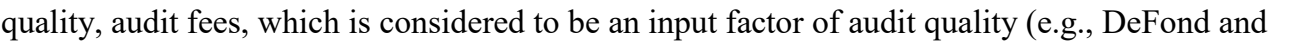

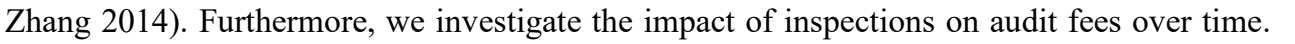

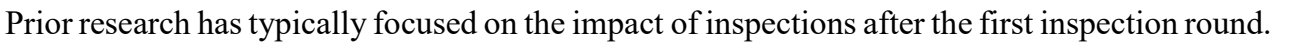

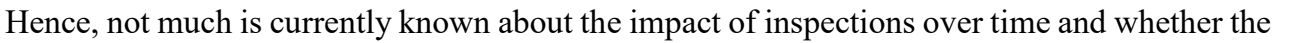

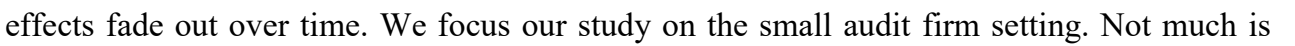

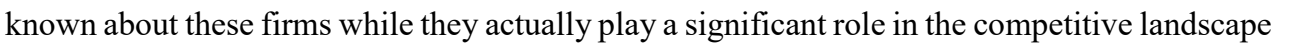

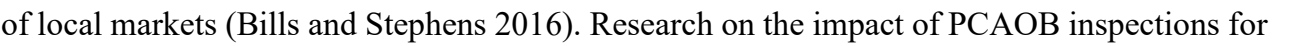

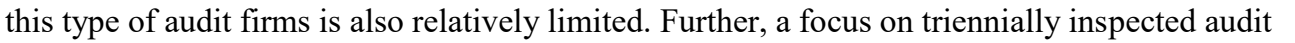

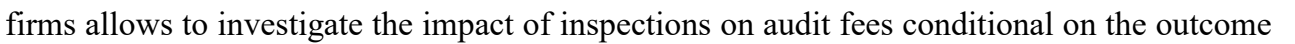

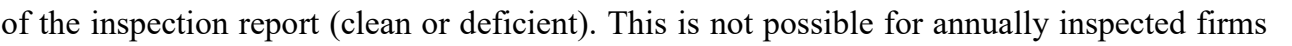

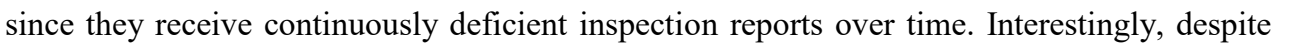

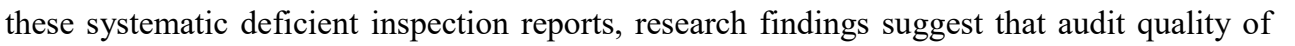

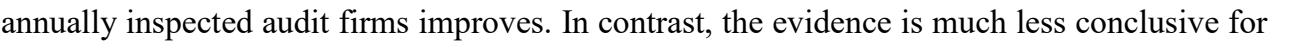
प

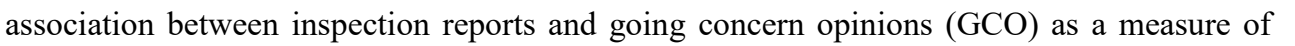

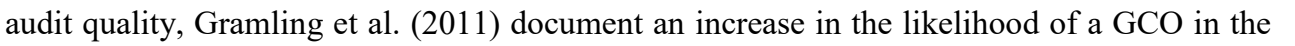

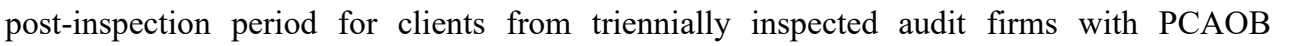

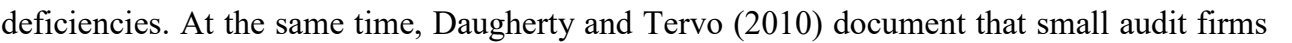

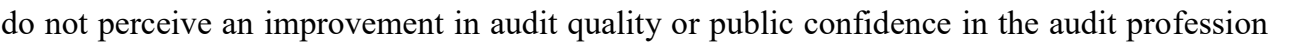
ए

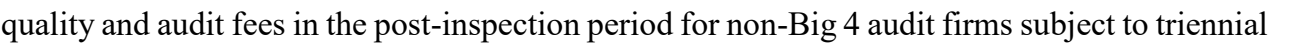

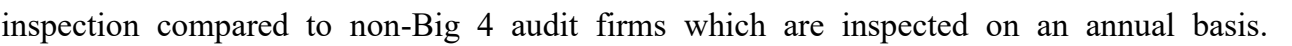

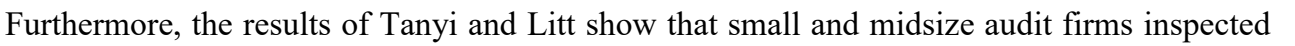

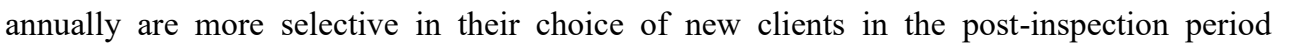

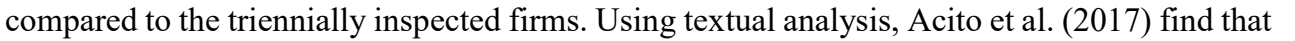

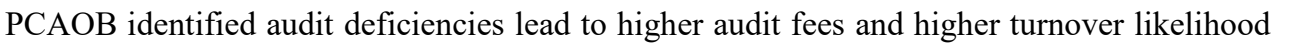

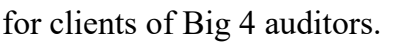

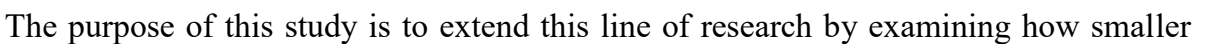

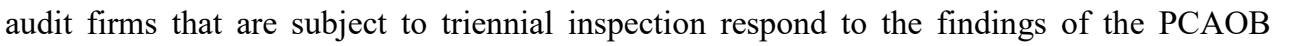




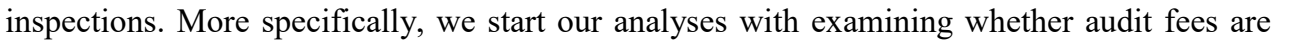

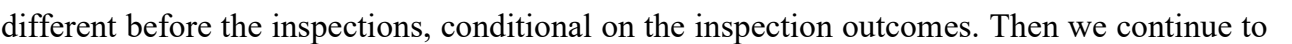

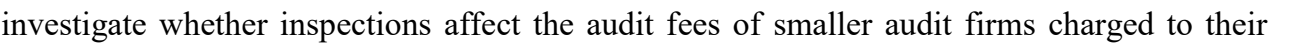

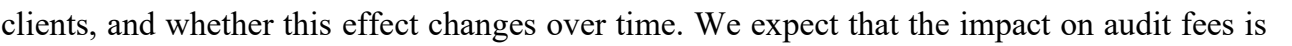

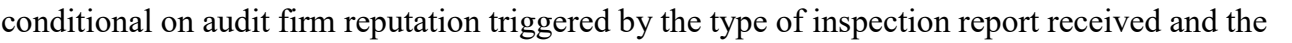

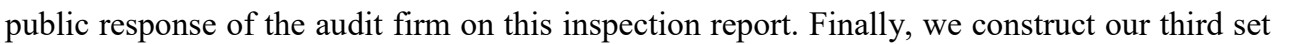

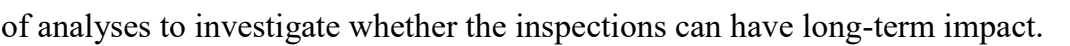

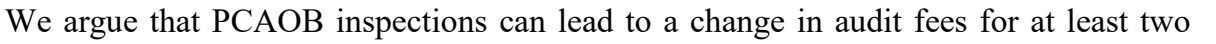
ए ए

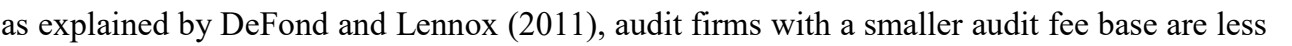

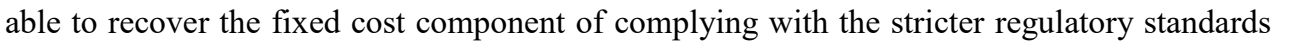

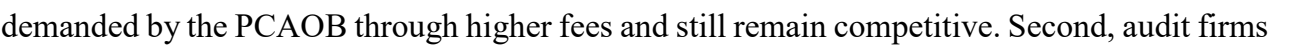

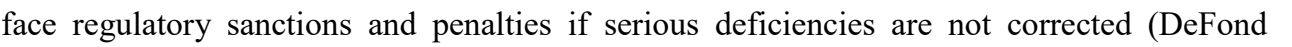

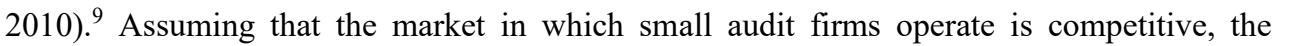

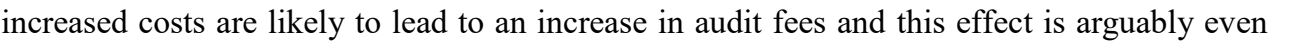

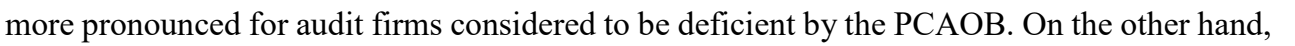

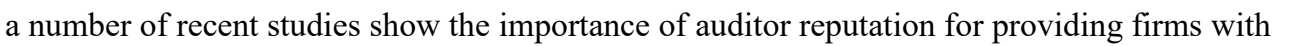

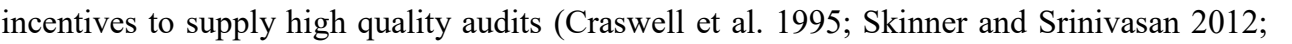

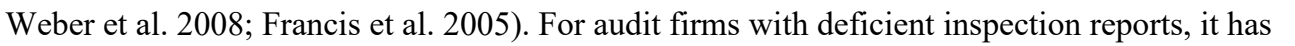

been documented that it can harm the auditor's reputation resulting in an adverse effect on

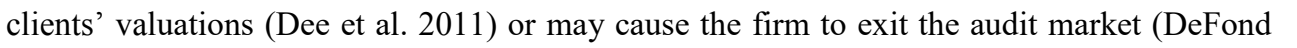

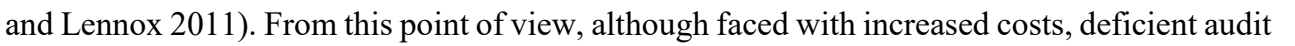

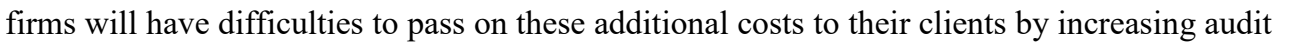
पाणाएा

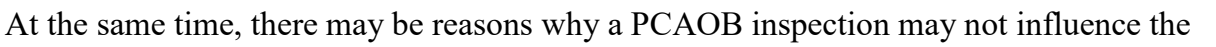

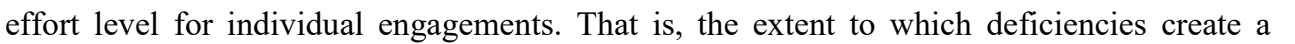

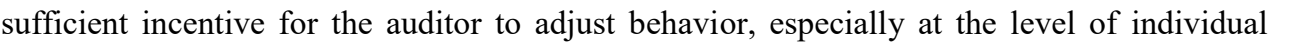

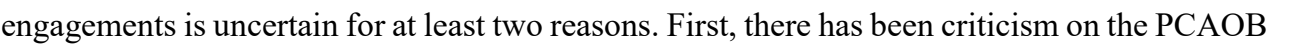

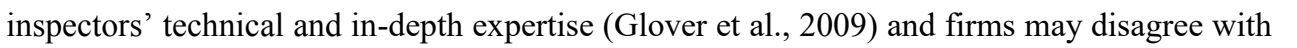
the inspector's finding

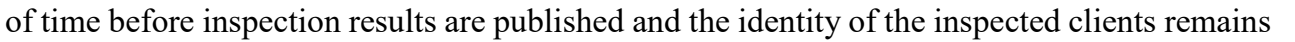

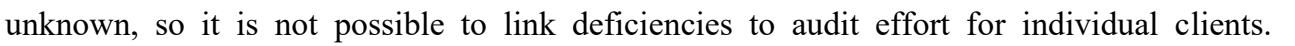

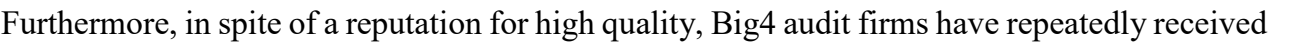

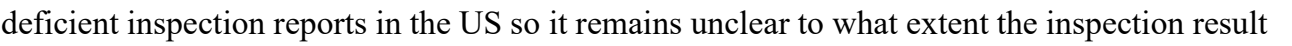

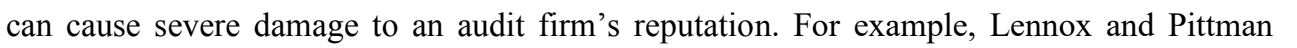

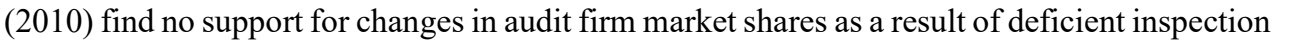
HIIIIIIIIIIIIIIIIIIII)

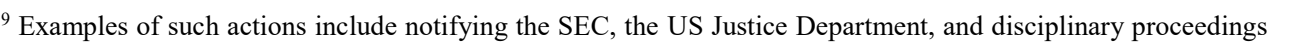

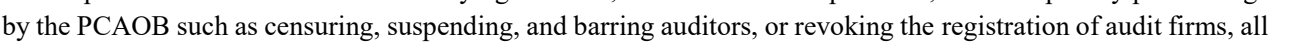

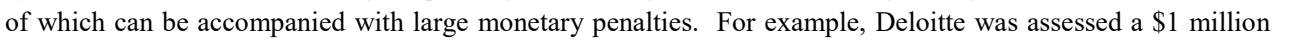

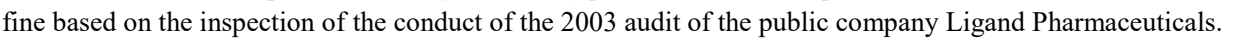




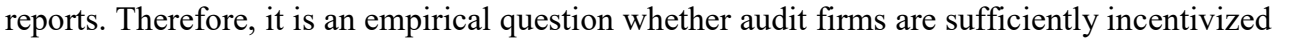

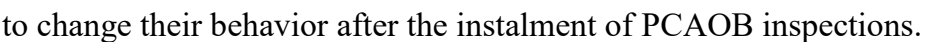

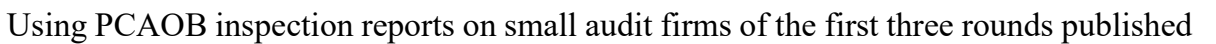

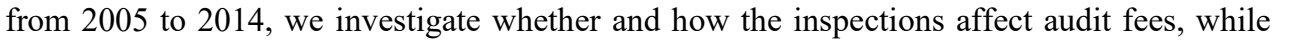

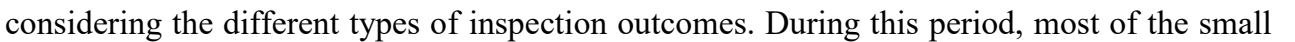

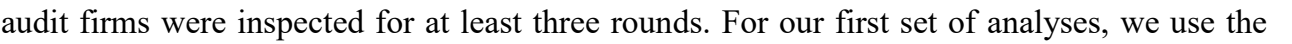

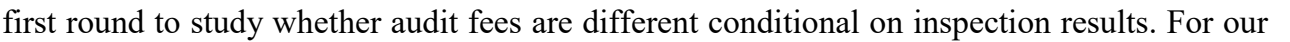

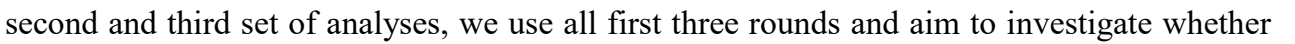

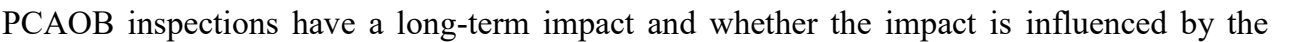
inspection findings and audit firm's responses to the inspection findings. Wh

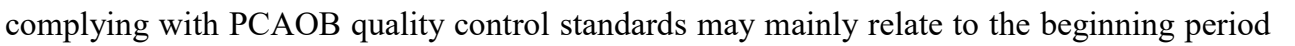

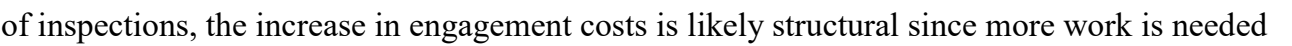

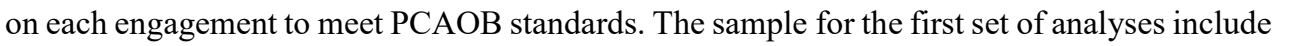

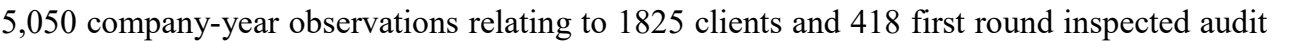

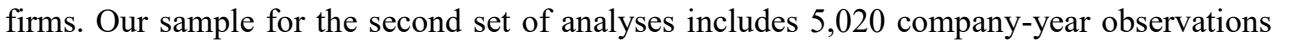

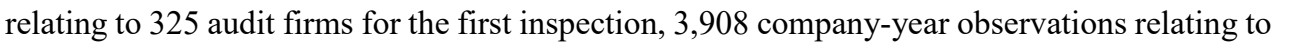

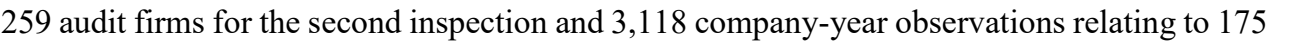

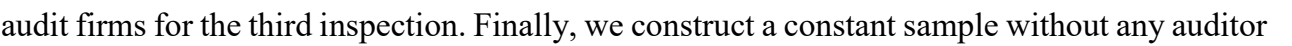

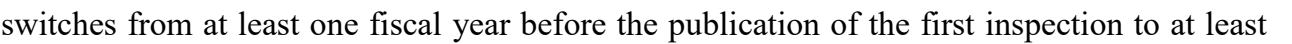

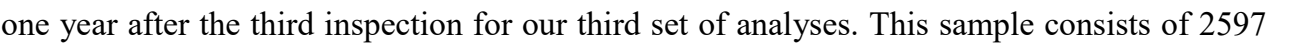

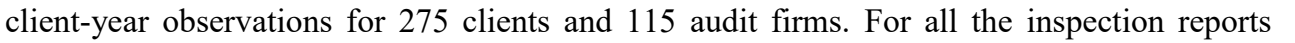

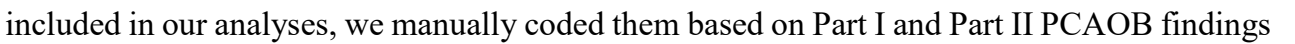
as well as the audit firms' responses to those findings. $\square$

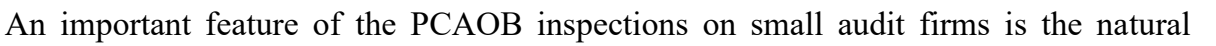

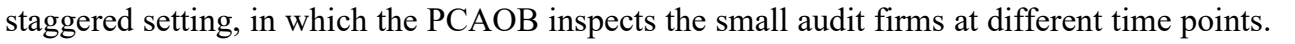

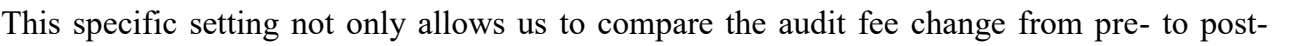

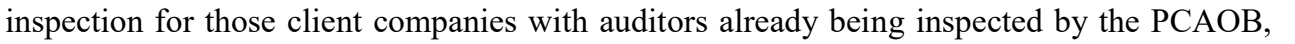

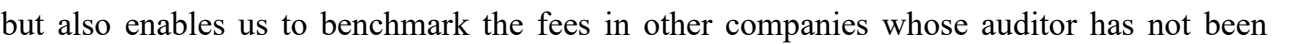

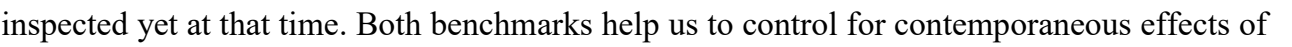

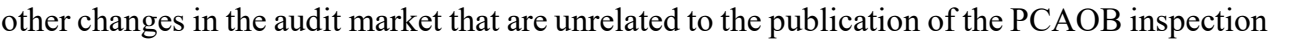

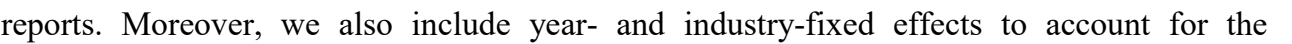

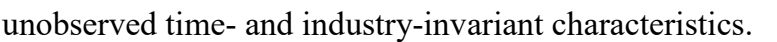

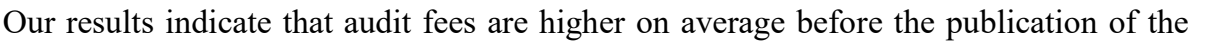

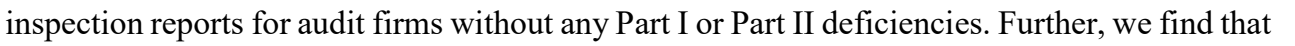

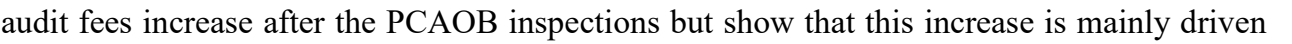

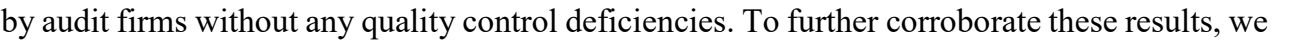

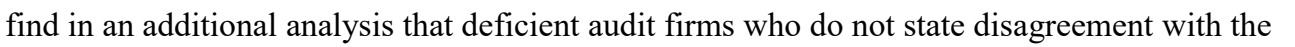

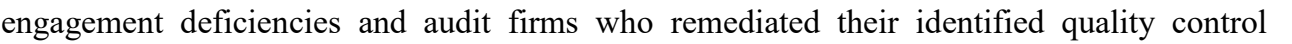

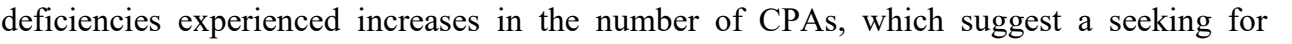

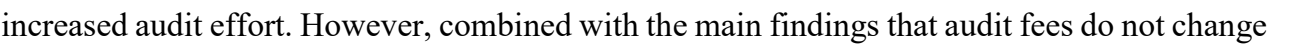

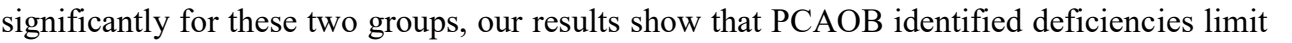




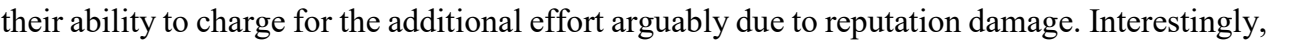

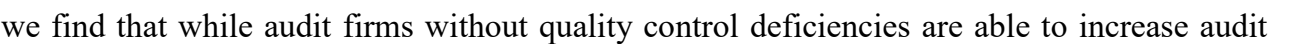

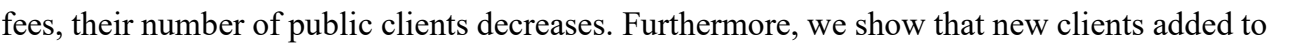

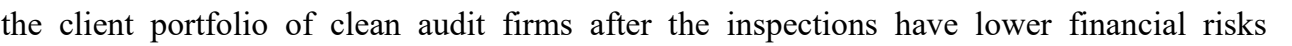

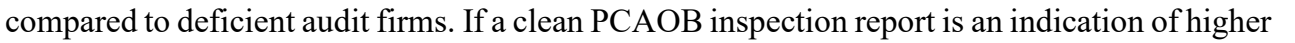

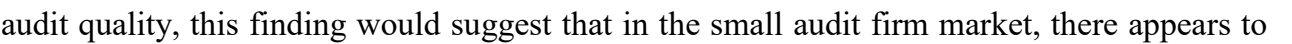

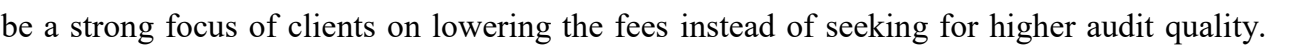

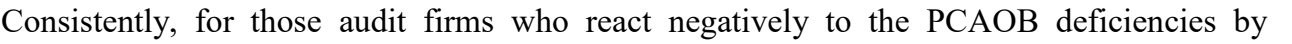

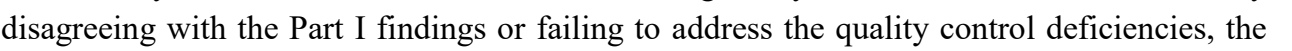

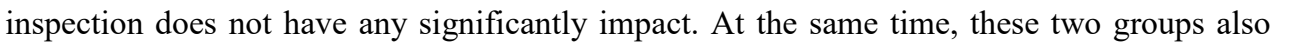

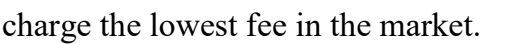

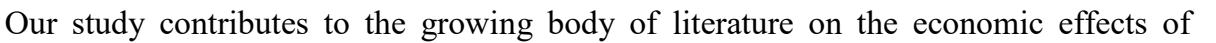

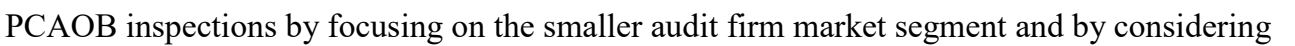
different dimensions of audit firms' behavior. Recent studies mainly document positive effects

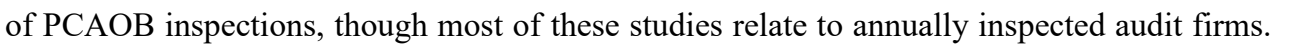

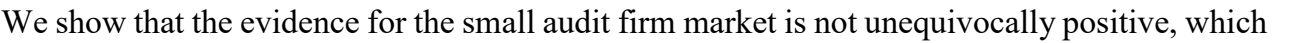

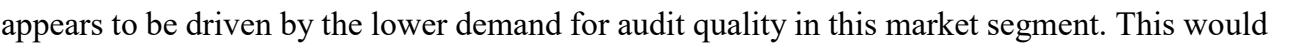

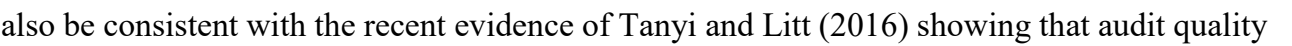

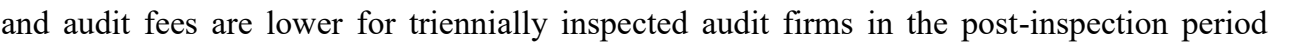

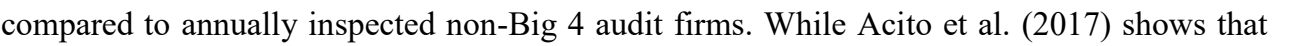

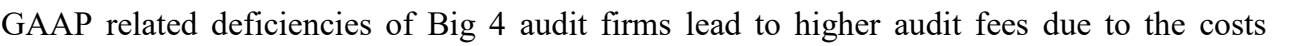

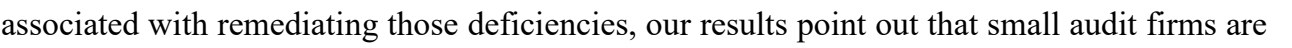

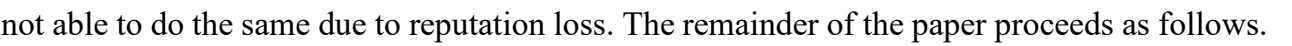

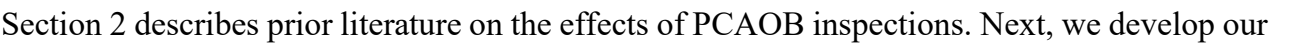

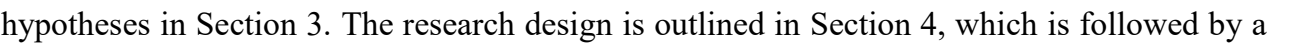

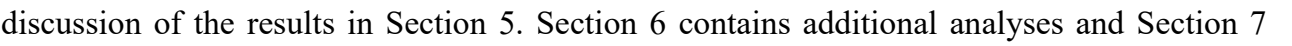

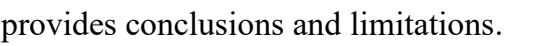

\subsection{Background}

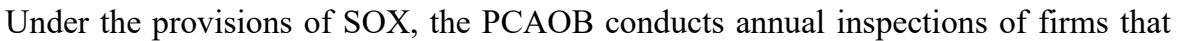

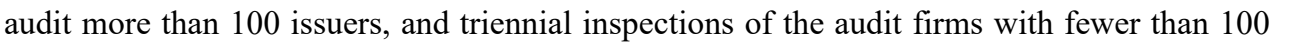
registrant clients (the latter referred to as "small audit firms" hereafter). Alo $\square \square \square \square \square \square \square \square$ evaluation of an audit firm's quality control policies and procedures, the inspection process ए।

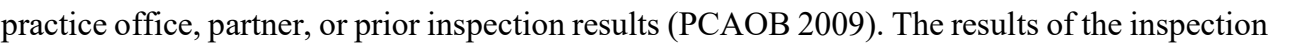

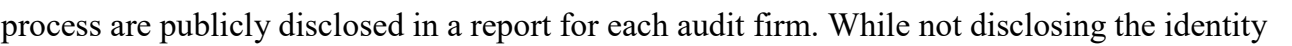

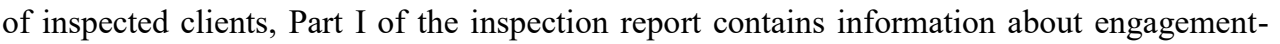

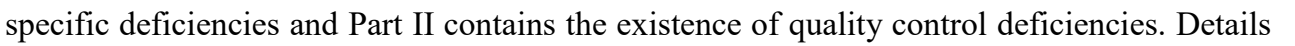

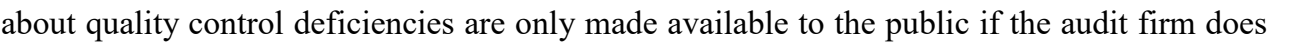

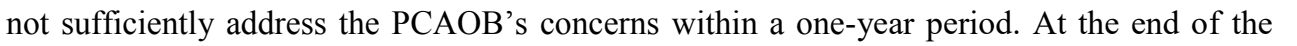

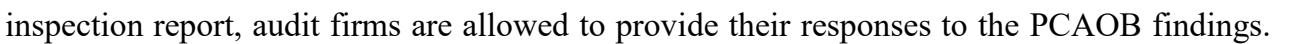


In the course of this paper, the term "deficient" is used for inspection reports that contain one

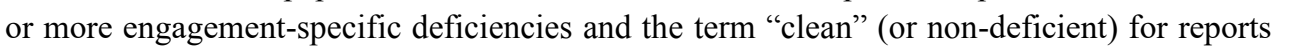

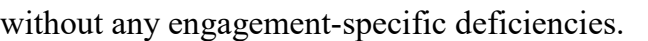

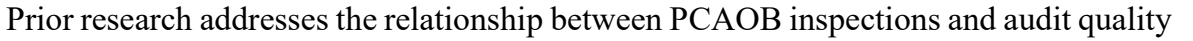

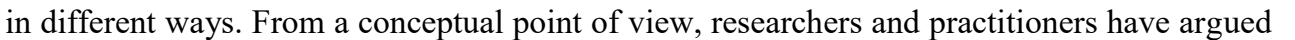

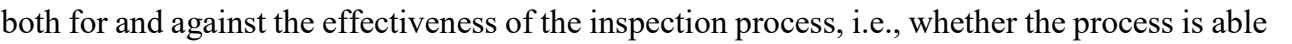

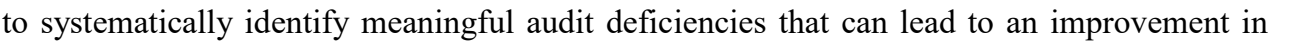

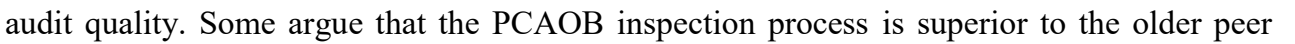

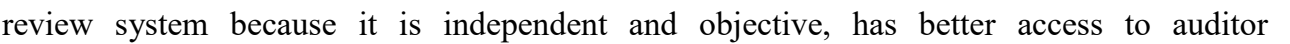

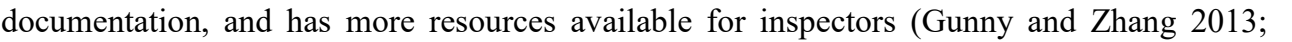

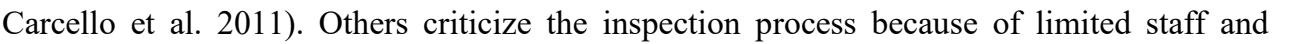

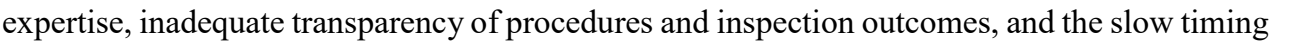

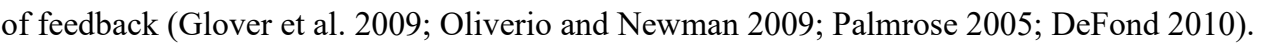

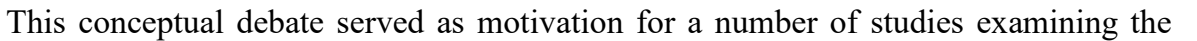

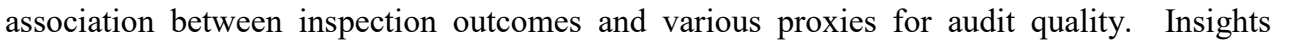

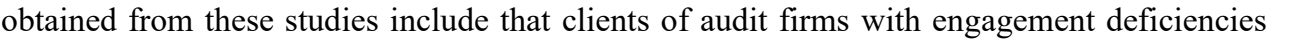

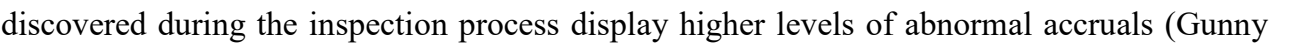

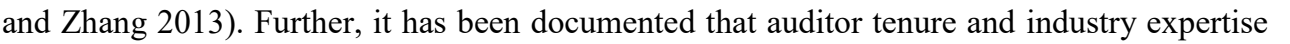

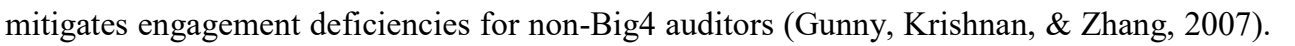

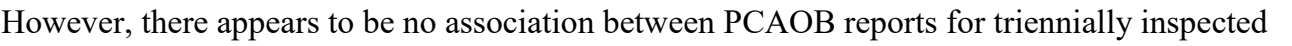

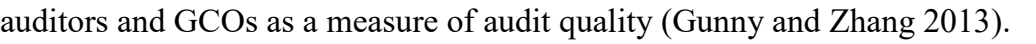

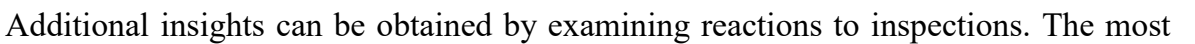

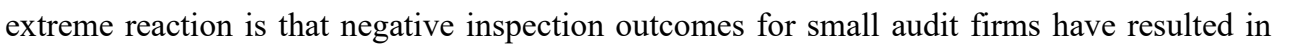

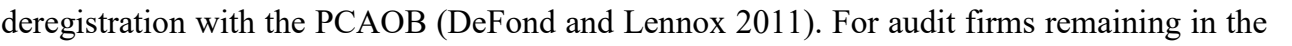

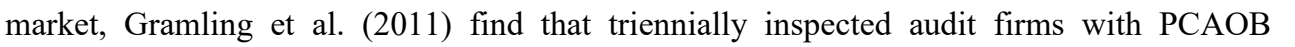

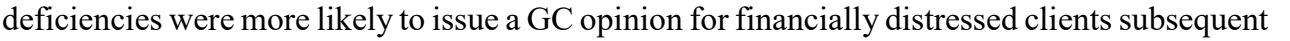

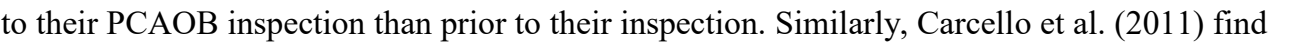

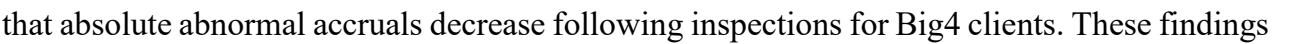

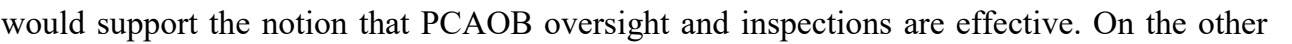

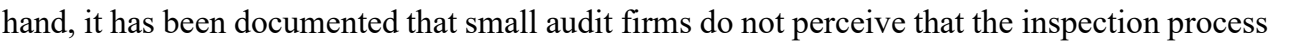
प्र

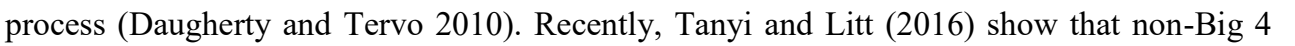

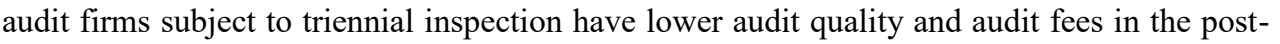

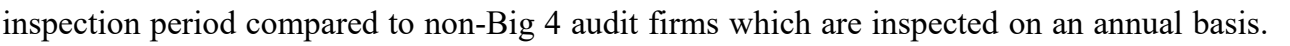

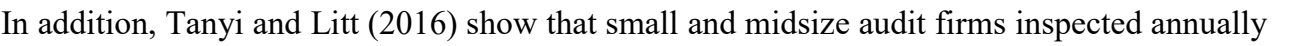

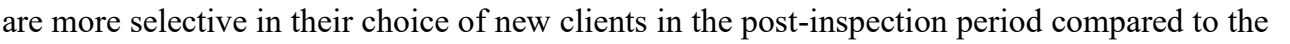

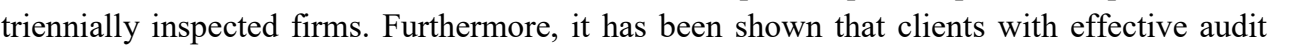

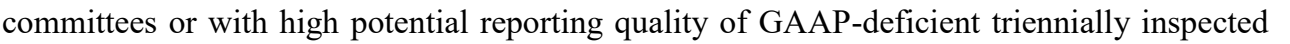

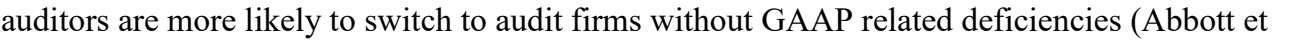

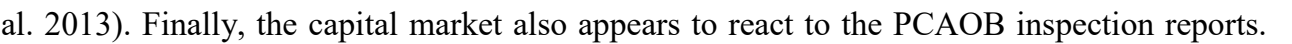

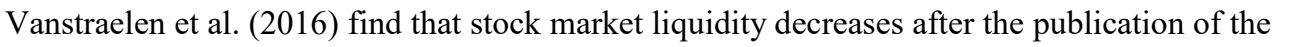




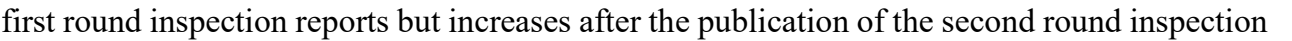

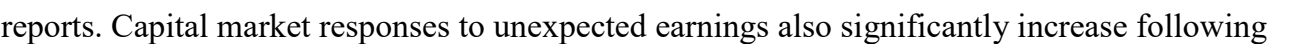

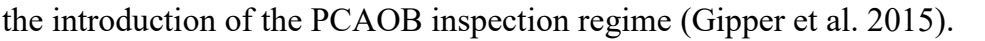

\subsection{Theoretical background and development of hypotheses}

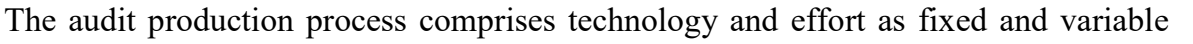

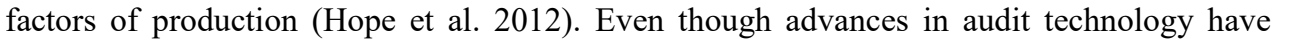

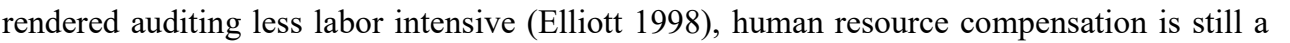

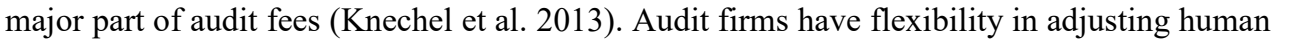

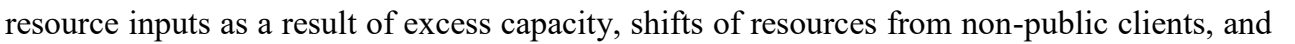

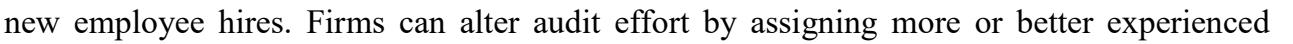
personnel to a client's team, or let the existing team members conduct more work. In either

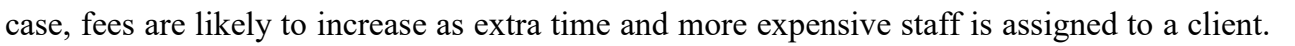

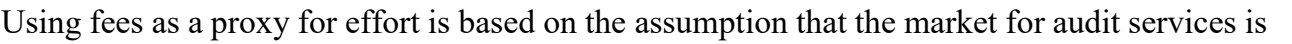

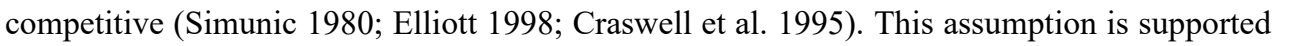

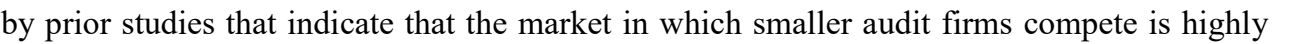
ए

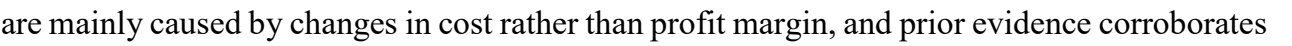

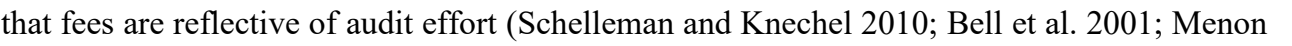

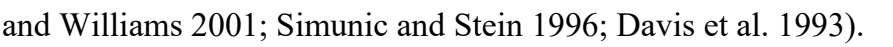

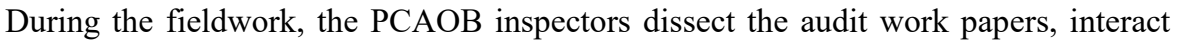

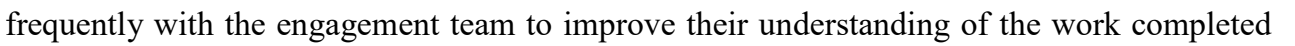

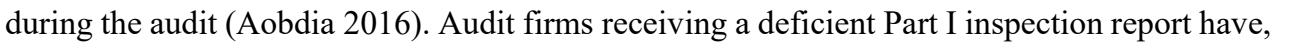
in the opinion of the PCAOB inspectors, failed to "obtain sufficient competent evidential

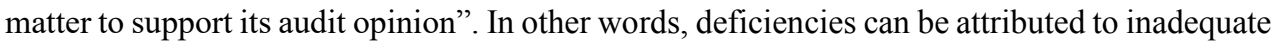

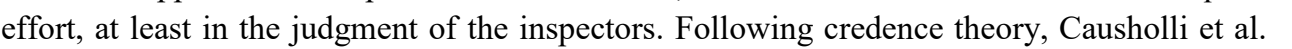

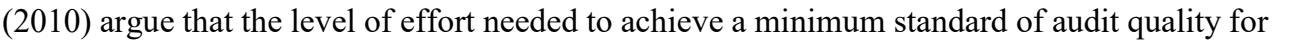
ए ए।

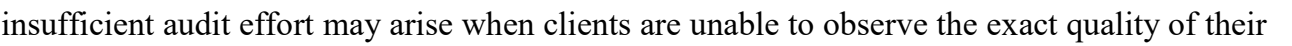

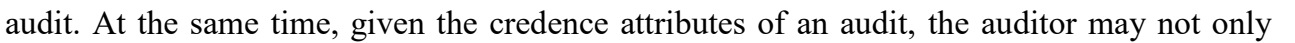

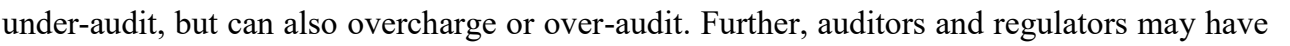
differing opinions as to what constitutes sufficient evidence and documentation since auditor's

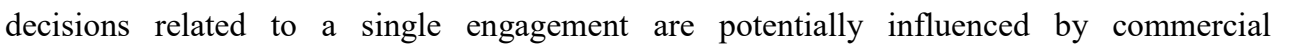

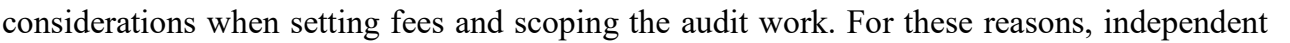

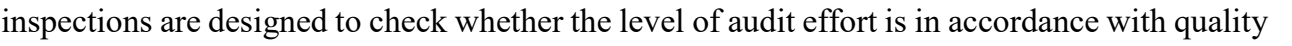

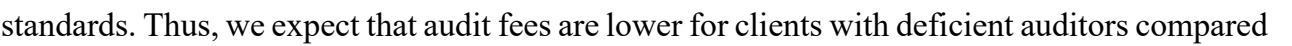

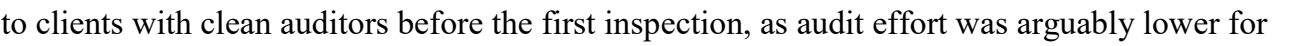

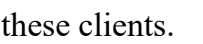

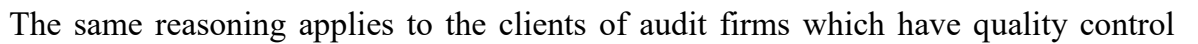
deficiencies (QCDs). An audit firm's quality control system aims to provide reasonable 
assurance that the firm's personnel comply with applicable profession standards and the firm's

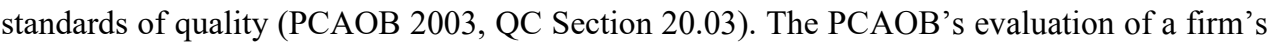

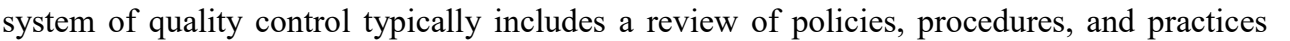

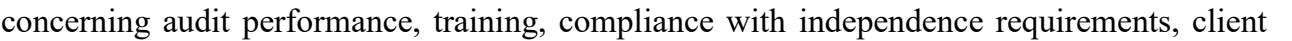

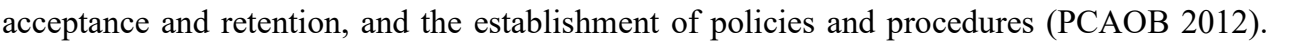

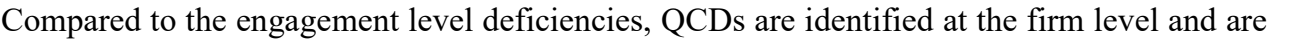

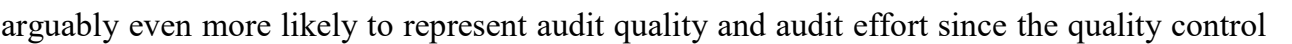

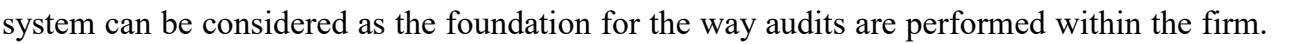

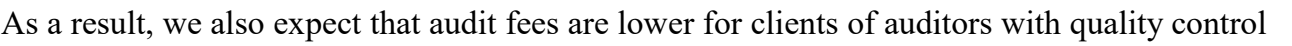

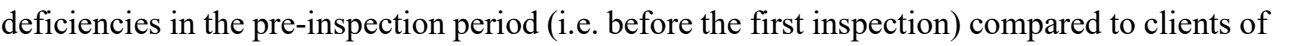

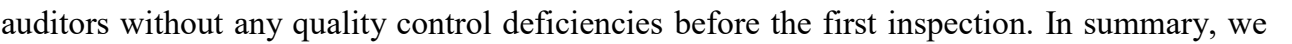

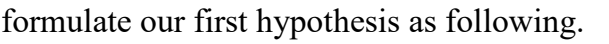

\section{$\square \square$ Audit fees in the pre-inspection period are different conditional on the inspection outcome.}

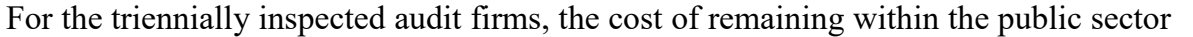
increases after the instalment of the PCAOB inspections. In particular, the PCAOB's strict

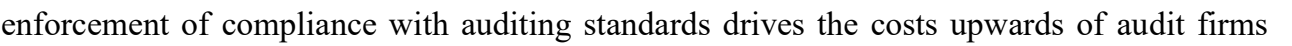

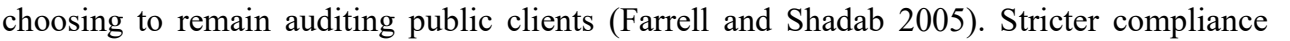

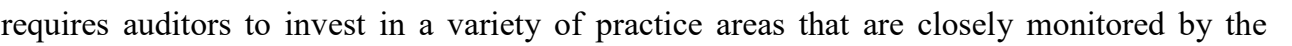
प

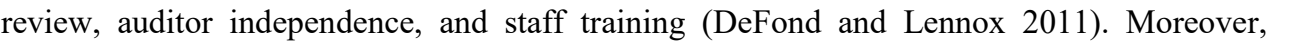

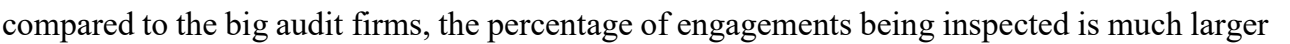

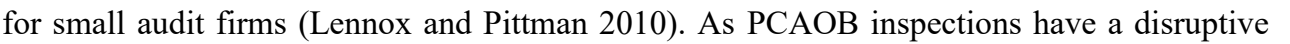
impact on auditors' normal activities, examining a higher proportion of their clients imposes a

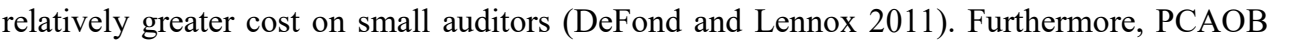

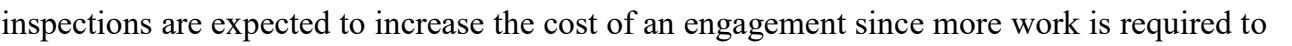

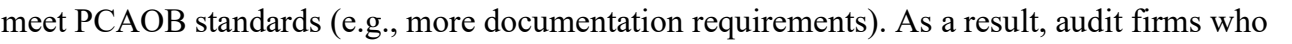

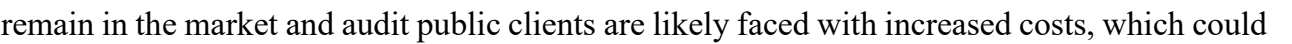

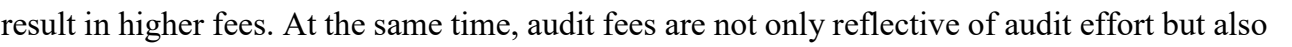

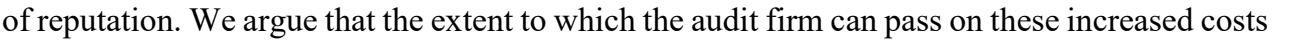

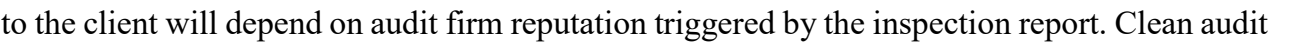

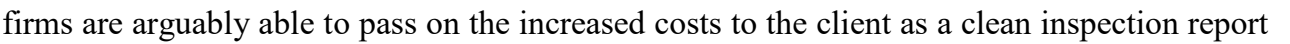

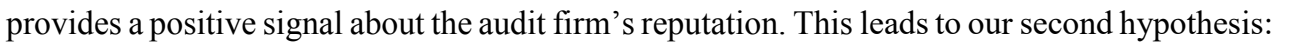

$\square \square \square$ Clients of triennially inspected clean audit firms are associated with an increase in audit fees in the post-inspection period, compared to the pre-inspection period.

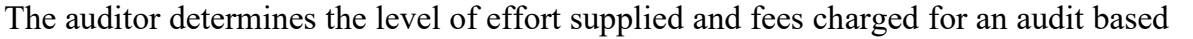

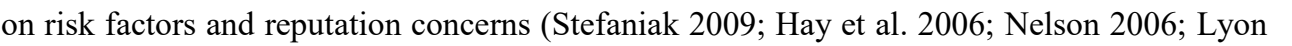

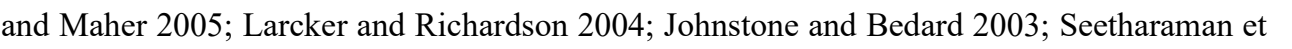

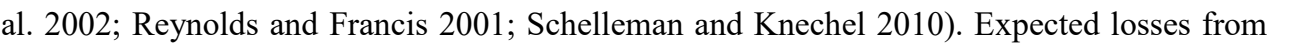

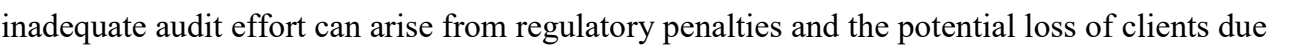




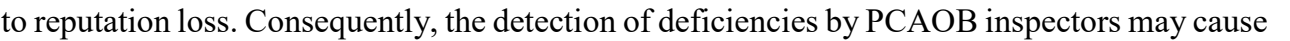

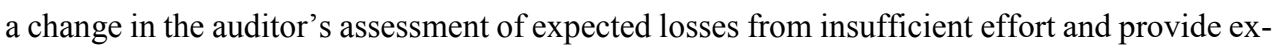

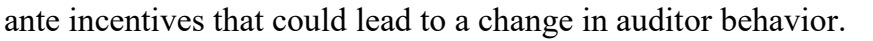

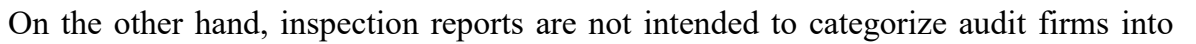

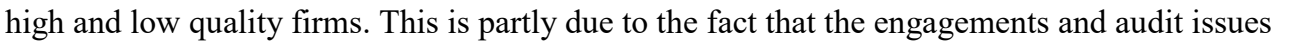

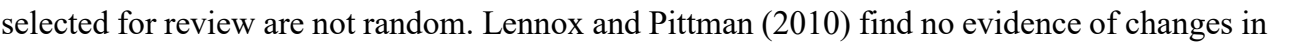

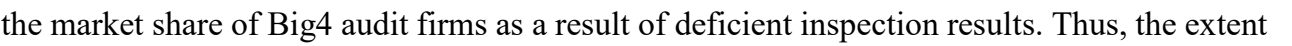

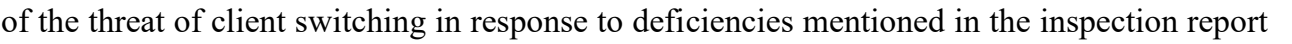

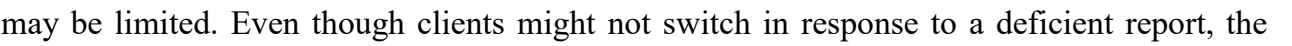

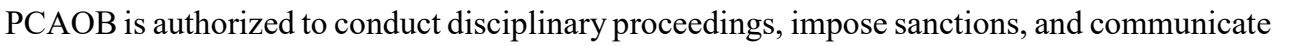

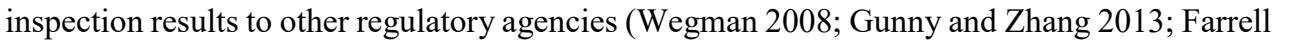

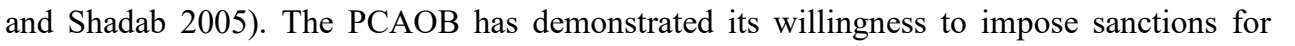

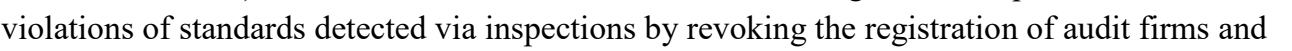

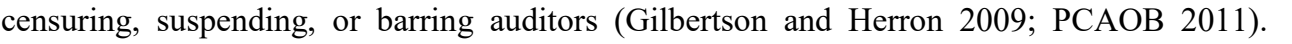

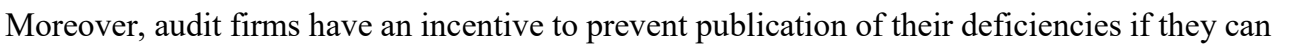

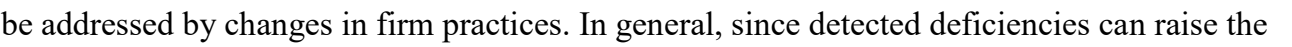

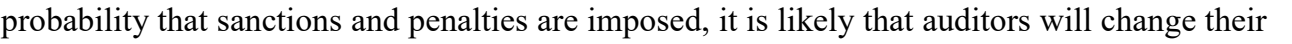

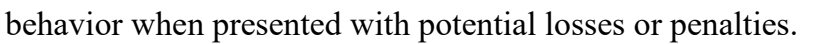

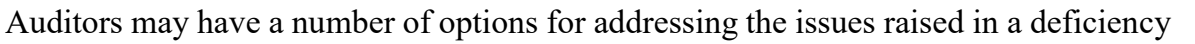

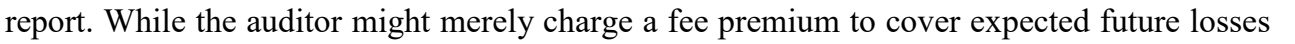

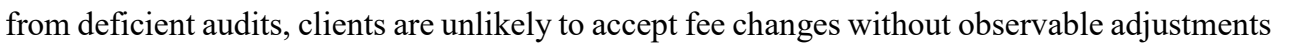

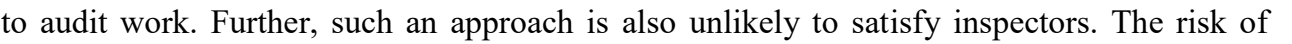

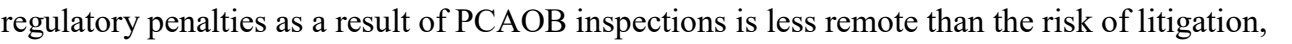

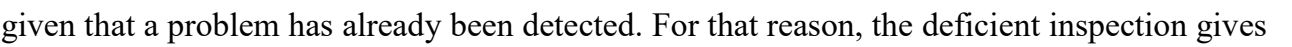

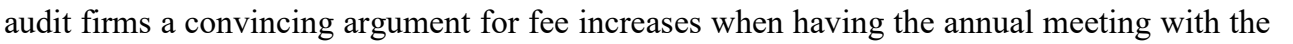
audit committee to determine current year's audit fees, i.e., previous fees may have been

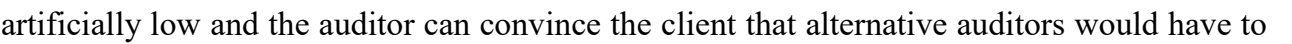

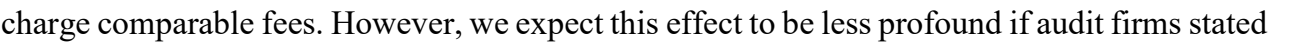

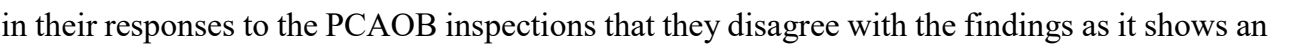

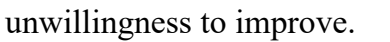

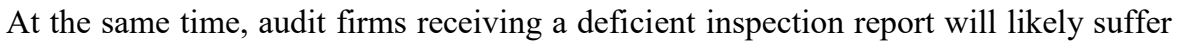

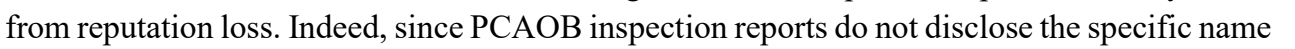

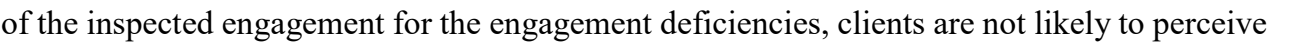
ए ए

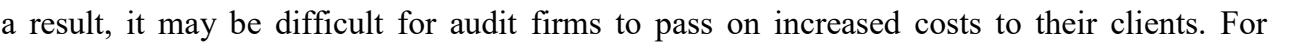

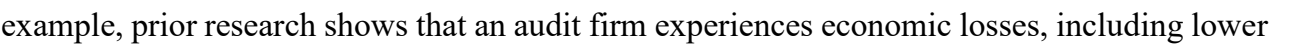

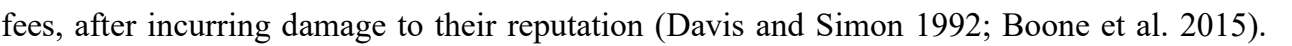

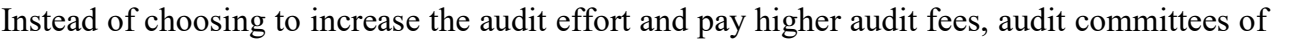

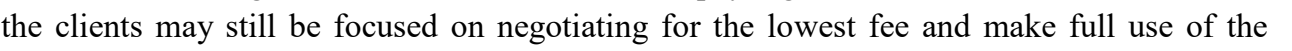

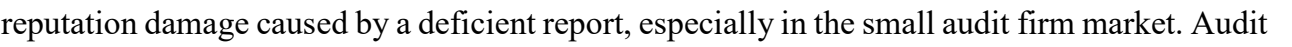

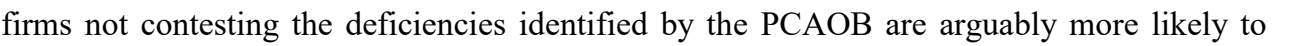

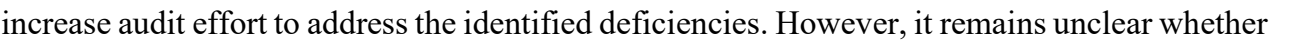




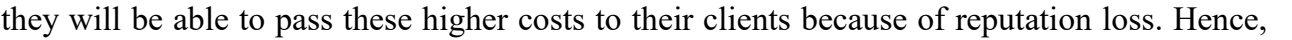

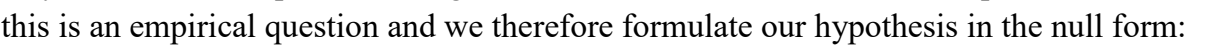

$\square \square \square$ There is no difference in audit fees for clients of triennially inspected deficient audit firms not contesting the PCAOB findings in the post-inspection period, compared to the pre-inspection period.

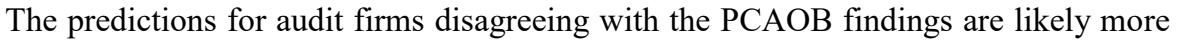

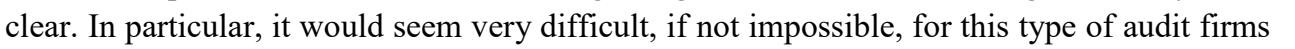

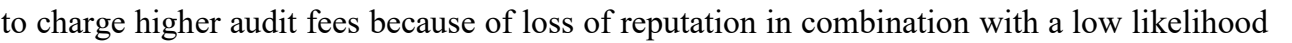
पाயா

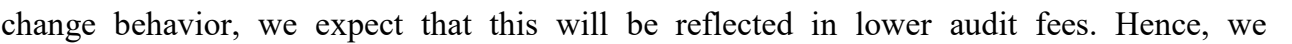

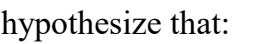

$\square \square \square$ Clients of triennially inspected deficient audit firms disagreeing with the $P C A O B$ findings are associated with a decrease in audit fees in the postinspection period, compared to the pre-inspection period.

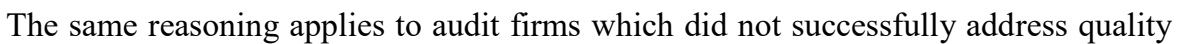

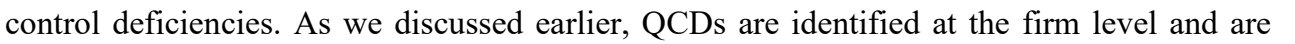

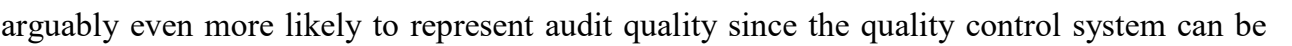

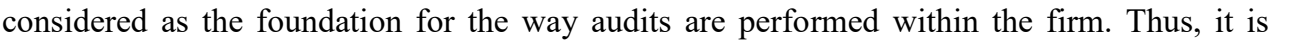

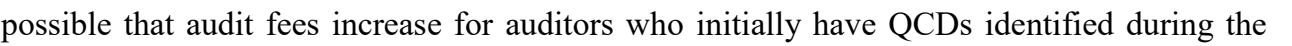

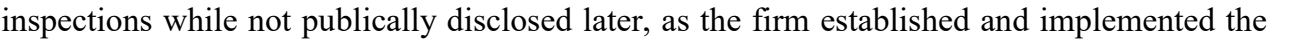

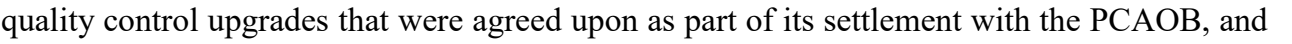

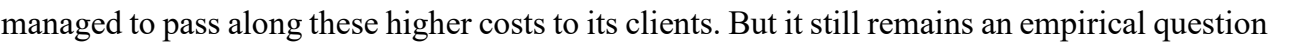

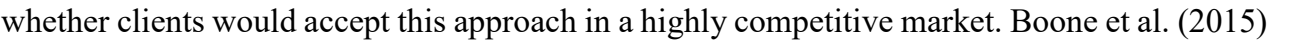

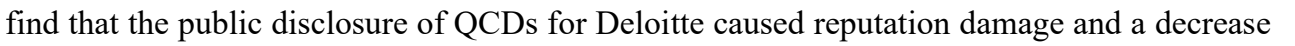
in Deloitte's audit fee growth rates. We argue this could also apply to small audit firms with

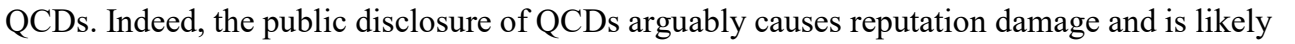

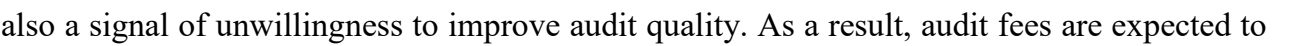

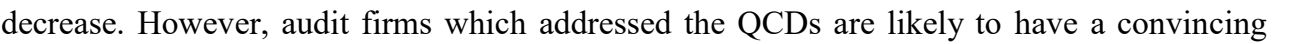

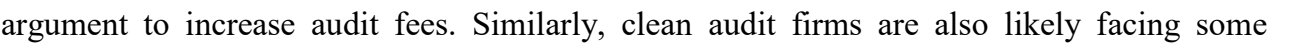
ए ए

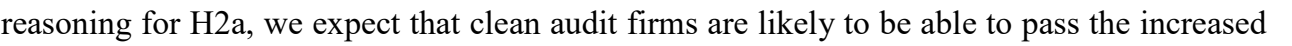

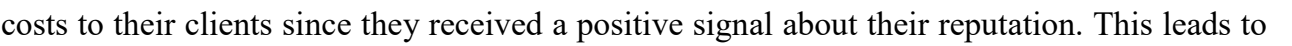

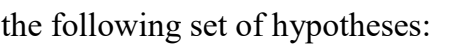


$\square \square \square$ Clients of triennially inspected audit firms without identified quality control deficiencies are associated with an increase in audit fees in the post-inspection period, compared to the pre-inspection period.

$\square \square \square$ Clients of triennially inspected audit firms with identified quality control deficiencies which are addressed within one year are associated with an increase in audit fees in the post-inspection period, compared to the preinspection period.

$\square \square \square$ Clients of triennially inspected audit firms with disclosed quality control deficiencies are associated with a decrease in audit fees in the post-inspection period, compared to the pre-inspection period.

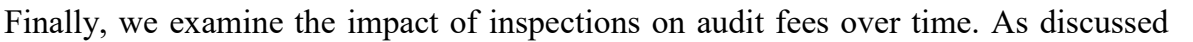

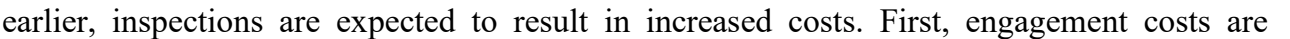

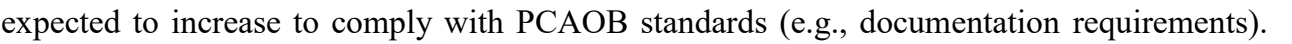

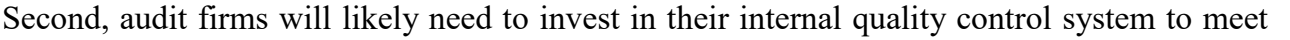

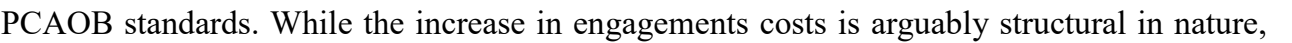

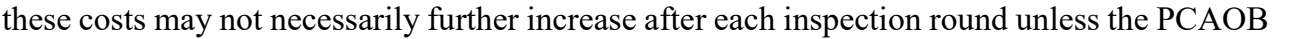

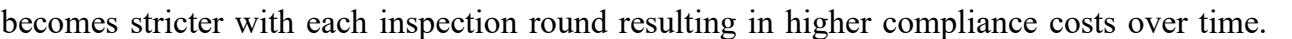

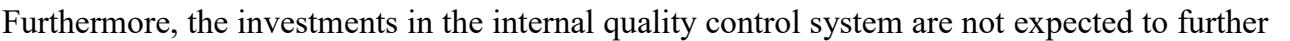
ए

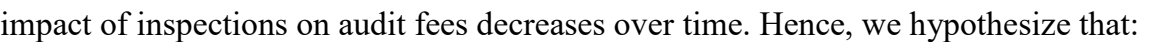

$\square \square$ The magnitude of change in audit fees from pre- to post inspection decrease over time. $\square$

\subsection{Research design}

\subsubsection{Sample selection}

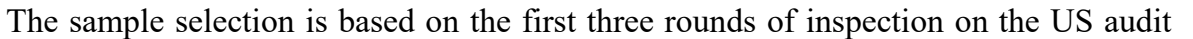

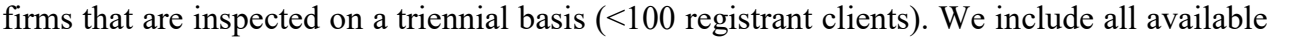

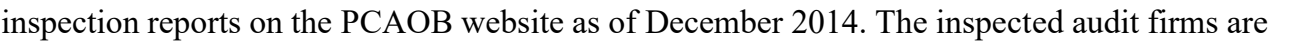

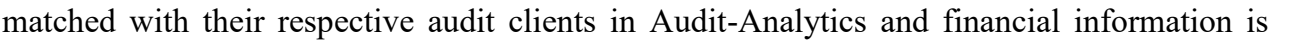

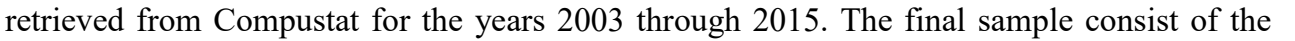

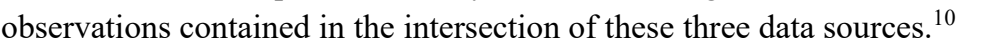

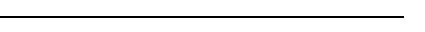

$\square \square \square \square \square$ Analytics neither contains all inspected audit firms nor the full set of an audit firm's clients, it is not

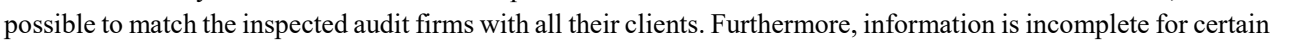

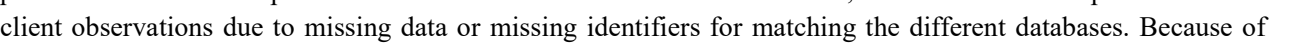
ए
} 


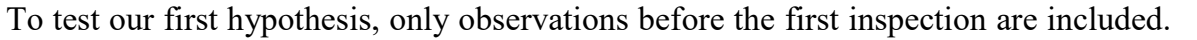

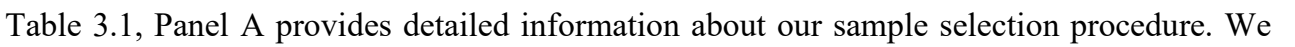

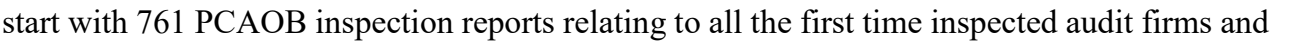

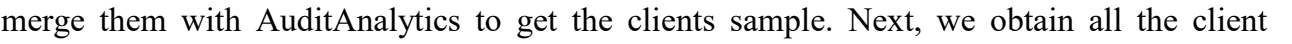

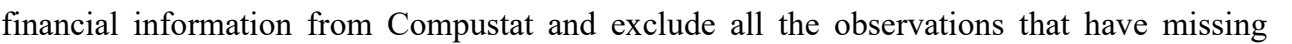

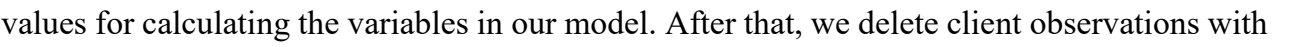

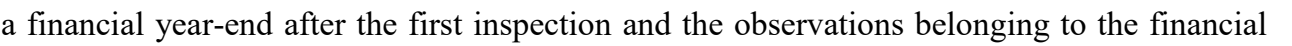

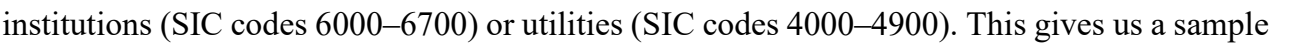

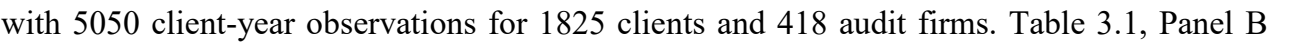

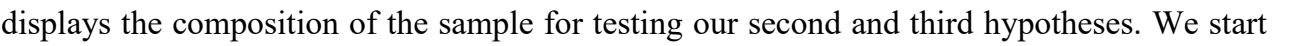

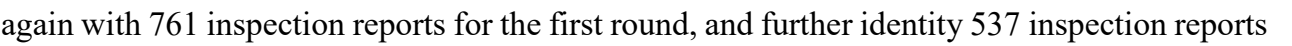

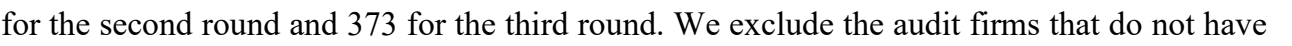

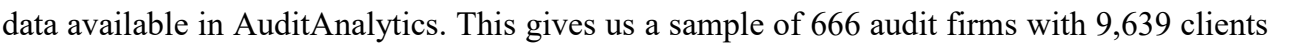

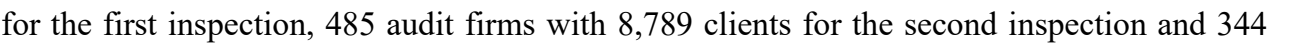

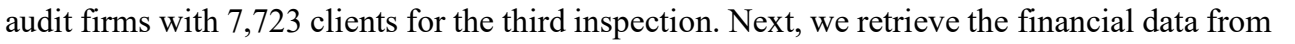

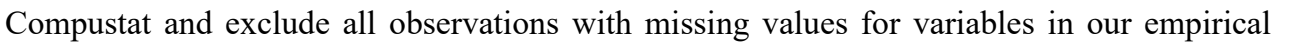

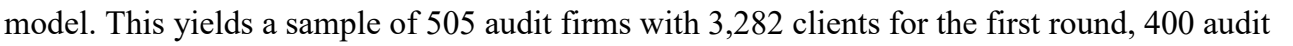

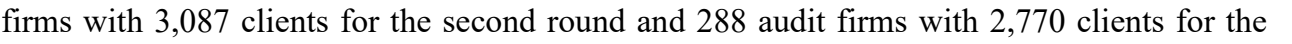
प

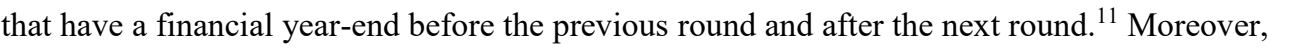

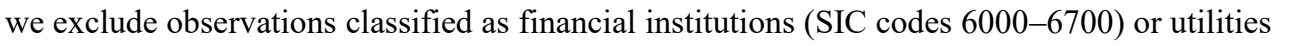

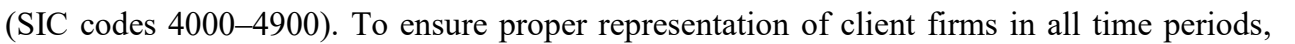

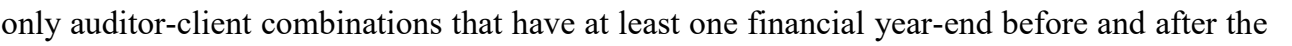

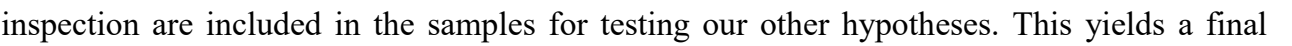

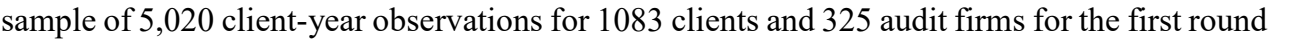

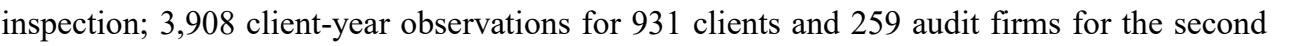

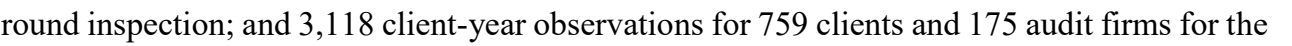

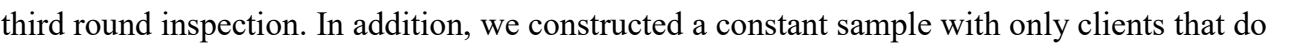

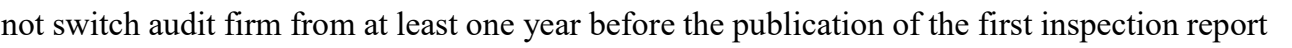

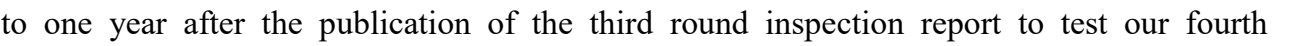

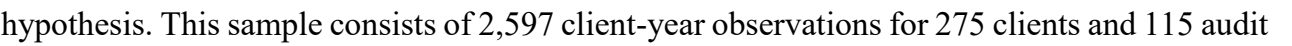

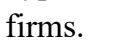

For each inspection report, we manually code the type of the report as "DEF" or "CLEAN", depending on whether any engagement specific deficiency is disclosed in Part I of

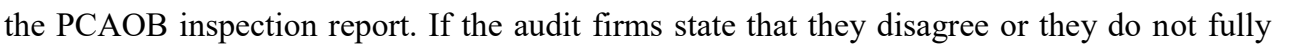
agree with the PCAOB findings, they were coded as "DISAGREE". Alternatively, if they do not disagree, they were coded as "OTHER". We further manually code the inspection reports as "NONQCD" if no quality control deficiency is identified during the inspection, "QCD" if any quality control deficiency is identified, "QCD $D$ " if any quality control deficiency is

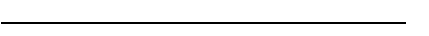

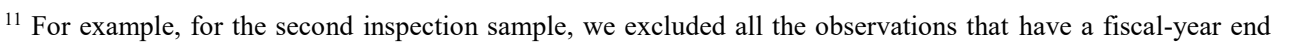

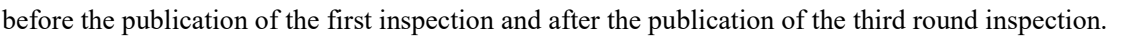




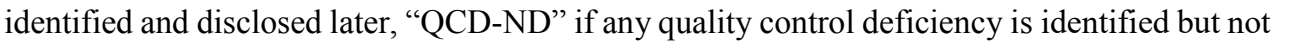

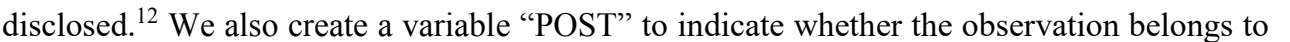

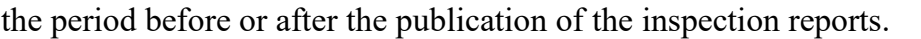

Table 3.1: Sample selection procedure

\begin{tabular}{|c|c|c|c|}
\hline \multicolumn{4}{|l|}{ Panel A: Sample for $\mathrm{H1}$} \\
\hline Number of Audit firms (number of clients) & \multicolumn{3}{|c|}{ Pre-first inspection } \\
\hline Originally from PCAOB website $\square$ & \multicolumn{3}{|c|}{$761 \square$} \\
\hline -without data from AuditAnalytics $\square$ & \multicolumn{3}{|c|}{$666(9639) \square$} \\
\hline -without data from Compustat $\square$ & \multicolumn{3}{|c|}{$578(4131) \square$} \\
\hline -missing values for variables used in the model $\square$ & \multicolumn{3}{|c|}{$505(3282) \square$} \\
\hline $\begin{array}{l}\text {-observations with year-end after the first } \\
\text { inspection } \square\end{array}$ & \multicolumn{3}{|c|}{$444(2003) \square$} \\
\hline -SIC 6000-6700 and SIC4000-4900 $\square$ & \multicolumn{3}{|c|}{$418(1825) \square$} \\
\hline \multicolumn{4}{|l|}{ Panel B: Samples for $\mathrm{H} 2$ and $\mathrm{H3}$} \\
\hline Number of Audit firms (number of clients) & $\begin{array}{c}\text { First } \\
\text { inspection } \\
\end{array}$ & $\begin{array}{c}\text { Second } \\
\text { inspection }\end{array}$ & $\begin{array}{c}\text { Third } \\
\text { inspection } \\
\end{array}$ \\
\hline Originally from PCAOB website $\square$ & $761 \square$ & $537 \square$ & $373 \square$ \\
\hline -without data from AuditAnalytics $\square$ & $666(9639) \square$ & $485(8789) \square$ & $344(7723) \square$ \\
\hline -without data from Compustat $\square$ & $578(4131) \square$ & $450(3893) \square$ & $329(3513) \square$ \\
\hline -missing values for variables used in the model $\square$ & $505(3282) \square$ & $400(3087) \square$ & $288(2770) \square$ \\
\hline $\begin{array}{l}\text {-observations with year-end after the next inspection and } \\
\text { before previous inspection }\end{array}$ & $487(2603) \square$ & $369(2193) \square$ & $252(1739) \square$ \\
\hline -SIC 6000-6700 and SIC4000-4900 $\square$ & $465(2383) \square$ & $358(2045) \square$ & $242(1640) \square$ \\
\hline $\begin{array}{l}\text {-observations without at least one fiscal year before and one } \\
\text { fiscal year after the inspection } \square\end{array}$ & $325(1083) \square$ & $259(931) \square$ & $175(759) \square$ \\
\hline
\end{tabular}

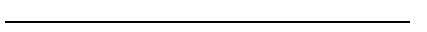

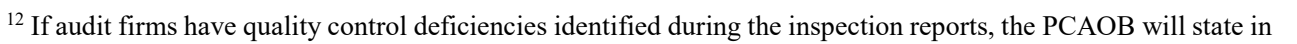

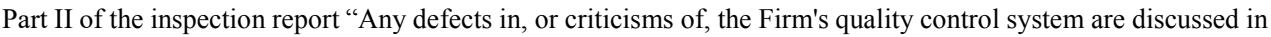

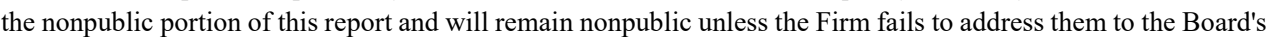

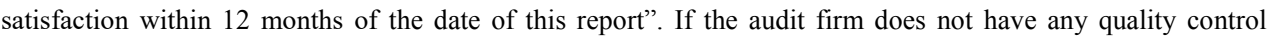
deficiency identified, the PCAOB will state in part II of the inspection report: "The inspection team did not identify

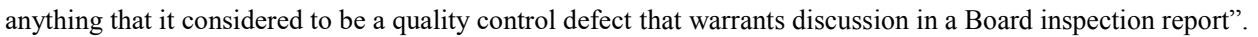




\subsubsection{Empirical models}

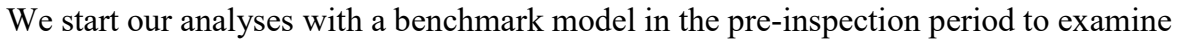

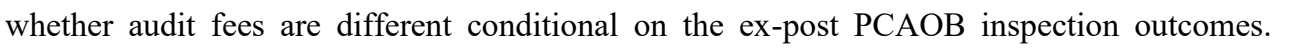

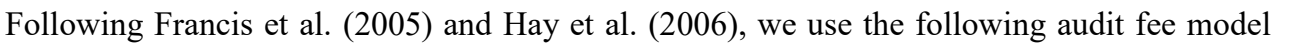

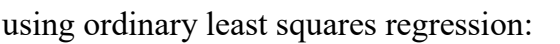

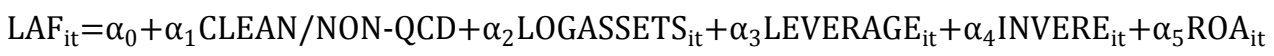

$$
\begin{aligned}
& +\alpha_{6} \text { LOSS }_{\text {it }}+\alpha_{7} \text { FOREIGN }_{\text {it }}+\alpha_{8} \text { BUSY }_{\text {it }}+\alpha_{9} \text { OPINION }_{\text {it }}+\alpha_{10} \text { LOGSEG }_{\text {it }}+\alpha_{11} \text { SHORT }_{\text {it }} \\
& +\alpha_{12} \text { LOGAVG_ASSET }+\alpha_{12} \text { LOGTOTAL_FEE }+ \text { Year fixed effects } \\
& + \text { Industry fixed effects }+\delta(3.1)
\end{aligned}
$$

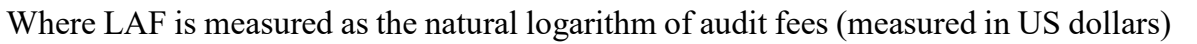

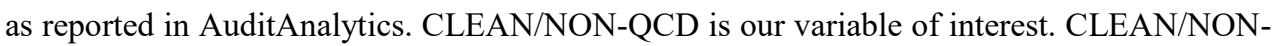

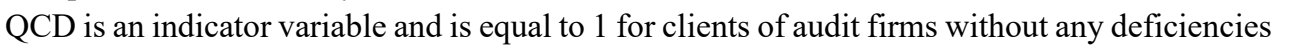
ए

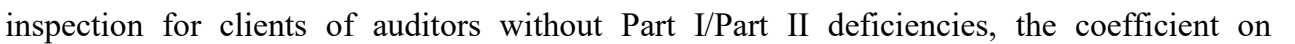

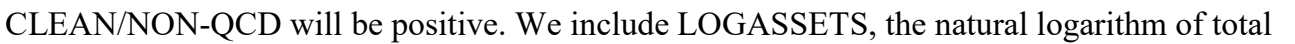

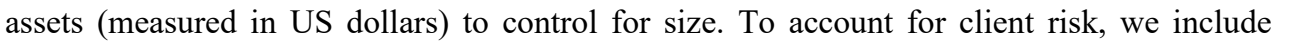

LEVERAGE, the sum of the company's current and long term debt divided by total assets, and

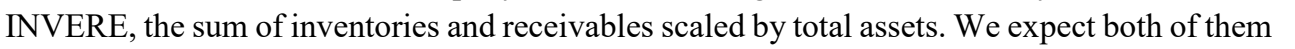
ए

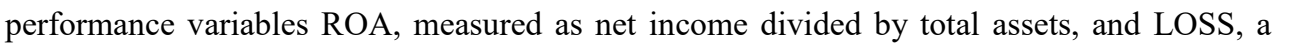

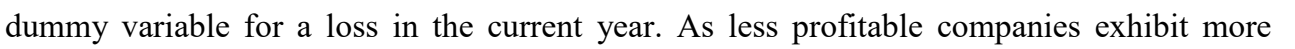

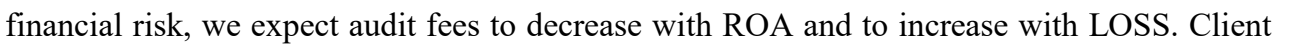

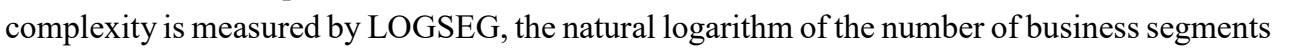

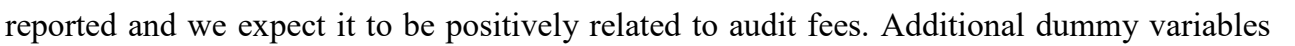

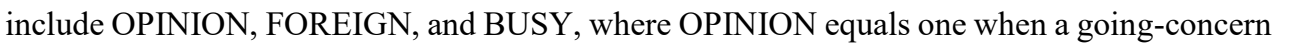

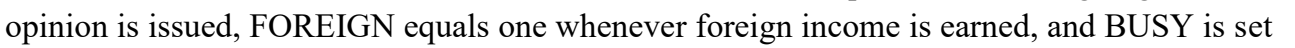

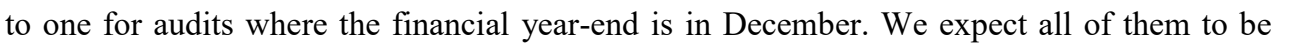

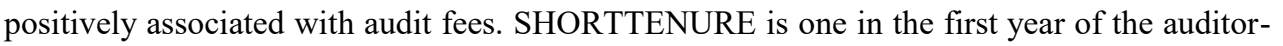

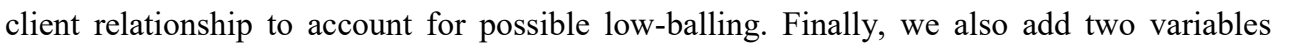

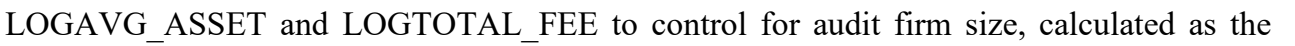

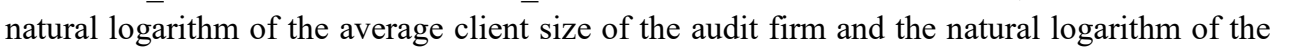

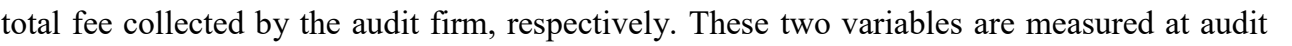

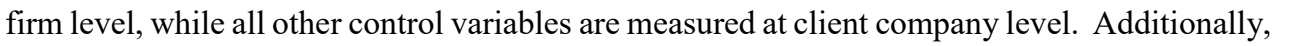

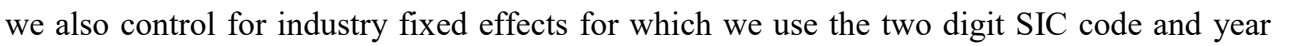

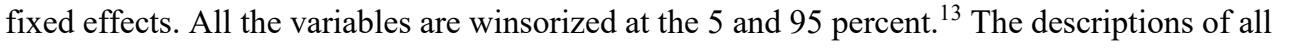

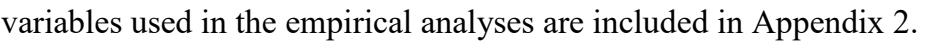

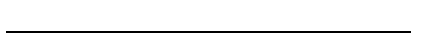

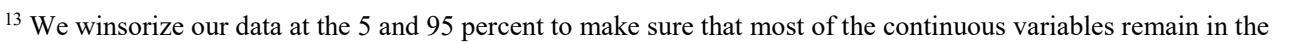

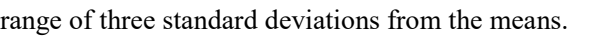




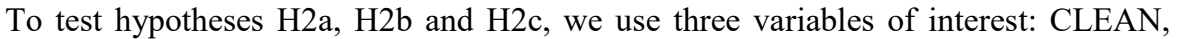

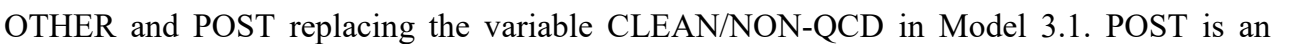
ए ए। प

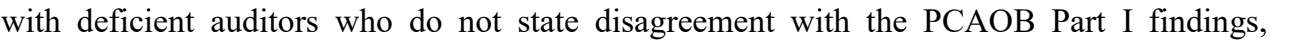

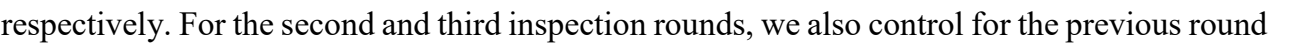

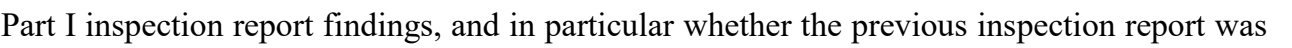

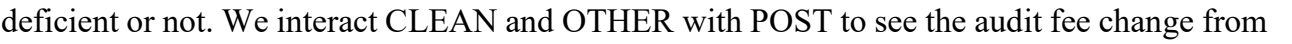

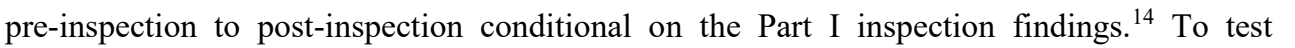

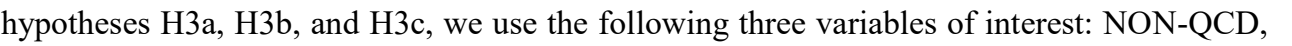

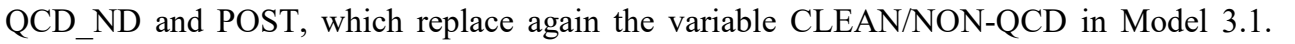

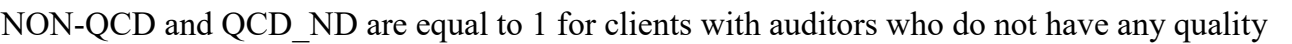

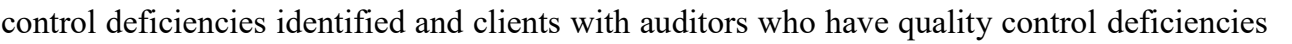
एण ए एव

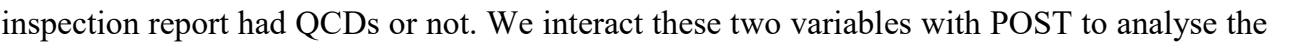

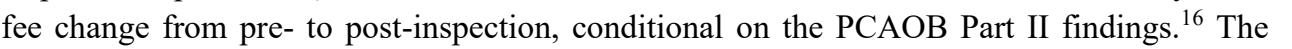

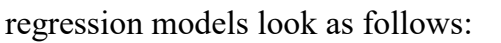

$$
\begin{aligned}
& \text { LAF }_{\mathrm{it}}=\alpha_{0}+\alpha_{1} \text { CLEAN }+\alpha_{2} \text { POST }+\alpha_{3} \text { CLEAN } * \text { POST }+\alpha_{4} \text { OTHER } \\
& +\alpha_{5} \text { OTHER } * \text { POST }+\alpha_{6} \text { LOGASSETS }_{\text {it }}+\alpha_{7} \text { LEVERAGE }_{i t}+\alpha_{8} \text { INVERE }_{i t}+\alpha_{9} \text { ROA }_{\text {it }} \\
& +\alpha_{10} \text { LOSS }_{\text {it }}+\alpha_{11} \text { FOREIGN }_{\text {it }}+\alpha_{12} \text { BUSY }_{\text {it }}+\alpha_{13} \text { OPINION }_{\text {it }}+\alpha_{14} \text { LOGSEG }_{\text {it }}+\alpha_{15} \text { SHORT }_{\text {it }} \\
& +\alpha_{16} \text { LOGAVG_ASSET }+\alpha_{17} \text { LOGTOTAL_FEE+Year fixed effects } \\
& + \text { Industry fixed effects }+\delta(3.2)
\end{aligned}
$$

$$
\begin{aligned}
& \mathrm{LAF}_{\mathrm{it}}=\alpha_{0}+\alpha_{1} \text { NON_QCD }+\alpha_{2} \text { POST }+\alpha_{3} \text { NON_QCD } * \text { POST }+\alpha_{4} \text { QCD_ND }
\end{aligned}
$$

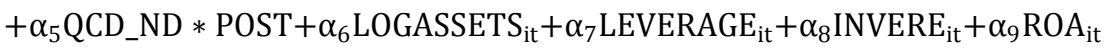

$$
\begin{aligned}
& +\alpha_{10} \text { LOSS }_{\text {it }}+\alpha_{11} \text { FOREIGN }_{\text {it }}+\alpha_{12} \text { BUSY }_{\text {it }}+\alpha_{13} \text { OPINION }_{\text {it }}+\alpha_{14} \text { LOGSEG }_{\text {it }}+\alpha_{15} \text { SHORT }_{\text {it }} \\
& +\alpha_{16} \text { LOGAVG_ASSET }+\alpha_{17} \text { LOGTOTAL_FEE }+ \text { Year fixed effects } \\
& + \text { Industry fixed effects }+\delta \text { (3.3) }
\end{aligned}
$$

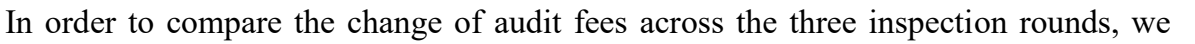

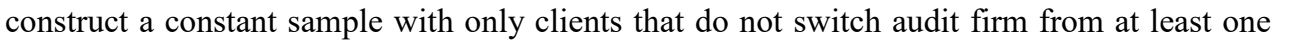

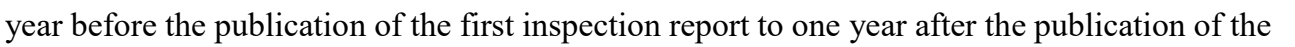
ए

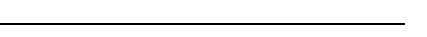

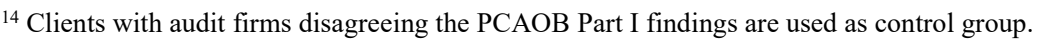

The PCAOB (2003) stated that "Deficiencies in individual audit, attest, review, and compilation engagements

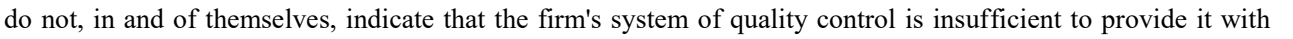
reasonable assurance that its personnel comply with applicable professional standards." However, we find that

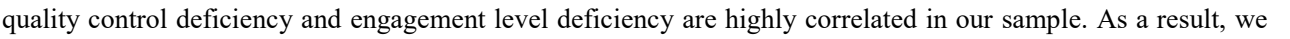

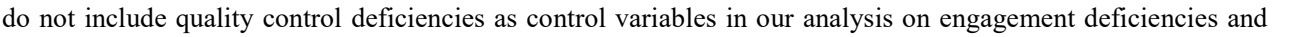
पणापापणाए

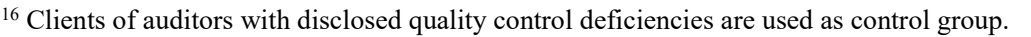




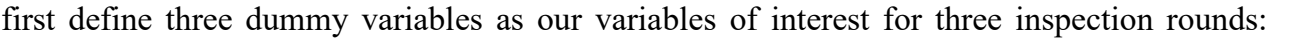

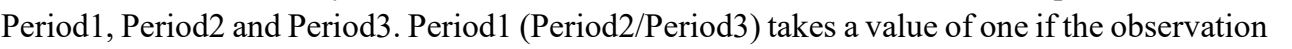

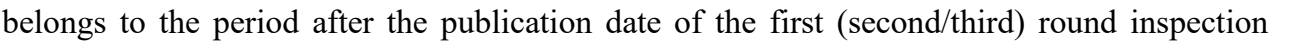

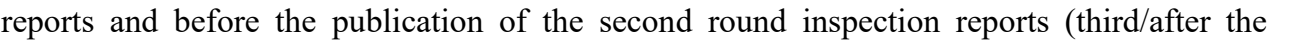

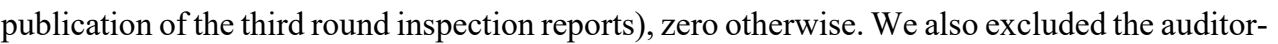

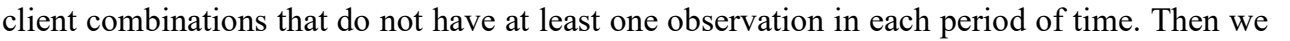

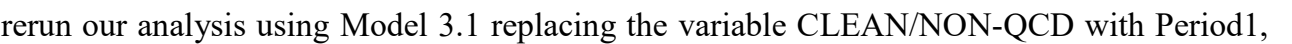

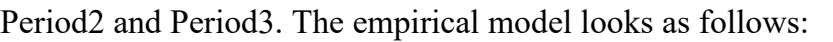

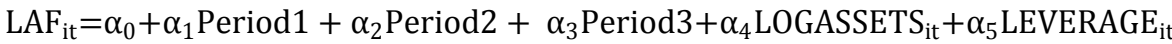 $+\alpha_{6}$ INVERE $_{i t}+\alpha_{7}$ ROA $_{\text {it }}+\alpha_{8}$ LOSS $_{i t}+\alpha_{9}$ FOREIGN $_{\text {it }}+\alpha_{10}$ BUSY $_{\text {it }}+\alpha_{11}$ OPINION $_{\text {it }}$

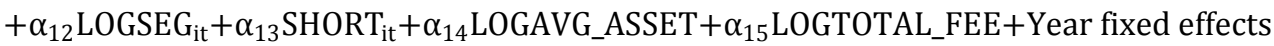 + Industry fixed effects $+\delta \quad(3.4)$ \\ $\square$ \\ $\square$}

\subsection{Empirical results}

\subsubsection{Descriptive statistics}

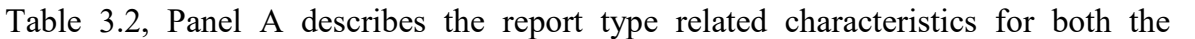
ए

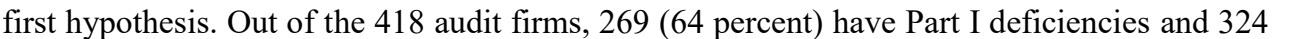

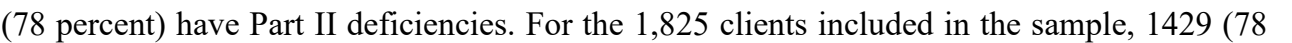

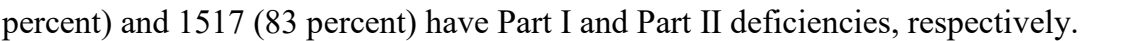

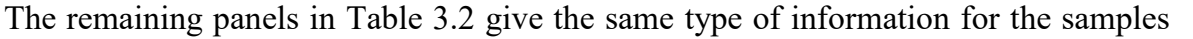

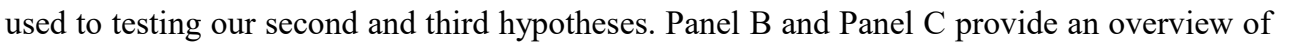

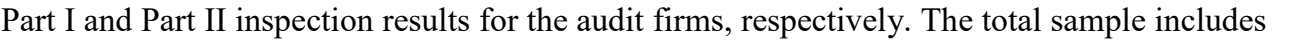

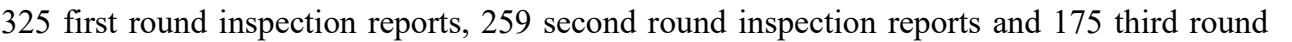
ए

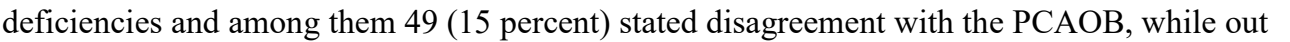

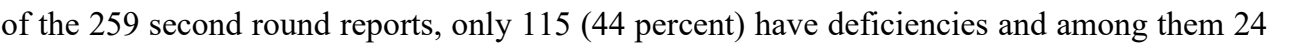

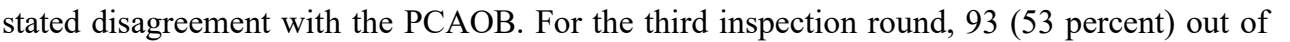

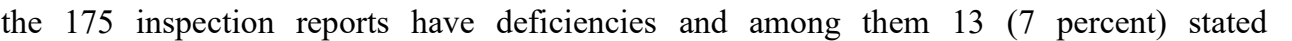

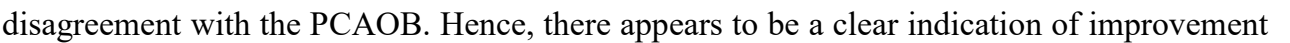

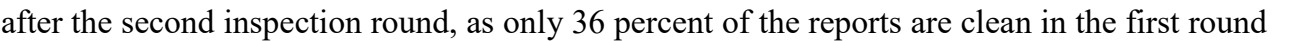

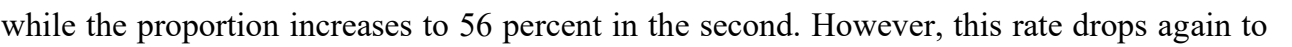

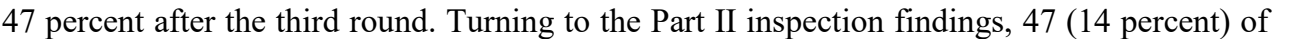

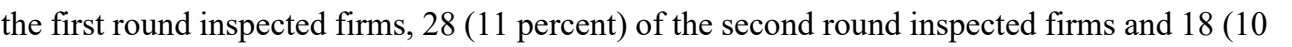

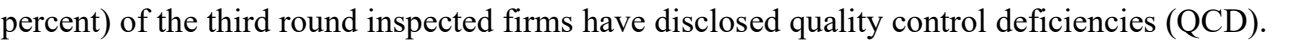

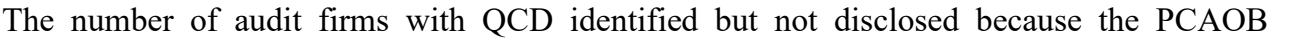

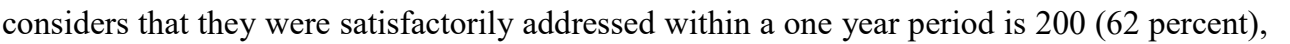

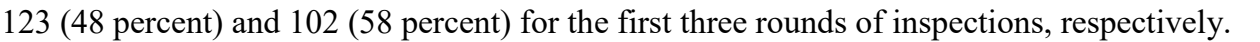




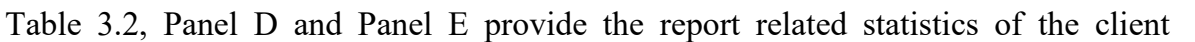

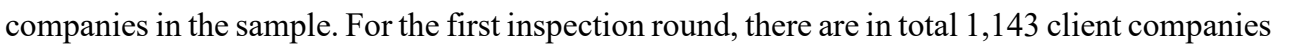

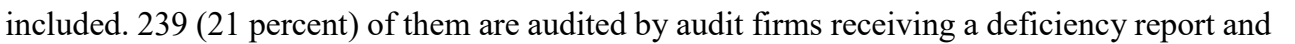

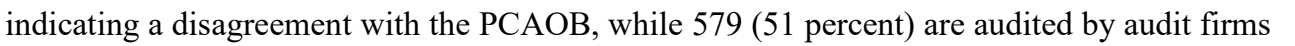

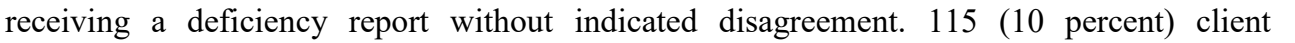

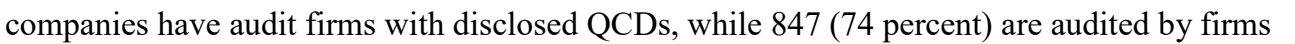

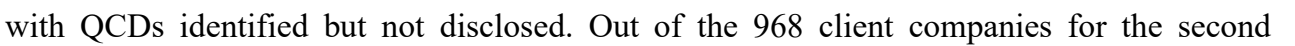

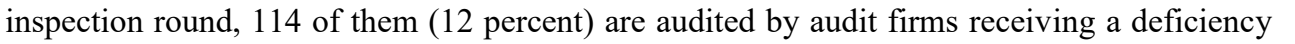

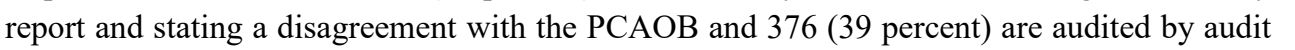
प ए

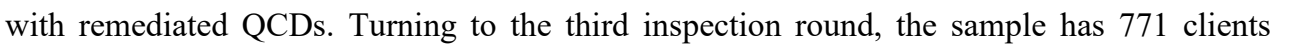

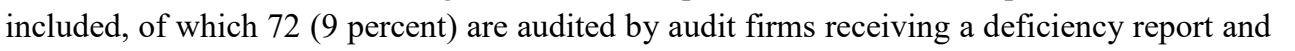

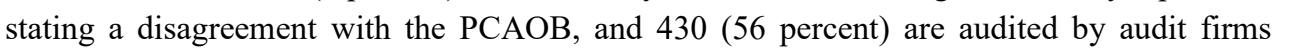

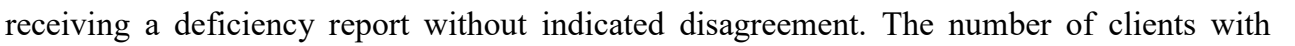
பாயா

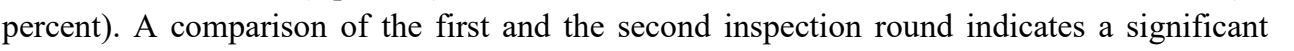

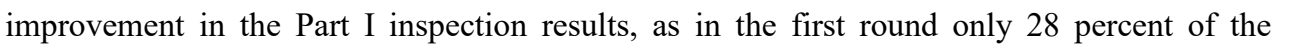

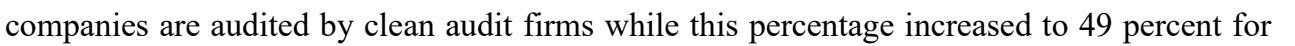
ए

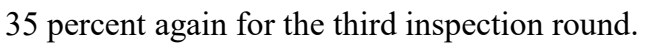

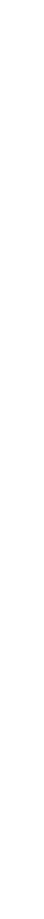


Table 3.2: Report related statistics

\begin{tabular}{|c|c|c|c|c|c|c|}
\hline \multicolumn{7}{|c|}{ Panel A: Auditor and client characteristics for $\mathrm{H1} \square$} \\
\hline$\square$ & \multicolumn{3}{|c|}{ 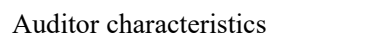 } & \multicolumn{3}{|c|}{ 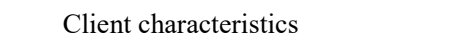 } \\
\hline$\square$ & $\square \square$ & \multicolumn{2}{|c|}{ 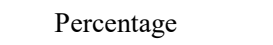 } & $\square \square$ & \multicolumn{2}{|c|}{ पाणाणाणा } \\
\hline 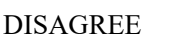 & $\square \square$ & \multicolumn{2}{|l|}{ पाण } & $\square 11$ & \multicolumn{2}{|r|}{$\square \square \square$} \\
\hline 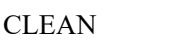 & $\square$ & \multicolumn{2}{|l|}{ पाए } & $\amalg \square$ & \multicolumn{2}{|r|}{ 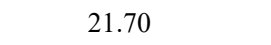 } \\
\hline 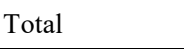 & $\square 1 \square$ & \multicolumn{2}{|l|}{$\square \square$} & $\square 11$ & \multicolumn{2}{|r|}{$\square \square$} \\
\hline प्म०० & $\square$ & \multicolumn{2}{|l|}{ पाम } & $\square \square$ & \multicolumn{2}{|r|}{ पाए } \\
\hline 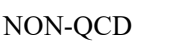 & $\square$ & \multicolumn{2}{|l|}{$\square ण$} & $\square \square$ & \multicolumn{2}{|r|}{ पाएण } \\
\hline 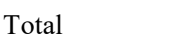 & $\square \square$ & \multicolumn{2}{|l|}{$\square 1$} & $\square 11$ & \multicolumn{2}{|r|}{$\square 10$} \\
\hline \multicolumn{7}{|c|}{ Panel B: Auditor characteristics with Part I findings for $\mathrm{H} 2$ and $\mathrm{H3}$} \\
\hline$\square$ & \multicolumn{2}{|c|}{ First-round $\square$} & $\mathrm{Sec}$ & $d$-round $\square$ & \multicolumn{2}{|c|}{ Third-round $\square$} \\
\hline$\square$ & $\square \square$ & पाणापाणए & $\square \square$ & पாणாயா & $\square \square$ & पणणाणाए \\
\hline 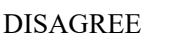 & $\square$ & $\square ण \square$ & $\square$ & एणा & $\square$ & एणा \\
\hline प्रणमा & $\square \square$ & पाम & $\square$ & पणम & $\square$ & पाम \\
\hline प्राप्र० & $\square \square$ & $\square$ & एा & पणम & $\square$ & पाए \\
\hline प्णाण & $\square \square$ & $\square \square$ & एा & एण & एा & $\square \square$ \\
\hline
\end{tabular}

Table 3.2 continued

\begin{tabular}{|c|c|c|c|c|c|c|}
\hline \multicolumn{7}{|c|}{ Panel C: Auditor characteristics with Part II findings for $\mathrm{H} 2$ and $\mathrm{H3}$} \\
\hline$\square$ & \multicolumn{2}{|c|}{ First-round $\square$} & \multicolumn{2}{|c|}{ Second-round $\square$} & \multicolumn{2}{|c|}{ Third-round $\square$} \\
\hline$\square$ & $\square \square$ & $\square\|\|\|\| \| \square$ & $\square \square$ & $\square \mid\|\|\|\| \| \square$ & $\square \square$ & 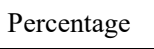 \\
\hline प्मपण & $\square$ & $\square 10$ & $\square$ & 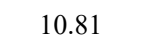 & $\square$ & $\square ण \square$ \\
\hline 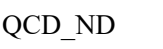 & $\square \square$ & $\square ण \square$ & पा & $\square ण \square$ & $\square \square$ & पाण \\
\hline 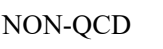 & $\square$ & $\square$ & पाम & पाण & $\square$ & पाणा \\
\hline प्णाणा & $\square \square$ & $\square \square$ & $\square$ & $\square \square$ & $\square \square$ & $\square \square$ \\
\hline
\end{tabular}

Panel D: Client characteristics with Part I findings for $\mathrm{H} 2$ and $\mathrm{H3}$

\begin{tabular}{|c|c|c|c|c|c|c|}
\hline \multirow{2}{*}{$\frac{\square}{\square}$} & \multicolumn{2}{|c|}{ First-round $\square$} & \multicolumn{2}{|c|}{ Second-round $\square$} & \multicolumn{2}{|c|}{ Third-round $\square$} \\
\hline & $\square \square$ & पण\|ापाप & $\square \square$ & 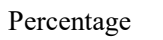 & $\square \square$ & 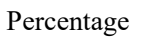 \\
\hline 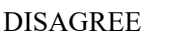 & $\square \Pi$ & पाण & $\square \Pi$ & पाणा & $\square$ & पाण \\
\hline 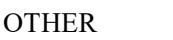 & $\square \Pi \square$ & पणत & $\square \square$ & पण口 & $\square \square$ & पाल \\
\hline 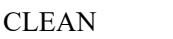 & $\square \square$ & पाणाप & $\square \Pi$ & पाएव & $\square \square$ & पाणा \\
\hline प्णाण & $\square \Pi 1$ & $\square \square$ & $\square \Pi$ & $\square \square$ & $\square \square$ & $\square \square$ \\
\hline
\end{tabular}


Table 3.2 continued

\begin{tabular}{|c|c|c|c|c|c|c|}
\hline \multicolumn{7}{|c|}{ Panel E: Clientcharacteristics with Part II findings for $\mathrm{H} 2$ and $\mathrm{H3} \square$} \\
\hline$\square$ & \multicolumn{2}{|c|}{ First-round $\square$} & \multicolumn{2}{|c|}{ Second-round $\square$} & \multicolumn{2}{|c|}{ Third-round $\square$} \\
\hline$\square$ & $\square \square$ & पण\|ापाप & $\square \square$ & $\square \square\|\| \square \square \square$ & $\square \square$ & 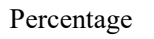 \\
\hline प्रणप & $\square \square$ & पणा & $\square$ & $\square \square$ & $\square$ & एणा \\
\hline प्वपण & $\square \square$ & $\square 10$ & $\square \square$ & $\square 101$ & $\square \square$ & पणा \\
\hline 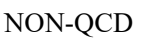 & $\square \square$ & $\square \prod \square$ & $\square \square$ & $\square \square$ & $\square \square$ & $\square \square \square$ \\
\hline पणाएा & $\square \prod \square$ & $\square \square \square$ & $\square \square$ & $\square \square$ & $\square \square$ & $\square \square$ \\
\hline
\end{tabular}

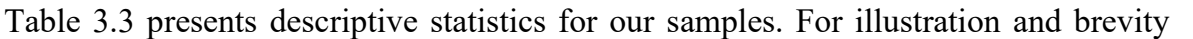

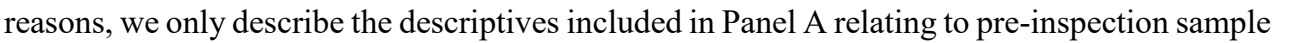

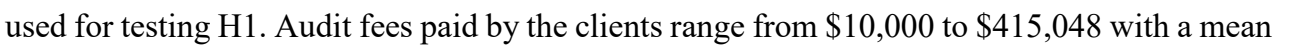

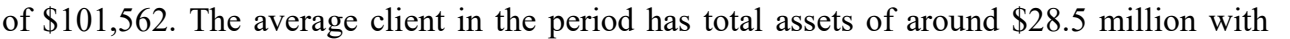
ए ए।

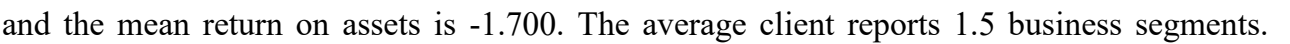

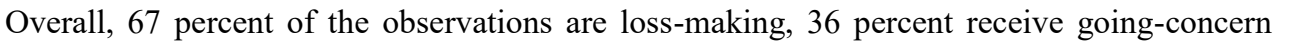

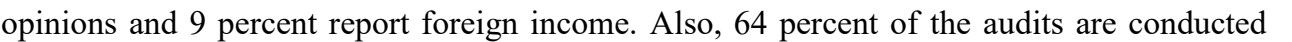

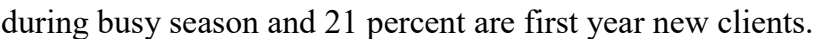


Table 3.3: Descriptive statistics

\begin{tabular}{|c|c|c|c|c|c|c|}
\hline \multicolumn{7}{|c|}{ Panel A: Pre-inspection sample for H1 } \\
\hline 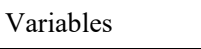 & $\square \square$ & $\square \square \square$ & $\square \square \square \square$ & $\square \square \square$ & $\square \square$ & $\square \square \square$ \\
\hline 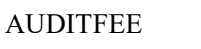 & $\square ण \square$ & $\square ा \Pi 1 \square$ & $\square \square \square \square$ & $\square \mid \Pi \| \square$ & $\square \square \square \square$ & पायाम \\
\hline 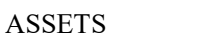 & $\square \square \square$ & पणामाप & 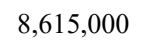 & पणमापए & $\square|\square| \square$ & 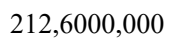 \\
\hline 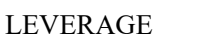 & पणा & $\square ण 10$ & $\square ण \square$ & 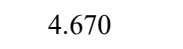 & $\square \square \square \square$ & 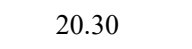 \\
\hline 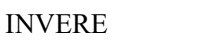 & $\square \square \square$ & $\square \square \square \square$ & $\square|\square| \square$ & $\square \square \square$ & $\square$ & $\square[\mid \square$ \\
\hline$\square \square \square \square$ & $\square \square \square \square$ & एवाप & एणाए & पणाए & एणाए & 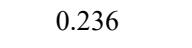 \\
\hline$\square \square \square \square \square$ & पण口प & पणाए & $\square \square \square$ & पण口ए & 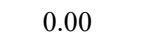 & पाए \\
\hline 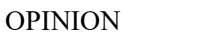 & पण口ए & पणाए & $\square \square \square$ & पणाए & पाए & पाए \\
\hline 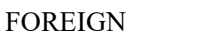 & 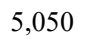 & पणाए & 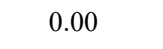 & पणाए & पाए। & पाए \\
\hline$\square \square \square \square \square$ & पण口ए & पणाए & 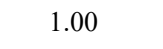 & पणाए & पाए & $\square \mathrm{पाए}$ \\
\hline 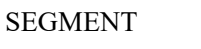 & पण口ए & 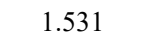 & $\square \square \square$ & पणाए & पाए। & $\square \square \square$ \\
\hline 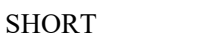 & $\square \square \square$ & $\square \square \square \square$ & $\square ण \square$ & 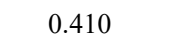 & $\square \square \square$ & $\square \square \square$ \\
\hline 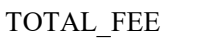 & पण口ए & पणापाए & पणाणाए & पणापाप & पाणाप & पामापा \\
\hline 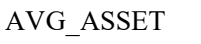 & $\square \square \square$ & पामापए & 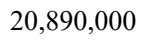 & पाாआणम & एणाणाए & 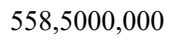 \\
\hline
\end{tabular}

Panel B: First round inspection sample for $\mathrm{H} 2$ and $\mathrm{H} 3$

\begin{tabular}{|c|c|c|c|c|c|c|}
\hline पणतापाए & $\square \square$ & $\square \Pi \square$ & पषणम & $\square \square \square$ & $\square \square$ & $\square \square$ \\
\hline 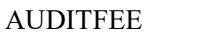 & पणाप & $\square\|\square\|$ & $\square \square \prod \square$ & $\square\|\| \square$ & $\square \| \square \square$ & पाणाप \\
\hline 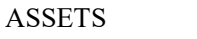 & $5,020 \square$ & $36,730,000 \square$ & $12,750,000 \square$ & $54,980,000 \square$ & $57,000 \square$ & $212,600,000 \square$ \\
\hline 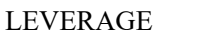 & 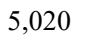 & पणाए & 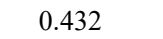 & पाला & $\square \square \prod \square$ & $\square \square \square$ \\
\hline 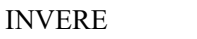 & $\square \square \square$ & $\square \square \square$ & 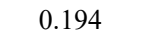 & 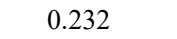 & $\square \square \square$ & $\square \square \square$ \\
\hline$\square \square \square \square$ & पाणाप & एणाए & एणाए & पाला & एणाए & $\square[1 \square$ \\
\hline प्र०ण & $\square \square \square$ & $\square \square \square$ & 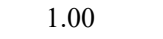 & पामा & 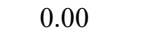 & 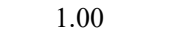 \\
\hline 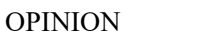 & पाणा & पामा & $\square \square$ & पाला & $\square \square \square$ & $\square \square$ \\
\hline 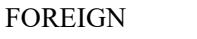 & $\square \square \square$ & 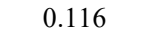 & पाण & पामा & पाए & पाम \\
\hline 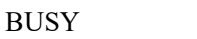 & पाणा & पाणा & $\square \square$ & पाए & 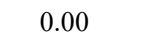 & $\square \square \square$ \\
\hline 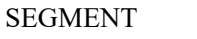 & $\square \square \square$ & $\square \square \square$ & 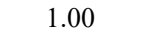 & पाए & 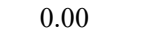 & $\square \square \square$ \\
\hline 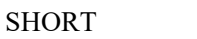 & 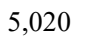 & 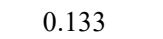 & 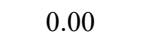 & पाणा & 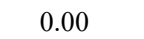 & 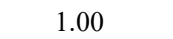 \\
\hline 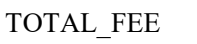 & $5,020 \square$ & $3,212,000 \square$ & $1,503,000 \square$ & $3,864,000 \square$ & $91,751 \square$ & $13,970,000 \square$ \\
\hline 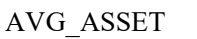 & $5,020 \square$ & $90,220,000 \square$ & $31,530,000 \square$ & $142,400,000 \square$ & $1,019,000 \square$ & $558,500,000 \square$ \\
\hline
\end{tabular}




\section{Table 3.3 Continued}

\begin{tabular}{|c|c|c|c|c|c|c|}
\hline \multicolumn{7}{|c|}{ Panel C: Second round inspection sample for $\mathrm{H} 2$ and $\mathrm{H3}$} \\
\hline 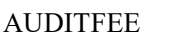 & $3,908 \square$ & $142,070 \square$ & $103,629 \square$ & $118,893 \square$ & $10,000 \square$ & $426,000 \square$ \\
\hline 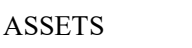 & $3,908 \square$ & $43,650,000 \square$ & $16,220,000 \square$ & $61,590,000 \square$ & $62,000 \square$ & $216,800,000 \square$ \\
\hline 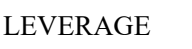 & $\square \square \square$ & 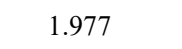 & पणाए & पणाए & $\square \square \Pi 11$ & $\square ण \square$ \\
\hline 四 $\square \square \square \square$ & $\square[\square$ & 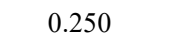 & $\square[1 \square$ & $\square \square \square$ & $\square \square \square$ & $\square \square \square$ \\
\hline प००० & पणाए & एणाए & पणाम & पणाए & एणाप & पणाप \\
\hline $\begin{array}{l}\square \\
\square \square\end{array}$ & $\square \square \square \square$ & $\square \square \square$ & $\square ण \square$ & पणाए & $\square \square \square$ & $\square ण \square$ \\
\hline 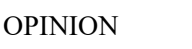 & पणाए & पणाए & 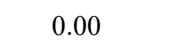 & पणाए & पणा & पणा \\
\hline 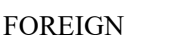 & पणाए & पणाए & 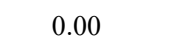 & पणाए & $\square ण \square$ & पणा \\
\hline पिम०० & पणाए & पणाए & 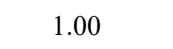 & पणाए & पाण & पाम \\
\hline 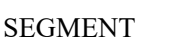 & $\square \square \square$ & $\square \square \square$ & $\square \square \square$ & 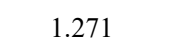 & पण口 & $\square \square \square$ \\
\hline 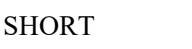 & 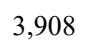 & 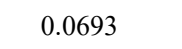 & 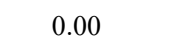 & पणाए & पाम & पाण \\
\hline 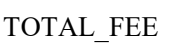 & $3,908 \square$ & $3,465,000 \square$ & $1,771,000 \square$ & $3,921,000 \square$ & $100,622 \square$ & $14,320,000 \square$ \\
\hline 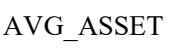 & $3,908 \square$ & $114,300,000 \square$ & $47,840,000 \square$ & $162,600,000 \square$ & $1,012,000 \square$ & $584,200,000 \square$ \\
\hline \multicolumn{7}{|c|}{ Panel D: Third round inspection sample for $\mathrm{H} 2$ and $\mathrm{H3}$} \\
\hline 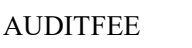 & $3,118 \square$ & $150,547 \square$ & $117,473 \square$ & $118,465 \square$ & $11,000 \square$ & $432,136 \square$ \\
\hline 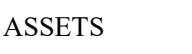 & $3,118 \square$ & $45,210,000 \square$ & $17,050,000 \square$ & $63,710,000 \square$ & $69,000 \square$ & $219,900,000 \square$ \\
\hline 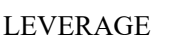 & $3,118 \square$ & $1.861 \square$ & $0.41 \square$ & $4.235 \square$ & $0.0493 \square$ & $18.49 \square$ \\
\hline एविएव & $3,118 \square$ & $0.247 \square$ & $0.187 \square$ & $0.23 \square$ & $\square \square$ & $0.719 \square$ \\
\hline$\square \square \square \square$ & $3,118 \square$ & $-1.378 \square$ & $-0.125 \square$ & $3.342 \square$ & $-14.5 \square$ & $0.238 \square$ \\
\hline 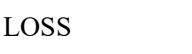 & $3,118 \square$ & $0.639 \square$ & $1.00 \square$ & $0.48 \square$ & 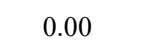 & $1.00 \square$ \\
\hline 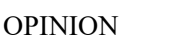 & $3,118 \square$ & $0.296 \square$ & $\square \square$ & $0.456 \square$ & पाए & $1.00 \square$ \\
\hline 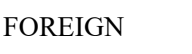 & $3,118 \square$ & $0.158 \square$ & 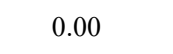 & $0.365 \square$ & पणा & $1.00 \square$ \\
\hline प्व०० & $3,118 \square$ & $0.637 \square$ & $1.00 \square$ & $0.481 \square$ & पणा & $1.00 \square$ \\
\hline 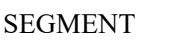 & $3,118 \square$ & $1.581 \square$ & $1.00 \square$ & $1.28 \square$ & पणा & $10.00 \square$ \\
\hline 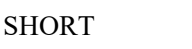 & $3,118 \square$ & $0.0712 \square$ & 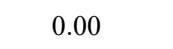 & $0.257 \square$ & पाण & $1.00 \square$ \\
\hline 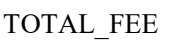 & $3,118 \square$ & $4,411,000 \square$ & $2,038,000 \square$ & $4,597,000 \square$ & $114,056 \square$ & $14,490,000 \square$ \\
\hline 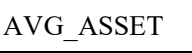 & $3,118 \square$ & $138,100,000 \square$ & $66,540,000 \square$ & $178,900,000 \square$ & $1,229,000 \square$ & $600,900,000 \square$ \\
\hline \multicolumn{7}{|c|}{ Panel E: Constant sample for $\mathrm{H4}$} \\
\hline 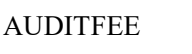 & $\square \square \square$ & $\square \square \square \square$ & $\square \square \square \square$ & $\square|\square| \square$ & 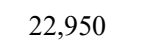 & 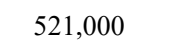 \\
\hline 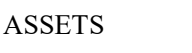 & एणाए & पालापा & पणाणाए & पालापा & पाणाए & पामापाए \\
\hline 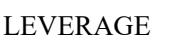 & पणाए & पणाप & पाणाए & पणाए & 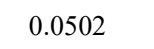 & पापा \\
\hline 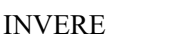 & $\square \square \square \square$ & 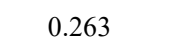 & एणाए & पणाए & $\square$ & पणाए \\
\hline प००० & पणाए & एणाए & पणाया & पणाए & एणाए & पणाप \\
\hline प्व०० & पापा & पणाप & पणाप & पाणा & पाणा & 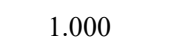 \\
\hline
\end{tabular}




\begin{tabular}{|c|c|c|c|c|c|c|}
\hline \multicolumn{7}{|c|}{ Table 3.3 continued } \\
\hline 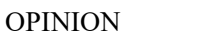 & पाप & 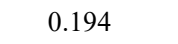 & $\square ण 11$ & पामा & पामा & पाए \\
\hline 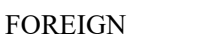 & $\square \square \square \square$ & $\square ण \square$ & $\square ण \square$ & पणाए & पणाए & पणाप \\
\hline$\square \square \square \square \square$ & 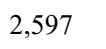 & पणाए & पणाए & पणाए & पणाए & पापाप \\
\hline 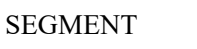 & 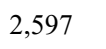 & 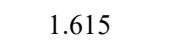 & 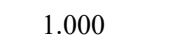 & 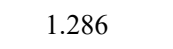 & पणाए & 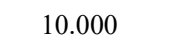 \\
\hline 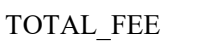 & पणाए & पणापाप & पणमापा & पणापाप & पाणाप & पाणापामा \\
\hline 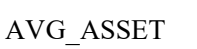 & $\square ण \square$ & 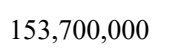 & 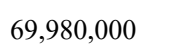 & पाणाणा & पणाणाप & $\square \square \square म ा प$ \\
\hline
\end{tabular}

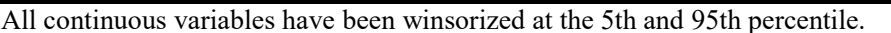

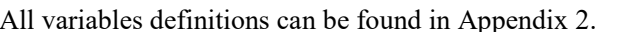

$\square$

\subsubsection{Univariate results}

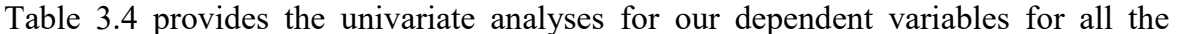

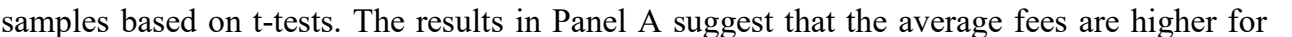

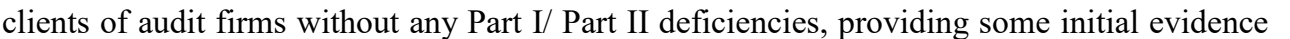

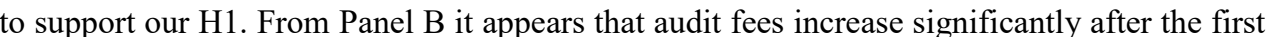
inspection, irrespective of the inspection findings and the audit firms' responses to those

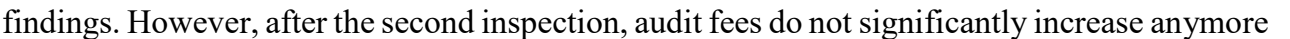

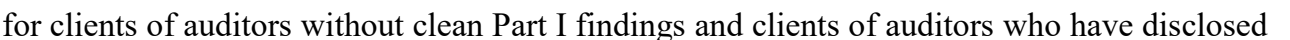

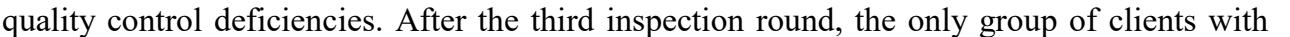

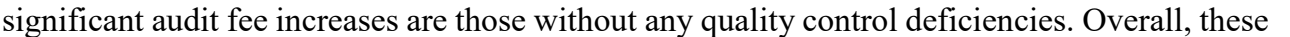

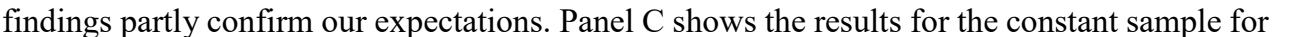

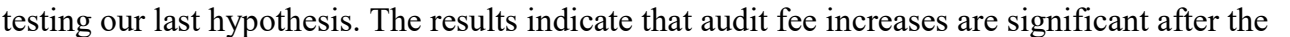

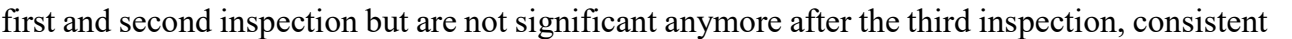

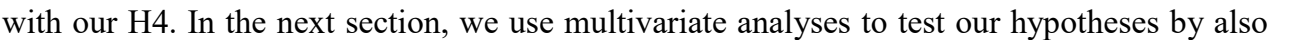

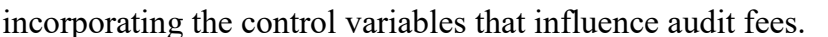

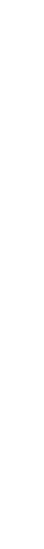




\begin{tabular}{|c|c|c|c|c|c|c|c|c|}
\hline \multicolumn{9}{|c|}{ Table 3.4: Univariate analysis } \\
\hline \multicolumn{9}{|c|}{ 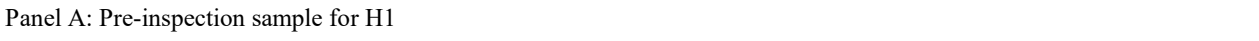 } \\
\hline पणाणाणाण & $\square \square \square \square$ & प्पिएव & \multicolumn{2}{|c|}{$\square \square$} & प्पिए & \multicolumn{2}{|c|}{ 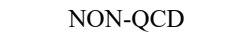 } & पा血四 \\
\hline$\square$ & पापा & $\square\|\| ा \mid$ & \multicolumn{2}{|c|}{ पाणाएा } & पापा & \multicolumn{2}{|c|}{ 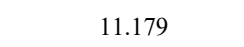 } & 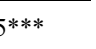 \\
\hline \multicolumn{9}{|c|}{ 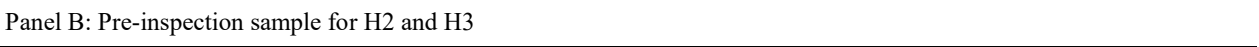 } \\
\hline$\square$ & \multicolumn{3}{|c|}{ 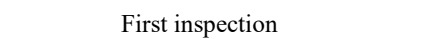 } & \multicolumn{3}{|c|}{ 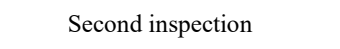 } & \multicolumn{2}{|c|}{ 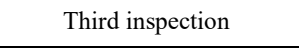 } \\
\hline पणाएापाए & $\square \square$ & $\square \square \mathbb{U}$ & $\square \square$ & $\square \square$ & $\square \square \mathbb{W}$ & $\square \square$ & 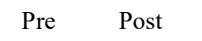 & प्राण \\
\hline 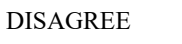 & एणाए & एाएण & एणाएण & एणाए & पामा & एणा & पயए पाए & एणाए \\
\hline 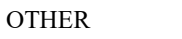 & 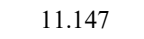 & 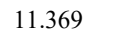 & पणाएा & 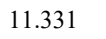 & 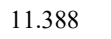 & पामा & $\square \square \square \square \square ा म$ & $\square \amalg$ \\
\hline$\square \square \square \square \square \square$ & 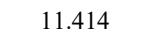 & 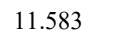 & पालाया & 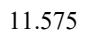 & 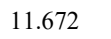 & पणा1ाए & 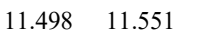 & पणाए \\
\hline 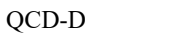 & पाण & पाणा & एणा1ए & पाणाए & पणाए & एणाए & पणाए पाण & पाणाए \\
\hline प्पषणिए & पणाए & 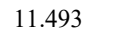 & एणा111 & $\square ण 11$ & पामा & एणा1ए & पणाम पामा & पणाए \\
\hline 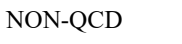 & 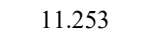 & $\square \mid \Pi 1 \square$ & $\square \mid 11111$ & $\square ा \Pi 1 \square$ & $\square \mid 111$ & $\square \mid 11111$ & $\square ण 11 \square \square ा ए$ & $\square ण 11 \square$ \\
\hline \multicolumn{9}{|c|}{ 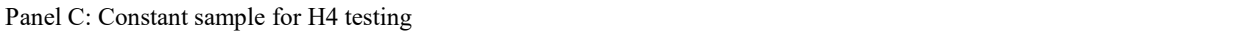 } \\
\hline पणायाणाणा & 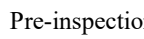 & 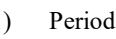 & 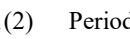 & $\Pi \| \mathbb{\square} \square$ & 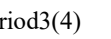 & 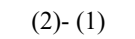 & 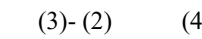 & 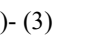 \\
\hline$\square$ & 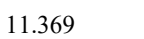 & 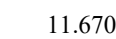 & पामा & $\square$ & पाए & पणाएण & एणाणा एण & $\Pi \square$ \\
\hline
\end{tabular}

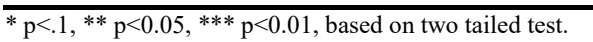

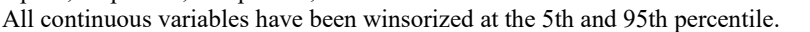

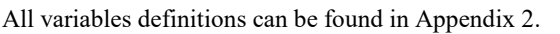

$\square$

\subsubsection{Multivariate results}

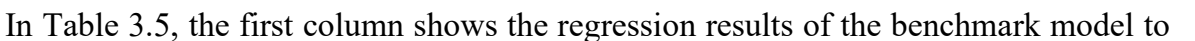

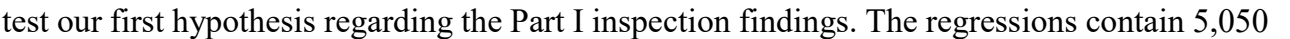

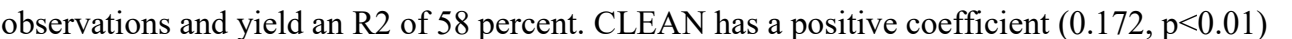

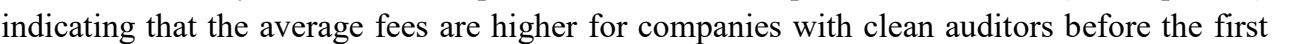

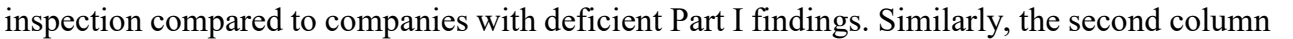

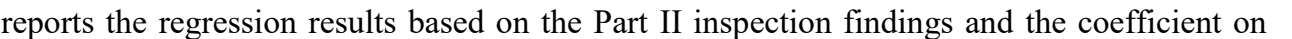
a

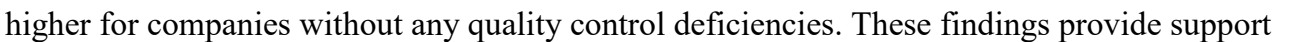

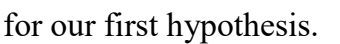

$\square$
$\square$
$\square$
$\square$
$\square$ 
Table 3.5: Pre-inspection audit fee analysis

\begin{tabular}{|c|c|c|}
\hline 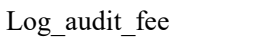 & 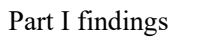 & 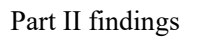 \\
\hline CLEAN $\square$ & पणाएाप & $\square$ \\
\hline$\square$ & पाणाण & $\square$ \\
\hline NON-QCD $\square$ & $\square$ & 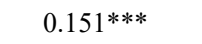 \\
\hline$\square$ & $\square$ & पाणाण \\
\hline LOGASSETS $\square$ & 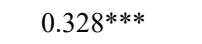 & पणायाए \\
\hline$\square$ & पाणाण & पाणाण \\
\hline LEVERAGE $\square$ & पायाएा & पायाएा \\
\hline$\square$ & पाणाणा & पाणाण \\
\hline INVERE $\square$ & 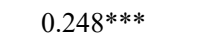 & पणापाए \\
\hline$\square$ & पाणाण & पाणाण \\
\hline $\mathrm{ROA} \square$ & एणागाया & पाणाया \\
\hline$\square$ & पण口卄ाम & पण口卄10 \\
\hline LOSS $\square$ & 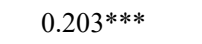 & 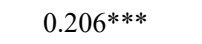 \\
\hline$\square$ & पाणापा & एणापाप्य \\
\hline FOREIGN $\square$ & 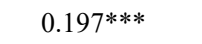 & $\square \square ा 11 \square$ \\
\hline$\square$ & 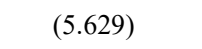 & एणापाप्य \\
\hline BUSY $\square$ & पणामाप & $\square \square\|\Pi\| \square$ \\
\hline$\square$ & पाणापा & एणापाप \\
\hline OPINION $\square$ & पणामाप & 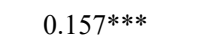 \\
\hline$\square$ & पाणापा & एणापाए \\
\hline 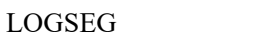 & पामाया & पायाएम \\
\hline$\square$ & एणाणाप & एणाणाप \\
\hline 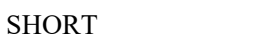 & एणाए & पणाग \\
\hline$\square$ & पण口卄ा1 & पण口卄ा1 \\
\hline 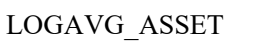 & एणायाम & पणायाप \\
\hline$\square$ & पाणापा & पाणापा \\
\hline 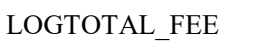 & पणायाम & पणायाप \\
\hline$\square$ & पापापाप & पाणाए \\
\hline 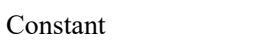 & 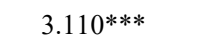 & $\square \square \prod म ा \square$ \\
\hline$\square$ & पाणाएा & पाणाए \\
\hline पएणाणमाए & $\square ण \square$ & पणाए \\
\hline पणाणाण & पाएव & पाएा \\
\hline पणाणाणाणम & 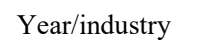 & 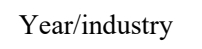 \\
\hline पणमणणमण & पणाए & पणाए \\
\hline
\end{tabular}

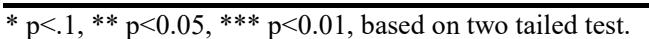




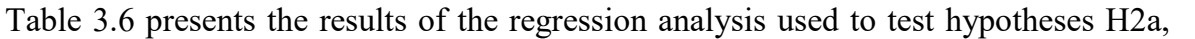

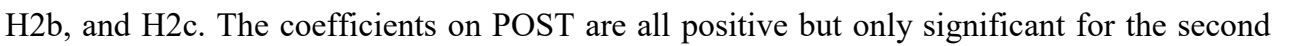

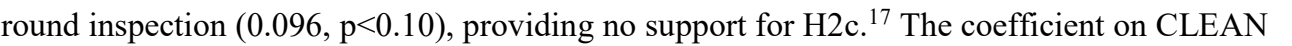

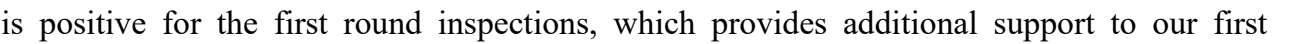

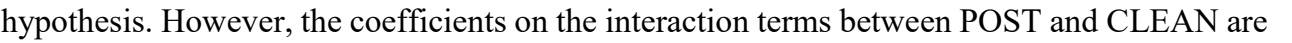

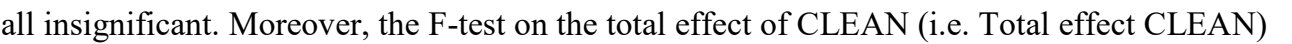

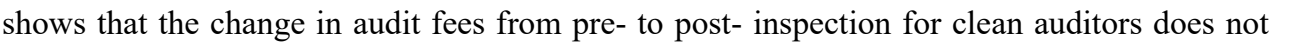

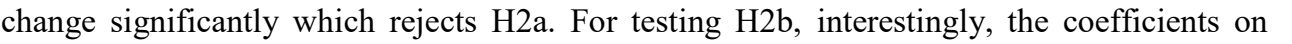

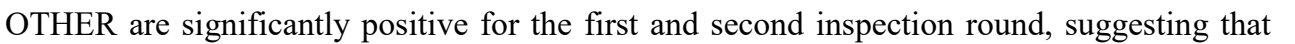

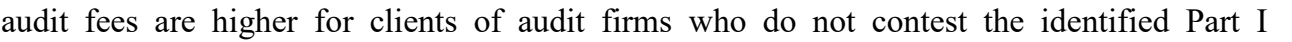

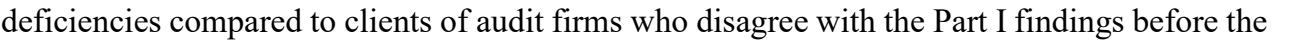

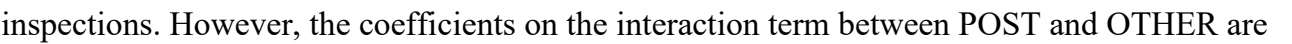

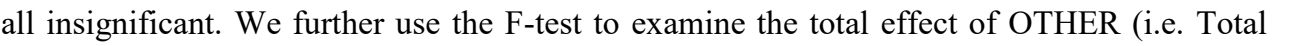

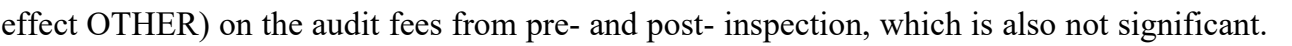

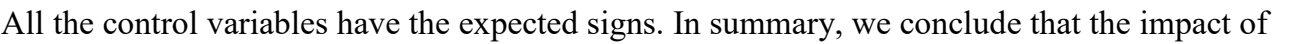

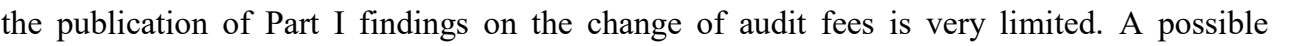

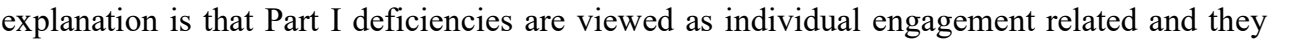

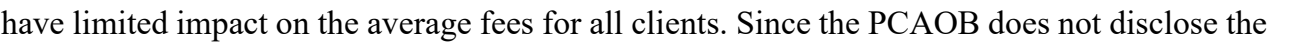

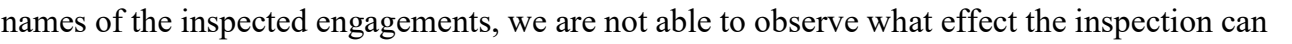

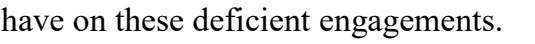

$\square$

$\square$

$\square$

Table 3.6: Regression results with Part I findings

\begin{tabular}{|c|c|c|c|}
\hline पमाणामणए & 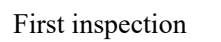 & पणमाणमणम & 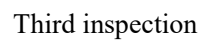 \\
\hline POST $\square$ & $\square \square 10$ & 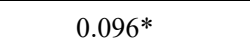 & $\square \square 1 \square$ \\
\hline$\square$ & पाणाण & पाणाण & पाणाण \\
\hline CLEAN $\square$ & पालाएा & पाणा11ए & पाणाण \\
\hline$\square$ & एणाणा & पाणाएा & एणा।ण \\
\hline POST*CLEAN $\square$ & एणाए & पाणा & $\square ण 11$ \\
\hline$\square$ & एणापाए & 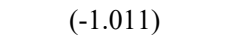 & एणाएव \\
\hline OTHER $\square$ & एणाएम & पणाए & पाणा \\
\hline$\square$ & पणमाण & एणाएण & पणाणा \\
\hline POST*OTHER $\square$ & एणाए & एणाए & $\square ण 1 \square$ \\
\hline
\end{tabular}

mmm mmm mmm

पா

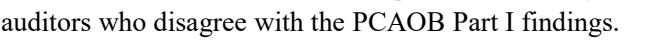




\begin{tabular}{|c|c|c|c|}
\hline \multicolumn{4}{|c|}{ Table 3.6 continued } \\
\hline$\square$ & एणाणाण & एणा।ाण & 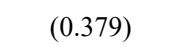 \\
\hline FIRST_DEF $\square$ & $\square$ & पायाए & $\square$ \\
\hline$\square$ & $\square$ & पणाणाण & $\square$ \\
\hline SECOND_DEF $\square$ & $\square$ & $\square$ & पाणाएा \\
\hline$\square$ & $\square$ & $\square$ & पण口卄ा \\
\hline LOGASSETS $\square$ & पामाए & पामाए & पामाए \\
\hline$\square$ & एणाणा & एाणा।ण & एापापा \\
\hline LEVERAGE $\square$ & पालापा & $\square ण 111 \square$ & पामापा \\
\hline$\square$ & एणापा & एणामा & एणाएण \\
\hline INVERE $\square$ & पणाएा & पणाएण & पाणाएा \\
\hline$\square$ & पाणाण & पणाएण & पाणाण \\
\hline $\mathrm{ROA} \square$ & पामाएा & पामापा & पाणाएा \\
\hline$\square$ & पण口णाए & पणमाण & एणाणाए \\
\hline LOSS $\square$ & पामाए & एणाएम & एणाएा \\
\hline$\square$ & पाणाण & पाणाण & पाणाएण \\
\hline FOREIGN $\square$ & पणाणाए & पणाएण & पणाएाए \\
\hline$\square$ & पणाण & पाणाण & पणाणा \\
\hline BUSY $\square$ & 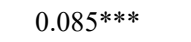 & 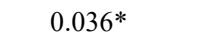 & पणाए \\
\hline$\square$ & पणाणा & யாणाण & पणाणा \\
\hline OPINION $\square$ & पणामए & 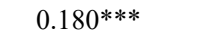 & पणापाए \\
\hline$\square$ & पाणाण & पाणाणा & पाणाए \\
\hline 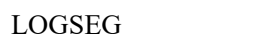 & $\square ण 11 \square$ & 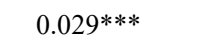 & एणाए \\
\hline$\square$ & पाणा & पाणाण & पणाणा \\
\hline 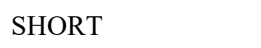 & एणाणाए & घणाणाए & एणागाए \\
\hline$\square$ & पण口卄ाए & पण口卄ाण & पण口卄ाण \\
\hline 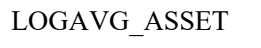 & एणाएए & पणाणए & पामाएम \\
\hline$\square$ & एणाएा & एणापा & एणाएा \\
\hline 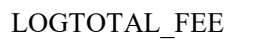 & एणाएम & पणामा & एणाएा \\
\hline$\square$ & एवाणा & एवाणा & एवामा \\
\hline 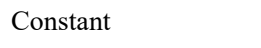 & पामाए & एणामा & एणाएाए \\
\hline$\square$ & एणाणा & एणाणाण & पाणाण \\
\hline 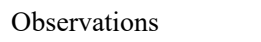 & पणाए & पणाए & 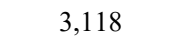 \\
\hline पषणमाण & पणाए & एणाए & पणाए \\
\hline पणमाणमणण & 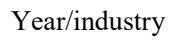 & 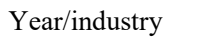 & 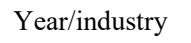 \\
\hline 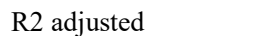 & पाणा & पाणा & पाणाए \\
\hline
\end{tabular}




\begin{tabular}{|c|c|c|c|}
\hline \multicolumn{4}{|c|}{ Table 3.6 continued } \\
\hline F test Total effect CLEAN & 0.051 & 0.005 & 0.038 \\
\hline F test Total effect OTHER & 0.032 & 0.005 & 0.044 \\
\hline
\end{tabular}

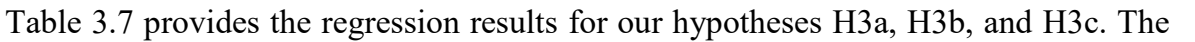

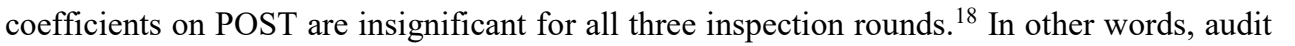

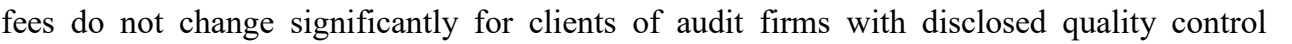

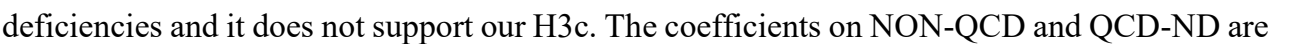

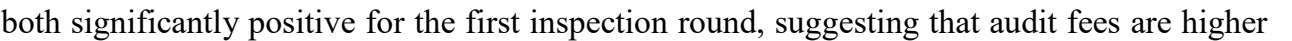

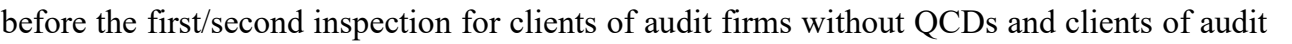

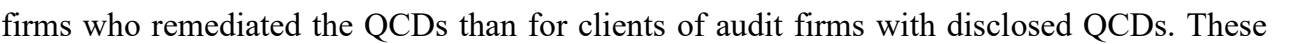

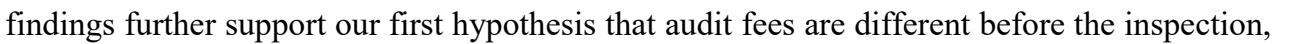

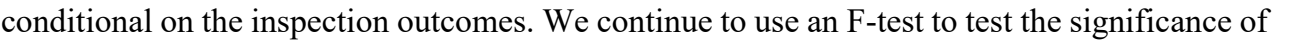

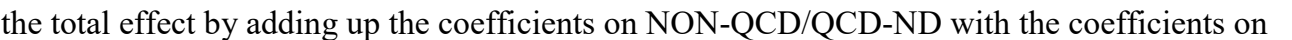

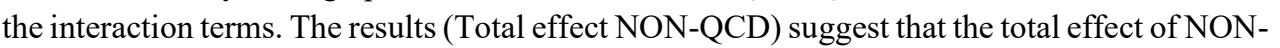

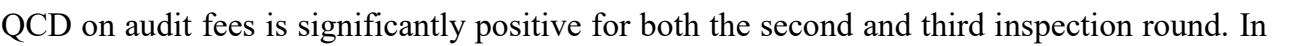

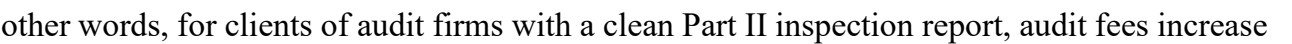

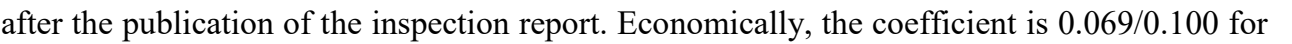

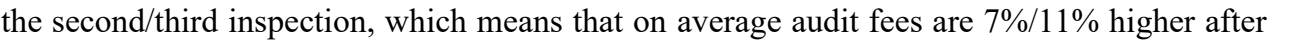

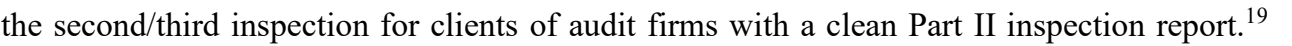

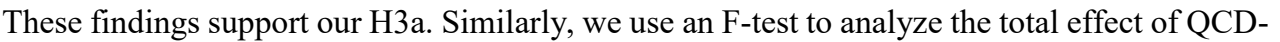

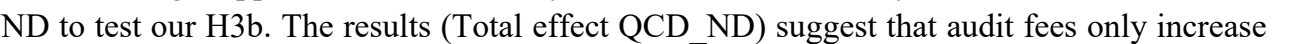

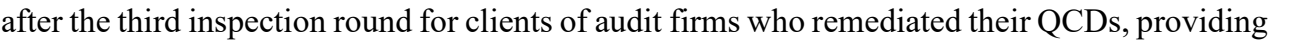

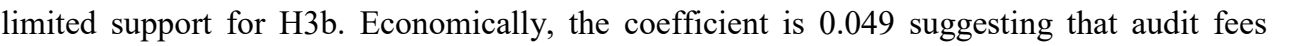

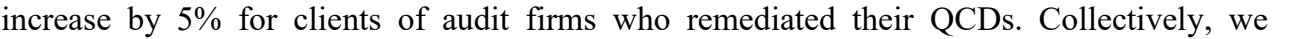

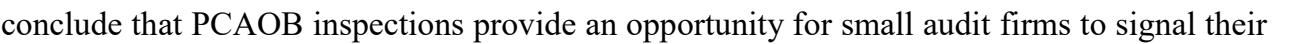

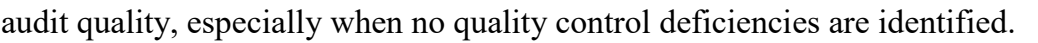

$\square$

$\square$

$\square$

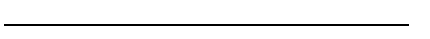

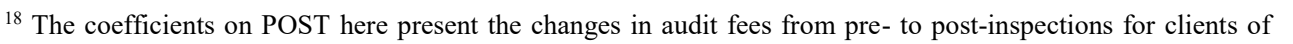

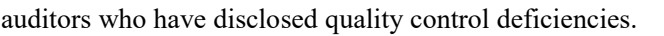

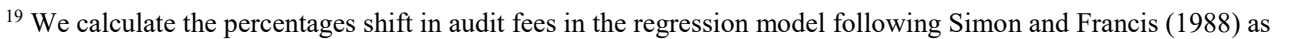

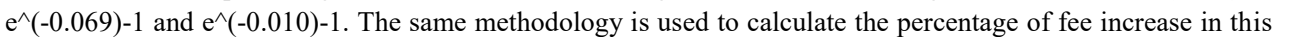
पालापाएा
\end{abstract}


Table 3.7: Regression results with Part II findings

\begin{tabular}{|c|c|c|c|}
\hline 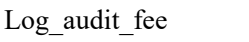 & 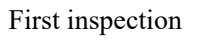 & 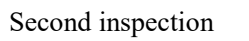 & 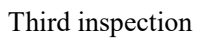 \\
\hline POST $\square$ & पाणा & 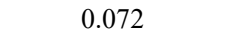 & $\square ण \square$ \\
\hline$\square$ & पाणा|ण & एणापा & एापाए \\
\hline 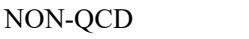 & 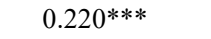 & 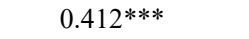 & एणाए \\
\hline$\square$ & पाणामा & एवामा & 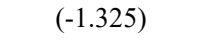 \\
\hline 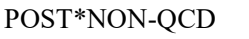 & 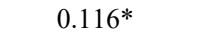 & एणाए & 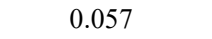 \\
\hline$\square$ & पाणा1ण & पण口卄ा1 & पाणापा \\
\hline QCD-ND $\square$ & पामापा & पायापा & एणाए \\
\hline$\square$ & पाणा1ण & पाणापा & 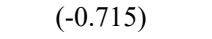 \\
\hline POST*QCD-ND $\square$ & पणाए & घालाए & पाण \\
\hline$\square$ & पाणामा & घणामा & पाणापा \\
\hline FIRST_QCD $\square$ & $\square$ & पायाता & $\square$ \\
\hline$\square$ & $\square$ & घण口卄ा1 & $\square$ \\
\hline SECOND_QCD $\square$ & $\square$ & $\square$ & घणामाप \\
\hline$\square$ & $\square$ & $\square$ & पण口冋|ण \\
\hline LOGASSETS $\square$ & पायामा & $\square \square\|\| \square$ & पणाया \\
\hline$\square$ & एणाणए & पाणा|ण & एाणाए \\
\hline LEVERAGE $\square$ & पायामा & 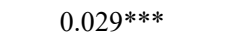 & पायाप \\
\hline$\square$ & पाणापा & पाणापा & पापाए \\
\hline INVERE $\square$ & $\square[111 \square$ & पणायाम & पणाताप \\
\hline$\square$ & पाणापा & 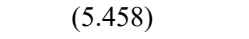 & एणाएा \\
\hline $\mathrm{ROA} \square$ & एामाया & एापाया & घणामाए \\
\hline$\square$ & 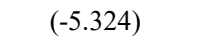 & घणमाणा & एणाणाण \\
\hline LOSS $\square$ & 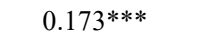 & पणापाए & पणाПए \\
\hline$\square$ & पण口卄ा & யणमाप & पाणाण \\
\hline FOREIGN $\square$ & पणापाए & पणापाए & पणाएम \\
\hline$\square$ & पाणापा & पाणाप & पाणाए \\
\hline BUSY $\square$ & पणाया & एणा & $\square ण \square$ \\
\hline$\square$ & एाणापा & एणाणा & पाणाण \\
\hline OPINION $\square$ & पणामाए & पणापाए & पणाПए \\
\hline$\square$ & पाणाए & एाणाप & एणाएण \\
\hline 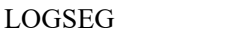 & पणामाए & $\square ण 111 \square$ & पणाए \\
\hline$\square$ & पण口णा & एणाणा & एणाए \\
\hline प्व००० & घणामाए & षापामा & घणामाए \\
\hline$\square$ & पणाणाण & घणमाणए & 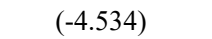 \\
\hline
\end{tabular}




\begin{tabular}{|c|c|c|c|}
\hline \multicolumn{4}{|c|}{ Table 3.7 continued } \\
\hline 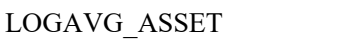 & एणाएाए & एणाएम & पणाएा \\
\hline$\square$ & एणाण & एणाण & एणाए \\
\hline 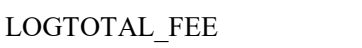 & पणामा & पणाएम & पणाएा \\
\hline$\square$ & पाणाए & पाणाणा & पाणाए \\
\hline 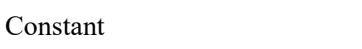 & पामाए & पामाएम & पणाएण \\
\hline$\square$ & पणाणाण & घणाणा & पणाणा \\
\hline पणயणाणाए & एणाए & पणाए & पणाए \\
\hline पणमाणा & पाणाए & पणाए & पणाए \\
\hline 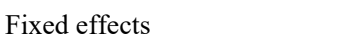 & 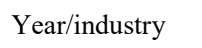 & 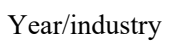 & 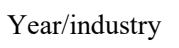 \\
\hline पणाणाणाए & $\square \square$ & $\square ण 11$ & $\square ण 11$ \\
\hline $\begin{array}{l}\text { F test Total effect NON- } \\
\text { QCD }\end{array}$ & $0.071 \square$ & $0.069 \square \square$ & $\mathbf{0 . 1 0 0} \square \square$ \\
\hline$F$ test Total effect QCD-ND & $0.029 \square$ & $0.044 \square$ & $0.049 \square$ \\
\hline
\end{tabular}

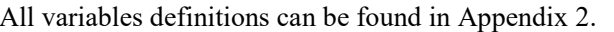

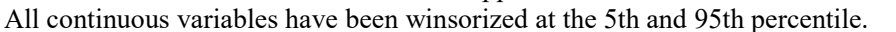

$\square$

$\square$

$\square$

$\square$

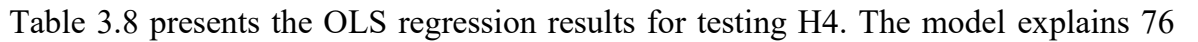

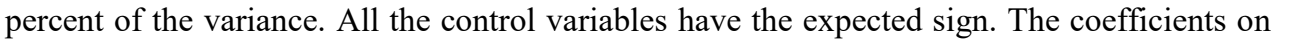

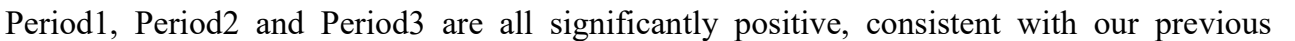
ए

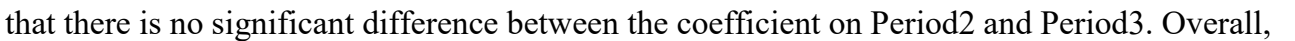

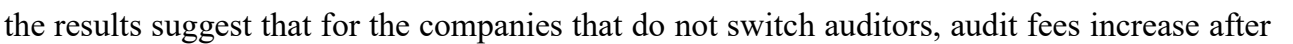

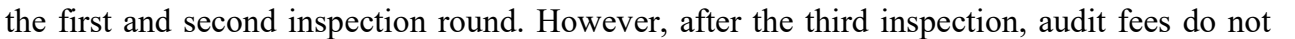

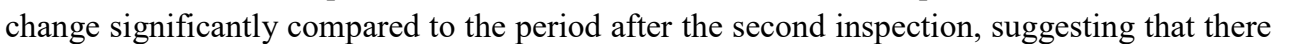
|

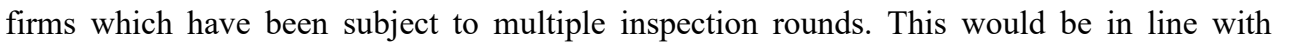

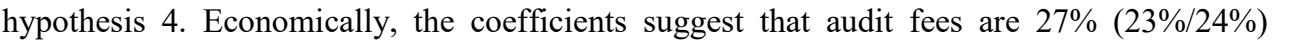

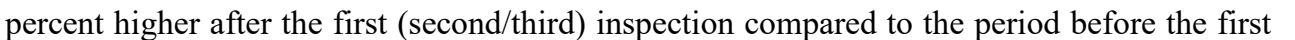

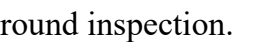

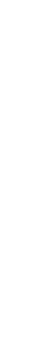


Table 3.8: OLS regression with constant sample

\begin{tabular}{|c|c|}
\hline 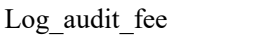 & $\square$ \\
\hline 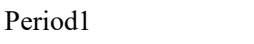 & पणापा \\
\hline$\square$ & एणाएा \\
\hline पाणाए। & पणामा \\
\hline$\square$ & एणापा \\
\hline पाणाए। & पामाए \\
\hline$\square$ & पाणाए \\
\hline LOGASSETS $\square$ & पणामा \\
\hline$\square$ & एणाएण \\
\hline LEVERAGE $\square$ & एणाएम \\
\hline$\square$ & पाणाण \\
\hline INVERE $\square$ & एणाएा \\
\hline$\square$ & एपापा \\
\hline $\mathrm{ROA} \square$ & एणामा \\
\hline$\square$ & घण口卄ाए \\
\hline LOSS $\square$ & पणाएम \\
\hline$\square$ & पापाएा \\
\hline FOREIGN $\square$ & पणमापए \\
\hline$\square$ & पणाएा \\
\hline BUSY $\square$ & पणाम \\
\hline$\square$ & एणाएण \\
\hline OPINION $\square$ & पणामा \\
\hline$\square$ & एणाएा \\
\hline 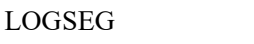 & एणाएा \\
\hline$\square$ & पणाणा \\
\hline 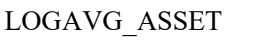 & पणाए \\
\hline$\square$ & पाणाण \\
\hline 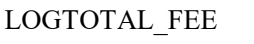 & पामाएम \\
\hline$\square$ & पण口卄ाण \\
\hline पणामाप्या & पणापाए \\
\hline$\square$ & पणाणा \\
\hline 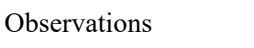 & 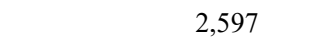 \\
\hline पणாमाए & पणाए \\
\hline 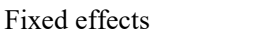 & 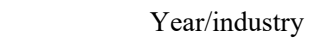 \\
\hline पणमाणमाण & 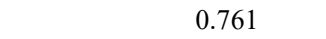 \\
\hline
\end{tabular}

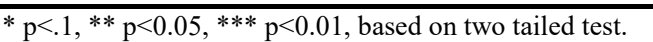




\subsection{Additional analyses}

\subsubsection{Personnel adjustments}

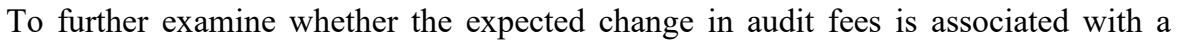

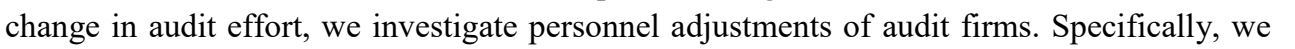

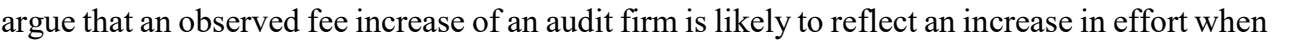

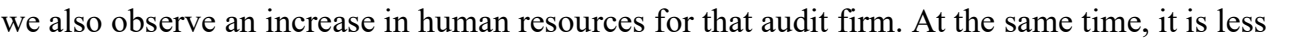

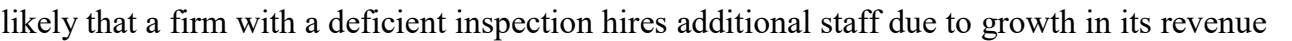

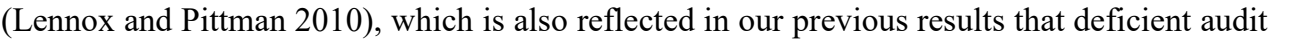
प

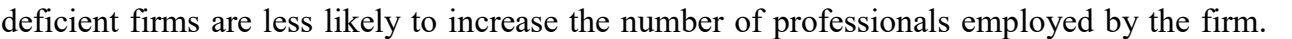

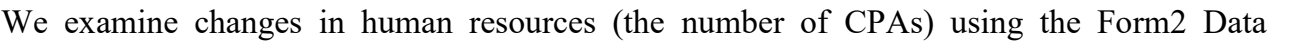

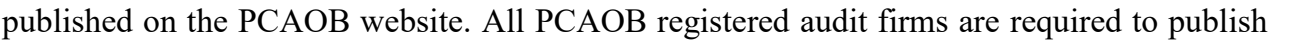

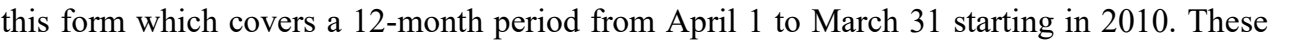

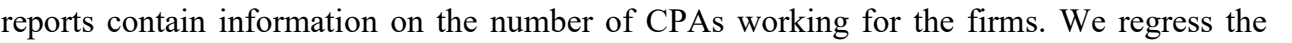

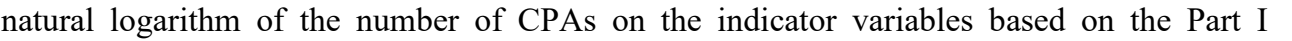

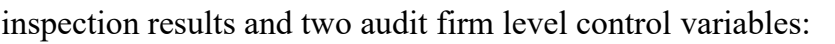

$\square$

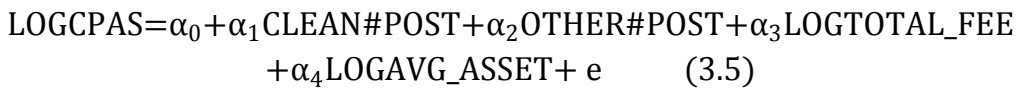

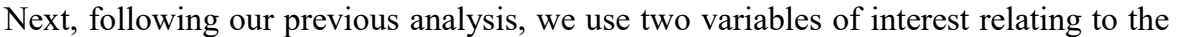

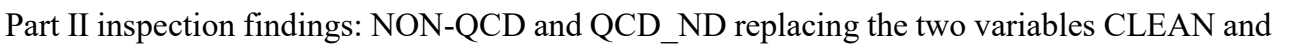

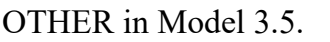

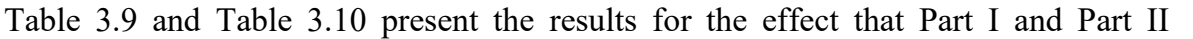

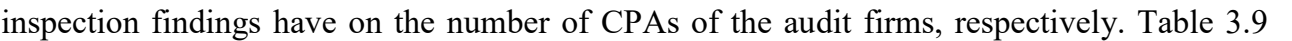

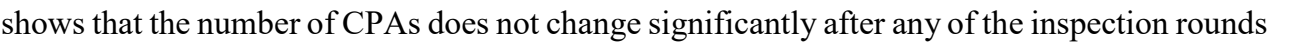
प

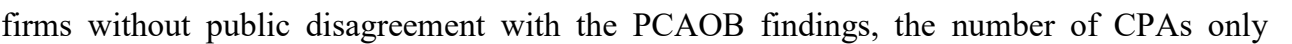

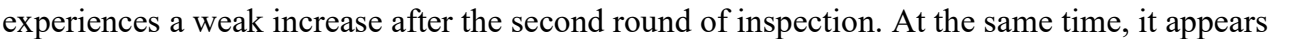

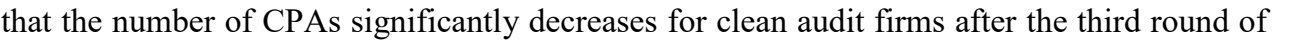

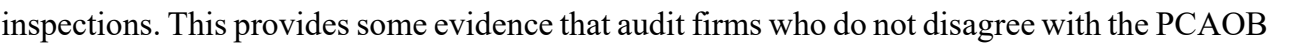

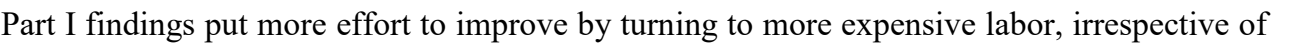

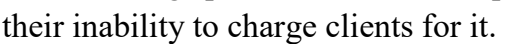

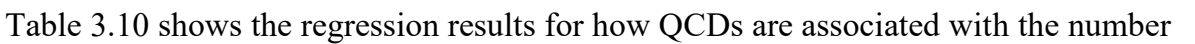

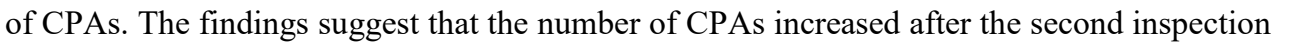
ए

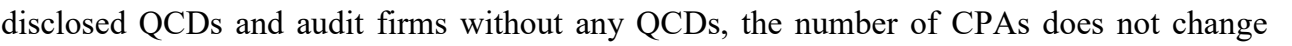

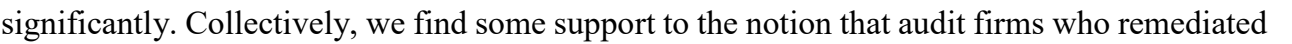
ए ए। 


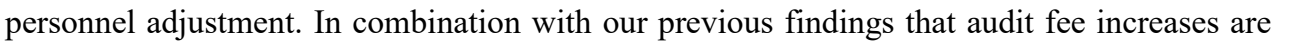

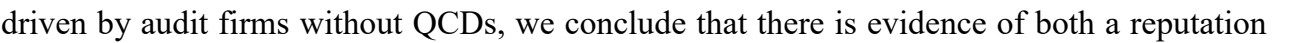

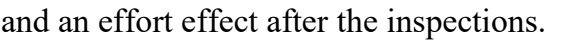

\begin{tabular}{|c|c|c|c|}
\hline 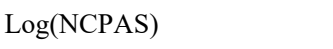 & 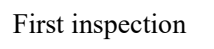 & 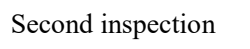 & 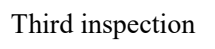 \\
\hline POST $\square$ & पणाए & पणाए & पाणा \\
\hline$\square$ & एயாमा & एणाण & पण口卄ाण \\
\hline CLEAN $\square$ & एणाएाए & एणाएाए & एणाएण \\
\hline$\square$ & एणाएण & पण口卄ा & पाणाण \\
\hline CLEAN*POST $\square$ & पाणाए & पाणा & पाणा \\
\hline$\square$ & पणाणाम & पणाणाण & पणाणाण \\
\hline OTHER $\square$ & पणा1ण & $\square ण 11$ & पाणा \\
\hline$\square$ & पणाणा & एणाण & पण口卄ाम \\
\hline OTHER*POST $\square$ & एवाणा & 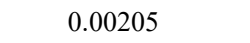 & पामाप \\
\hline$\square$ & घणाणा & पाणा1ण & पणाण \\
\hline 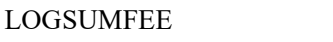 & पाणाएा & पणा1मा & पणामा \\
\hline$\square$ & एणा।ण & एणाणाए & पाणाण \\
\hline 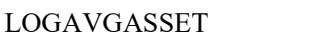 & पाणाएम & पणमाएा & एणाएा \\
\hline$\square$ & पणाणा & पणाणा & पणाणा \\
\hline पणाणा & पाणा1ए & पाणाए & एखाएाए \\
\hline$\square$ & पणाणाण & 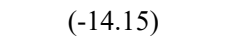 & एणाणाए \\
\hline 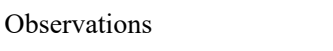 & $\square \square$ & $\square \square$ & $\square$ \\
\hline पாणाणம & पणाए & पणाए & पणाए \\
\hline 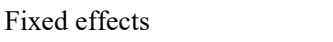 & $\square \square \mathbb{~}$ & $\square \square \square$ & $\square \square \square$ \\
\hline पमाणाणमाण & $\square ण 11$ & $\square ण 1 \square$ & पणाए \\
\hline F test Total effect CLEAN & -0.015 & 0.152 & $-0.223 *$ \\
\hline F test Total effect OTHER & 0.077 & $0.374 * *$ & -0.039 \\
\hline
\end{tabular}

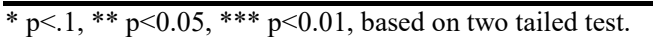

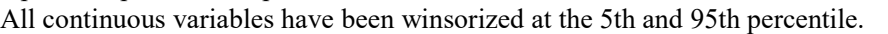

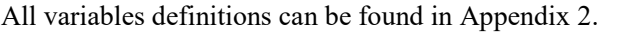


Table 3.10: Regression results with Part II findings

\begin{tabular}{|c|c|c|c|}
\hline पणाण & 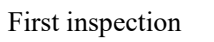 & 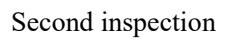 & 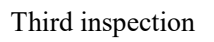 \\
\hline POST $\square$ & पणाप & $\square ण 10$ & पणाप \\
\hline$\square$ & एणाएण & एणाएण & पणाणा \\
\hline 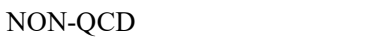 & पाणाए & पाएाएा & पाणाएा \\
\hline$\square$ & एणाए & पाणाए & पणाए \\
\hline 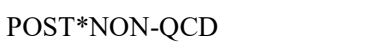 & एवाण & एणाए & एवाण \\
\hline$\square$ & पणाणाण & पण口卄ाण & पणाणाए \\
\hline QCD-ND $\square$ & पणाएण & पामाए & पणागाए \\
\hline$\square$ & एणाए & யாणा & एणाण \\
\hline $\mathrm{POST}^{*} \mathrm{QCD}-\mathrm{ND} \square$ & एवाए & पणाए & एणाए \\
\hline$\square$ & पण口卄ाण & पण口卄10 & पण口卄ामा \\
\hline 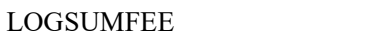 & पामाएा & पाणाए & पागाएा \\
\hline$\square$ & पाणाए & एणाणा & पाणाए \\
\hline 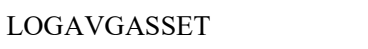 & पालाएा & एणाएा & एणाणाए \\
\hline$\square$ & एणाएा & एणाण & पाणाणा \\
\hline 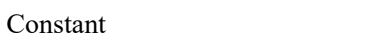 & एणामाए & एणापाए & एणामाए \\
\hline$\square$ & पणाणाण & पण口卄ाण & पणाणाए \\
\hline 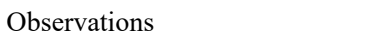 & $\square \square$ & $\square \square$ & $\square \square$ \\
\hline पणणाण & $\square ण 1$ & $\square ण 10$ & $\square ण 11$ \\
\hline 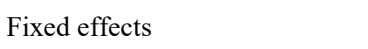 & $\square \square \square$ & $\square \square \square$ & $\square \square \square$ \\
\hline 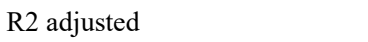 & पणाए & $\square ण 11$ & पणाए \\
\hline $\begin{array}{l}\text { F test Total effect NON- } \\
\text { QCD }\end{array}$ & एवाण & एवाण & एणाए \\
\hline F test Total effect QCD-ND $\square$ & $\square \square \square$ & एणाए & पणाए \\
\hline
\end{tabular}

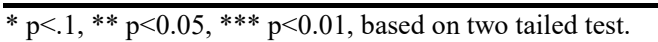

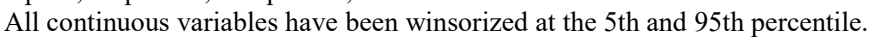

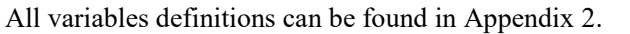




\subsubsection{Changes in the number of clients}

In addition to audit fee changes, we also investigate the clients' reaction from another

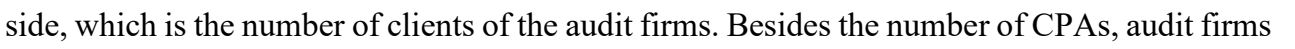

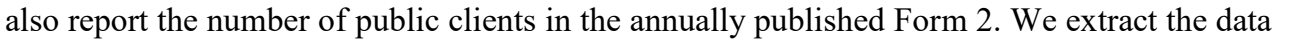

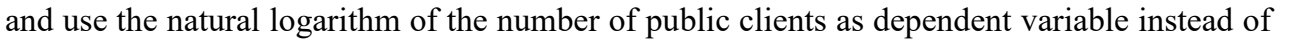

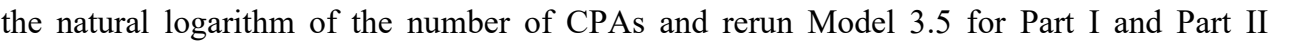

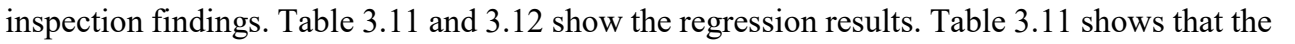

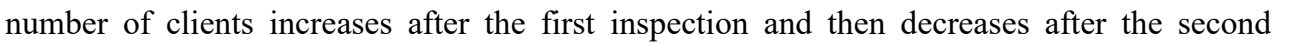
प ए एण

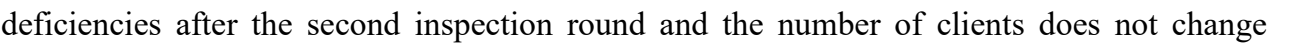

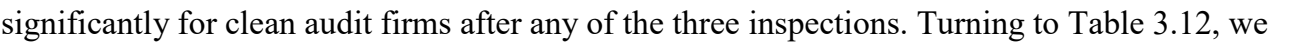

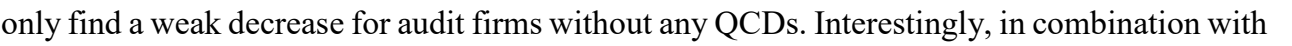

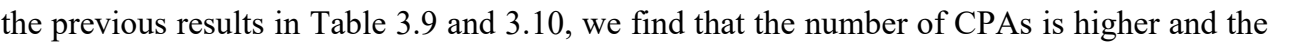

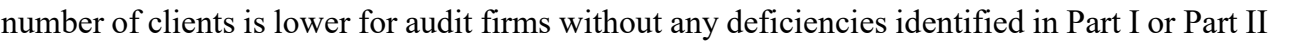

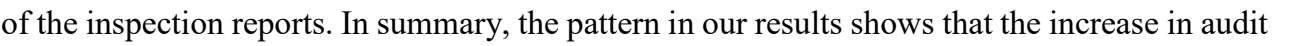

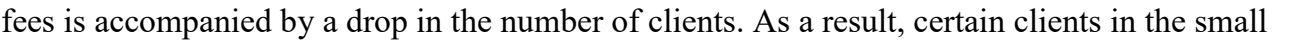

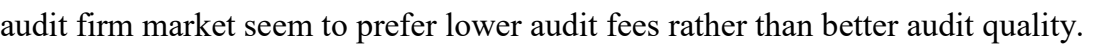

\section{$\square$}

\subsubsection{Total audit fee change}

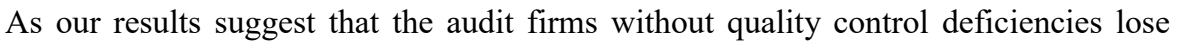

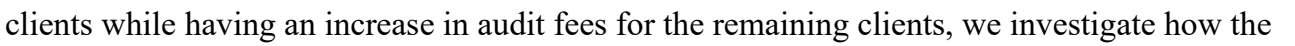

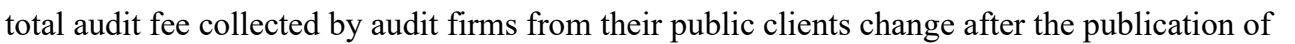
ए

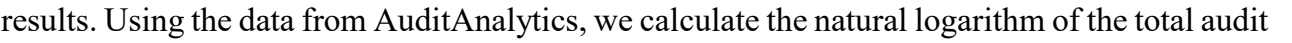

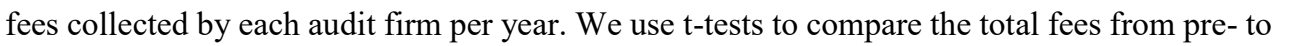

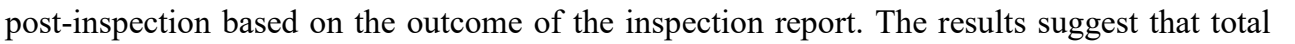

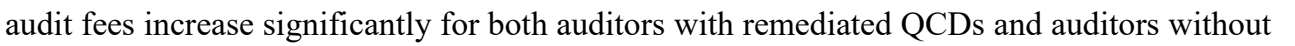

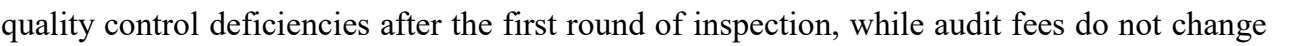

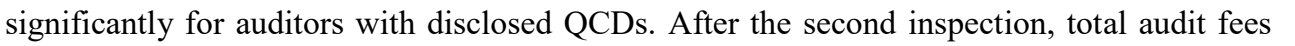

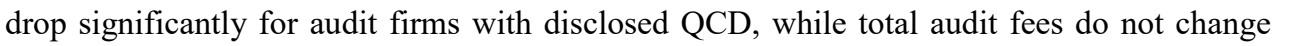

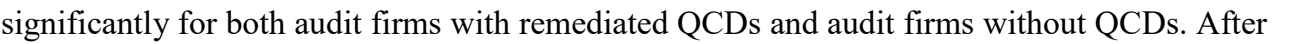

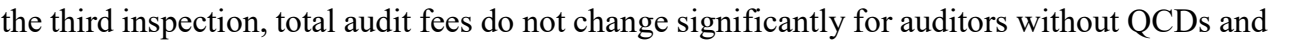

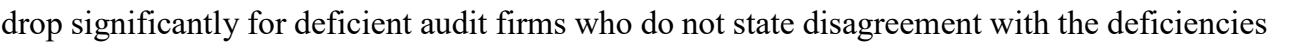

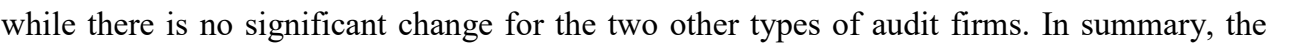

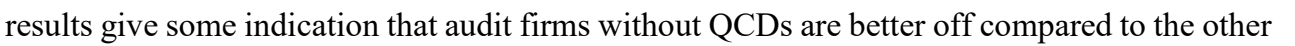

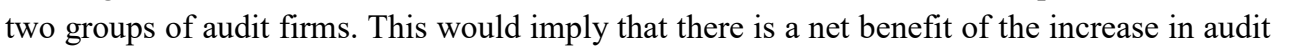

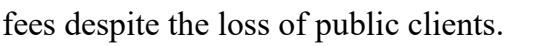


Table 3.11: Regression results with Part I findings

\begin{tabular}{|c|c|c|c|}
\hline 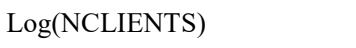 & 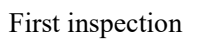 & 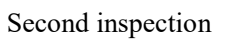 & 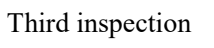 \\
\hline POST $\square$ & $\square \square 111 \square$ & पाणाए & 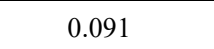 \\
\hline$\square$ & யणाण & पण口卄ाण & एणाण \\
\hline CLEAN $\square$ & पणाणा & पाणाएा & एणाए \\
\hline$\square$ & पण口卄ाण & पणाणाण & पणाणाण \\
\hline CLEAN*POST $\square$ & एवाण & $\square \square \square$ & एणाए \\
\hline$\square$ & पण口卄ाण & पाणाण & पण口णाण \\
\hline OTHER $\square$ & एणाए & पाणाए & पणा \\
\hline$\square$ & वणाणा & पण口卄ा & पणामण \\
\hline OTHER*POST $\square$ & एणाए & पणाए & पणाए \\
\hline$\square$ & एणाएा & एणाणा & पणाणाप \\
\hline 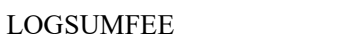 & पालाएा & पालाएण & पणाया \\
\hline$\square$ & 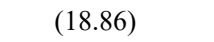 & पाणाए & एणाणा \\
\hline 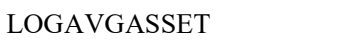 & एणाएा & एणाएाए & एणाएाए \\
\hline$\square$ & पण口卄ाए & एणाणाए & एणाणाए \\
\hline पणाणाणा & पाणा|ाए & पाणाएा & एणाएाए \\
\hline$\square$ & एणाएाए & एणाणाण & एणाणाए \\
\hline 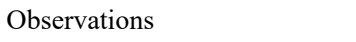 & $\square \square$ & $\square \square$ & $\square \square$ \\
\hline पणாणா & पणाए & एणाए & पणाए \\
\hline 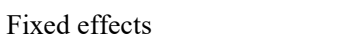 & $\square \square \square$ & पणा & $\square \square \square$ \\
\hline 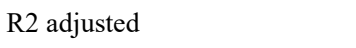 & पणाए & $\square ण 1 \square$ & पणा \\
\hline F test Total effect CLEAN $\square$ & पाएा & पाणाए & पणाए \\
\hline F test Total effect OTHER $\square$ & पणाए & யாणा & पणाए \\
\hline
\end{tabular}

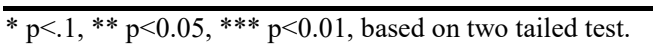

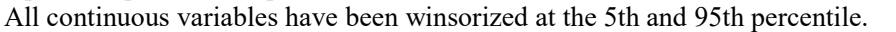

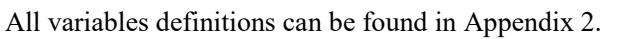




\begin{tabular}{|c|c|c|c|}
\hline 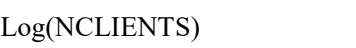 & 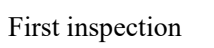 & 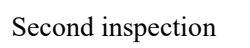 & 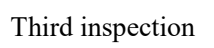 \\
\hline POST $\square$ & एाणाए & एणाए & एवाण \\
\hline$\square$ & पणाणाएा & पण口卄ा1 & पण口णाण \\
\hline 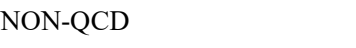 & एणामा & एயாमाए & एणाएाए \\
\hline$\square$ & पणाणाए & पणाणाए & पण口卄10 \\
\hline 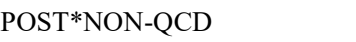 & पणाप & पणाएण & पाणाए \\
\hline$\square$ & एणाणाण & एाणाए & 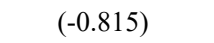 \\
\hline QCD-ND $\square$ & एवाण & एणाए & एणाएाए \\
\hline$\square$ & पण口卄ाएा & पण口卄ाम & पण口卄ाए \\
\hline POST*QCD-ND $\square$ & एणाए & एणाप & 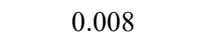 \\
\hline$\square$ & पाणाण & पण口卄ाण & एवाणाए \\
\hline 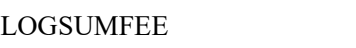 & पालाए & पणागाए & पणागाए \\
\hline$\square$ & एणाणा & पणाणा & पण口ाण \\
\hline 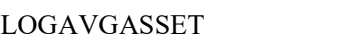 & एயाया & एाणाए & एயாाएए \\
\hline$\square$ & 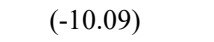 & पण口卄ाए & पण口卄ामा \\
\hline पमाणा & पाणाएा & एणाएाए & एणाएाए \\
\hline$\square$ & पण口卄ामा & एणाणाए & पण口ण10 \\
\hline 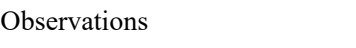 & $\square \square$ & $\square$ & $\square \square$ \\
\hline पயणाणा & पणाए & पणाए & पणाए \\
\hline 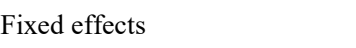 & पणा & $\square \square \square$ & $\square \square \square$ \\
\hline 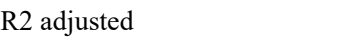 & पणाए & पणाए & पणाए \\
\hline $\begin{array}{l}\text { F test Total effect NON- } \\
\text { QCD }\end{array}$ & एणाए & पाणाए & एणाएम \\
\hline F test Total effect QCD-ND $\square$ & एणाए & एणाए & ஐس冋口 \\
\hline
\end{tabular}

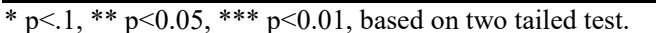

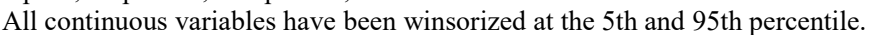

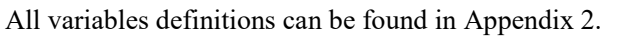


Table 3.13: Change in total audit fees

\begin{tabular}{|c|c|c|c|c|}
\hline 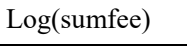 & $\square \square \square$ & $\square \square \mathbb{\square}$ & $\square \square \square$ & $\square\|\mid\| \| \square$ \\
\hline \multicolumn{5}{|c|}{ 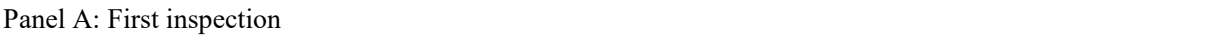 } \\
\hline 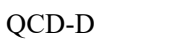 & $\square \square \square$ & $\square ण \square$ & $\square[1 \square$ & पण口卄 \\
\hline परणषण & $\square \amalg \square$ & 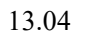 & एणा & 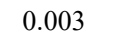 \\
\hline पㅁㅁㅁㅁ & $\square|\square| \square$ & 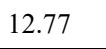 & $\square[1 \square$ & $\square[1 \square$ \\
\hline \multicolumn{5}{|c|}{ 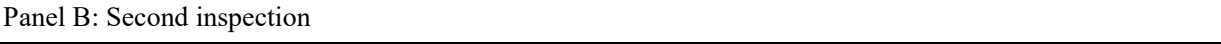 } \\
\hline 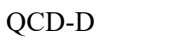 & $\square \square \square$ & 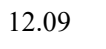 & पाणा & $\square \square \square$ \\
\hline 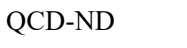 & पाणा & पाणा & पाणा & पामा \\
\hline 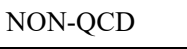 & 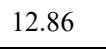 & $\square \mid ण 1 \square$ & पाणा & $\square \square \square$ \\
\hline \multicolumn{5}{|c|}{ 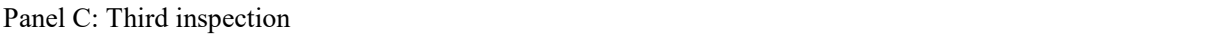 } \\
\hline 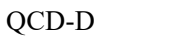 & $\square$ & पाण & एण口冋 & पण口म \\
\hline 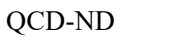 & पण口 & पाणा & पाणाए & पामा \\
\hline 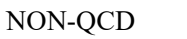 & $\square \square \square$ & पाण & एाणा & 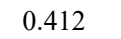 \\
\hline
\end{tabular}

\subsubsection{Financial risk of new clients after the inspections}

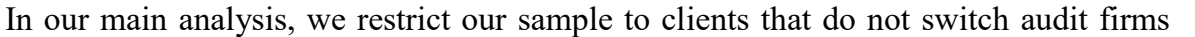

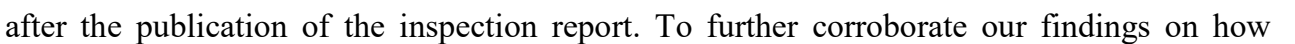

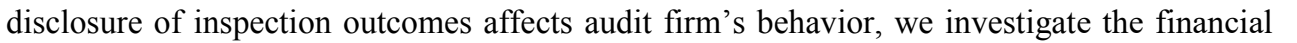

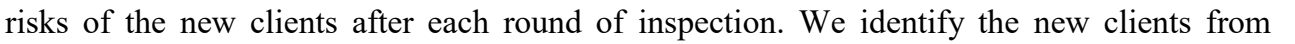

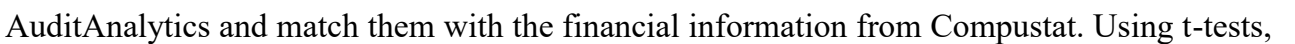

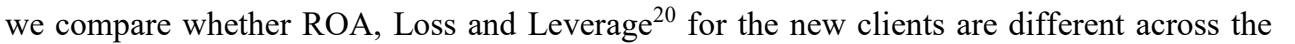

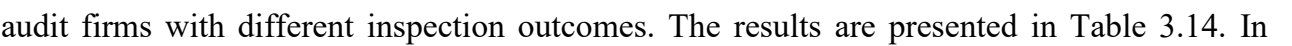

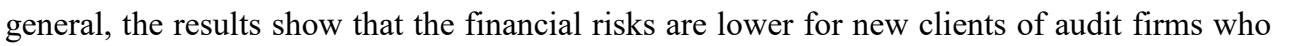

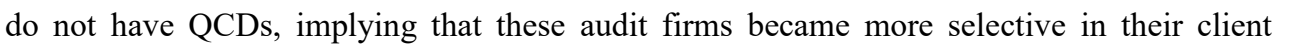

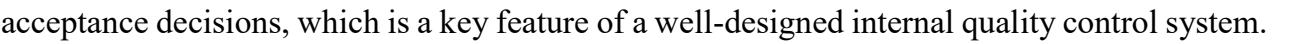

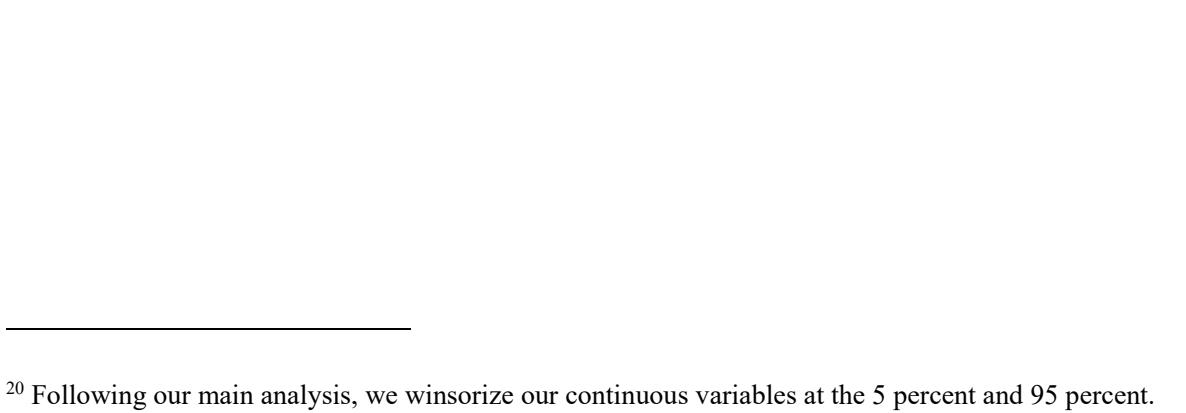


Table 3.14: Financial risks for the new clients after the inspections

\begin{tabular}{|c|c|c|c|c|c|c|}
\hline \multicolumn{7}{|c|}{ 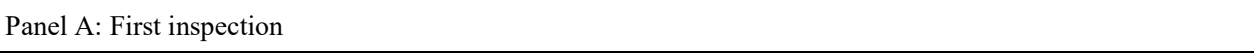 } \\
\hline$\square$ & 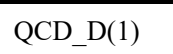 & 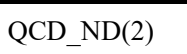 & 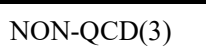 & 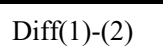 & 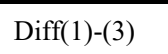 & 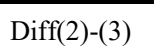 \\
\hline$\square \square \square \square$ & एणाए & एणाए & एणाए & पणामापा & पाणामाप & पणामाप \\
\hline 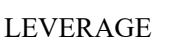 & 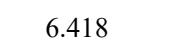 & $\square \square \square$ & $\square \square \square$ & 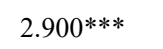 & 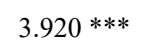 & $\square \square \prod \prod \square$ \\
\hline 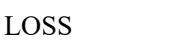 & पणाप & पणाप & पणाए & पणाए & पणायाप & पणापाप \\
\hline \multicolumn{7}{|c|}{ 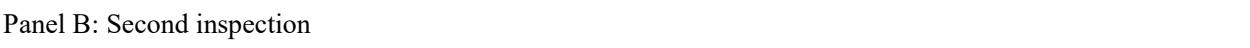 } \\
\hline$\square \square \square \square$ & पाणाए & एणाए & पाणाए & पाणायाप & 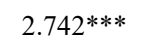 & पाणाए \\
\hline 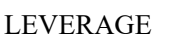 & पणाप & पणाप & पणाए & पणापा & 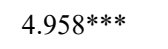 & पाणाए \\
\hline$\square \square \square \square \square$ & 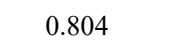 & पामा & 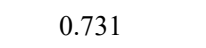 & पामाए & $\square \square \square \square$ & पामाप \\
\hline \multicolumn{7}{|c|}{ 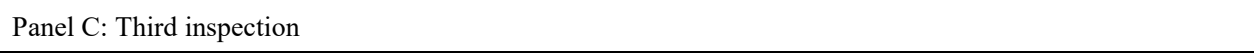 } \\
\hline$\square \square \square \square$ & एणाए & एणाए & एणाए & एणामाम & पामामाप & पण口卄 \\
\hline 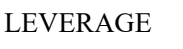 & 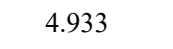 & पणाए & 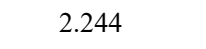 & पामापा & पणामाए & $\square \square \square \square$ \\
\hline प्वा० & पणाए & पणाप & पणाए & पणाए & 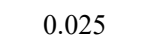 & पणाए \\
\hline
\end{tabular}

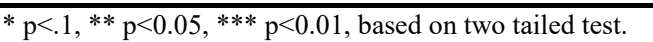

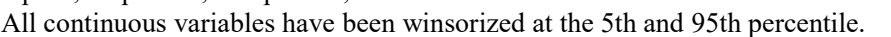

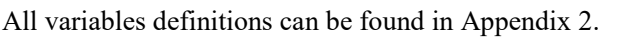

\subsubsection{Other additional tests}

To rule out the possibility that very small client companies' might have different pricing

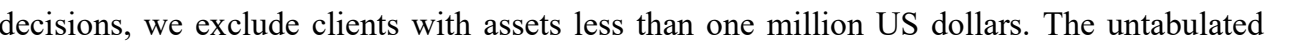

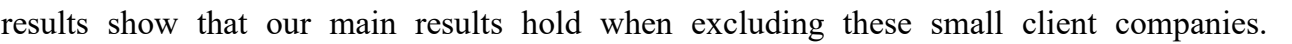

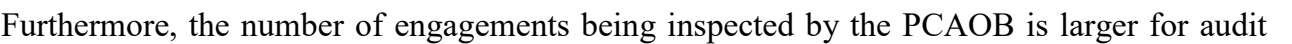
प

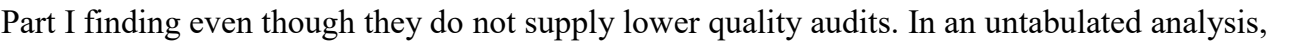

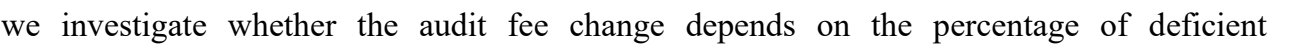

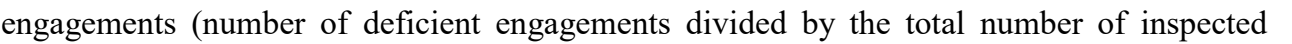

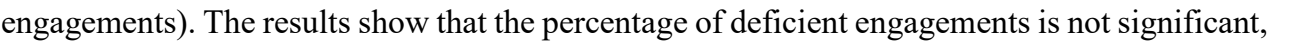

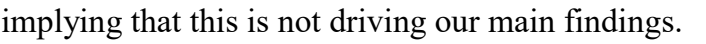

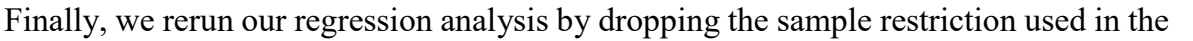

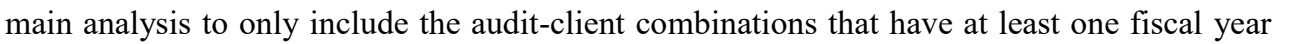

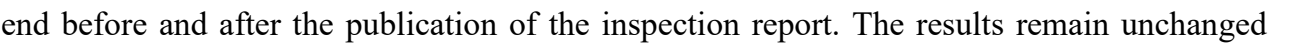

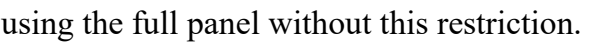




\subsection{Conclusion}

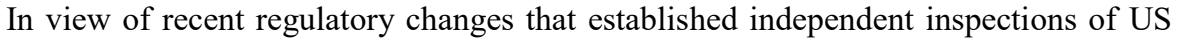

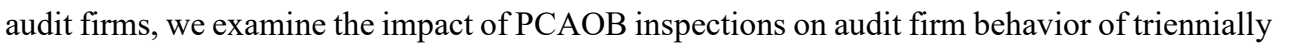
ए

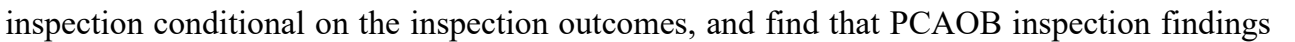

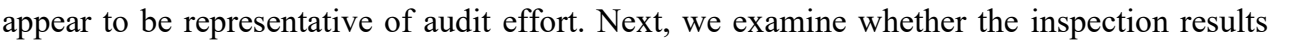

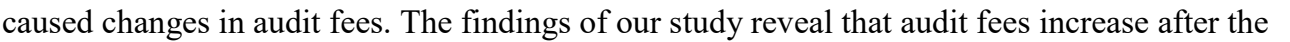

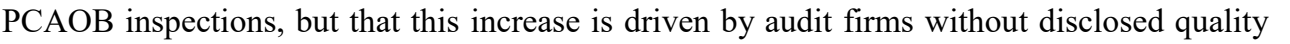

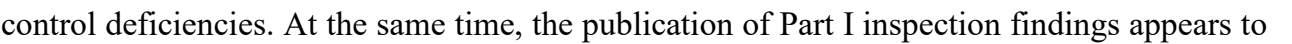

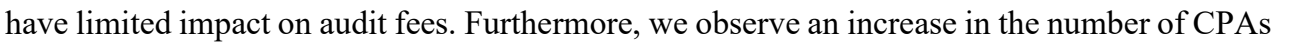

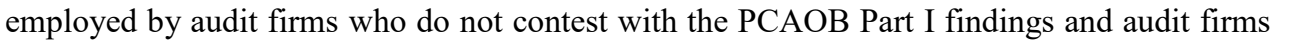

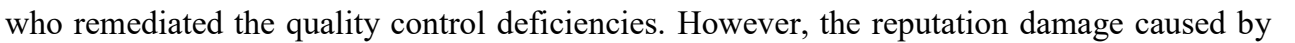

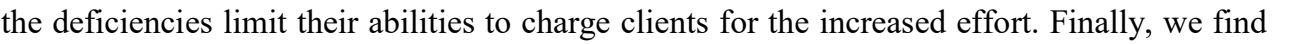
पाயா

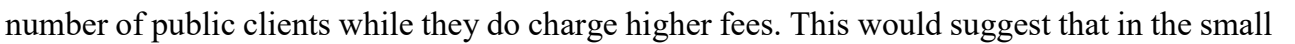

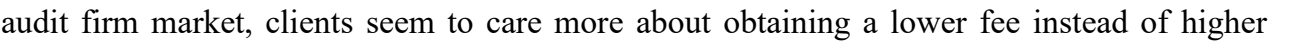

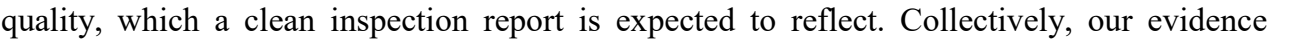

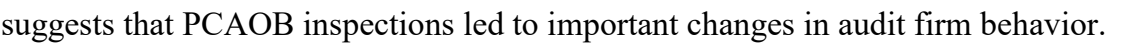

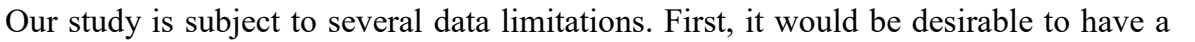

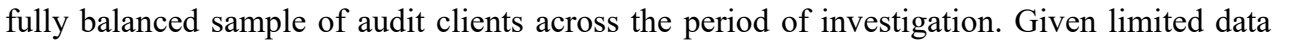

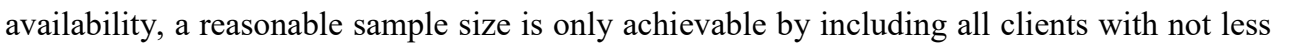
ए ए।

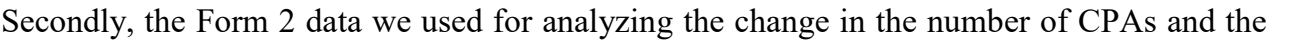

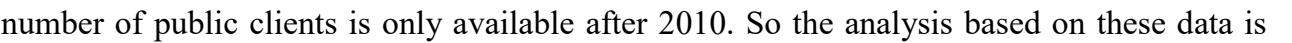

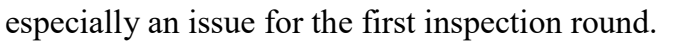

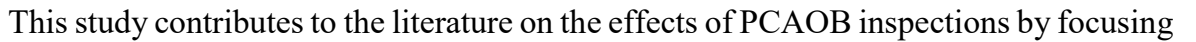

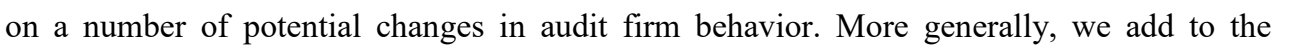

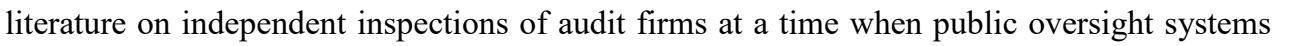

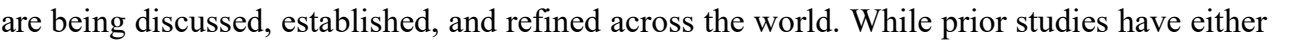

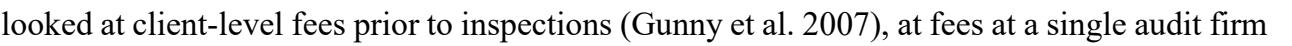

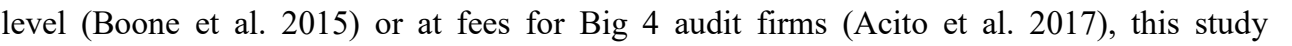

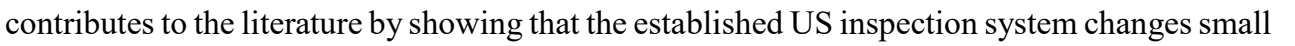
audit firms' behavior. While recent studies mainly relating to annually inspected audit firms ए।

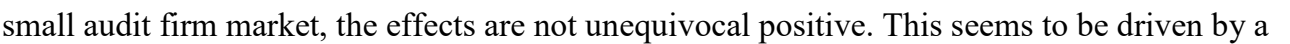

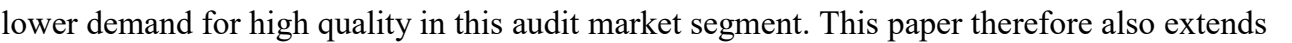

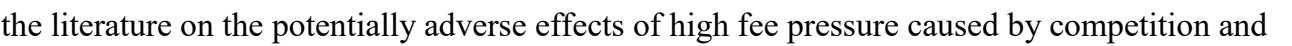

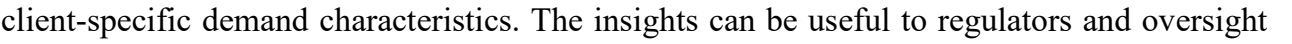

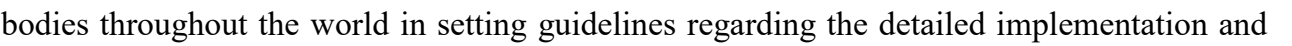

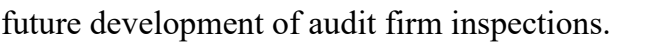

$\square$ 
Chapter 4: Market Reactions to Public Oversight: Evidence from the Netherlands 


\begin{abstract}

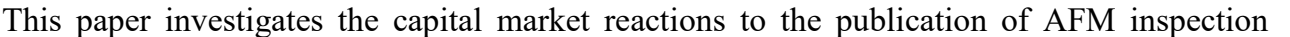

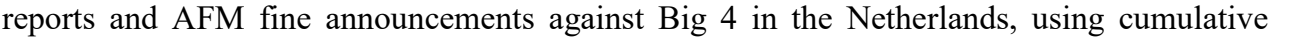

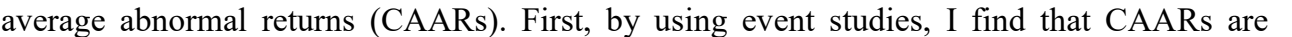
ए suggesting that these information does not change investors' perception of audit quality. For प

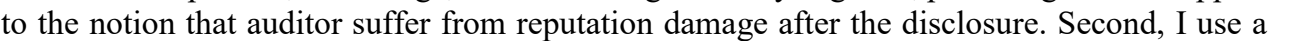

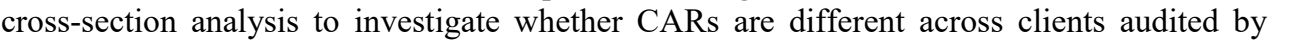

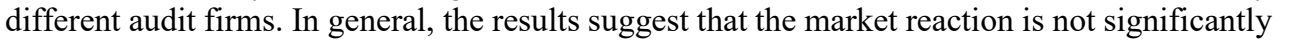

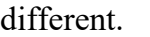




\subsection{Introduction}

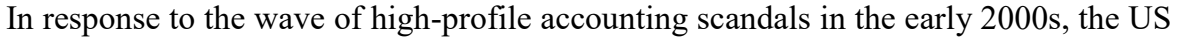

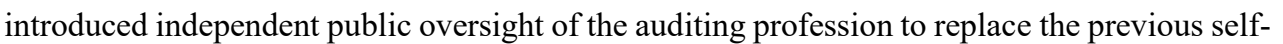

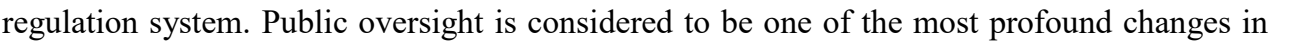

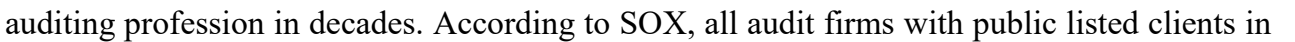

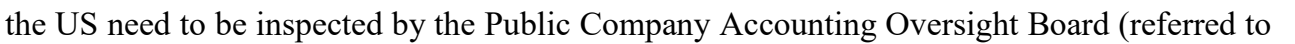

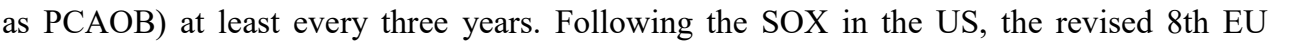

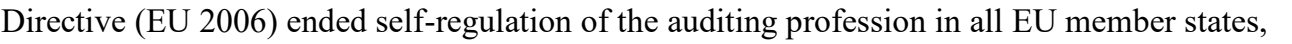

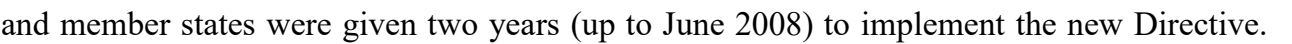

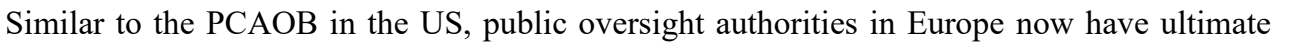

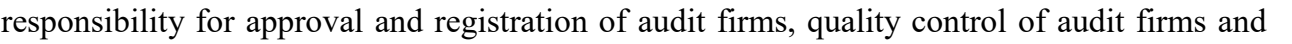

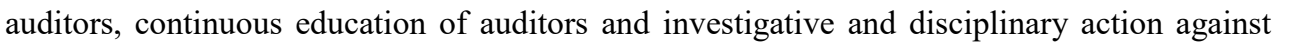

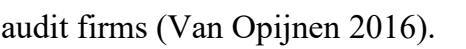

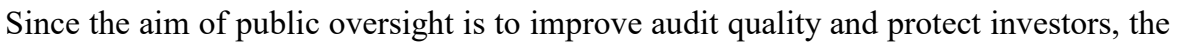

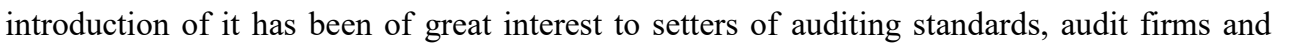

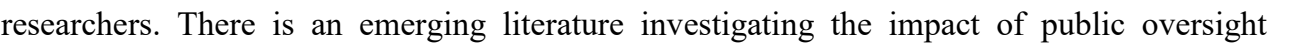

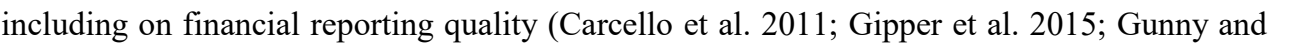

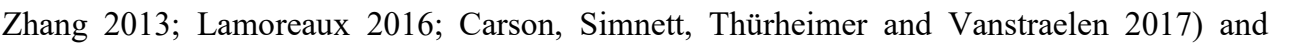

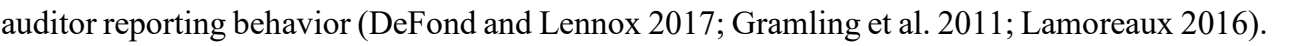

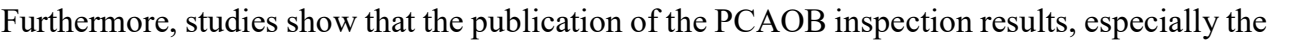

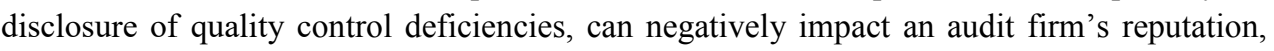

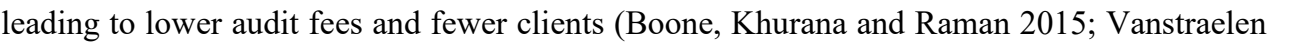

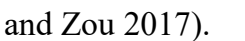

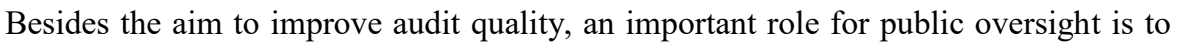

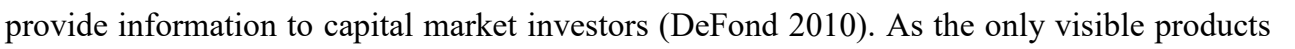

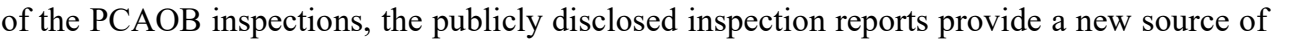

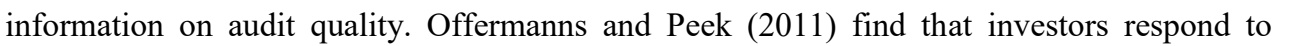

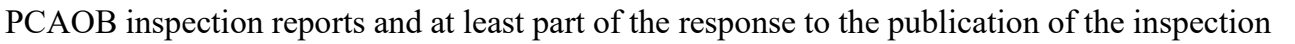
results can be attributed to revisions in investors' beliefs about accounting information quality.

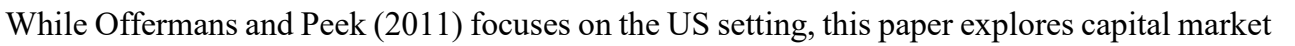

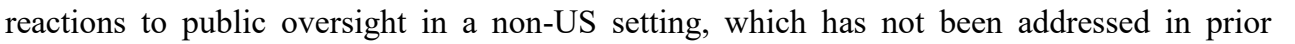

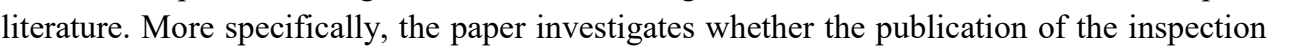

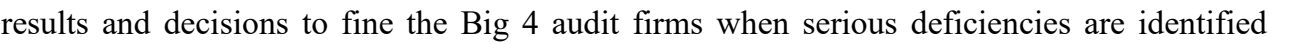

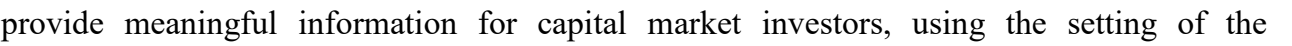

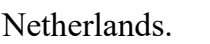

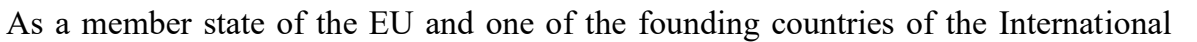

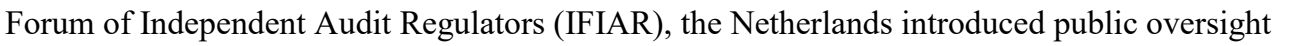

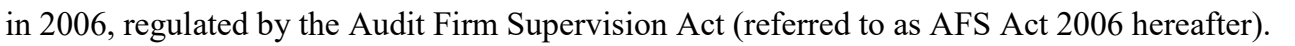

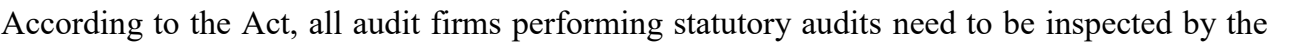

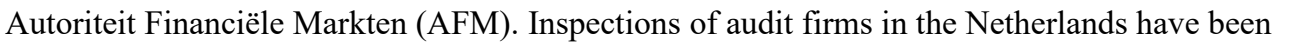




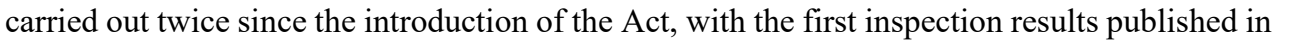

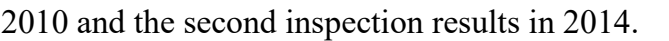

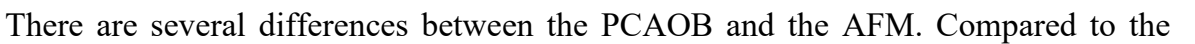

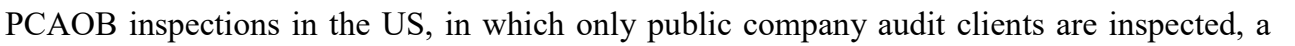

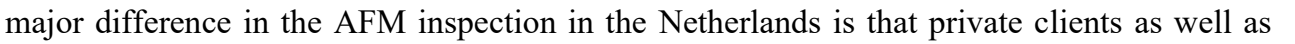

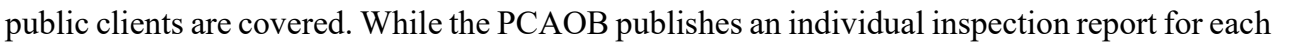

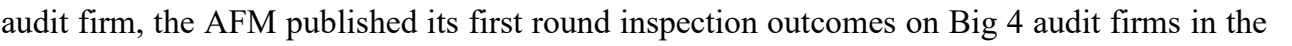

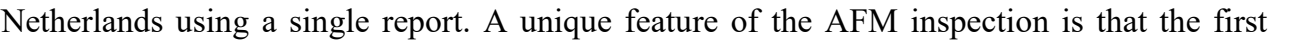

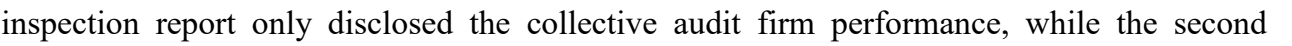

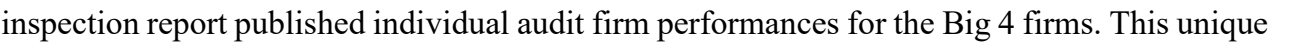

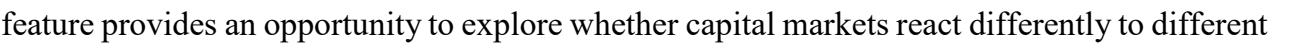

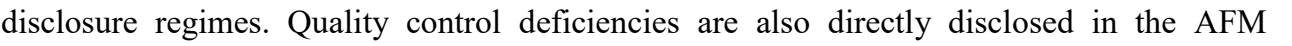

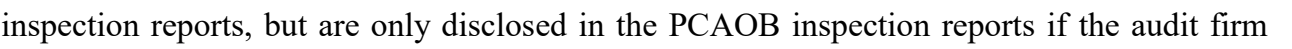

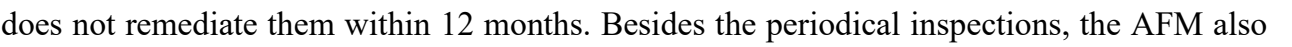

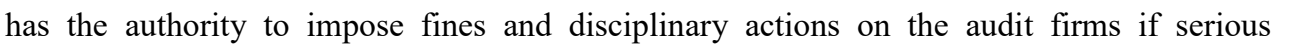

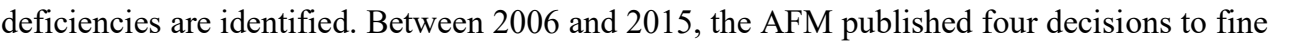

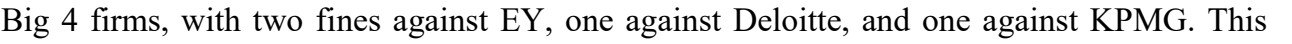

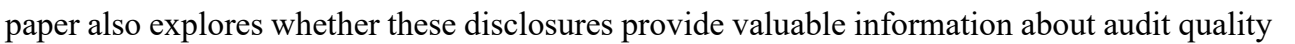

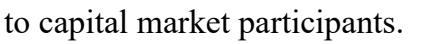

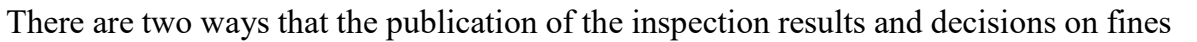

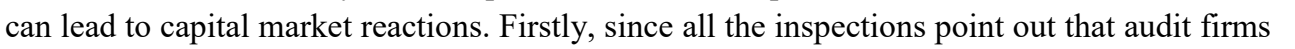

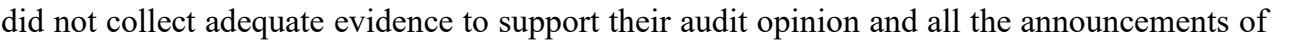

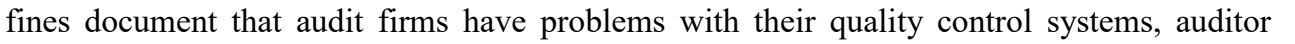

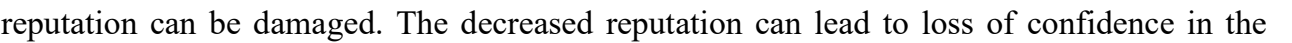

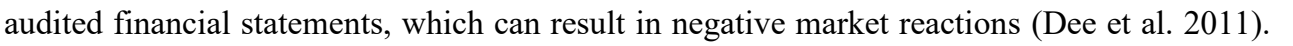

Secondly, negative inspection reports can increase investors' perceptions of potential penalties

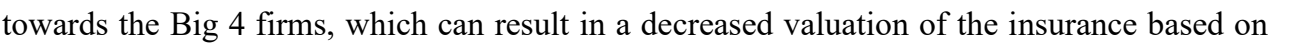

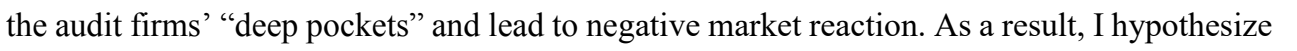

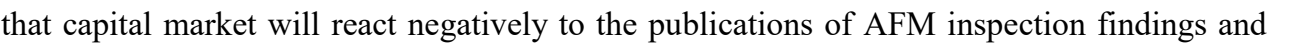

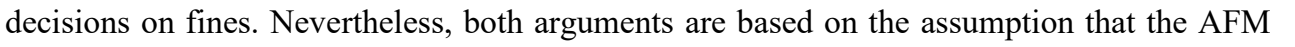

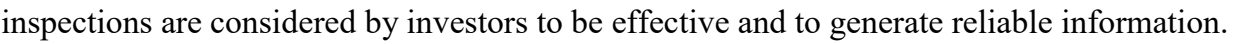

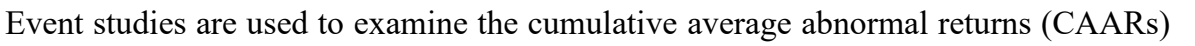

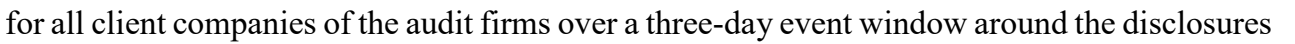
$\square \square \square \square$ inspection findings and AFM's decisions on fines, beginning at the day before the

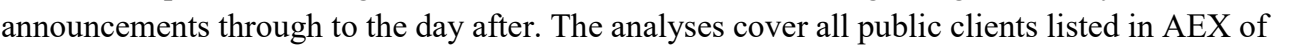

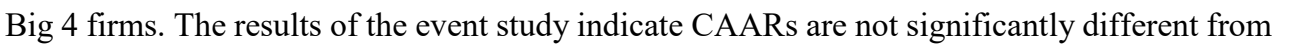

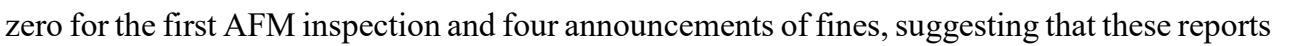

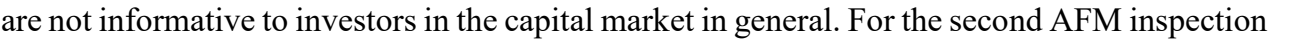

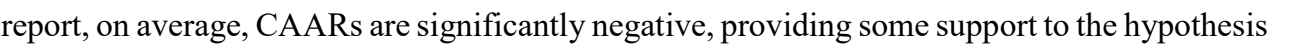

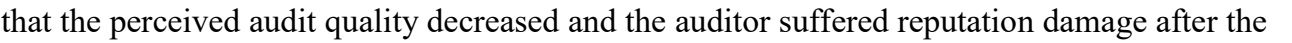

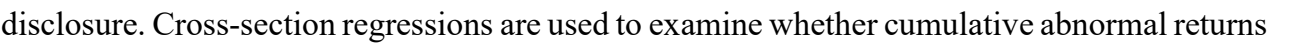

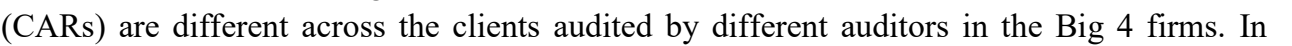


Market Reactions to Public Oversight: Evidence from the Netherlands $\square$

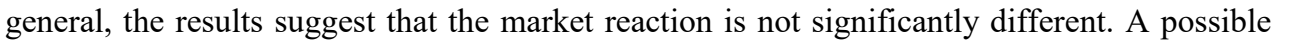

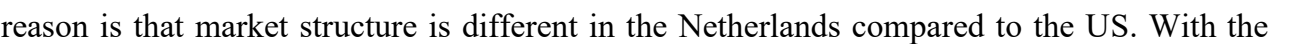

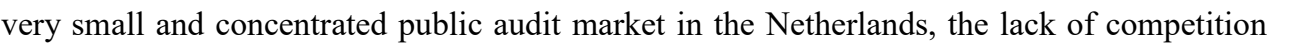

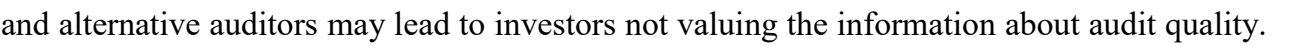

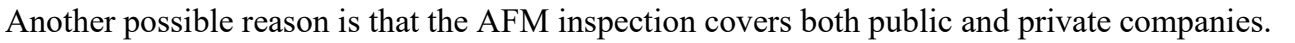

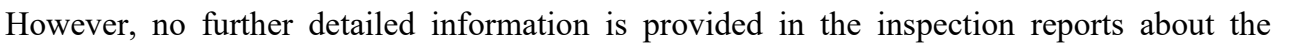

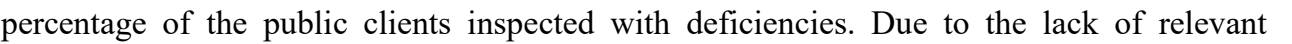

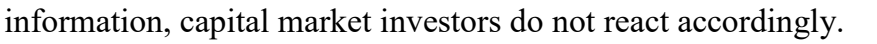

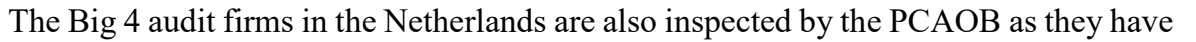

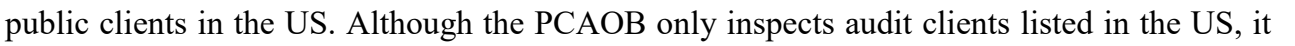

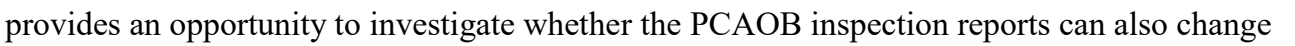
investors' perception of audit quality in the Netherlands. In additional analyses, I study the

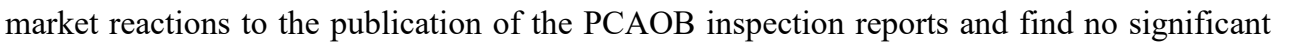

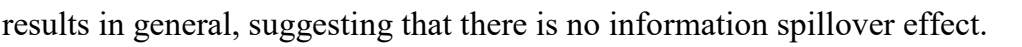

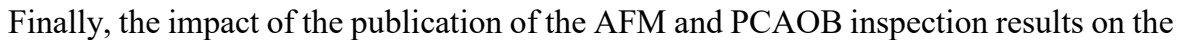

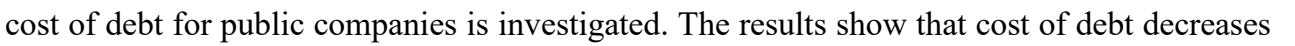

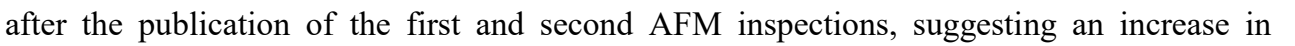

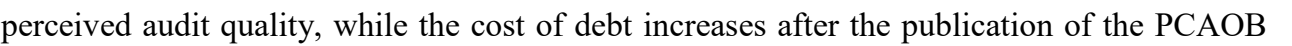

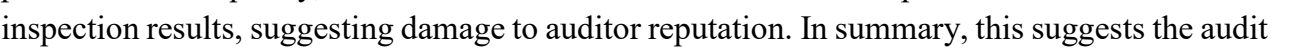

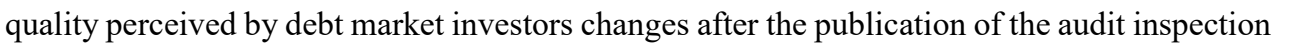
पा\|ातापा

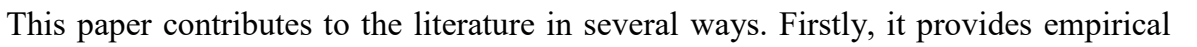

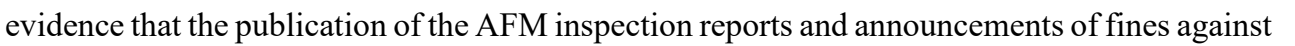

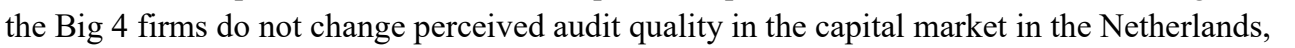

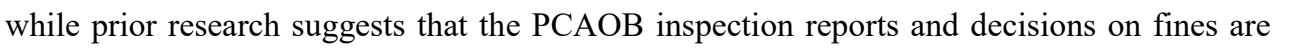

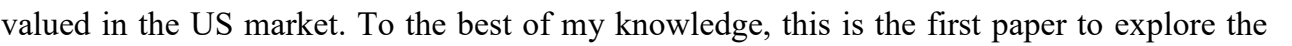

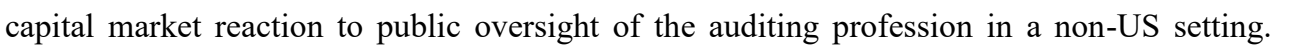

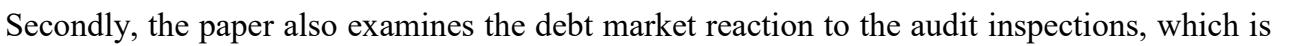

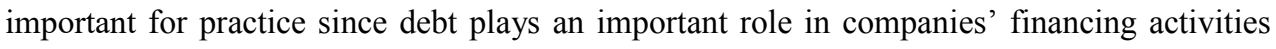

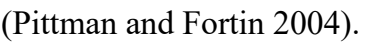

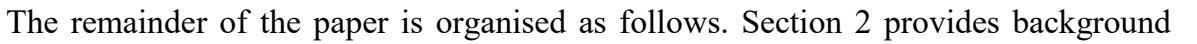

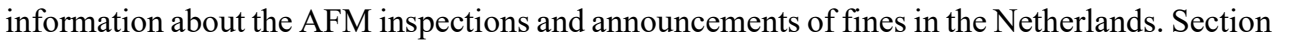

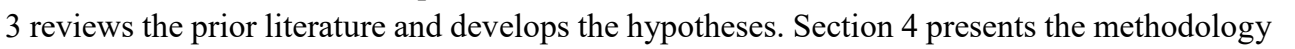

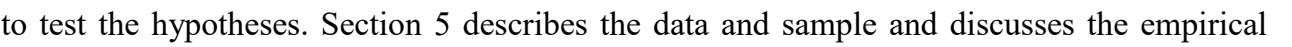
एणी

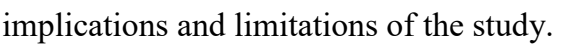




\subsection{Background}

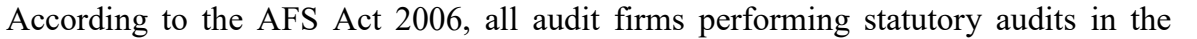

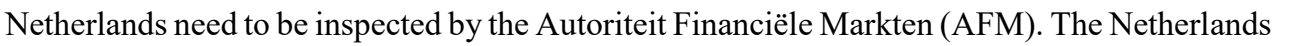

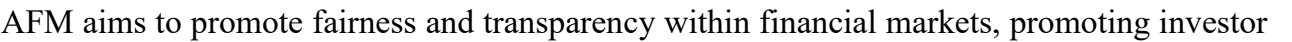

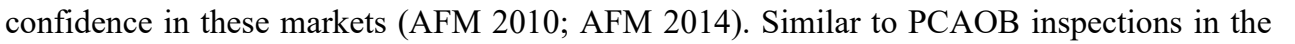

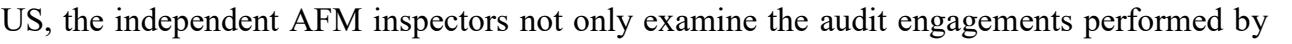

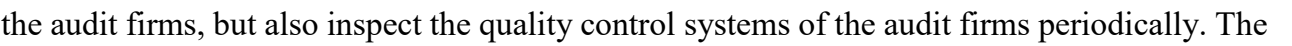

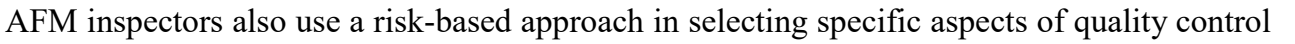

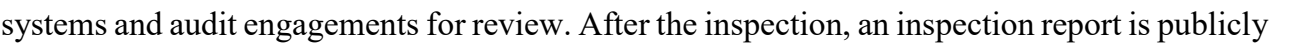

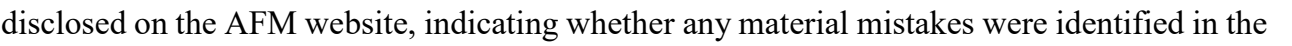

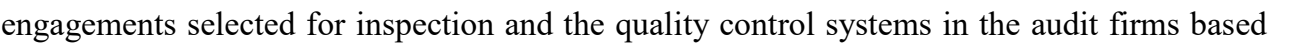
$\square$ the 'International Standard on Quality Control 1' (IAASB 2009b). Where material mistakes

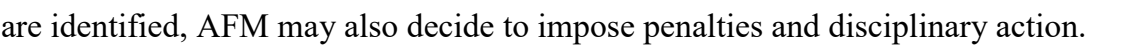

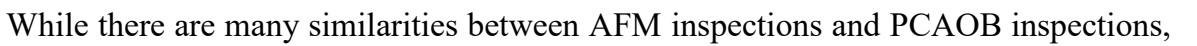

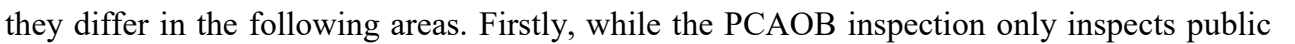

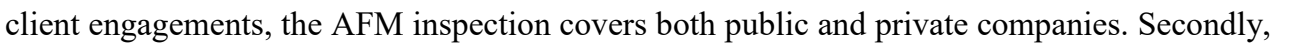

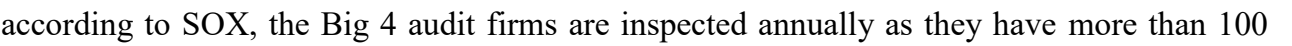

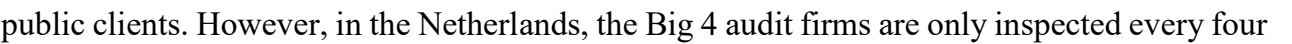

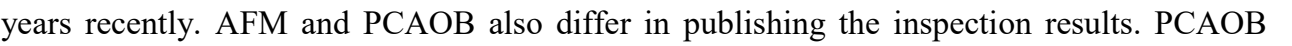

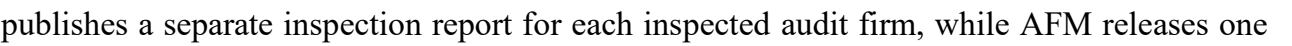

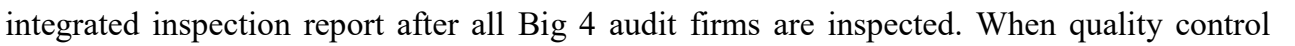

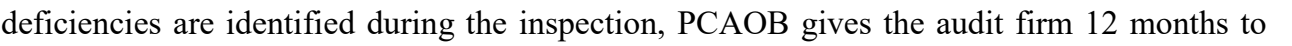

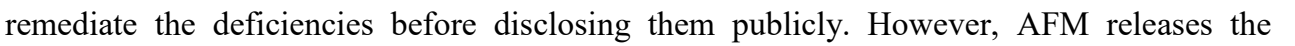

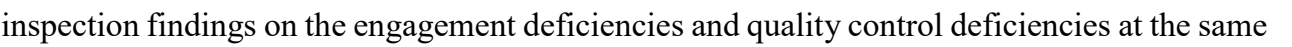
एवा

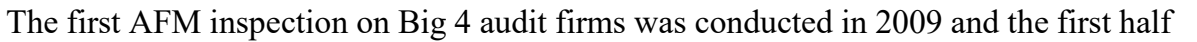

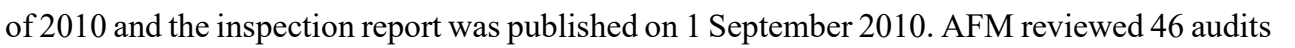

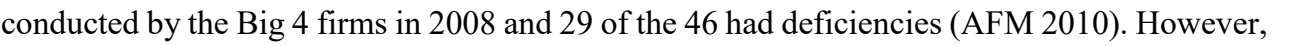

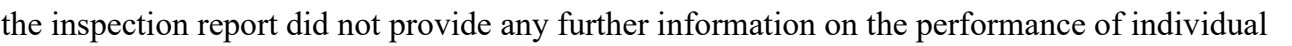

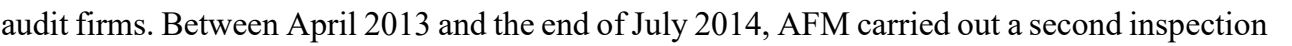

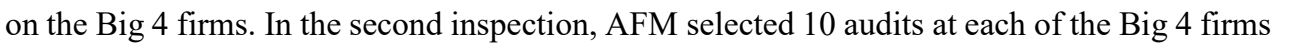

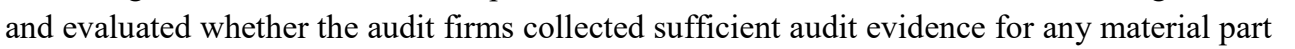
ए

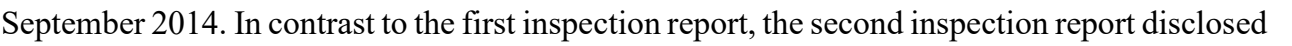

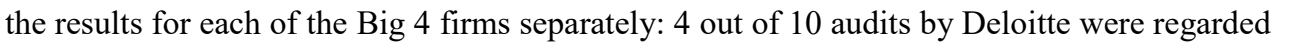

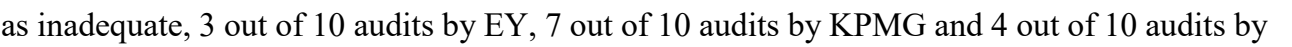

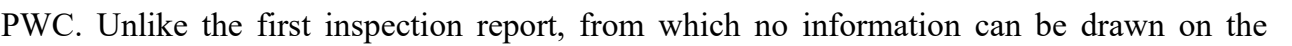

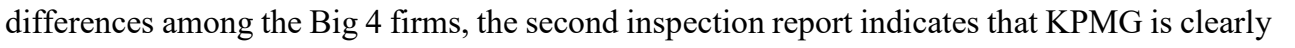

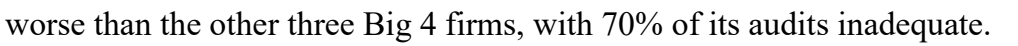

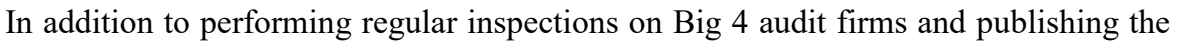

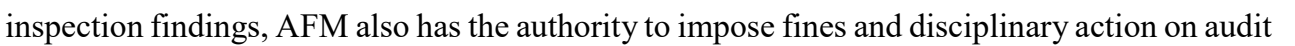


Market Reactions to Public Oversight: Evidence from the Netherlands $\square$

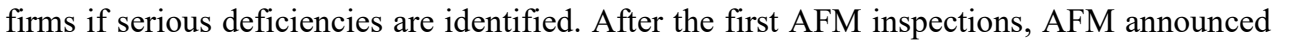
ए ए।

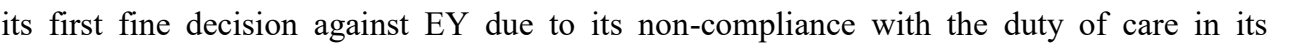

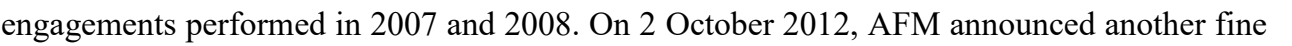

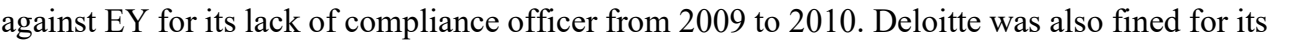

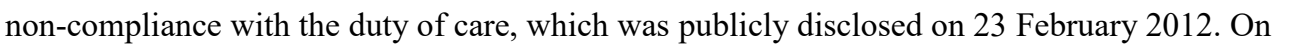

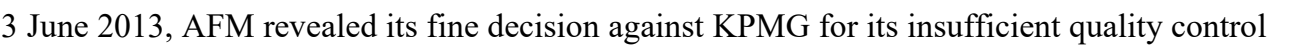

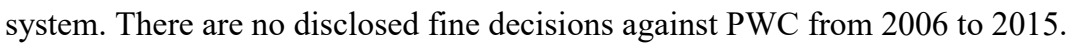

$\square$

\subsection{Prior literature and hypotheses development}

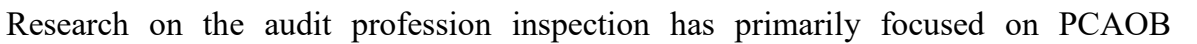
प

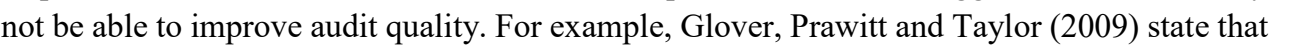

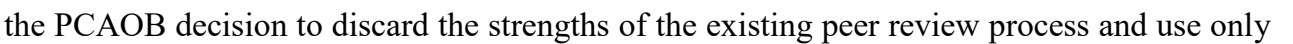
PCAOB staff in its inspections leads to inadequate expertise to effectively conduct "risk based"

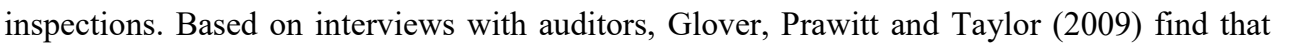

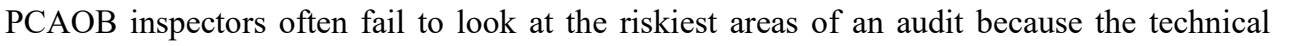
complexity of such areas is beyond the inspection team's expertise. At the same time, auditors

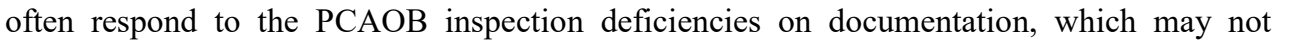
necessarily affect the auditor's opinion after remediation (Defond and Lennox 2017; Dowling,

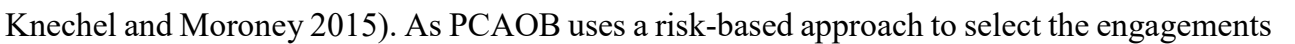

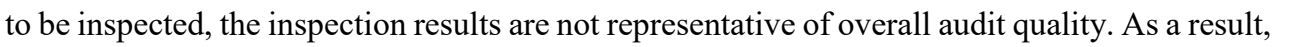

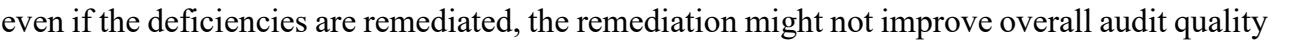

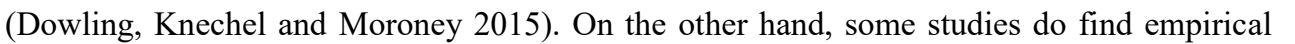

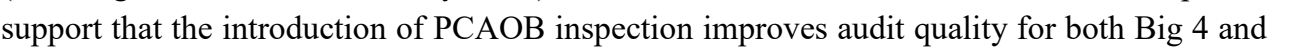

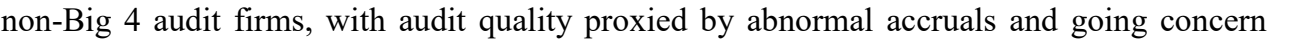

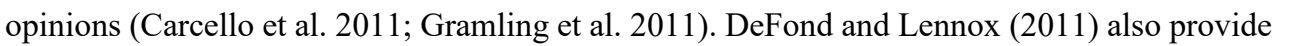

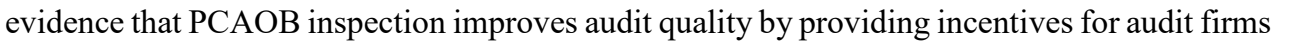

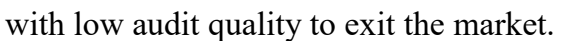

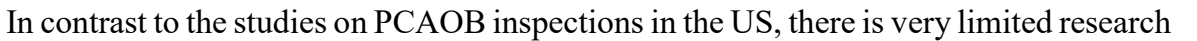

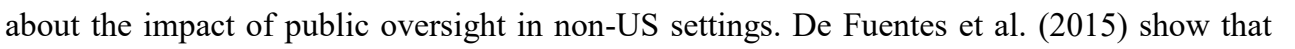

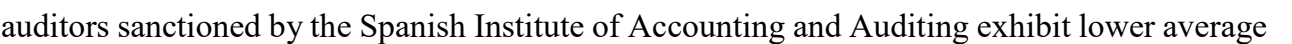

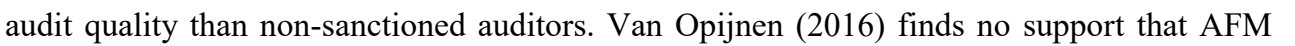

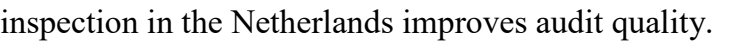

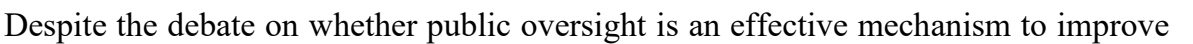

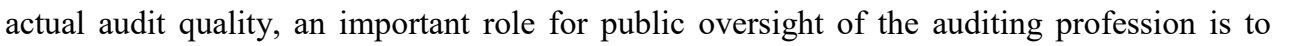

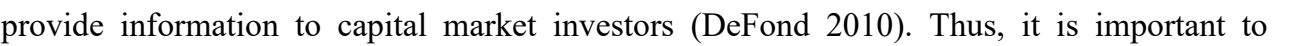

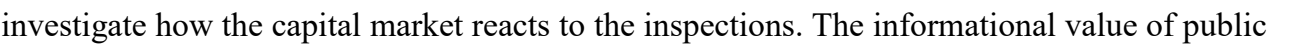

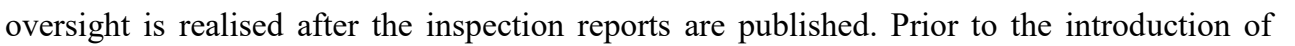

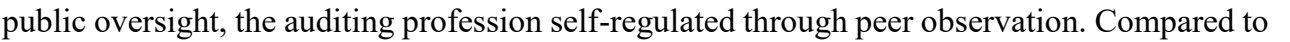




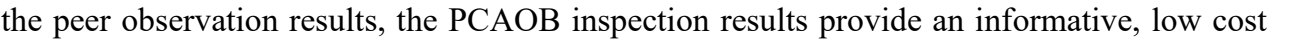

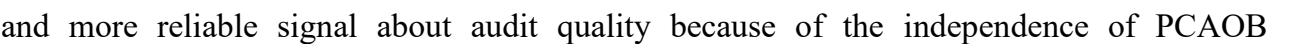

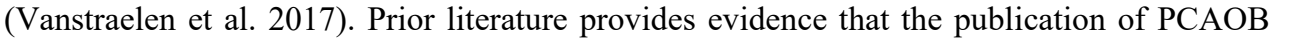
inspection reports and the subsequent sanctions change investors' perceived audit quality.

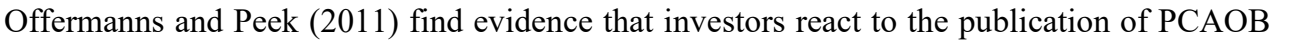

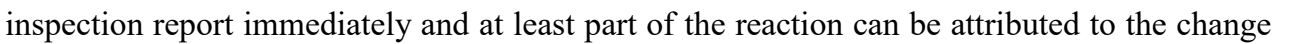

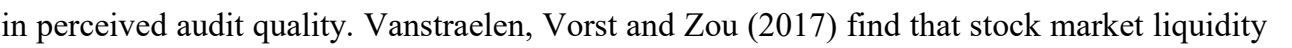

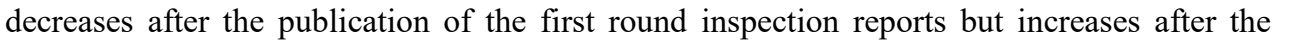

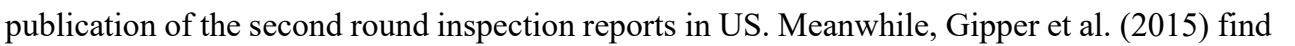

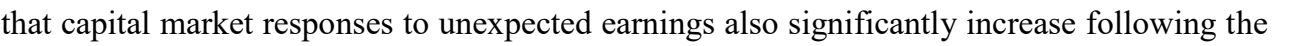
ए

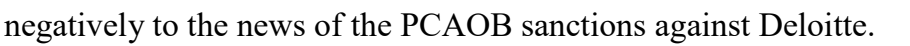

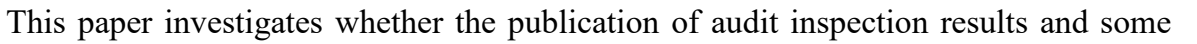

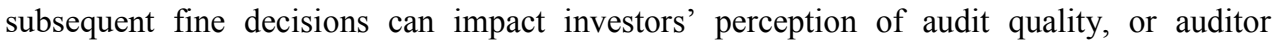

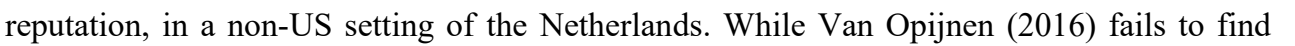

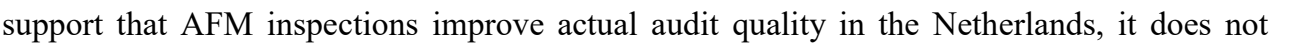

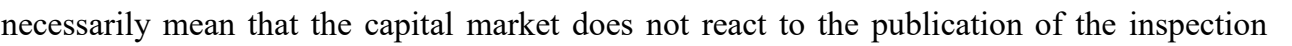

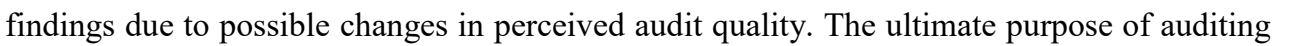

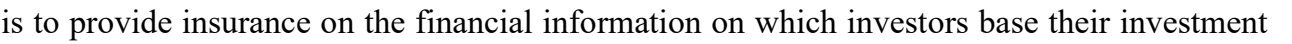

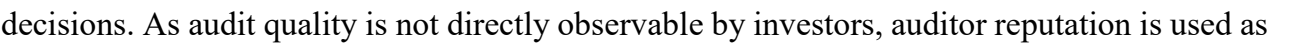

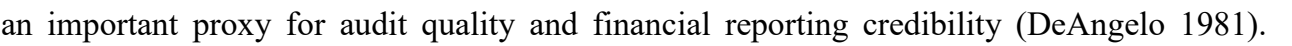

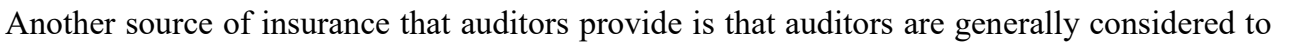
have "deep pockets" as investors are able to sue the auditor to partially recover their loss in the

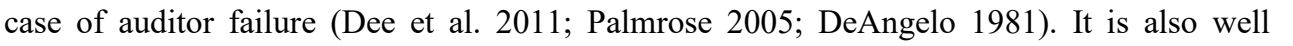

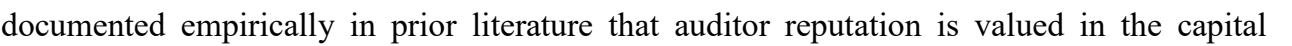

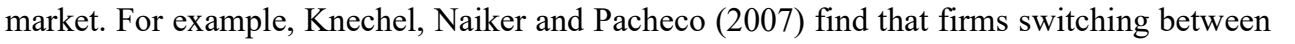

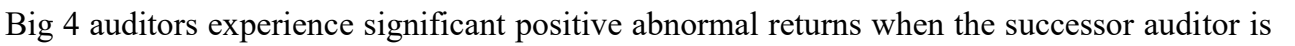

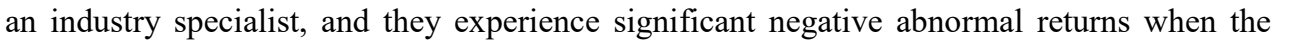

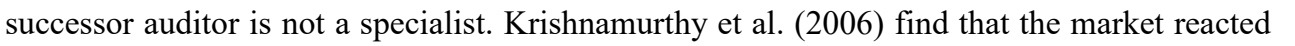
negatively to Andersen clients after the news about Andersen's

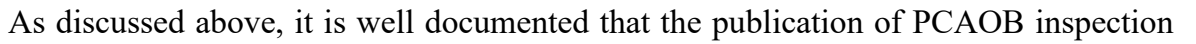
reports and the following sanction decisions changed investors' perceived audit quality in the

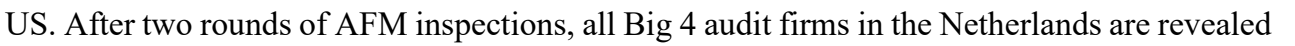
प

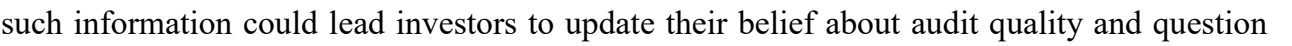

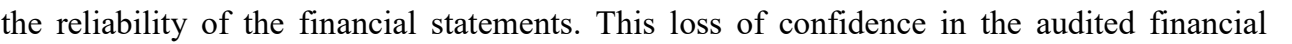
statements can lead investors to revise their valuation of the audit firms' clients, which could

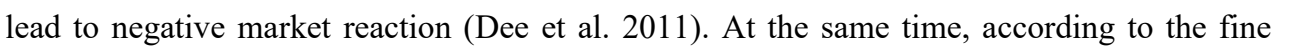

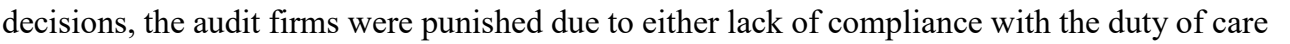

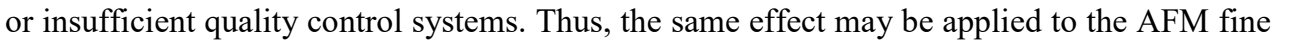

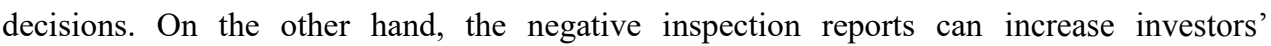


Market Reactions to Public Oversight: Evidence from the Netherlands $\square$

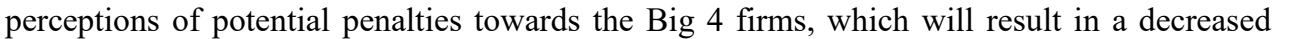
valuation of the insurance based on the audit firms" "deep pockets".

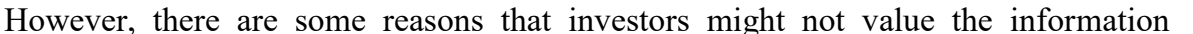

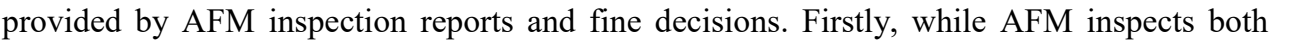

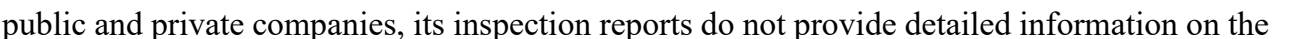

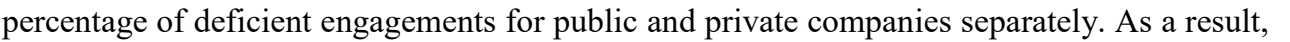
ए

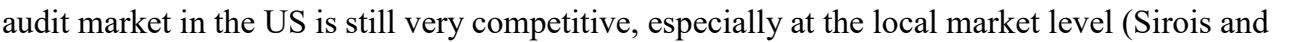

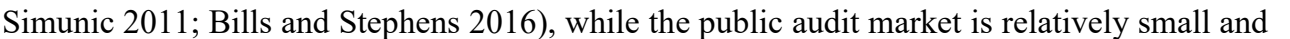

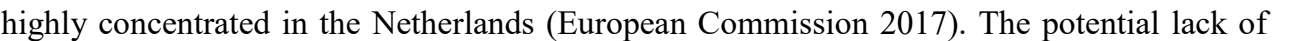

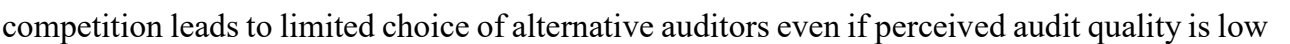

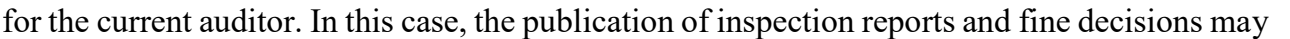

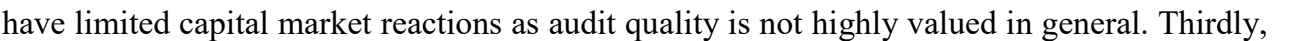

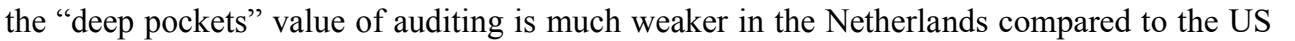

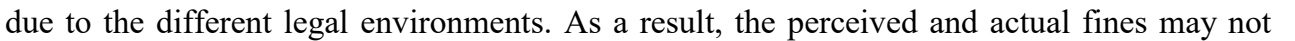
impact investor' valuation of audit quality. Last but not least, it is possible that investors

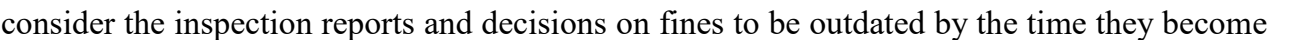

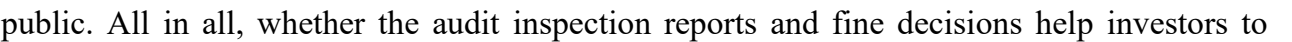

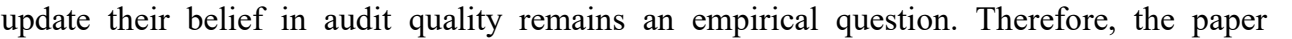

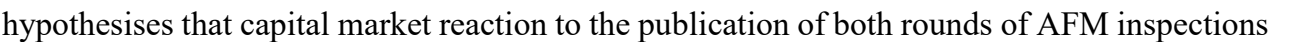

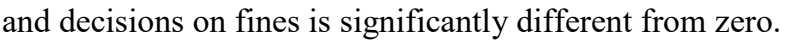

$\square \square$ Client firms' market reaction after the publication of the AFM inspection reports and decisions on fines is significantly different from zero. $\square$

$\square$

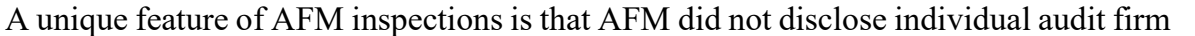

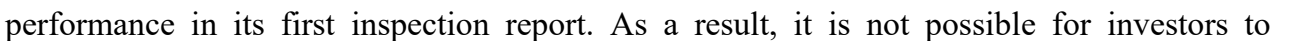

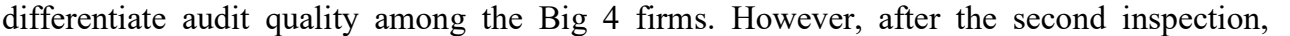

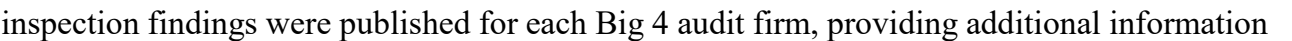

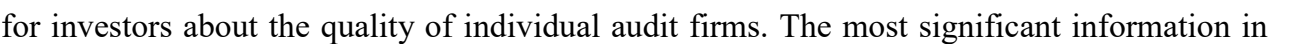

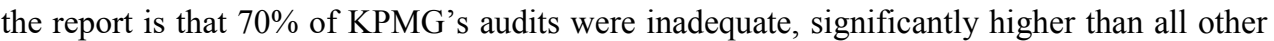

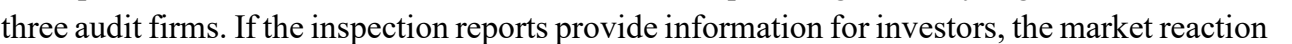

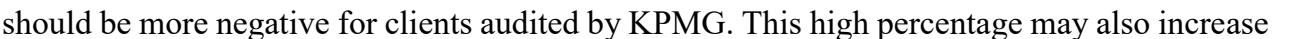
investors' anticipation of regulatory penalties towards KPMG by a larger extent, compared to

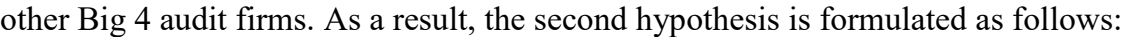

$\square \square \|$ The clients' magnitude of market reaction to the publication of the first AFM inspection report is not different among the Big 4 audit firms.

$\square$

$\square \square \amalg T$ The clients' magnitude of market reaction to the publication of the second AFM inspection report is different among the Big 4 audit firms. 


\subsection{Research design}

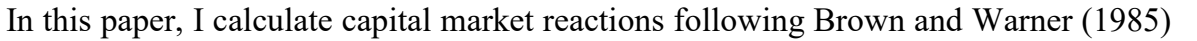

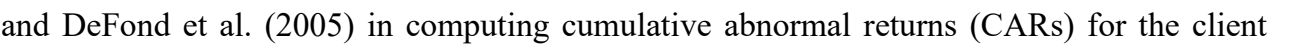

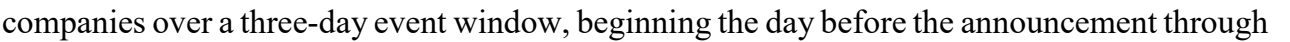

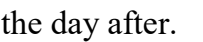

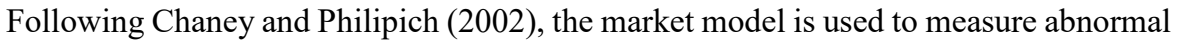

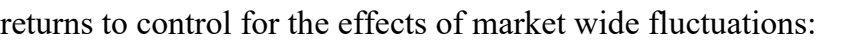

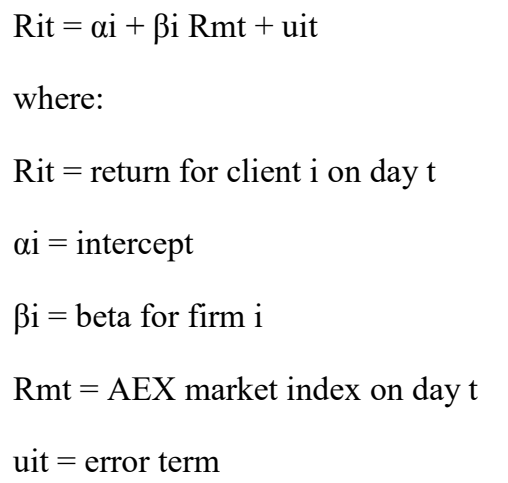

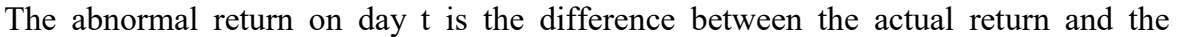

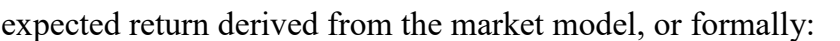

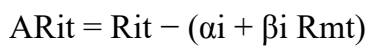

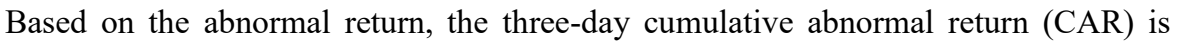

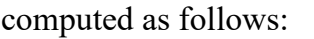

$$
C A R_{i t}=\sum_{t=-1}^{1} A R_{i t}
$$

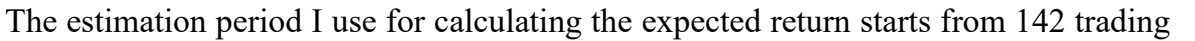

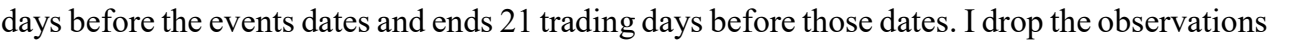

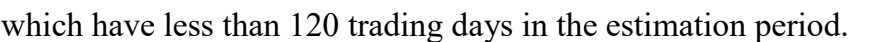

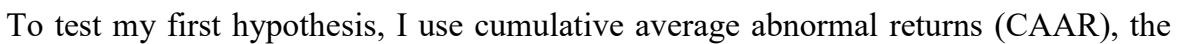

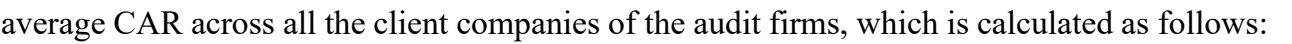

$$
C A A R=\frac{1}{n} \sum_{i=1}^{n} C A R_{i t} \square
$$

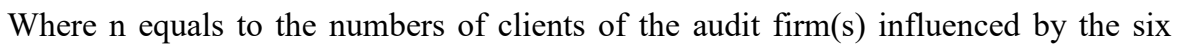

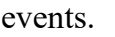

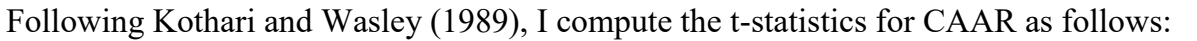


Market Reactions to Public Oversight: Evidence from the Netherlands $\square$

$$
\frac{C A A R}{S(C A A R) / \sqrt{n}} \square
$$

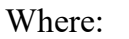

$$
S(C A A R)=\sqrt{\sum_{i=1}^{n}\left(C A R_{i t}-C A A R\right)^{2} /(n-1)}
$$

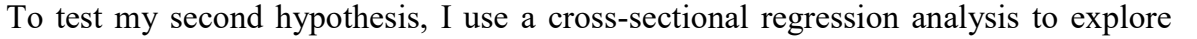

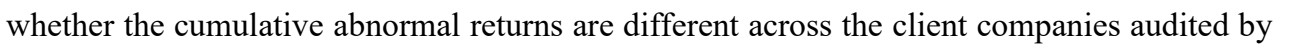

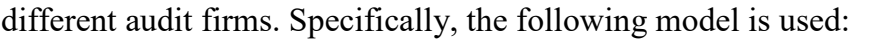

$$
\mathrm{CAR}_{\mathrm{it}}=\alpha+\beta 1 \mathrm{DT}_{\mathrm{it}}+\beta 2 \mathrm{EY}_{\mathrm{it}}+\beta 3 \mathrm{PWC}_{\mathrm{it}}+\beta 4 \mathrm{SIZE}_{\mathrm{it}}+\beta 5 \mathrm{LEV}_{\mathrm{it}}+\beta 6 \mathrm{GROWTH}_{\mathrm{it}}+\delta
$$

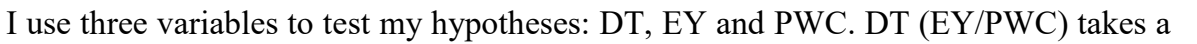

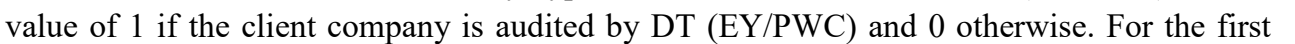
AFM inspection, as there is no information regarding individual audit firm's performa $\square \square \square \square$

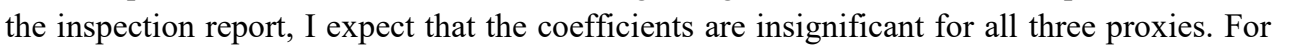

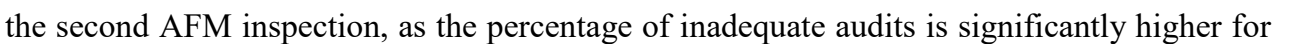

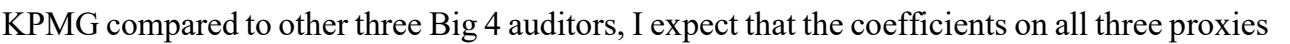

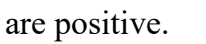

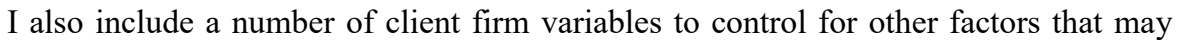
influence the market's reaction to the publication of the inspection reports. Klock (1994) argues

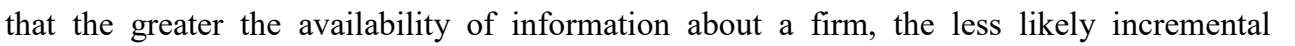

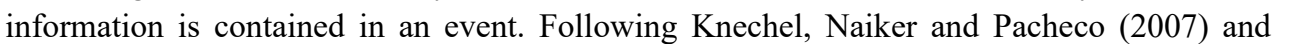

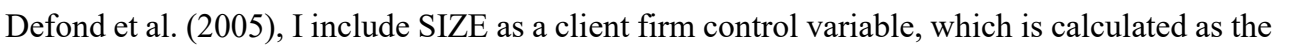

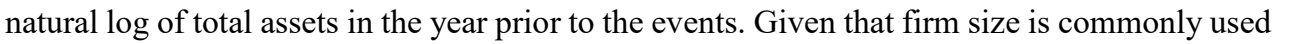

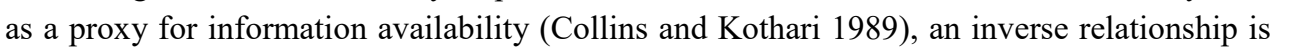

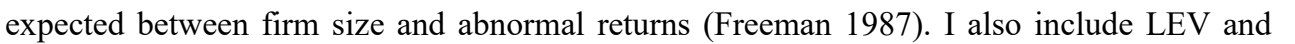

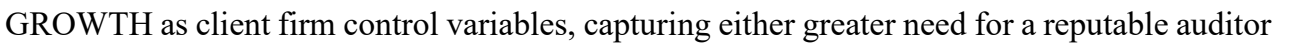
or increased risk of auditor litigation. LEV is the company's leverage ratio in the year before

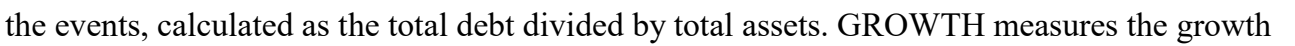

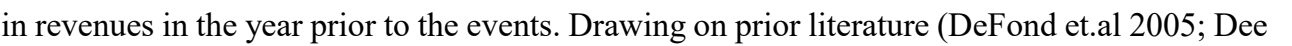

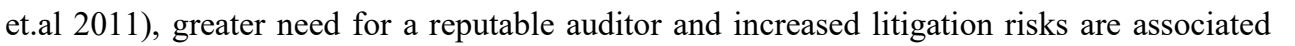

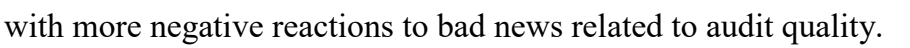




\subsection{Data, sample and results}

To explore investors' assessments of AFM inspection reports, I examine the cumulative

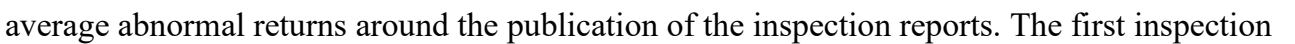

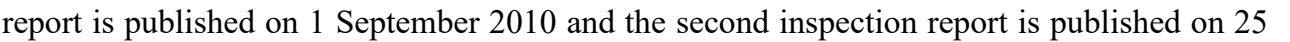

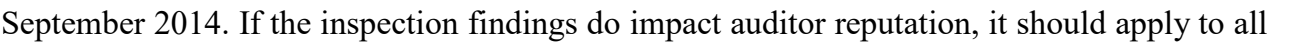

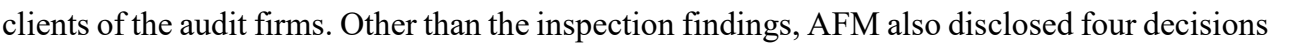

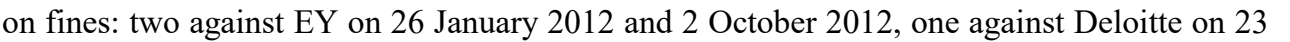

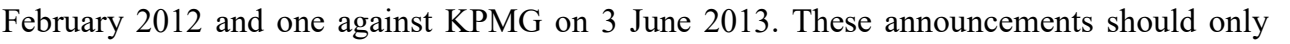
influence the punished audit firms' c

Table 4.1: Events dates and summaries

\begin{tabular}{ll}
\hline Event date $\square$ & Event summary $\square$ \\
\hline 1st September 2010 $\square$ & AFM disclosed its first inspection reports $\square$ \\
26th January 2012 $\square$ & AFM disclosed its fine against EY $\square$ \\
23th February 2012 $\square$ & AFM disclosed its fine against DT $\square$ \\
2nd October 2012 $\square$ & AFM disclosed another fine against EY $\square$ \\
3rd June 2013 $\square$ & AFM disclosed its fine against KPMG $\square$ \\
25th September 2014 $\square$ & AFM disclosed its second inspection reports $\square$
\end{tabular}

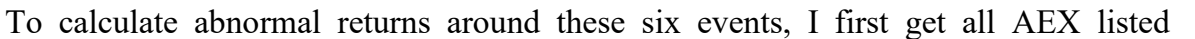
companies' daily returns and the AEX index from DataStream. Then I collect the auditor

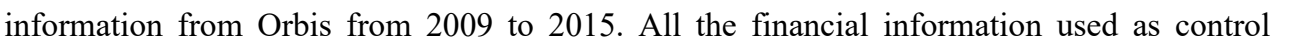

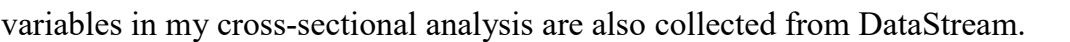

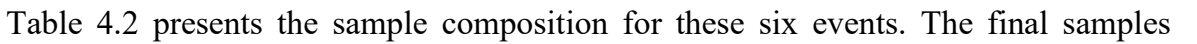
ए

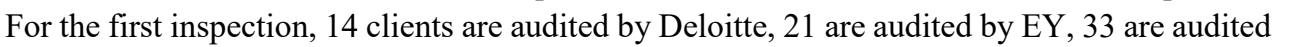

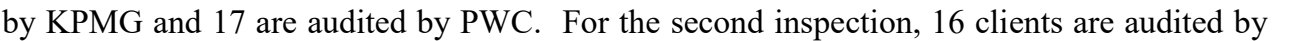

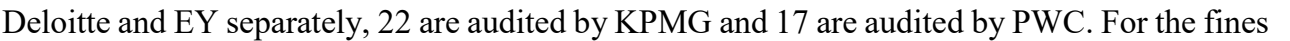

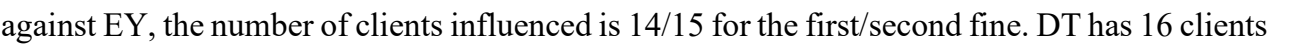

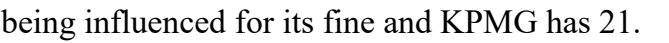

\begin{tabular}{|c|c|c|c|c|c|}
\hline Events $\square$ & Total $\square$ & DT $\square$ & $\mathrm{EY} \square$ & KPMG $\square$ & $\mathrm{PWC} \square$ \\
\hline First inspection $\square$ & $85 \square$ & $16 \square$ & $21 \square$ & $31 \square$ & $17 \square$ \\
\hline Second inspection $\square$ & $71 \square$ & $17 \square$ & $18 \square$ & $18 \square$ & $18 \square$ \\
\hline Fine 26th Jan $2012 \square$ & $--\square$ & $--\square$ & $14 \square$ & $--\square$ & $--\square$ \\
\hline Fine 23th Feb $2012 \square$ & $--\square$ & $16 \square$ & $--\square$ & $--\square$ & $--\square$ \\
\hline Fine 2 nd Oct2012 $\square$ & $--\square$ & $--\square$ & $15 \square$ & $--\square$ & $--\square$ \\
\hline Fine 3rd Jun 2013 $\square$ & $--\square$ & $--\square$ & $--\square$ & $21 \square$ & $--\square$ \\
\hline
\end{tabular}


Market Reactions to Public Oversight: Evidence from the Netherlands $\square$

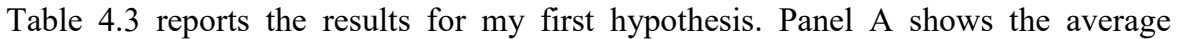

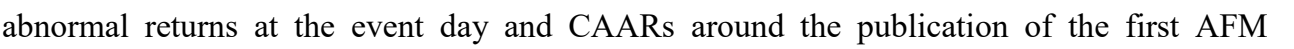

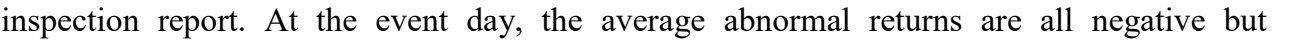

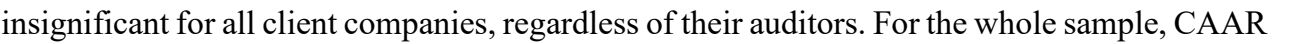

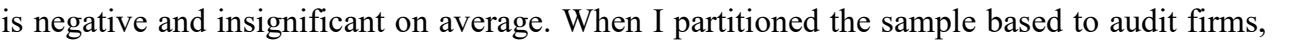

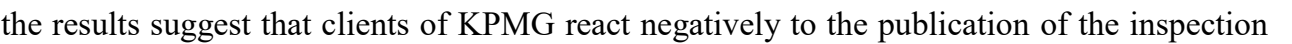

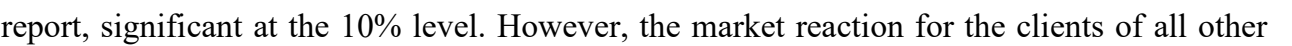

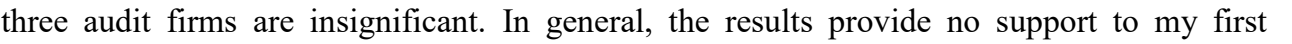

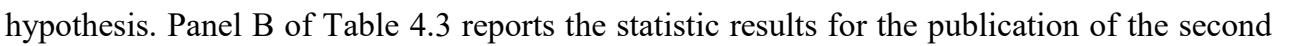

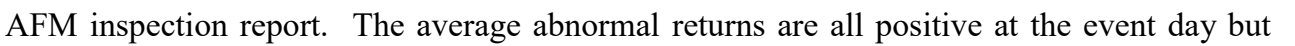
ए एम

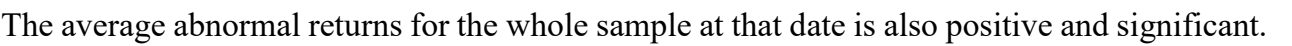

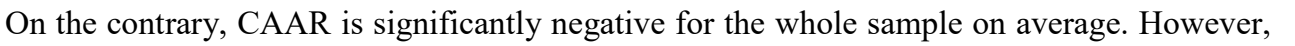

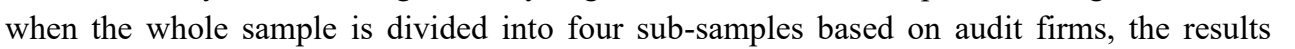

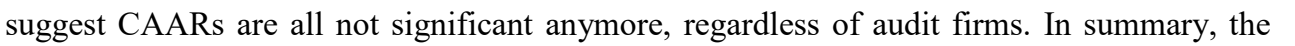

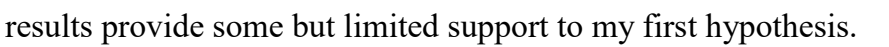

Table 4.3: CAARs for AFM inspections

\begin{tabular}{|c|c|c|c|c|c|}
\hline \multicolumn{6}{|c|}{ Panel A: First AFM inspection $\square$} \\
\hline Window $\square$ & Total $\square$ & $\mathrm{DT} \square$ & $\mathrm{EY} \square$ & KPMG $\square$ & $\mathrm{PWC} \square$ \\
\hline Event day $\square$ & $-0.0027 \square$ & $-0.0039 \square$ & $-0.0025 \square$ & $-0.0031 \square$ & $-0.0011 \square$ \\
\hline$[$ t-stat $] \square$ & $-1.18 \square$ & $-0.94 \square$ & $-0.51 \square$ & $-0.89 \square$ & $-0.17 \square$ \\
\hline CAAR $\square$ & $-0.0055 \square$ & $0.0049 \square$ & $-0.0098 \square$ & $-0.0088^{*} \square$ & $-0.0039 \square$ \\
\hline$[$ t-stat $] \square$ & $-1.26 \square$ & $0.45 \square$ & $-1.33 \square$ & $-1.97 \square$ & $-0.26 \square$ \\
\hline \multicolumn{6}{|c|}{ Panel B: Second AFM inspection $\square$} \\
\hline Window $\square$ & Total $\square$ & DT $\square$ & $\mathrm{EY} \square$ & KPMG $\square$ & $\mathrm{PWC} \square$ \\
\hline Event day $\square$ & $0.0057 * * * \square$ & $0.0040 \square$ & $0.0061 \square$ & $0.0038 * \square$ & $0.0088 * \square$ \\
\hline$[$ t-stat $] \square$ & $2.85 \square$ & $1.40 \square$ & $1.03 \square$ & $1.85 \square$ & $2.11 \square$ \\
\hline CAAR $\square$ & $-0.0061 \square$ & $-0.0047 \square$ & $-0.0051 \square$ & $-0.0044 \square$ & $-0.0010 \square$ \\
\hline$[$ t-stat $] \square$ & $-1.73 * \square$ & $-0.72 \square$ & $-0.59 \square$ & $-0.93 \square$ & $-1.25 \square$ \\
\hline
\end{tabular}

Robust t-statistics in parentheses, ${ }^{* * *} \mathrm{p}<0.01,{ }^{* *} \mathrm{p}<0.05,{ }^{*} \mathrm{p}<0.1 \square$

$\square$

$\square \square \Pi \|$. presents the market reactions to the AFM's announcement of fine decisions.

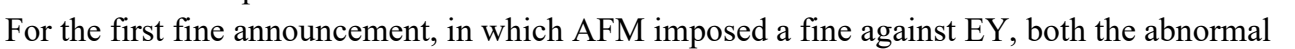

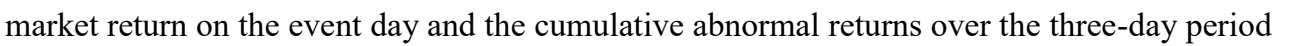

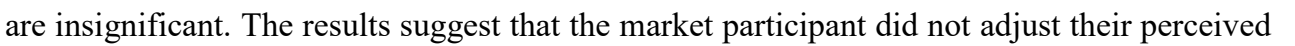

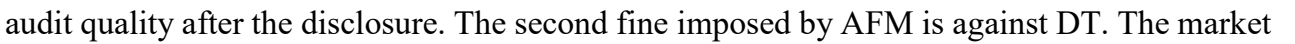

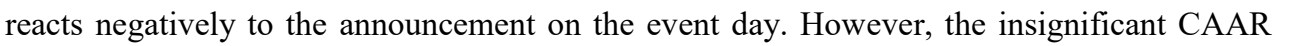

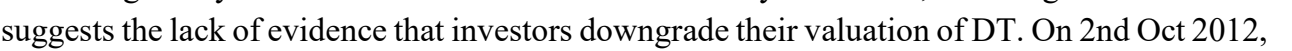




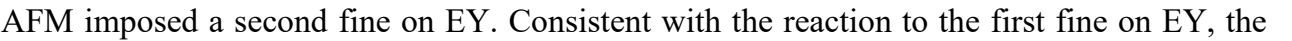

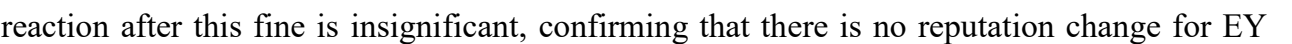

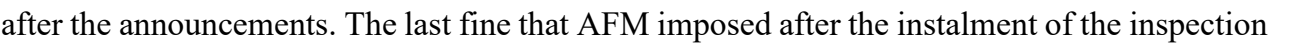

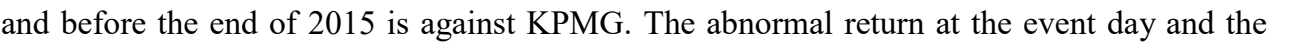

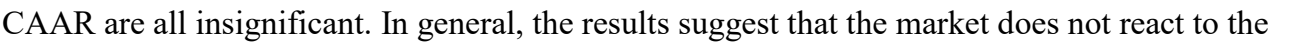
AFM's announcements of fine decisions against the audit firms. In other word, the valuation

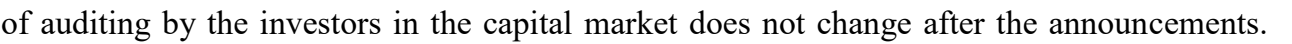

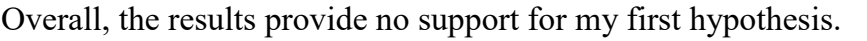

$\square$

\begin{tabular}{lcccc}
\hline \multicolumn{5}{c}{ Table 4.4: CAARs for AFM fines } \\
\hline Events $\square$ & Event day $\square$ & [t-stat] $\square$ & CAAR $\square$ & {$[$ t-stat] $\square$} \\
\hline 26th Jan 2012 against EY $\square$ & $-0.0043 \square$ & $-0.39 \square$ & $0.0178 \square$ & $1.52 \square$ \\
23th Feb 2012 against DT $\square$ & $-0.0150^{* * *} \square$ & $-2.99 \square$ & $-0.0034 \square$ & $-0.33 \square$ \\
2nd Oct2012 against EY $\square$ & $-0.0082 \square$ & $-1.69 \square$ & $-0.0449 \square$ & $-1.46 \square$ \\
3rd Jun 2013 against KPMG $\square$ & $-0.0010 \square$ & $-0.25 \square$ & $-0.0048 \square$ & $-0.73 \square$ \\
\hline
\end{tabular}

Robust t-statistics in parentheses, ${ }^{* * *} \mathrm{p}<0.01,{ }^{* *} \mathrm{p}<0.05,{ }^{*} \mathrm{p}<0.1 \square$

$\square$

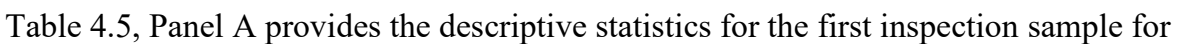

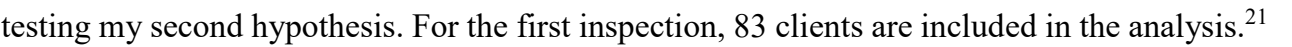

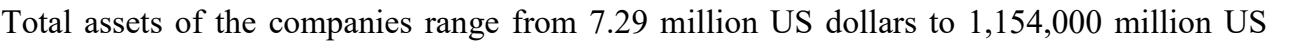

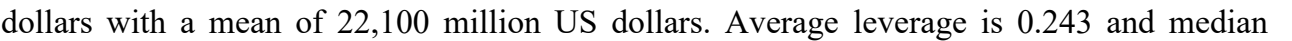

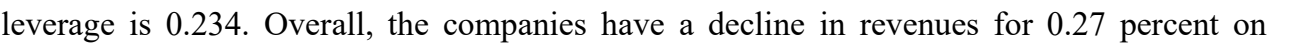

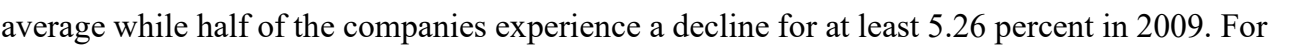

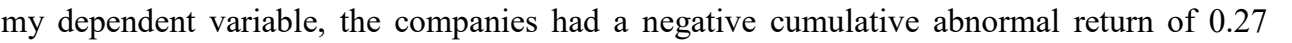

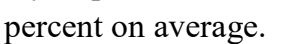

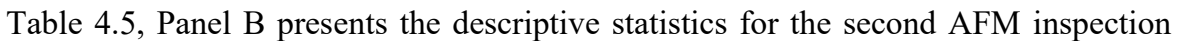

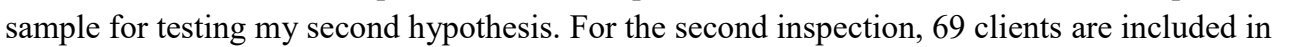

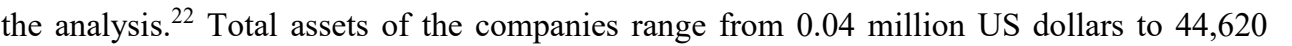

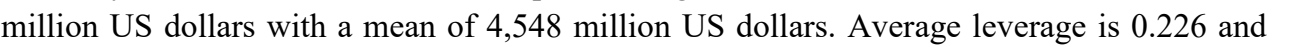

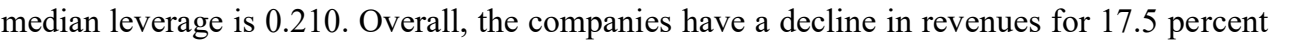

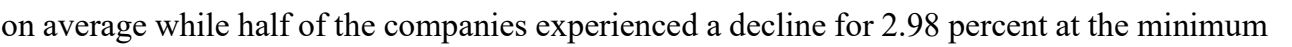

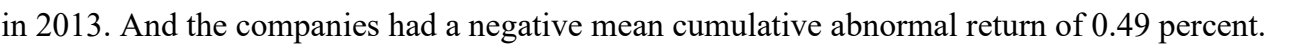

$\square$

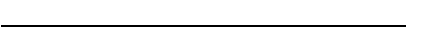

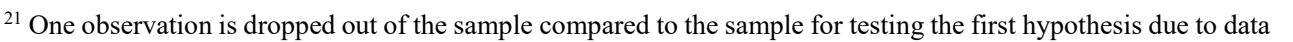

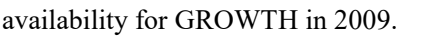

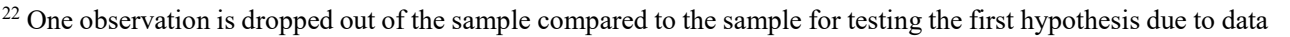

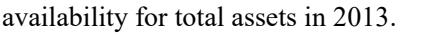


Market Reactions to Public Oversight: Evidence from the Netherlands

Table 4.5: Descriptive statistics for cross-section analysis

\begin{tabular}{|c|c|c|c|c|c|c|}
\hline \multicolumn{7}{|c|}{ Panel A: First AFM inspection $\square$} \\
\hline VARIABLES $\square$ & $\mathrm{N} \square$ & mean $\square$ & $\mathrm{p} 50 \square$ & $\mathrm{sd} \square$ & $\min \square$ & $\max \square$ \\
\hline SIZE $\square$ & $84 \square$ & $2.210 \mathrm{e}+07 \square$ & $924,598 \square$ & $1.298 \mathrm{e}+08 \square$ & $7,296 \square$ & $1.154 \mathrm{e}+09 \square$ \\
\hline LEV $\square$ & $84 \square$ & $0.243 \square$ & $0.234 \square$ & $0.158 \square$ & $0 \square$ & $0.854 \square$ \\
\hline GROWTH $\square$ & $84 \square$ & $-0.277 \square$ & $-5.26 \square$ & $52.1 \square$ & $-56.2 \square$ & $423.7 \square$ \\
\hline $\mathrm{CAR} \square$ & $84 \square$ & $-0.00272 \square$ & $-0.00352 \square$ & $0.0313 \square$ & $-0.103 \square$ & $0.0982 \square$ \\
\hline \multicolumn{7}{|c|}{ Panel B: Second AFM inspection $\square$} \\
\hline $\mathrm{SIZE} \square$ & $69 \square$ & $4.548 \mathrm{e}+06 \square$ & $1.006 \mathrm{e}+06 \square$ & $8.708 \mathrm{e}+06 \square$ & $40 \square$ & $4.462 \mathrm{e}+07 \square$ \\
\hline $\mathrm{LEV} \square$ & $69 \square$ & $0.226 \square$ & $0.210 \square$ & $0.156 \square$ & $0 \square$ & $0.597 \square$ \\
\hline GROWTH $\square$ & $69 \square$ & $-17.5 \square$ & $-2.98 \square$ & $90.9 \square$ & $-741.9 \square$ & $26.1 \square$ \\
\hline CAR $\square$ & $69 \square$ & $-0.00491 \square$ & $-0.00277 \square$ & $0.0281 \square$ & $-0.116 \square$ & $0.0703 \square$ \\
\hline
\end{tabular}

SIZE is calculated as the natural $\log$ of total assets in the year prior to the events. $L E V$ is the company's leverage ratio in the year before the events, calculated as the total debt divided by total assets. GROWTH measures the growth in revenues in the year prior to the events. $C A R$ is the cumulative abnormal returns over a three-day event window, beginning the day before the announcement through the day after.

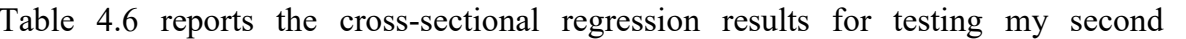

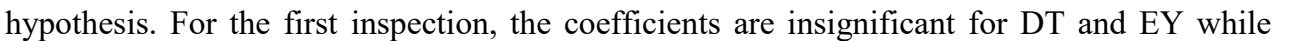

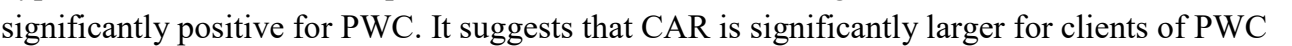

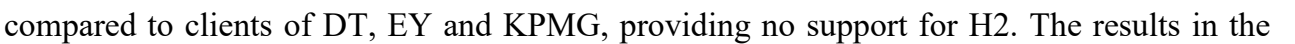

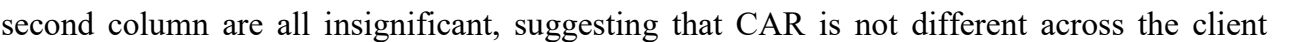

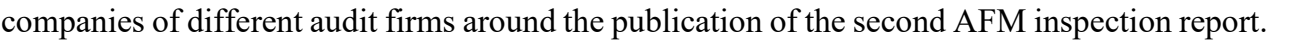

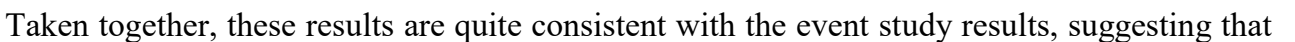
the capital market participants do not take the information provided in AFM's inspection

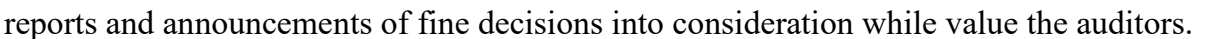


Table 4.6: Regression results for $\mathrm{H} 2$

\begin{tabular}{|c|c|c|}
\hline VARIABLES $\square$ & First inspection $\square$ & Second inspection $\square$ \\
\hline $\mathrm{DT} \square$ & $0.013 \square$ & $0.003 \square$ \\
\hline$\square$ & $(1.054) \square$ & $(0.366) \square$ \\
\hline $\mathrm{EY} \square$ & $-0.001 \square$ & $-0.002 \square$ \\
\hline$\square$ & $(-0.134) \square$ & $(-0.198) \square$ \\
\hline $\mathrm{PWC} \square$ & $0.018 * * \square$ & $-0.007 \square$ \\
\hline$\square$ & $(2.447) \square$ & $(-0.723) \square$ \\
\hline $\log (\mathrm{SIZE}) \square$ & $-0.000 \square$ & $0.000 \square$ \\
\hline$\square$ & $(-0.207) \square$ & $(0.026) \square$ \\
\hline LEV $\square$ & $0.026 \square$ & $-0.027 \square$ \\
\hline$\square$ & $(1.093) \square$ & $(-0.808) \square$ \\
\hline GROWTH $\square$ & $0.002 \square$ & $-0.001 \square$ \\
\hline$\square$ & $(0.381) \square$ & $(-0.688) \square$ \\
\hline Constant $\square$ & $-0.010 \square$ & $0.002 \square$ \\
\hline$\square$ & $(-0.534) \square$ & $(0.113) \square$ \\
\hline Observations $\square$ & $84 \square$ & $69 \square$ \\
\hline R-squared $\square$ & $0.092 \square$ & $0.041 \square$ \\
\hline R2 adjusted $\square$ & $0.0208 \square$ & $-0.0520 \square$ \\
\hline
\end{tabular}

Robust t-statistics in parentheses, $* * * \mathrm{p}<0.01, * * \mathrm{p}<0.05, * \mathrm{p}<0.1$

DT equals to 1 for companies audited by DT, 0 otherwise. EY equals to 1 for companies audited by EY, 0 otherwise. PWC equals 1 for companies audited by PWC, 0 otherwise. SIZE is calculated as the natural log of total assets in the year prior to the events. $L E V$ is the company's leverage ratio in the year before the events, calculated as the total debt divided by total assets. GROWTH measures the growth in revenues in the year prior to the events. The dependent variable $C A R$ is the cumulative abnormal returns over a three-day event window, beginning the day before the announcement through the day after for each client company. $\square$

\subsection{Additional analyses}

\subsubsection{Market reactions to $\mathrm{PCAOB}$ inspection reports}

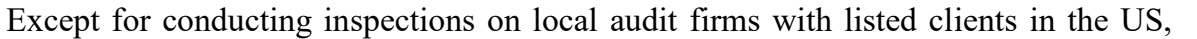

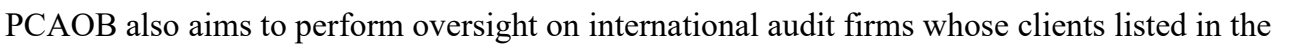

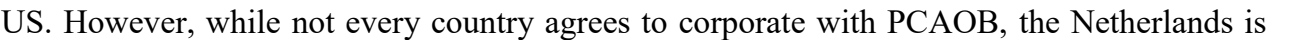

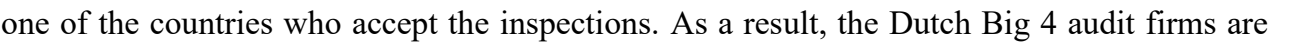

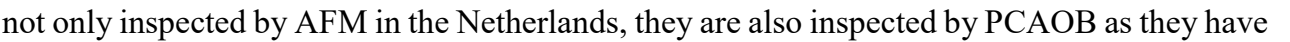

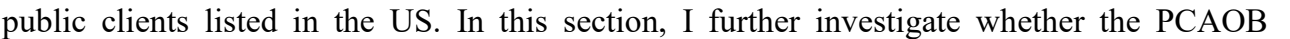

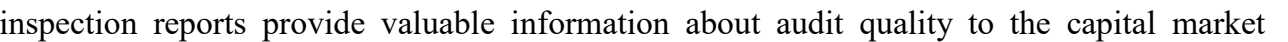

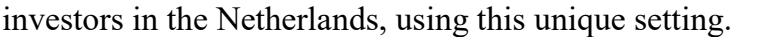


Market Reactions to Public Oversight: Evidence from the Netherlands $\square$

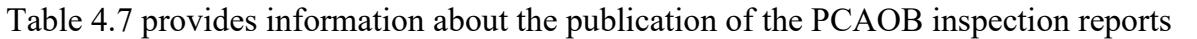

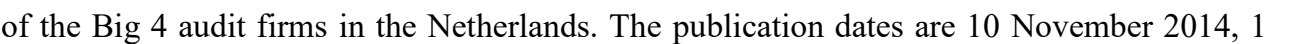

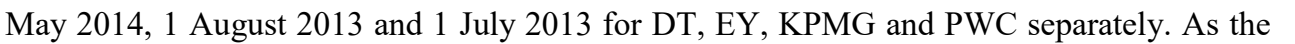

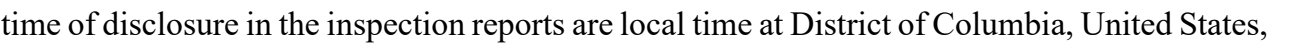

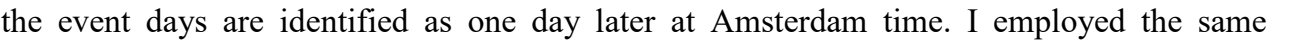

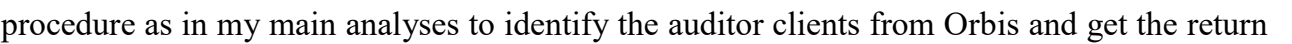

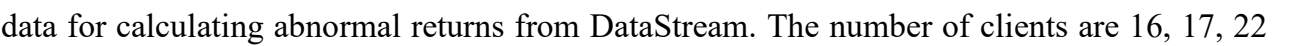

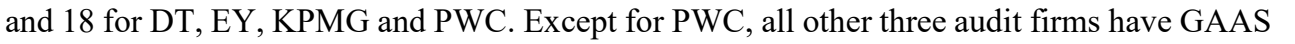

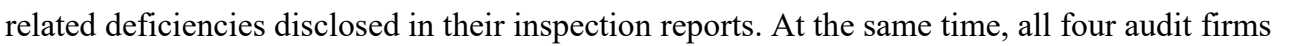

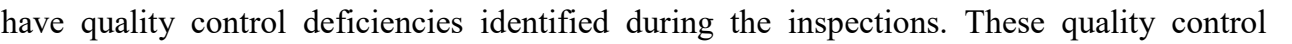

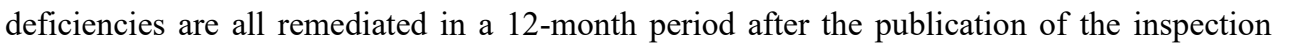

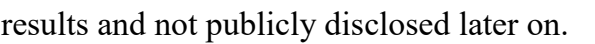

\begin{tabular}{lccccc}
\hline \multicolumn{5}{c}{ Table 4.7: PCAOB inspection information } \\
\hline Events $\square$ & Publication date US $\square$ & Event date $\square$ & Number of clients $\square$ & GAAS $\square$ & QCI $\square$ \\
\hline DT $\square$ & 10th Nov 2014 $\square$ & 11th Nov 2014 $\square$ & $16 \square$ & $1 \square$ & $1 \square$ \\
EY $\square$ & 1st May 2014 $\square$ & 2nd May 2014 $\square$ & $17 \square$ & $1 \square$ & $1 \square$ \\
KPMG $\square$ & 1st Aug 2013 $\square$ & 2nd Aug 2013 $\square$ & $22 \square$ & $1 \square$ & $1 \square$ \\
PWC $\square$ & 1st Jul 2013 $\square$ & 2nd Jul 2013 $\square$ & $18 \square$ & $0 \square$ & $1 \square$ \\
\hline$\square$ & $\square$
\end{tabular}

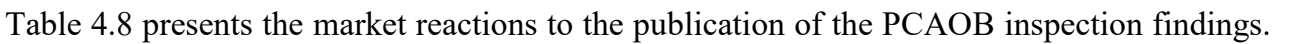

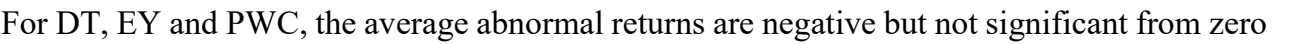

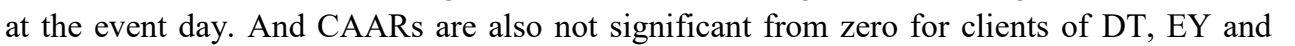
PWC. However, the market reacts positively to KPMG's inspection results, based on both the

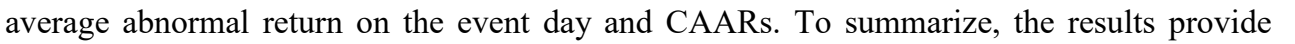

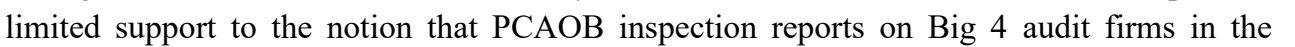

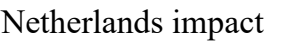

\begin{tabular}{lcccc}
\hline \multicolumn{5}{c}{ Table 4.8: CAAR for PCAOB inspections } \\
\hline Auditor $\square$ & Event day $\square$ & {$[$ t-stat $] \square$} & CAAR $\square$ & {$[$ t-stat $] \square$} \\
\hline DT $\square$ & $-0.0010 \square$ & $-0.33 \square$ & $0.0083 \square$ & $1.24 \square$ \\
EY $\square$ & $-0.0026 \square$ & $-0.35 \square$ & $-0.0016 \square$ & $-0.19 \square$ \\
KPMG $\square$ & $0.0145^{* *} \square$ & $2.26 \square$ & $0.0158^{* * *} \square$ & $2.92 \square$ \\
PWC $\square$ & $-0.0033 \square$ & $-0.50 \square$ & $0.0086 \square$ & $1.40 \square$ \\
\hline
\end{tabular}

Robust t-statistics in parentheses, ${ }^{* * *} \mathrm{p}<0.01,{ }^{* *} \mathrm{p}<0.05,{ }^{*} \mathrm{p}<0.1 \square$

$\square$ 


\subsubsection{Cost of debt analyses}

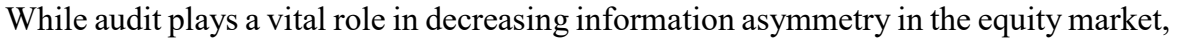

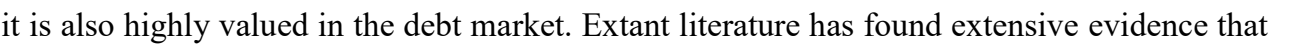

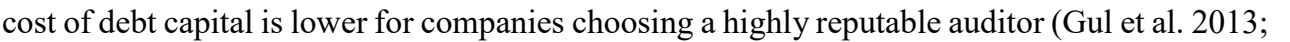

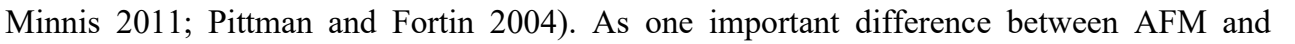

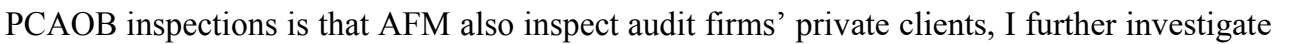

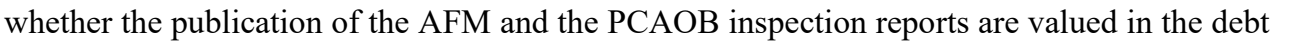

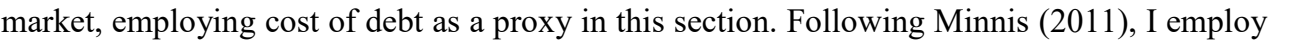

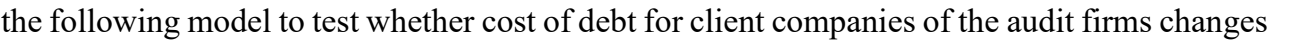

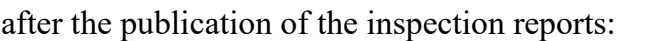

Cost of debt $\mathrm{i}_{\mathrm{it}+1}=\beta_{0}+\beta_{1}{ }^{*}$ Post $_{\mathrm{i}, \mathrm{t}+1}+\beta_{2}{ }^{*}$ InterestCoverage $\mathrm{i}, \mathrm{t}+\beta_{3}{ }^{*}$ CurrentRatio $_{\mathrm{i}, \mathrm{t}}+\beta_{4}{ }^{*} \mathrm{PPE}_{\mathrm{i}, \mathrm{t}}+$ $\beta 5_{5} \mathrm{LEV}_{\mathrm{i}, \mathrm{t}}+\beta_{6} * \operatorname{Ln}(\text { ASSETS })_{\mathrm{i} . \mathrm{t}}+\beta_{7} * \mathrm{GROWTH}_{\mathrm{i}, \mathrm{t}+1}+\beta_{8} * \mathrm{NegEquity}_{\mathrm{i}, \mathrm{t}}$ + Year fixed effects + Industry fixed effects $+\delta(3.2)$

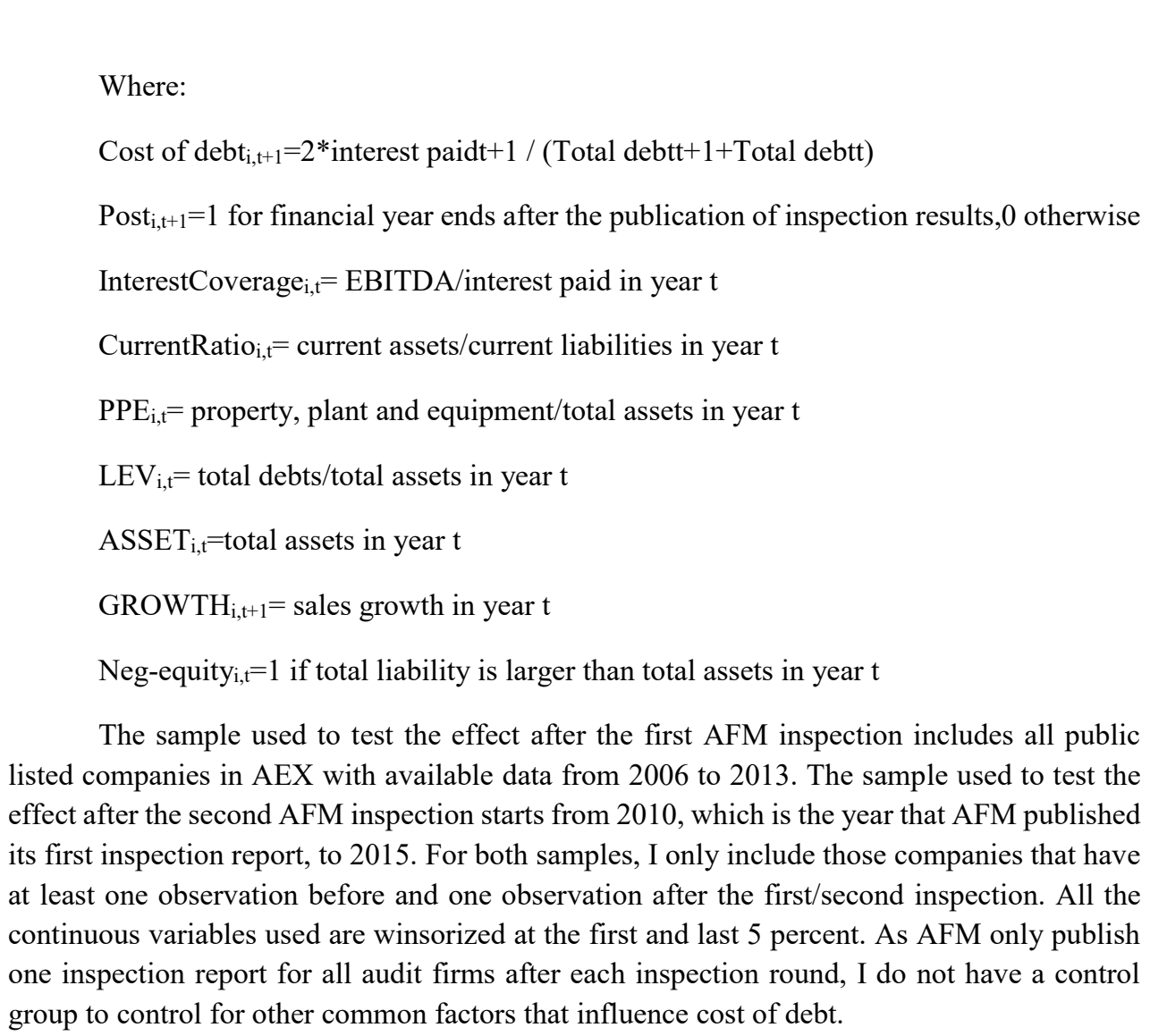

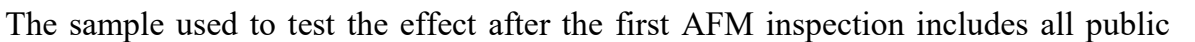

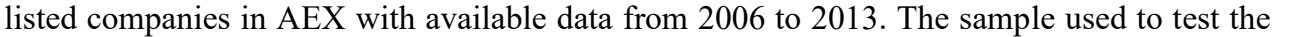

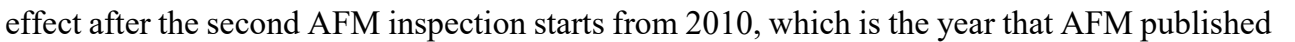
प

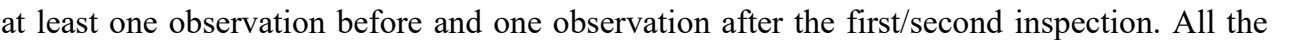

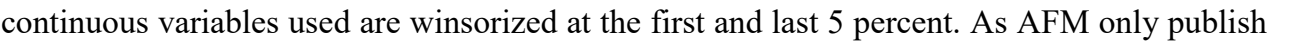

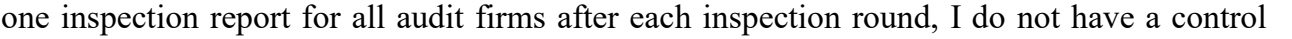

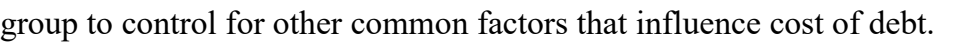


Market Reactions to Public Oversight: Evidence from the Netherlands $\square$

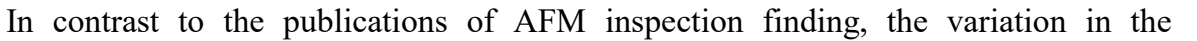

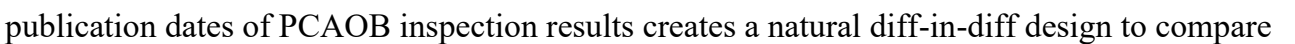
पा

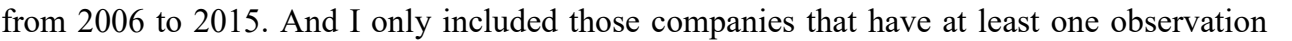

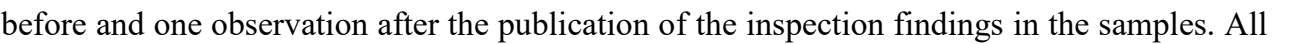

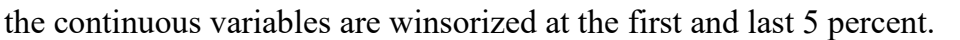

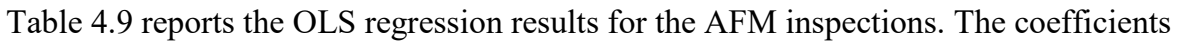

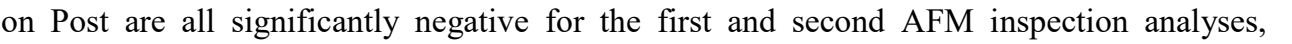

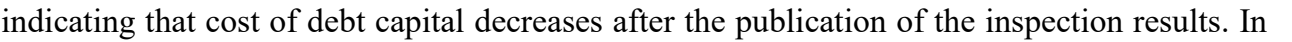

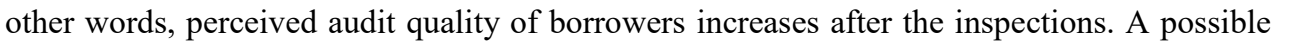

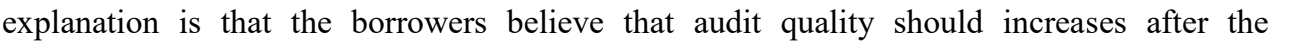
inspections, consistent with the AFM's mission to improve capital market participants'

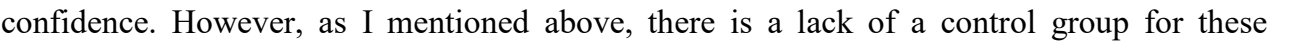

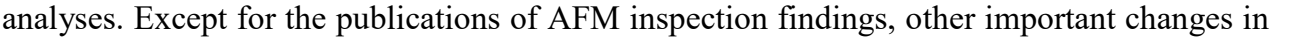
the audit market also happened during this period, including the disclosure of the audit firms' ए

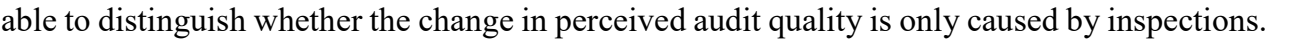

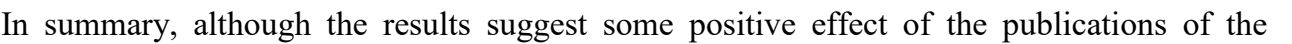

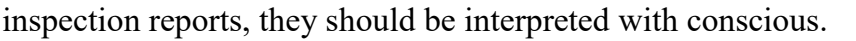

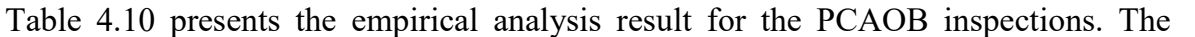

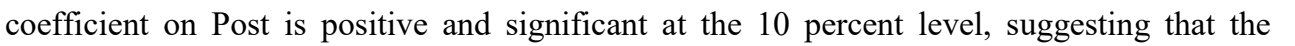
publication of PCAOB inspection reports do have spillover effect in the Netherlands' debt

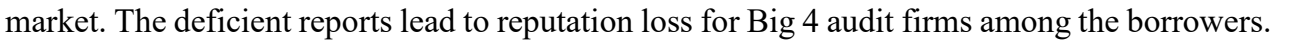

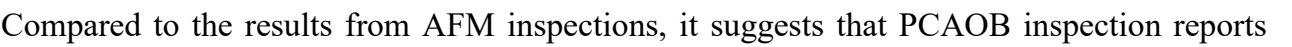

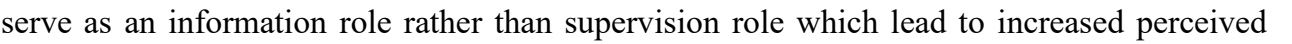

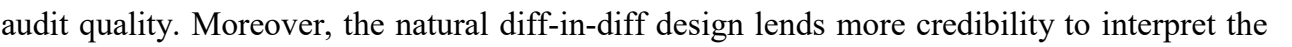

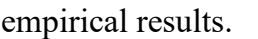

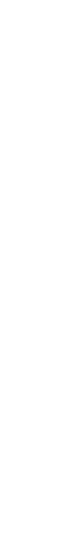


Table 4.9: Cost of Debt analysis AFM inspections

\begin{tabular}{|c|c|c|}
\hline VARIABLES $\square$ & First inspection $\square$ & Second inspection $\square$ \\
\hline Post $\square$ & $-0.0143 * * \square$ & $-0.0129 * \square$ \\
\hline$\square$ & $(-2.177) \square$ & $(-1.861) \square$ \\
\hline Interest coverage $\square$ & $0.000146 \square$ & $-0.000249 \square$ \\
\hline$\square$ & $(0.814) \square$ & $(-1.238) \square$ \\
\hline Current ratio $\square$ & $-0.00267 \square$ & $-0.0117 * * \square$ \\
\hline$\square$ & $(-0.487) \square$ & $(-2.256) \square$ \\
\hline PPE $\square$ & $-0.0472 * * * \square$ & $0.0235 \square$ \\
\hline$\square$ & $(-2.841) \square$ & $(1.232) \square$ \\
\hline LEV $\square$ & $-0.0650 * * \square$ & $-0.170 * * * \square$ \\
\hline$\square$ & $(-2.015) \square$ & $(-5.389) \square$ \\
\hline $\log ($ ASSET $) \square$ & $-0.00474 * * * \square$ & $-0.00153 \square$ \\
\hline$\square$ & $(-2.704) \square$ & $(-0.975) \square$ \\
\hline GROWTH $\square$ & $0.0364 * \square$ & $-0.00834 \square$ \\
\hline$\square$ & $(1.904) \square$ & $(-0.437) \square$ \\
\hline Neg-equity $\square$ & $0.0759 * * * \square$ & $0.0458 * * * \square$ \\
\hline$\square$ & $(3.434) \square$ & $(2.896) \square$ \\
\hline Constant $\square$ & $0.170 * * * \square$ & $0.136 * * * \square$ \\
\hline$\square$ & $(7.562) \square$ & $(4.704) \square$ \\
\hline Observations $\square$ & $324 \square$ & $285 \square$ \\
\hline R-squared $\square$ & $0.325 \square$ & $0.312 \square$ \\
\hline Fixed effects $\square$ & Year/industry $\square$ & Year/industry $\square$ \\
\hline R2 adjusted $\square$ & $0.281 \square$ & $0.259 \square$ \\
\hline
\end{tabular}

Robust t-statistics in parentheses, ${ }^{* * *} \mathrm{p}<0.01,{ }^{* *} \mathrm{p}<0.05,{ }^{*} \mathrm{p}<0.1 \square$

Cost of debt in year $\mathrm{t}+1$ equals to the interest paid in year $\mathrm{t}+1$ divided by the average total debt in year $\mathrm{t}$ and year $\mathrm{t}+1$; Post equals 1 for financial year ends after the publication of inspection results, 0 otherwise; Interest coverage is calculated as the earnings before tax, depreciation and amortization divided by interest paid. Current ratio equals to current asset divided by current liabilities; $P P E$ is the percentage of property, plant and equipment out of total assets; Growth is the increases in sales. Neg-equity equals to 1 if total liability is larger than total assets, 0 otherwise. 
Table 4.10: Cost of Debt analysis PCAOB inspections

\begin{tabular}{|c|c|}
\hline VARIABLES $\square$ & PCAOB inspection $\square$ \\
\hline Post $\square$ & $0.0130 * \square$ \\
\hline$\square$ & $(1.657) \square$ \\
\hline Interest coverage $\square$ & $-0.000279 * * \square$ \\
\hline$\square$ & $(-2.023) \square$ \\
\hline Current ratio $\square$ & $-0.00476 \square$ \\
\hline$\square$ & $(-1.122) \square$ \\
\hline PPE $\square$ & $-0.0199 * \square$ \\
\hline$\square$ & $(-1.690) \square$ \\
\hline LEV $\square$ & $-0.0956 * * * \square$ \\
\hline$\square$ & $(-4.166) \square$ \\
\hline $\log ($ ASSET $) \square$ & $-0.00134 \square$ \\
\hline$\square$ & $(-1.149) \square$ \\
\hline GROWTH $\square$ & $0.00709 \square$ \\
\hline$\square$ & $(0.502) \square$ \\
\hline Neg-equity $\square$ & $0.0383 * * * \square$ \\
\hline$\square$ & $(3.856) \square$ \\
\hline Constant $\square$ & $0.128 * * * \square$ \\
\hline$\square$ & $(5.981) \square$ \\
\hline Observations $\square$ & $396 \square$ \\
\hline R-squared $\square$ & $0.239 \square$ \\
\hline Fixed effects $\square$ & Year/industry $\square$ \\
\hline R2 adjusted $\square$ & $0.191 \square$ \\
\hline
\end{tabular}

Robust t-statistics in parentheses, *** $\mathrm{p}<0.01, * * \mathrm{p}<0.05, * \mathrm{p}<0.1$

Cost of debt in year $\mathrm{t}+1$ equals to the interest paid in year $\mathrm{t}+1$ divided by the average total debt in year $\mathrm{t}$ and year $\mathrm{t}+1$; Post equals 1 for financial year ends after the publication of inspection results, 0 otherwise; Interest coverage is calculated as the earnings before tax, depreciation and amortization divided by interest paid. Current ratio equals to current asset divided by current liabilities; $P P E$ is the percentage of property, plant and equipment out of total assets; Growth is the increases in sales. Neg-equity equals to 1 if total liability is larger than total assets, 0 otherwise. 


\subsection{Conclusion}

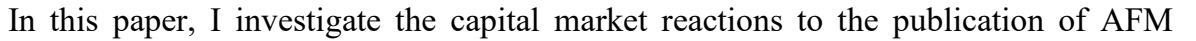
ए ए

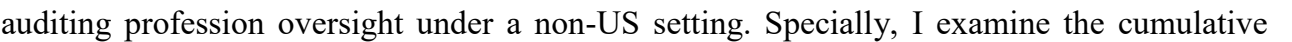

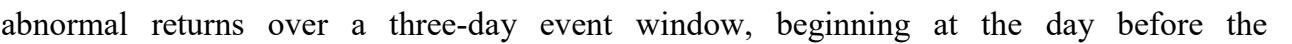

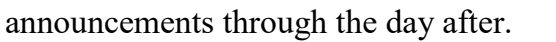

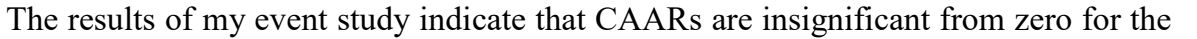

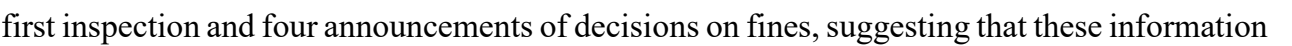
does not change investors' perception of audit quality. For the second inspection, on average,

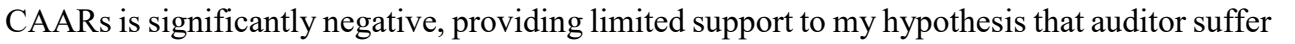

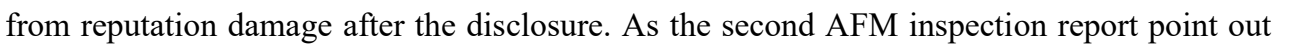

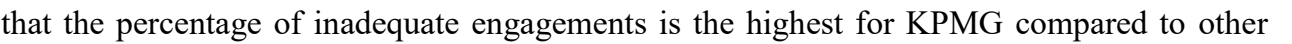

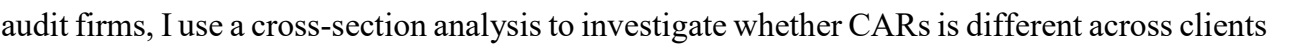

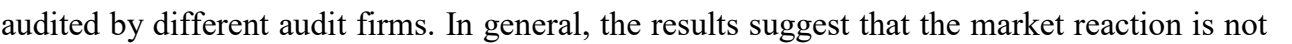

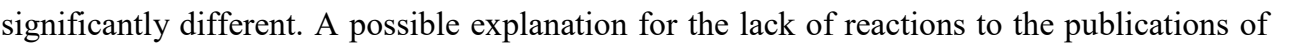
ए ए

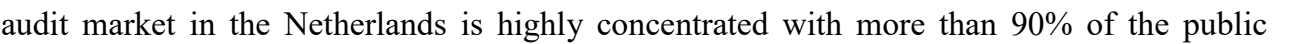

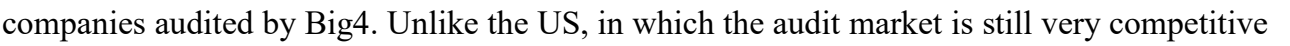

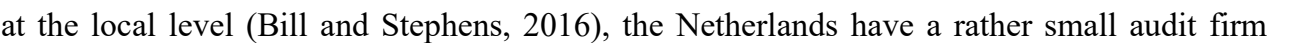

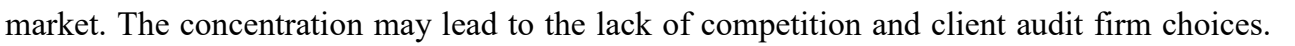

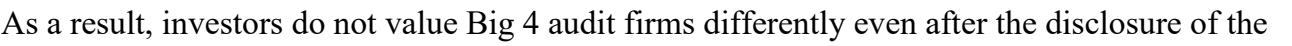

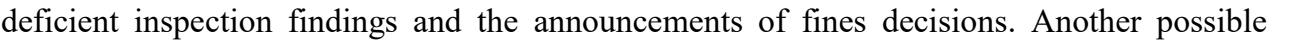

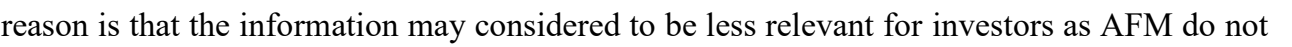

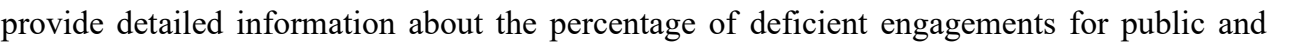

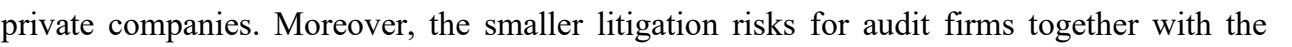

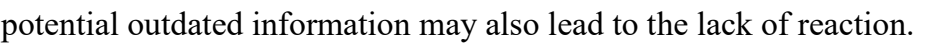

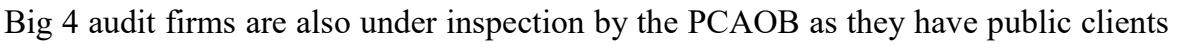

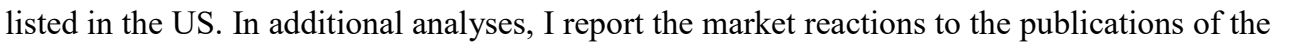

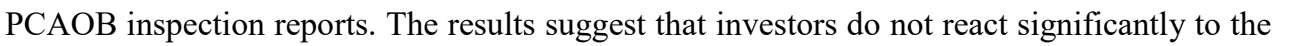

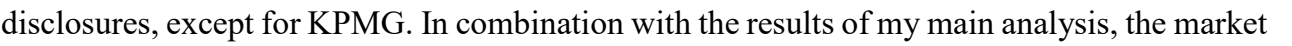

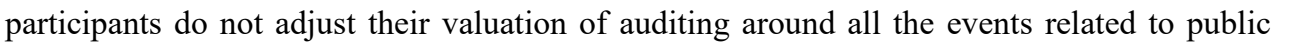

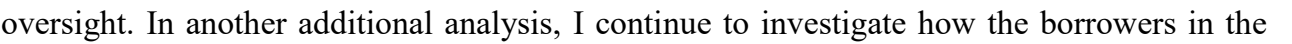

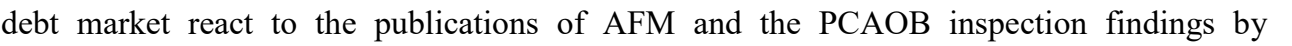

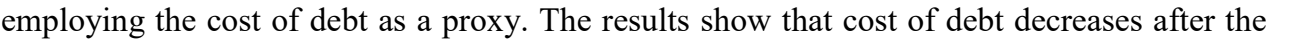

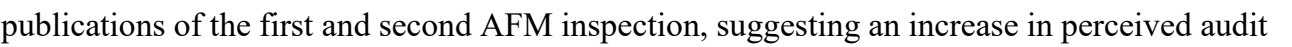

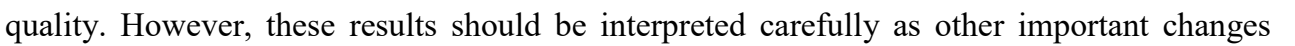

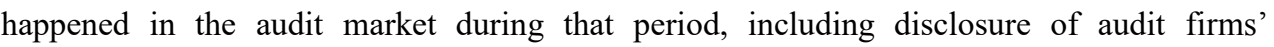

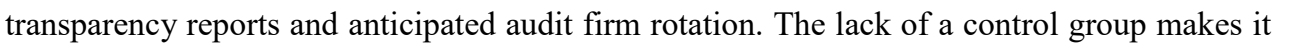

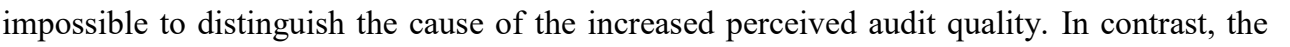

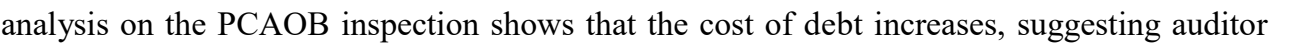


Market Reactions to Public Oversight: Evidence from the Netherlands

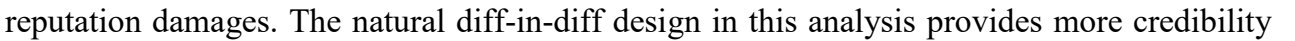

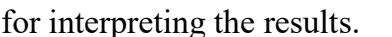

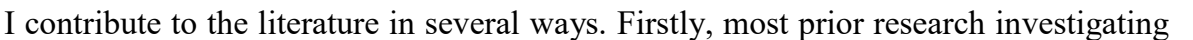

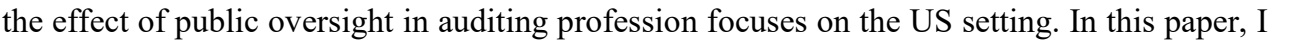

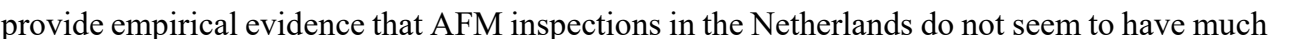

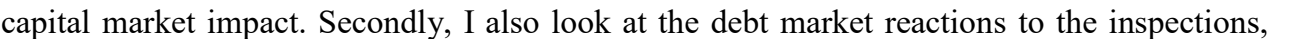

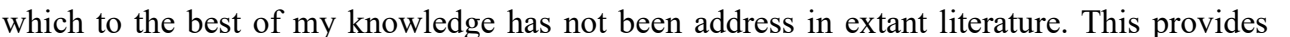
some guidance for practice since debt serves an ultimate important role in companies' financing

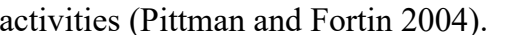

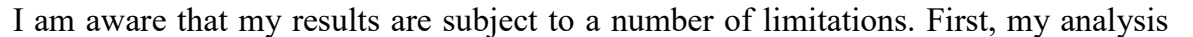

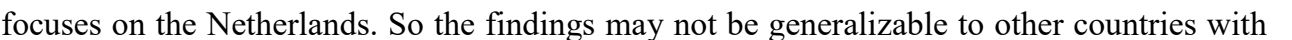

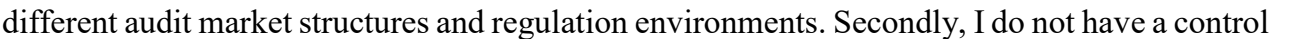

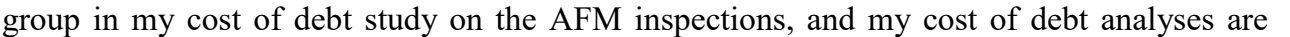

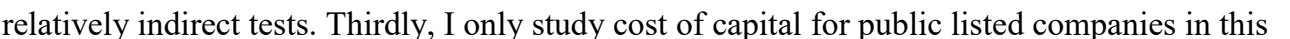

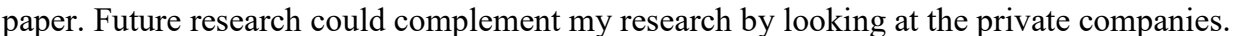



Chapter 5: Conclusion 


\subsection{Summary}

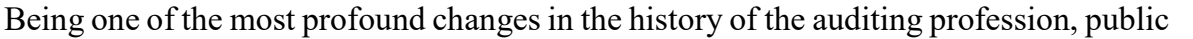

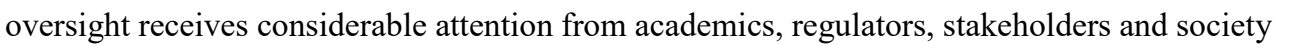

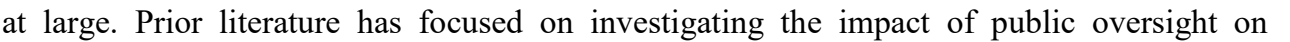

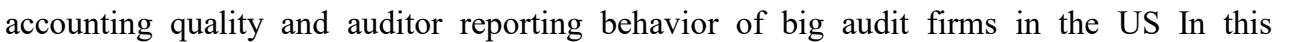

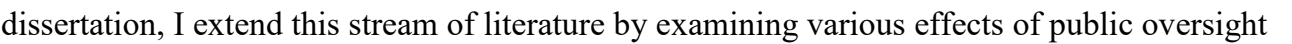

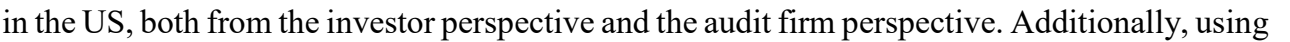

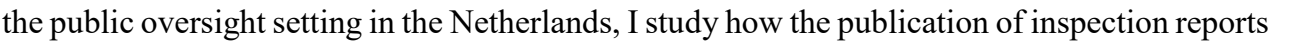

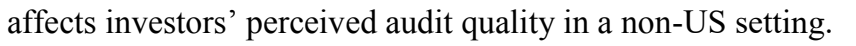

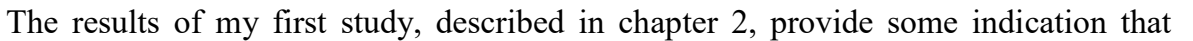
ए

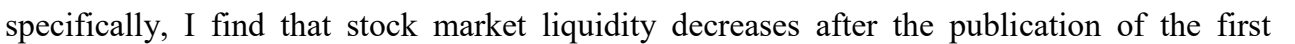

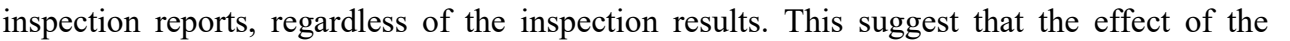

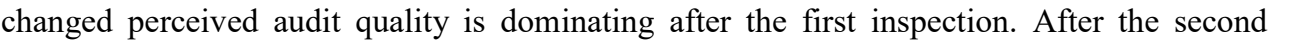

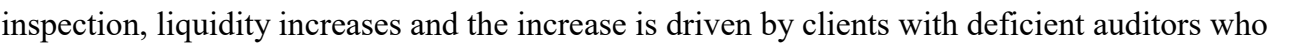

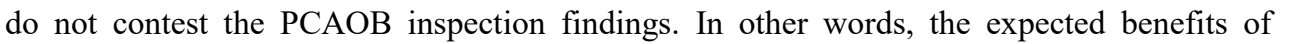

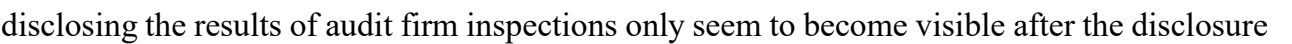

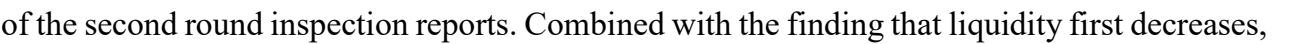

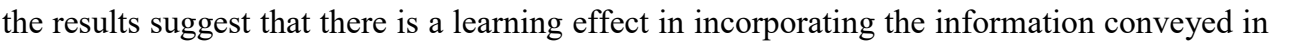

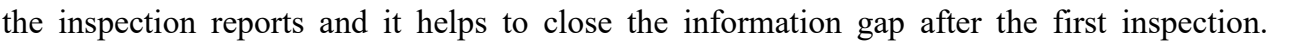

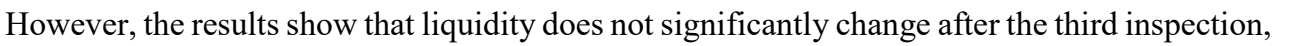

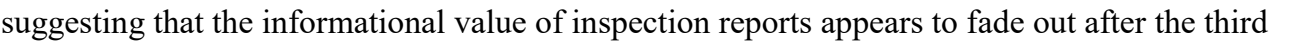

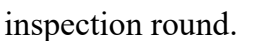

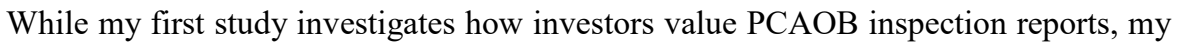

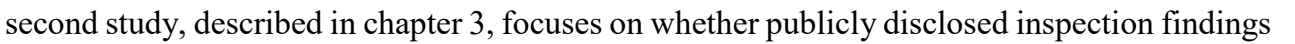

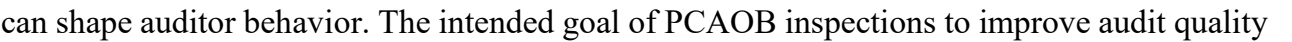

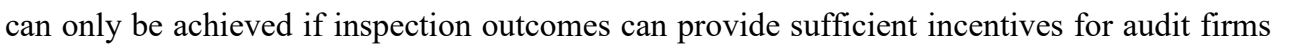

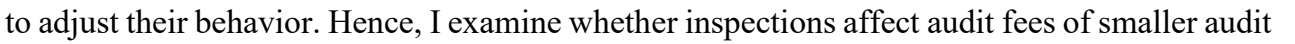

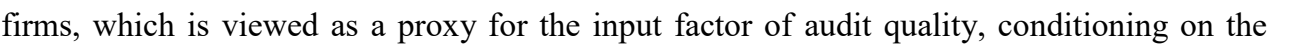

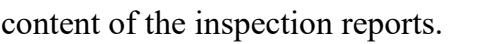

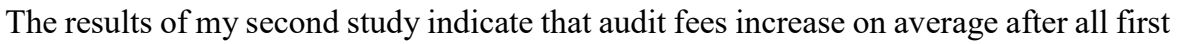

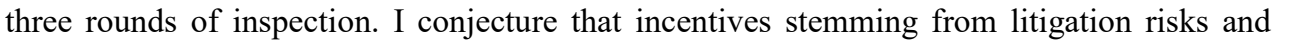

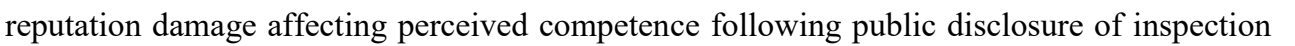

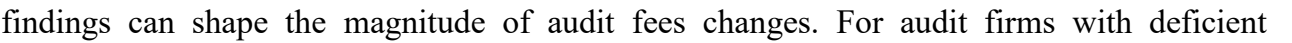
ए

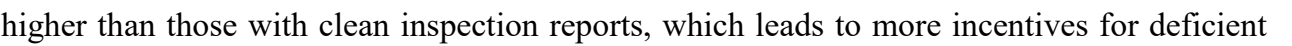

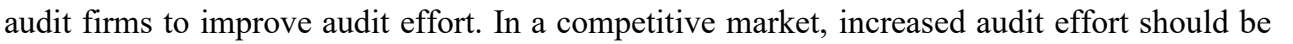
reflected in audit fees. At the same time, deficient audit firms' ability to raise their fees are

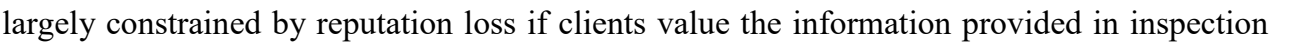

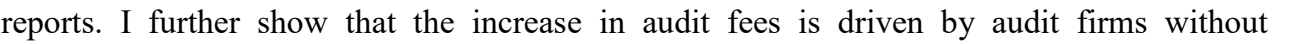

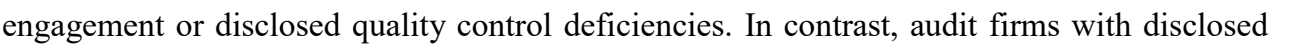




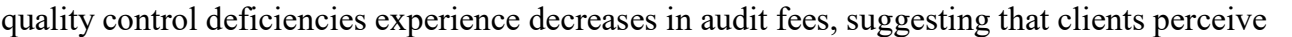

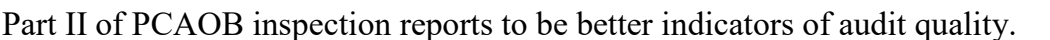

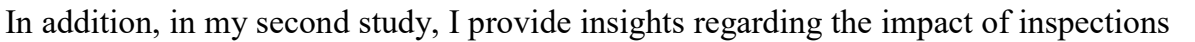

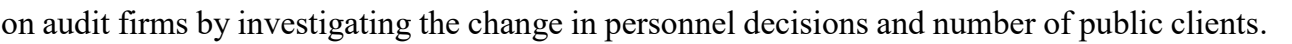

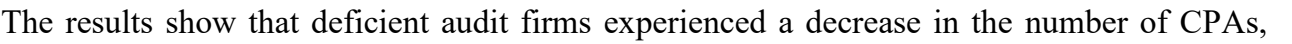

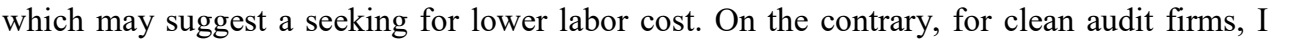

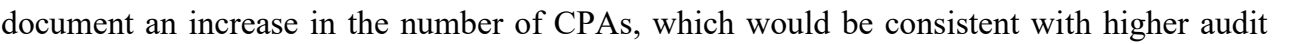

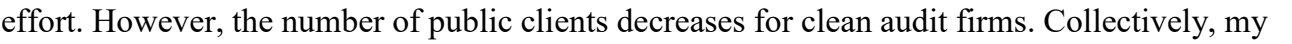

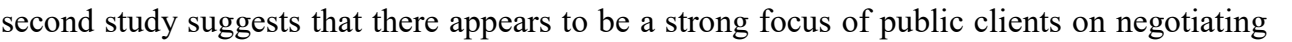

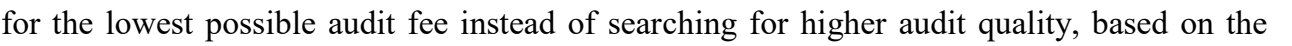

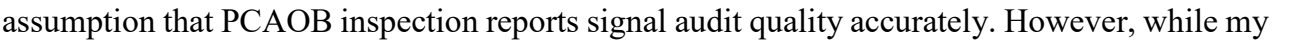

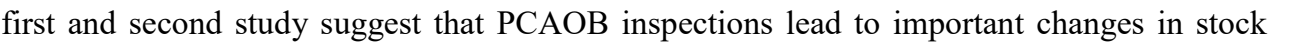

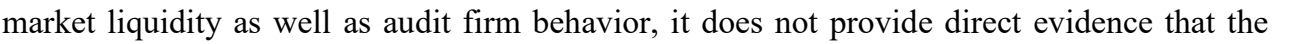

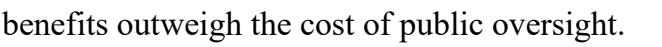

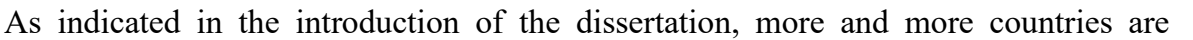
प

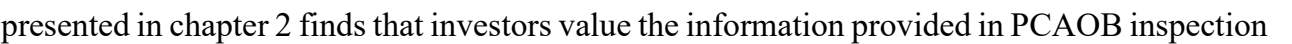

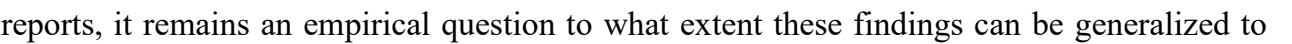

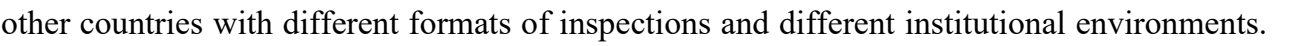

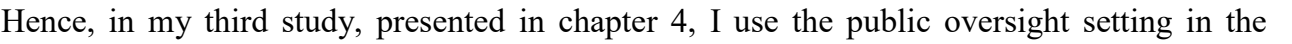

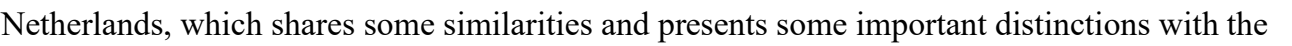

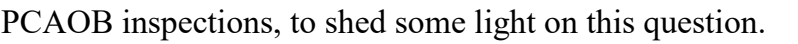

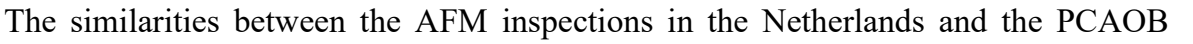

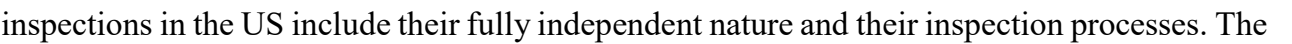

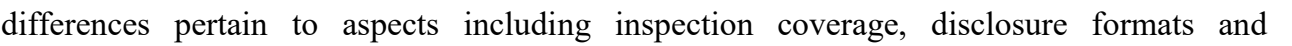

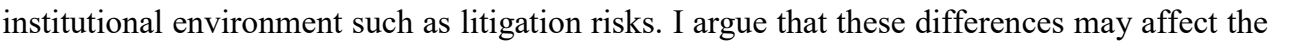
impact of inspection findings on investors' perceived audit quality. In my third study, I find

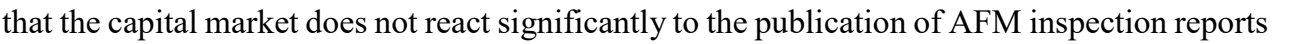
प

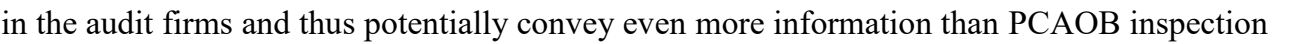

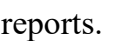

$\square$

\subsection{Contributions and future research}

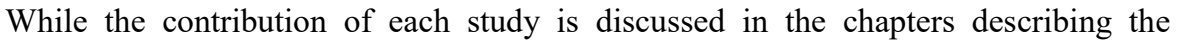

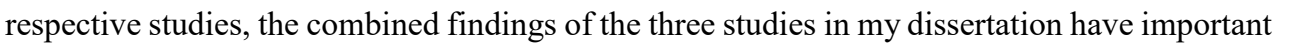

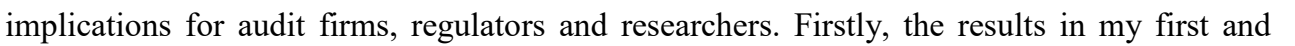

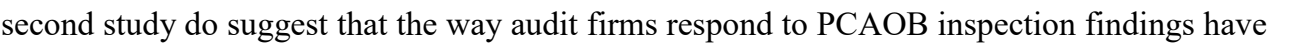

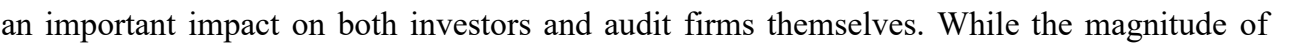

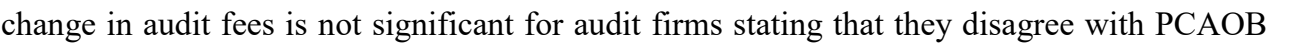

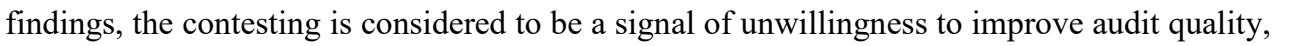




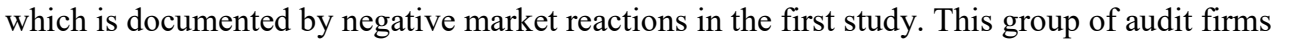

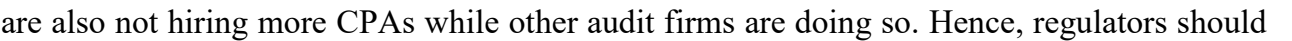

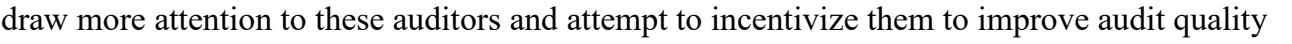

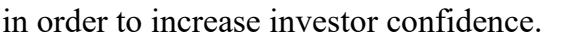

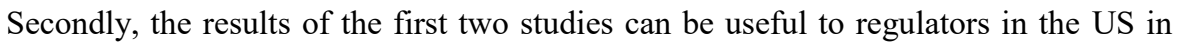

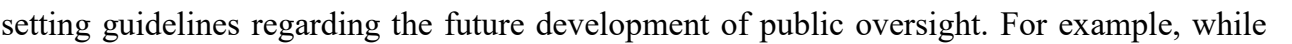

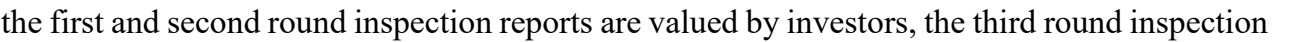

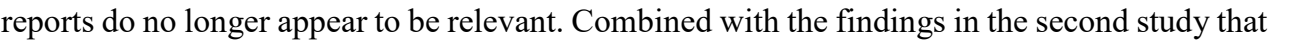

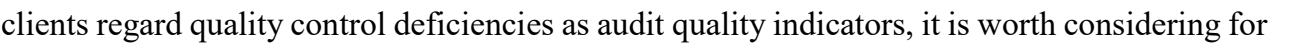

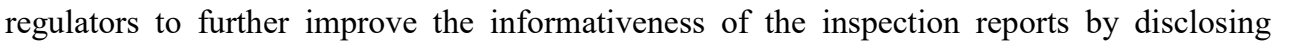

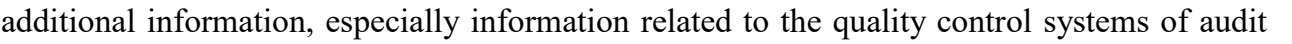

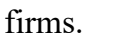

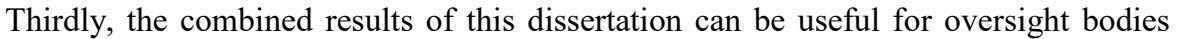

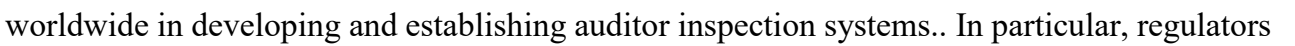

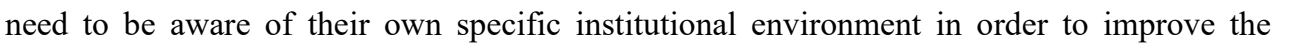

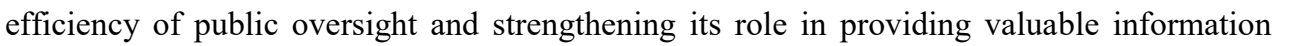
एण

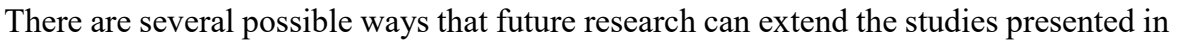

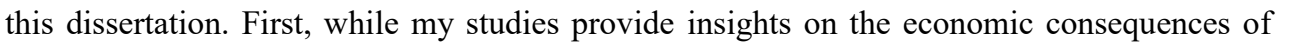

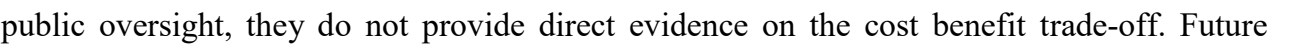

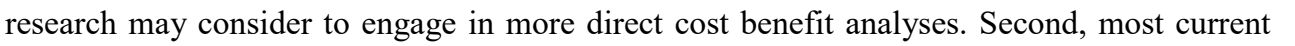

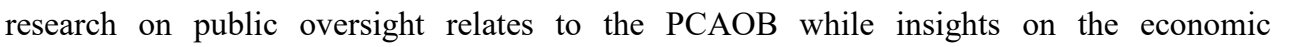

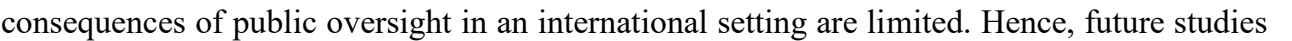

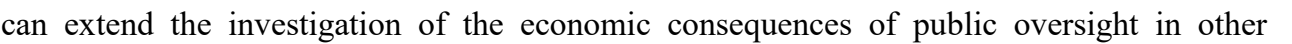

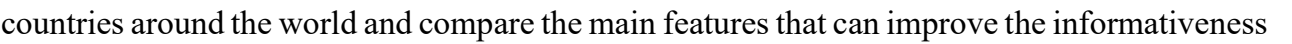

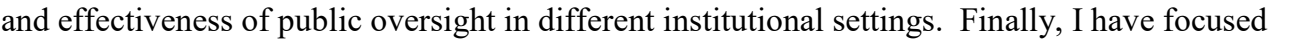

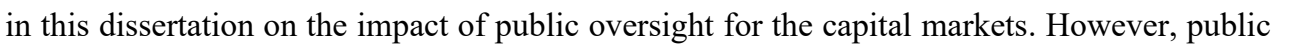

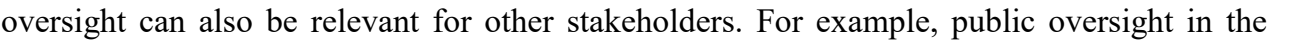

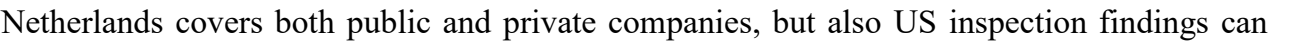

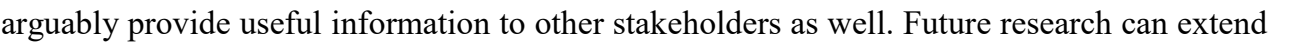

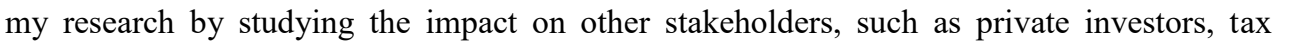

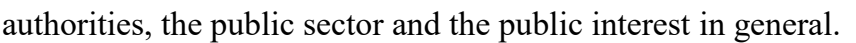




\section{References}

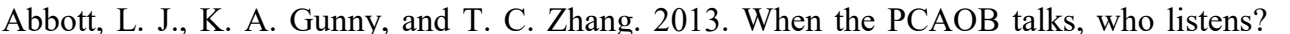

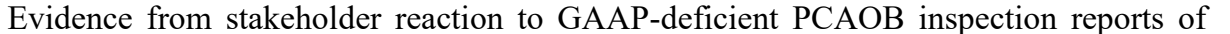

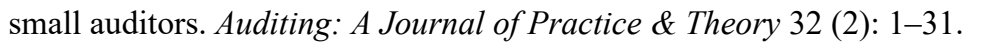

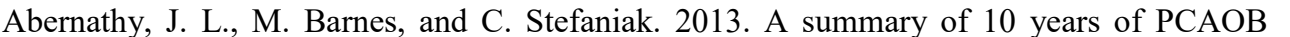

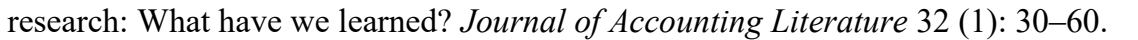

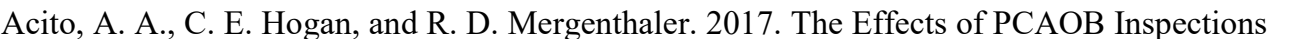

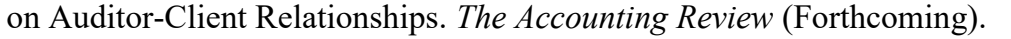

AFM. 2010. Report on general findings regarding audit quality and quality monitoring 1 (September). $\square$

2014. Results of the Inspection of the Quality of Statutory audits at the Big 4 Audit Firms (September): 1-121.

Akerlof, G. A. 1970. The Market for "Lemons": Quality Uncertainty and the Market

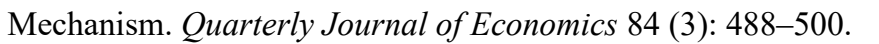

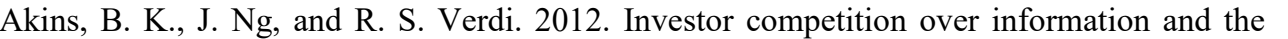

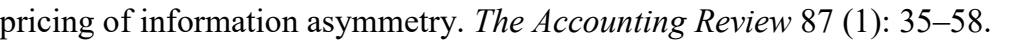

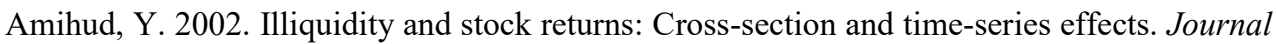
of Financial Markets $\square \square \square \square \square-\square \square$

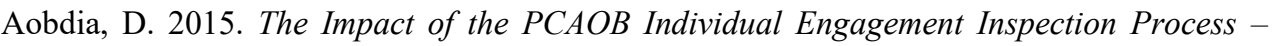

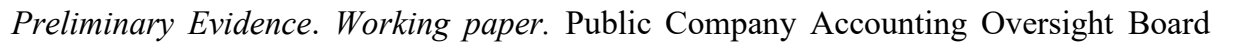

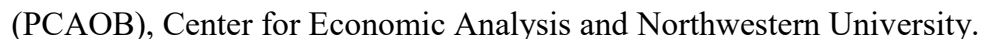

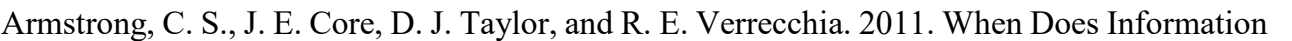

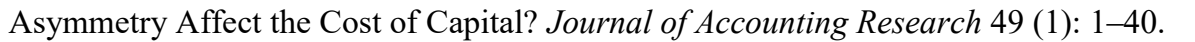

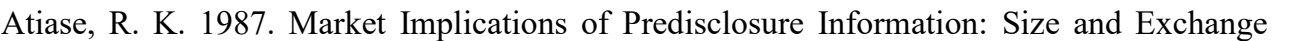

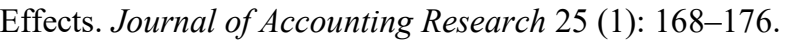

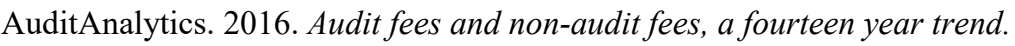

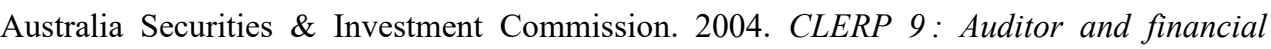
reporting obligations $\square$

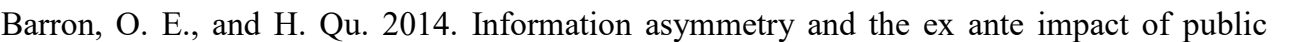

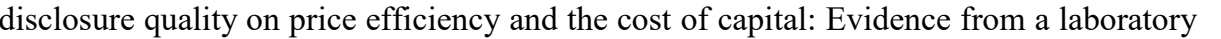

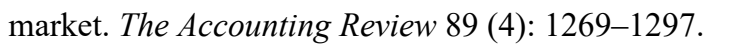

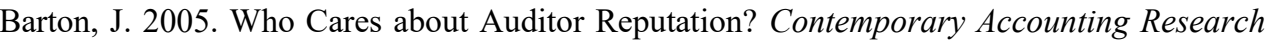

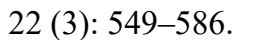

Bell, T. B., W. R. Landsman, and D. a Shackelford. 2001. Auditors' Perceived Business Risk and Audit Fees : Analysis and Evidence. Journal of Accounting Research $\square$

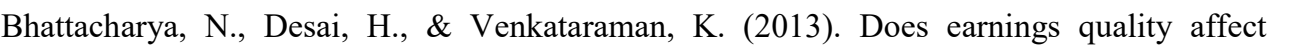

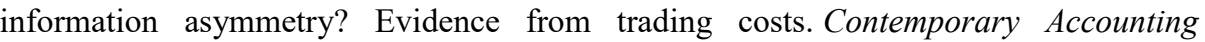
Research, पाणाणाणाणाणा

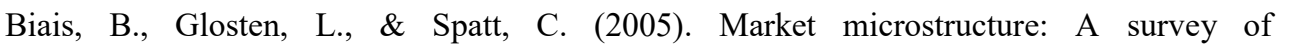

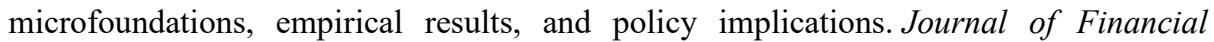

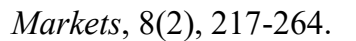

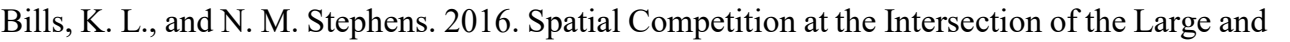

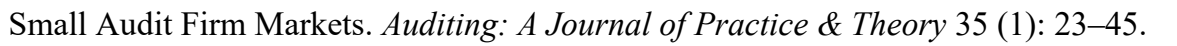


Boone, J. P., I. K. Khurana, and K. K. Raman. 2015. Did the 2007 PCAOB Disciplinary Order against Deloitte Impose Actual Costs on the Firm or Improve Its Audit Quality? The Accounting Review 90 (2): 405-441.

Brown, S. J., and J. B. Warner. 1985. Using Daily Stock Returns. Journal of Financial Economics 14 (1): 3-31. $\square$

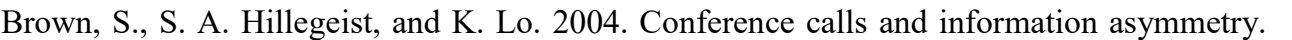

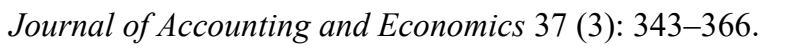

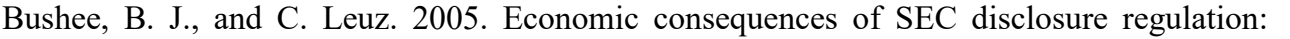

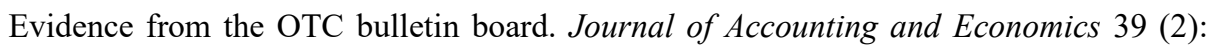
$\square-\square \square \square$

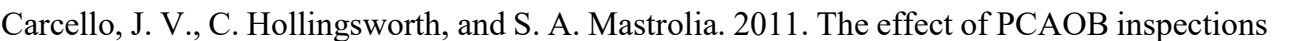

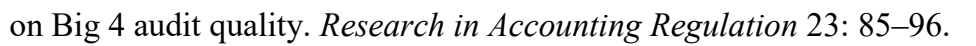

Carson, Simnett, Thürheimer and Vanstraelen. 2017. The effect of national inspection regimes on audit quality. Working paper, UNSW Sydney and Maastricht University.

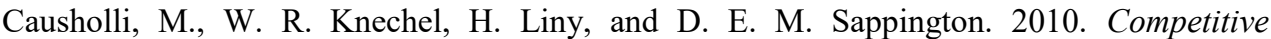
Procurement of a Credence Good: The Case of Auditing $\square$ Working paper. University of Kentucky, University of Florida and University of Houston $\square$

Chaney, P. K., and K. L. Philipich. 2002. Shredded reputation: The cost of audit failure. Journal of Accounting Research 40 (4): 1221-1245.

Chen, C. J. P., X. Su, and R. Zhao. 2000. An Emerging Market's Reaction to Initial Modified

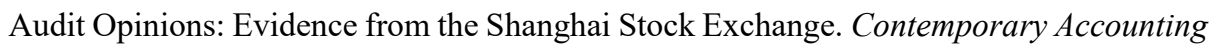

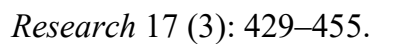

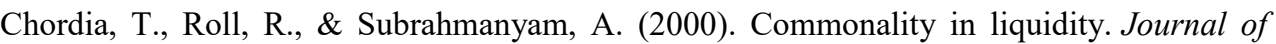

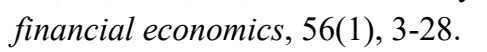

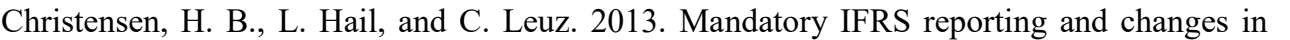

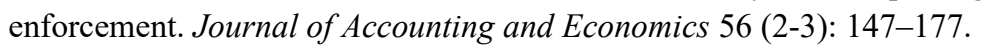

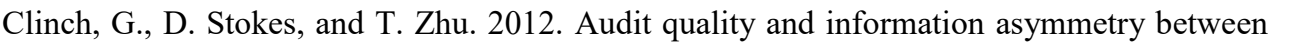

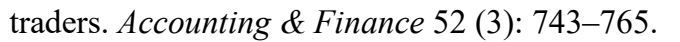

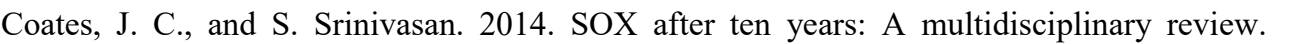

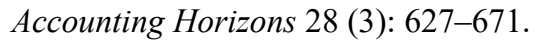

Collins, D. W., and S. P. Kothari. 1989. An analysis of intertemporal and cross-sectional determinants of earnings response coefficients. Journal of Accounting and Economics 11 (2-3): 143-181.

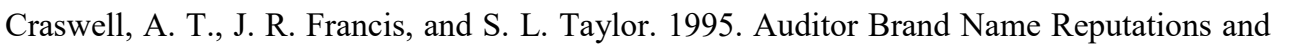

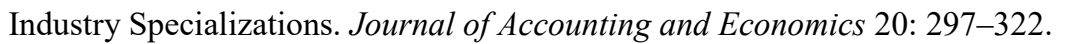

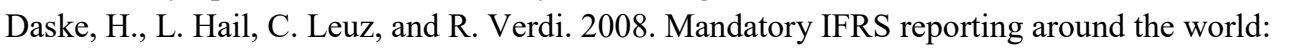

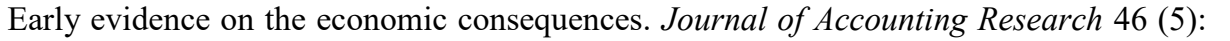
$\square \square-\square \Pi \| \square$

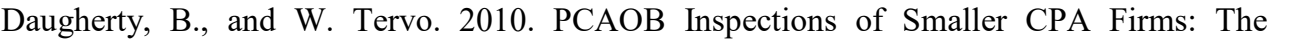

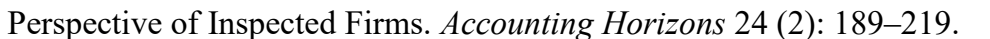

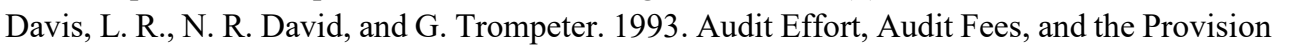

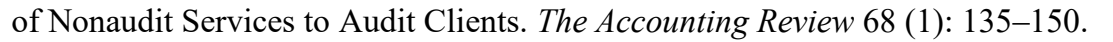

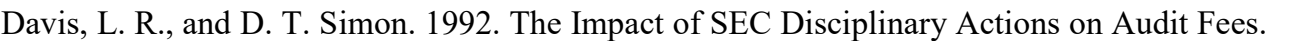
Auditing: A Journal of Practice \& Theory $\square \square \square \square \square \square-\square \square$ 
DeAngelo, L. E. 1981. Auditor size and audit quality. Journal of Accounting and Economics 3 (3): 183-199.

Dee, C. C., A. Lulseged, and T. Zhang. 2011. Client Stock Market Reaction to PCAOB Sanctions Against a Big 4 Auditor. Contemporary Accounting Research 28 (1): 263-291.

DeFond, M. L. 2010. How should the auditors be audited? Comparing the PCAOB Inspections with the AICPA Peer Reviews. Journal of Accounting and Economics 49 (1-2): 104-108.

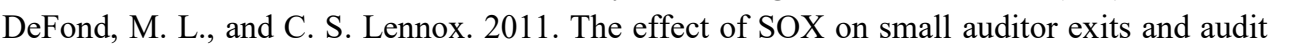
$\square \square \| \square \square$ Journal of Accounting and Economics $\square \square \square \square \square-\square \square$

DeFond, M. L., and C. S. Lennox. 2017. Do PCAOB Inspections Improve the Quality of Internal Control Audits? Journal of Accounting Research 55 (3): 591-627

DeFond, M. L., R. N. Hann, H. U. Xuesong, and E. Engel. 2005. Does the market value financial expertise on audit committees of boards of directors? Journal of Accounting Research 43 (2): 153-204.

De Fuentes, C., M. Illueca, and M. C. Pucheta-Martinez. 2015. External investigations and disciplinary sanctions against auditors: the impact on audit quality. SERIES 6 (3): 313347.

Dowling, C., W. R. Knechel, and R. Moroney. 2015. Public Oversight of Audit Firms: The Slippery-Slope of Enforcing Regulation.

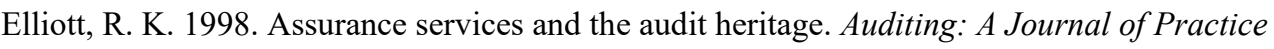

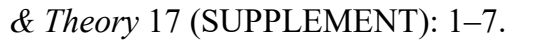

European Commission. 2017. Report from the commission to the council, the European cental bank, the European systemic risk risk board and the European Parliament.

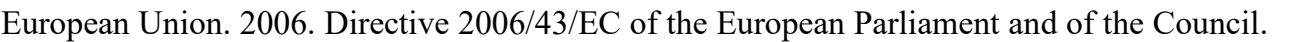

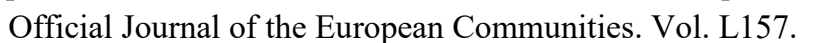

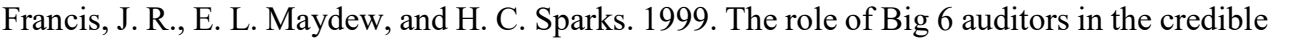

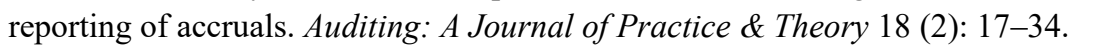

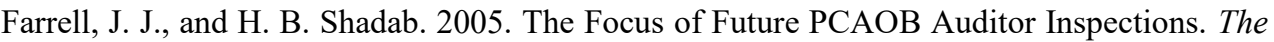
CPA Journal $\square \square\|1\| \square$

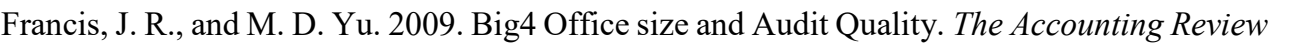

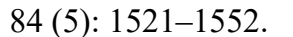

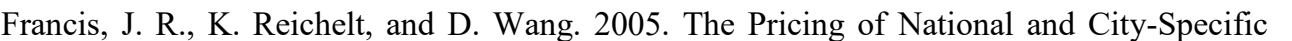

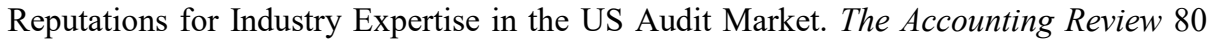

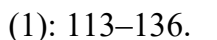

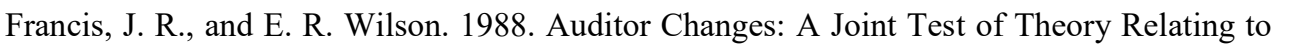

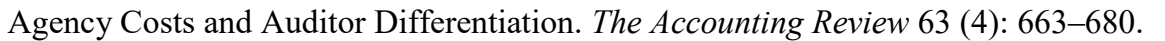

Freeman, R. N. 1987. The association between accounting earnings and security returns for large and small firms. Journal of Accounting and Economics 9 (2): 195-228.

Fu, R., A. Kraft, and H. Zhang. 2012. Discussion of "Financial reporting frequency, information asymmetry, and the cost of equity." Journal of Accounting and Economics $\square$ $\square \square \square-\square \square \square$

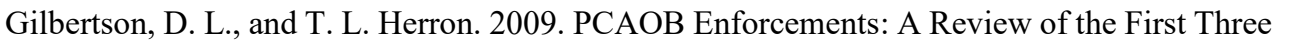

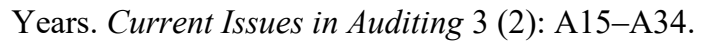

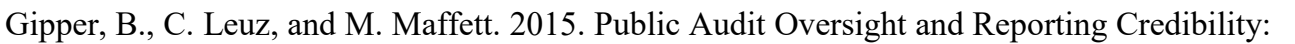

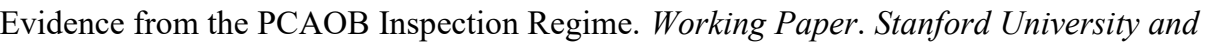


University of Chicago

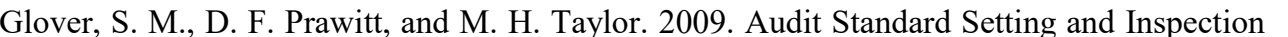

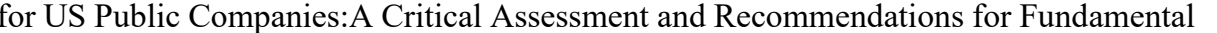

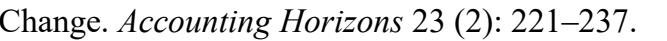

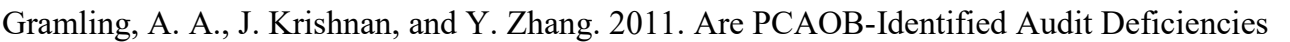

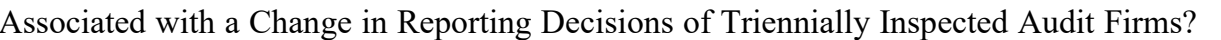

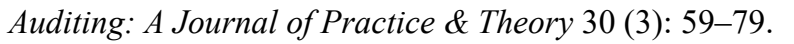

Gul, F. A., G. S. Zhou, and X. K. Zhu. 2013. Investor protection, firm informational problems, big $\mathrm{n}$ auditors, and cost of debt around the world. Auditing: A Journal of Practice \& Theory 32 (3): 1-30. $\square$

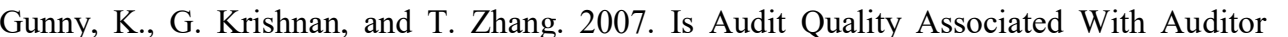

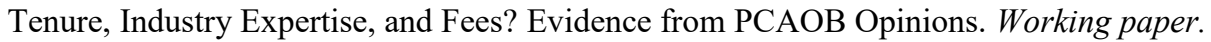
University of Colorado, George Mason University and Singapore Management University $\square$

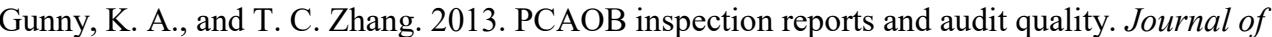

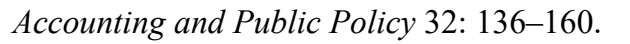

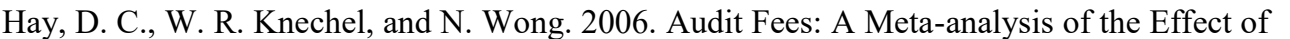

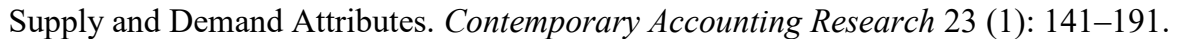

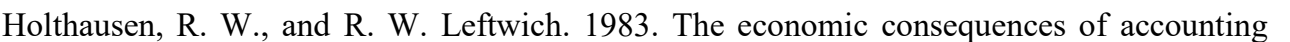

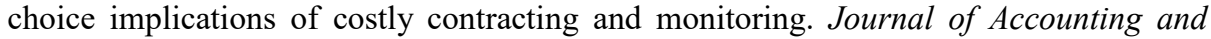

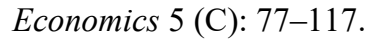

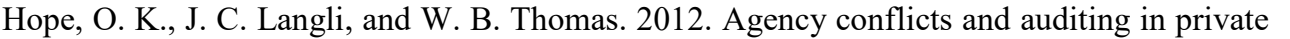

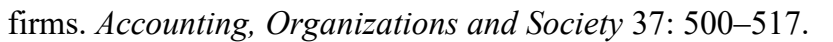

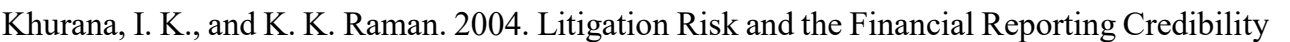

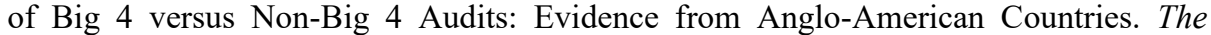

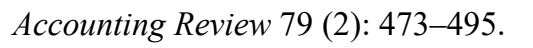

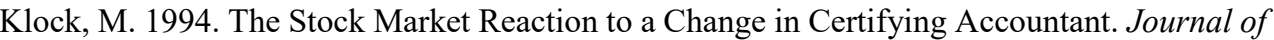

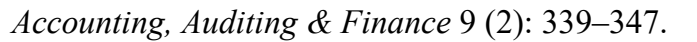

Knechel, W. R., V. Naiker, and G. Pacheco. 2007. Does Auditor Industry Specialization Matter? Evidence from Market Reaction to Auditor Switches. Auditing: A Journal of Practice \& Theory 26 (1): 19-45.

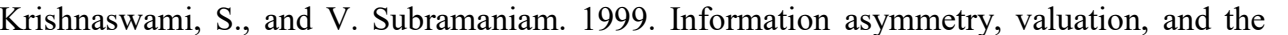

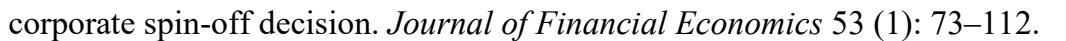

Krishnamurthy, S., J. Zhou, and N. Zhou. 2006. Auditor Reputation, Auditor Independence, and the Stock-Market Impact of Andersen's Indictment on Its Client Firms. Contemporary Accounting Research 23 (2): 465-490.

Lamoreaux, P. T. 2016. Does PCAOB inspection access improve audit quality? An examination of foreign firms listed in the United States. Journal of Accounting and Economics 61 (23): $313-337$.

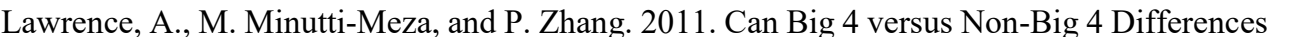
$\mathrm{m}$
$\mathrm{C}$

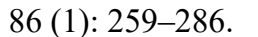

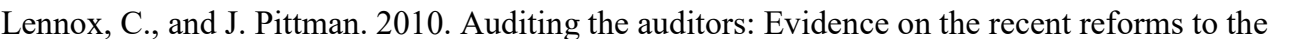

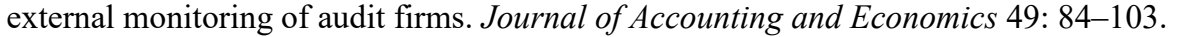




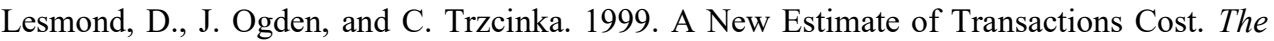

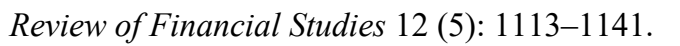

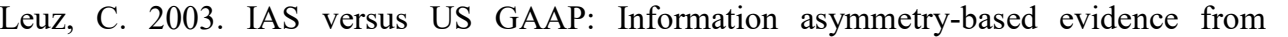

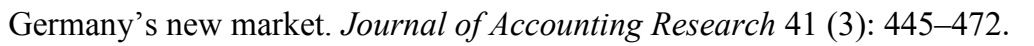

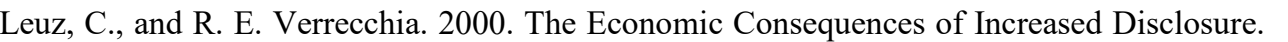

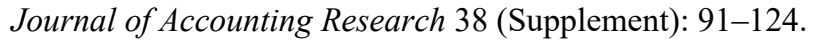

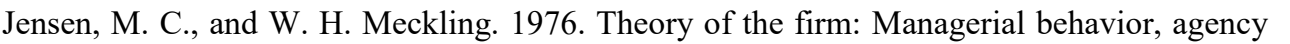

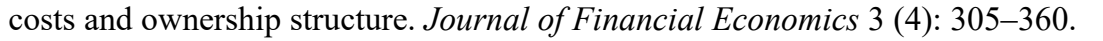

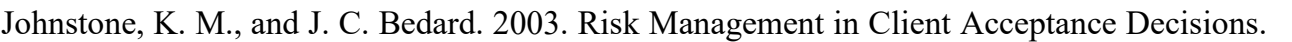

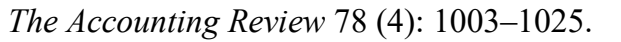

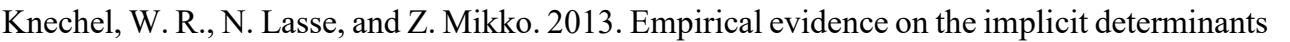

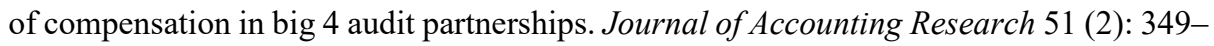
$\square 10$

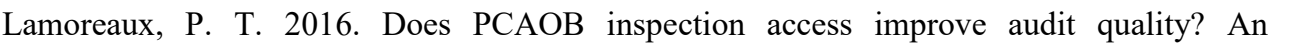

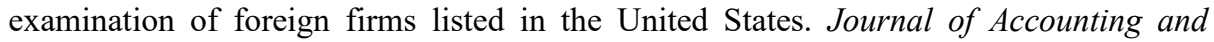

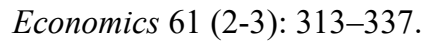

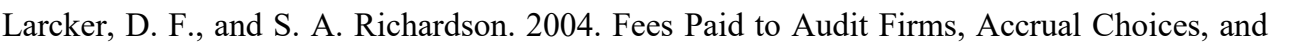

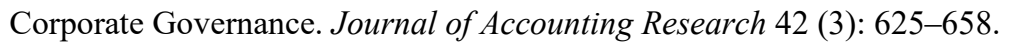

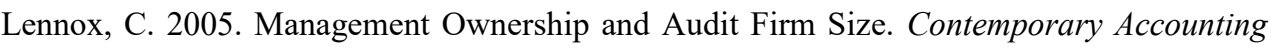

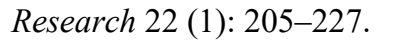

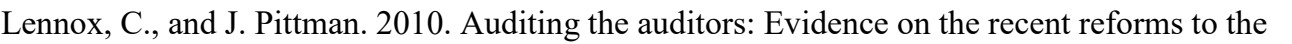

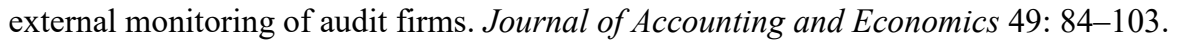

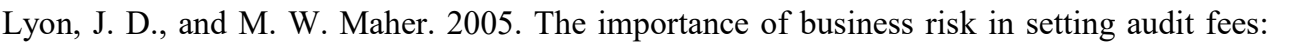

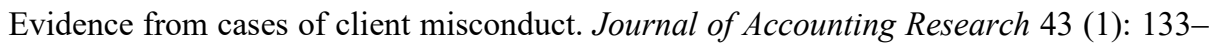
$\square \square \square$

Maijoor, S., and A. Vanstraelen. 2012. "Research opportunities in auditing in the EU,"

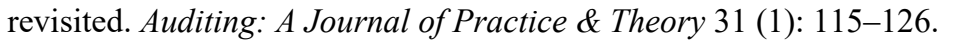

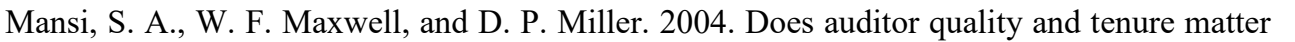

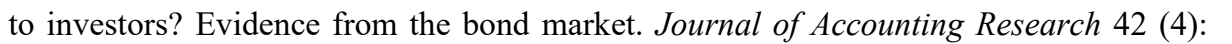
$\square+\square 1 \square$

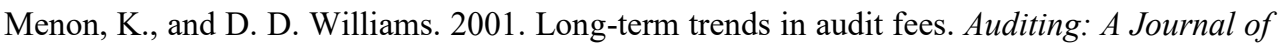

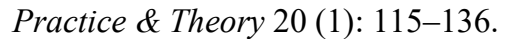

Minnis, M. 2011. The Value of Financial Statement Verification in Debt Financing: Evidence from Private US Firms. Journal of Accounting Research 49 (2): 457-506.

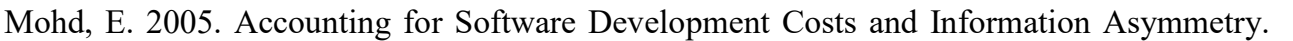

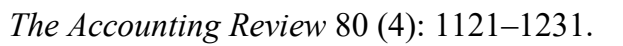

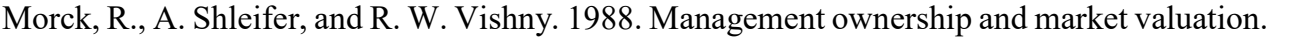

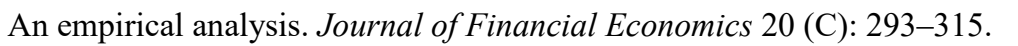

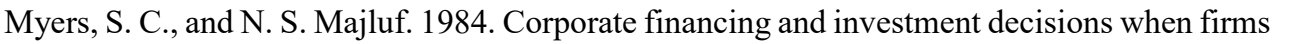

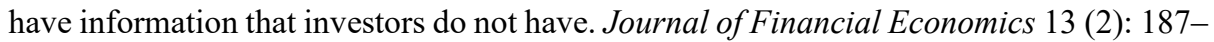
$\square \square \square$

Nelson, M. W. 2006. Ameliorating Conflicts of Interest in Auditing: Effects of Recent

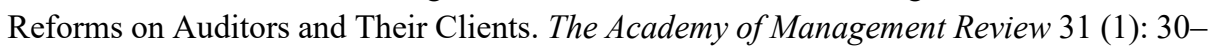
पाI 
Offermanns, M., and E. Peek. 2011. Investor Reactions to PCAOB Inspection Reports. working papers. Maastricht University. $\square$

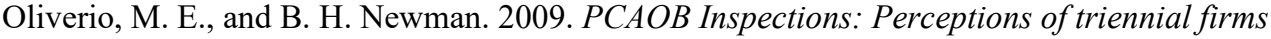
with no-deficiency inspections $\square$ Working paper. Pace University $\square$

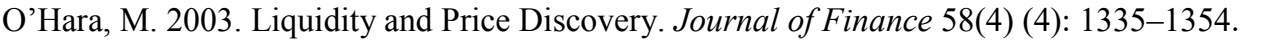

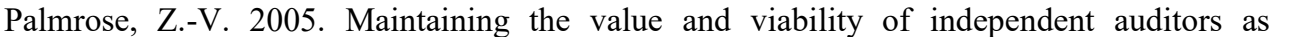

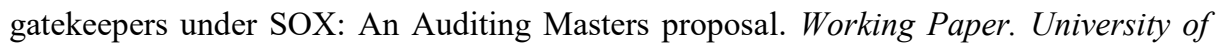
Southern California $\square$

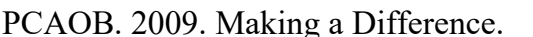

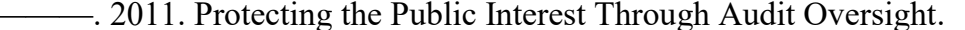

Pittman, J. A., and S. Fortin. 2004. Auditor choice and the cost of debt capital for newly public firms. Journal of Accounting and Economics 37 (1): 113-136.

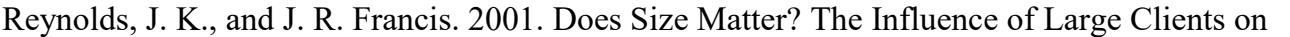

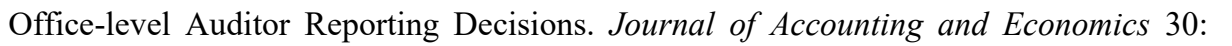
$\square+\square \square \square$

Ross, S. a. 1973. American Economic Association The Economic Theory of Agency: The

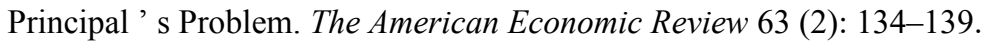

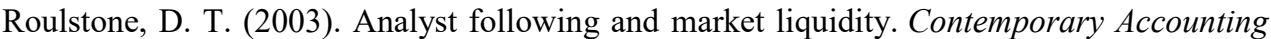

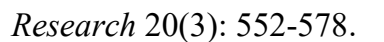

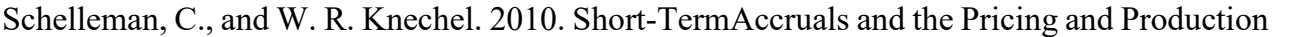

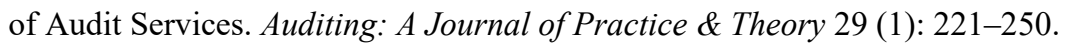

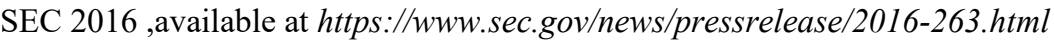

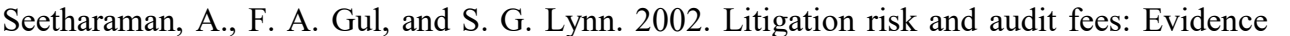

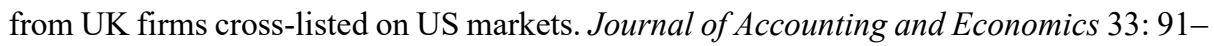
$\square \square \square$

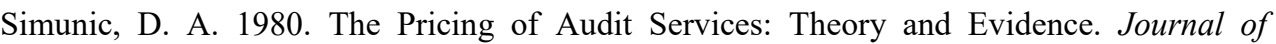

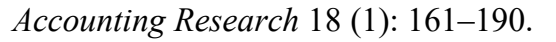

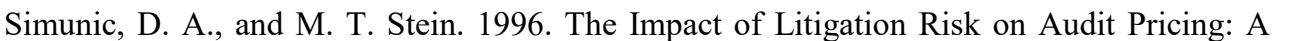

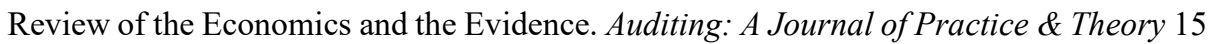
पामाणम-पाए

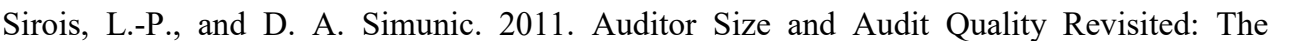

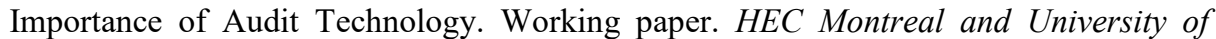
British Columbia $\square$

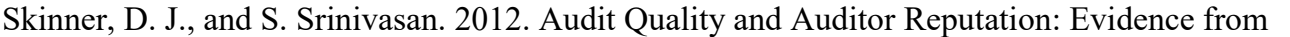

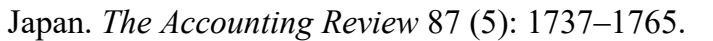

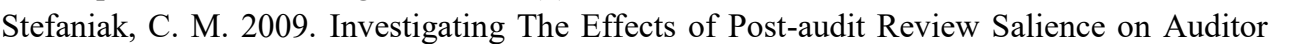

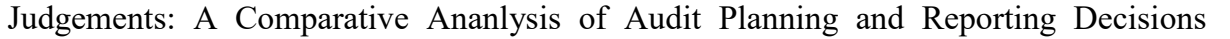

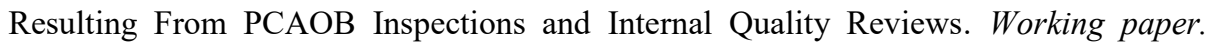
University of Alabama $\square$

Van Opijnen, M. 2016. Empirical Studies on Public Oversight,Working paper, Maastricht University. $\square$

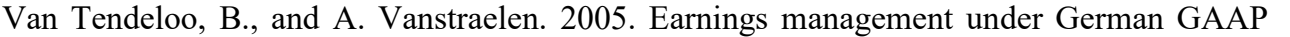

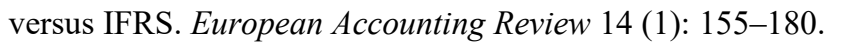

Vanstraelen, A., P. Vorst, and L. Zou. 2017. Economic Consequences of PCAOB Inspections : 
Impact on stock market liquidity over Time. Maastricht University.

Willenborg, M. 1999. Empirical Analysis of the Economic Demand for Auditing in the Initial Public Offerings Market. Journal of Accounting Research 37 (1): 225-238.

World Federation of Exchanges. 2016. Latest Statistics. In http://www.worldexchanges.org/statistics/ytd $\square$

Zhou, H. 2007. Auditing standards, increased accounting disclosure, and information asymmetry: Evidence from an emerging market. Journal of Accounting and Public Policy 26 (5): 584-620. 
Appendix 1: Variable definitions for Chapter2

Deficient equal to 1 for audit firms receiving PCAOB inspection reports with GAASrelated or GAAP-related deficiencies.

Disagree $\square \quad$ equal to1 for audit firms who state that they disagree or do not fully agree with the PCAOB findings.

Bid-ask spread $\square$ the yearly median quoted spread (i.e., difference between the bid and ask price divided by the midpoint and measured at the end of each trading day).

Price impact $\square \quad$ the yearly median of the Amihud (2002) illiquidity measure (i.e., daily absolute stock return divided by US\$ trading volume).

Zero Returns $\square \quad$ the proportion of trading days with zero daily stock returns out of all potential trading days in a given year.

Total trading a yearly estimate of total round-trip transaction costs (i.e., bid-ask spreads, costs $\square$ commissions, as well as implicit costs such as short-sale constraints or taxes) inferred from the series of daily security and aggregate market returns, as developed by Lesmond, Ogden, and Trzcinka (1999).

Post1(2/3) $\square \quad$ equal to 1 for observations belongs to the one year period after the publication of the first (second/third) round of inspection reports.

Def_disagree equal to 1 if the observation has a deficient auditor who disagreed with the inspection findings after the publication of the inspection report, zero otherwise.

Def_other equal to 1 if the observation has a deficient auditor who did not disagree with the inspection findings after the publication of the inspection report, zero otherwise.

Clean equal to 1 if the observation has a clean auditor after the publication of each round's inspection report, zero otherwise.

Size the yearly average of daily stock price times the number of shares outstanding (in US\$ millions).

ShareTurnover the annual US\$ trading volume divided by market value of outstanding equity. $\square$

Volatility the annual standard deviation of daily stock returns.

Analyst the number of analyst following the company in a given year. $\square$

Inst_holding the yearly average of number of shares hold by the institutional investors divided by the number of shares outstanding.

Def1 equal to 1 for audit firms receiving PCAOB inspection reports with GAASrelated or GAAP-related deficiency in the first inspection round. 
Def2 equal to 1 for audit firms receiving PCAOB inspection reports with GAASrelated or GAAP-related deficiency in the second inspection round.

Period1(2/3) equal to 1 if the observation belongs to the period after the publication date of the first (second/third) round inspection reports and before the publication of the second (third/one year period after the publication of the third) round inspection reports, zero otherwise.

Def1(2/3)_disag equal to 1 if the observation has a deficient auditor who disagreed with the ree inspection findings for the first (second/third) round of inspection and belongs to the period after the publication of the first (second/third) round inspection results and before the publication of the second (third/one year period after the publication of the third round of inspection reports) round of inspection reports, zero otherwise.

Def1(2/3)_other equal to 1 if the observation has a deficient auditor who did not disagree with the inspection findings for the first (second/third) round of inspections and belongs to the period after the publication of the first (second/third) round inspection results and before the publication of the second (third/one year period after the publication of the third round of inspection reports) round of inspection reports, zero otherwise.

Clean1/2/3 equal to 1 if the observation has a clean auditor for the first (second/third) round of inspection and belongs to the period after the publication of the first (second/third) round inspection results and before the publication of the second (third/one year period after the publication of the third round of inspection reports) round of inspection reports, zero otherwise.

Days the number of days between the publication of the current round and the next round inspection reports.

Period1(2/3) equal to1 if the observation belongs to the period after the publication of annual the first (second/third) inspection report and before the publication of the second (third/fourth) inspection report, zero otherwise. 


\section{Appendix 2: Variable definitions for Chapter3}

\begin{tabular}{|c|c|}
\hline AUDITFEE $\square$ & $\begin{array}{l}\text { Amount of audit fees paid by the client for the audit in the } \\
\text { particular financial year, measured in US dollars. }\end{array}$ \\
\hline ASSETS $\square$ & Total assets of the client firm, measured in US dollars. $\square$ \\
\hline INVERE $\square$ & $\begin{array}{l}\text { Sum of inventory and receivables of the client divided by total } \\
\text { assets. } \square\end{array}$ \\
\hline$R O A \square$ & Net income divided by total assets. $\square$ \\
\hline$L O S S \square$ & Indicator equal to one when net income is below zero. $\square$ \\
\hline OPINION $\square$ & Indicator equal to one when a going concern opinion was issued. \\
\hline$B U S Y \square$ & $\begin{array}{l}\text { Indicator equal to one when the financial year-end is in } \\
\text { December. }\end{array}$ \\
\hline FOREIGN $\square$ & Indicator equal to one when the client reports foreign income. $\square$ \\
\hline SEGMENT & Number of business segments of the company. $\square$ \\
\hline SHORT & Indicator equals to one for first year engagement as anew client. $\square$ \\
\hline TOTAL_FEE & Total audit fee collected by the auditor in a year. $\square$ \\
\hline$A V G \_A S S E T$ & Average client total assets of the audit firm. $\square$ \\
\hline DISAGREE & 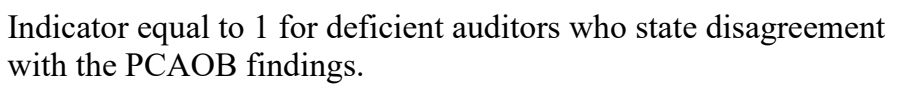 \\
\hline OTHER & 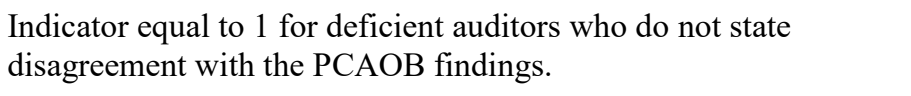 \\
\hline CLEAN & 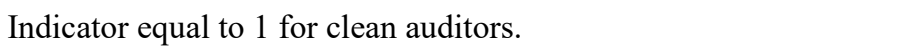 \\
\hline$Q C D \_D$ & 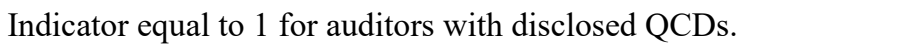 \\
\hline$Q C D \_N D$ & 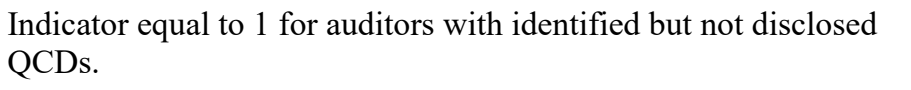 \\
\hline$N O N-Q C D$ & 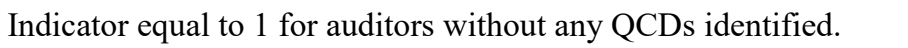 \\
\hline POST & 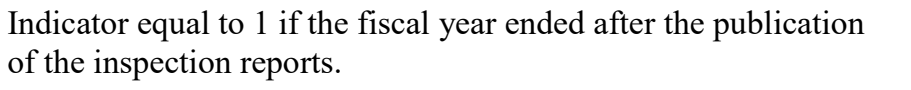 \\
\hline FIRST_DEF & 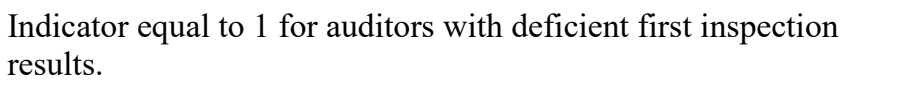 \\
\hline SECOND_DEI & 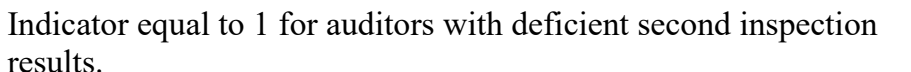 \\
\hline
\end{tabular}


FIRST-QCD

$S E C O N D-Q C D$

LOGNCPAS

LOGNCLIENTS

Period1

Period2

Period3

Period3

(2)

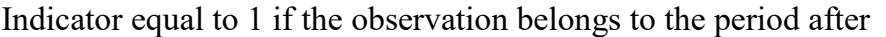

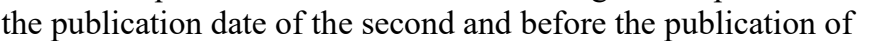

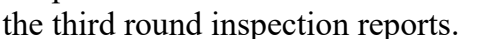

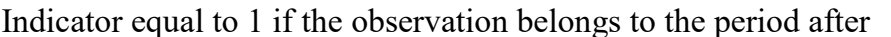

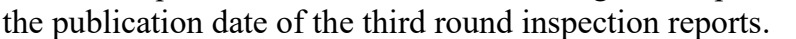




\section{Appendix 3: Variable definitions for Chapter4}

\begin{tabular}{|c|c|}
\hline$R_{i t}$ & Return for client $\mathrm{i}$ on day $\mathrm{t}$. \\
\hline$R_{m t}$ & AEX market index on day t. $\square$ \\
\hline$A R_{i t}$ & Abnormal return for client $\mathrm{i}$ on day $\mathrm{t} . \square$ \\
\hline$C A R_{i t}$ & Cumulative abnormal return for client $\mathrm{i}$ on day $\mathrm{t} . \square$ \\
\hline$C A A R_{i}$ & Cumulative average abnormal return for on day $\mathrm{t}$ for all clients. $\square$ \\
\hline$D T \square$ & Indicator equal to one if the client is audited by DT. $\square$ \\
\hline$E Y \square$ & Indicator equal to one if the client is audited by EY. $\square$ \\
\hline$P W C \square$ & Indicator equal to one if the client is audited by PWC. $\square$ \\
\hline$L E V_{i t}$ & $\begin{array}{l}\text { The client company's leverage ratio in the year before the events, } \\
\text { calculated as the total debt divided by total assets. }\end{array}$ \\
\hline GROWTH $H_{i t}$ & The growth in revenues in the year prior to the events. $\square$ \\
\hline Cost of debt $t_{i, t+1}$ & $\begin{array}{l}\text { The interest paid in year } t+1 \text { divided by the average total debt in } \\
\text { year } t+1 \text { and year } t .\end{array}$ \\
\hline$P O S T_{i, t+1}$ & $\begin{array}{l}\text { Equals } 1 \text { for financial year ends after the publication of } \\
\text { inspection results, } 0 \text { otherwise. }\end{array}$ \\
\hline InterestCoverage $e_{t}$ & 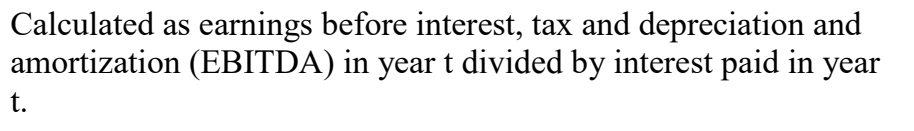 \\
\hline CurrentRatio $_{i, t}$ & 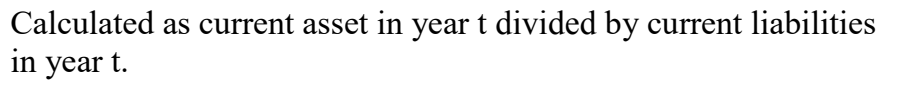 \\
\hline$P P E_{i, t}$ & 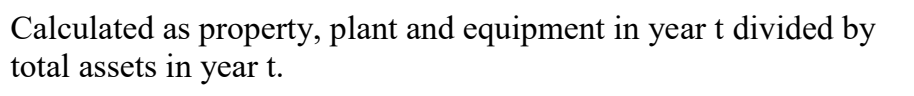 \\
\hline$L E V_{i, t}$ & 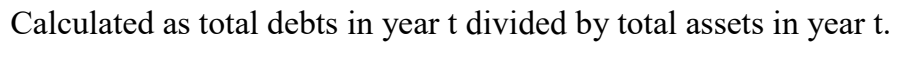 \\
\hline$A S S E T_{i, t}$ & 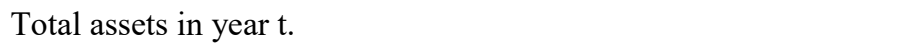 \\
\hline$G R O W T H_{i, t+1}$ & 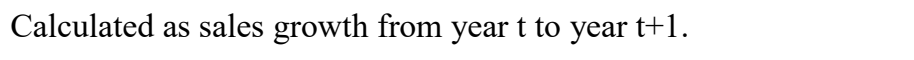 \\
\hline Neg-equity ${ }_{i, t}$ & 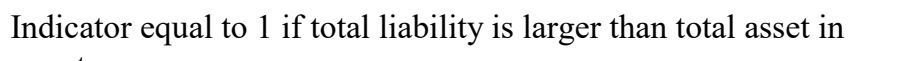 \\
\hline
\end{tabular}




\section{Appendix 4: Valorization-addendum}

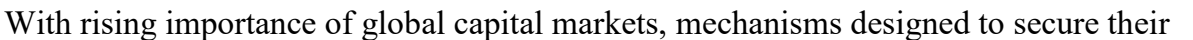

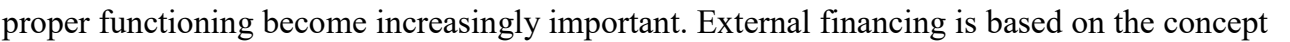

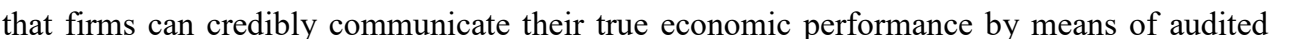

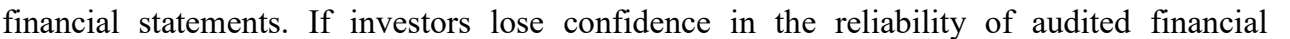
ए

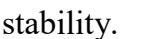

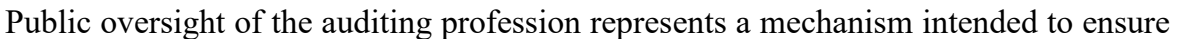

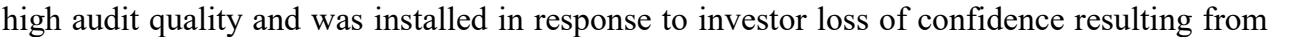

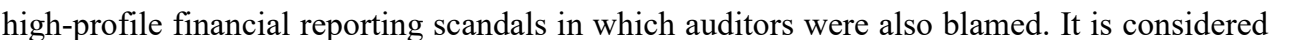

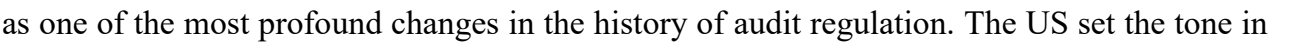

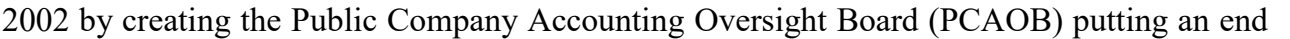

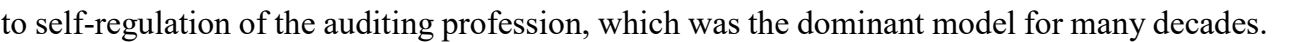

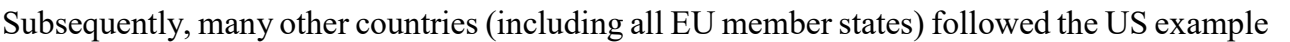

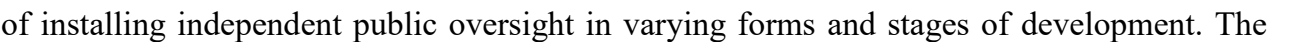

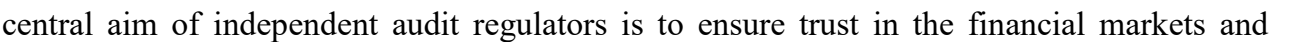

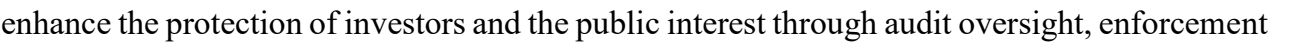

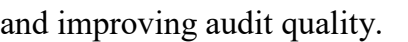

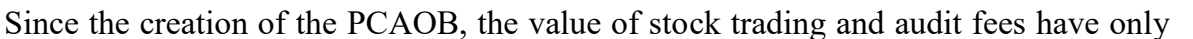

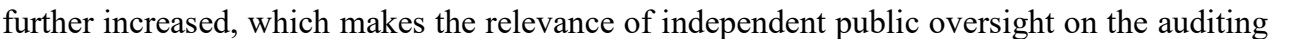

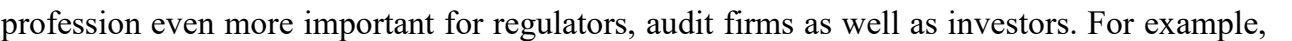

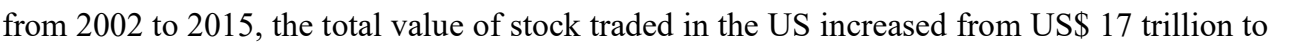

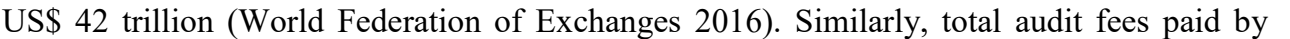

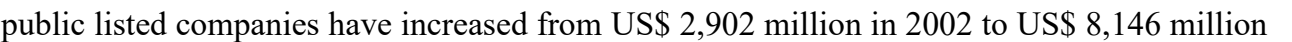

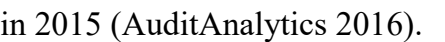

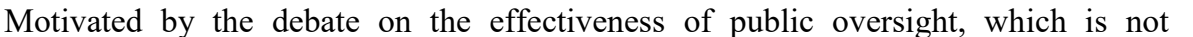

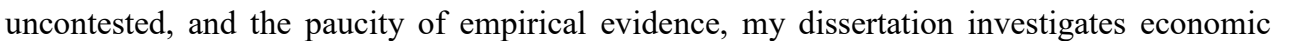

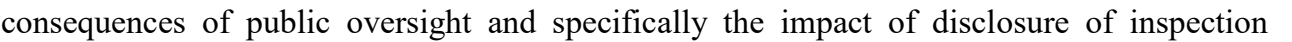

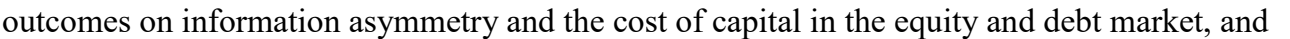

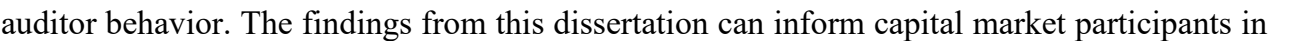

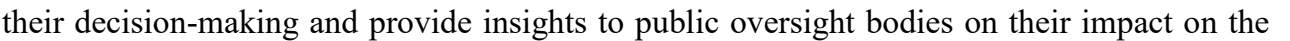

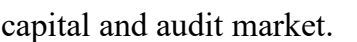

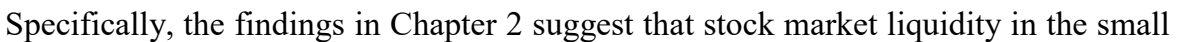

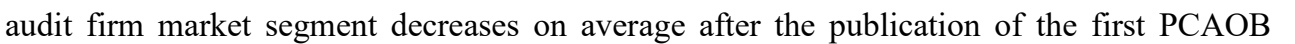

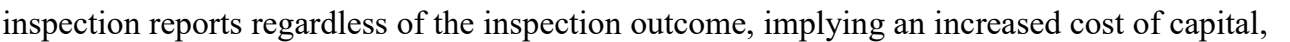

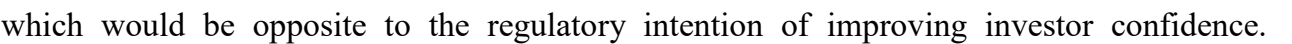

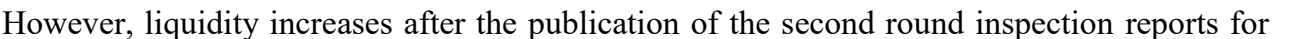
clients audited by clean auditors and deficient auditors who do not disagree with the PCAOB's

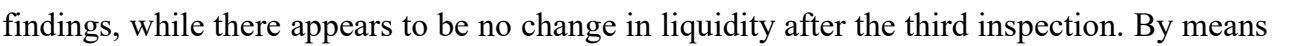

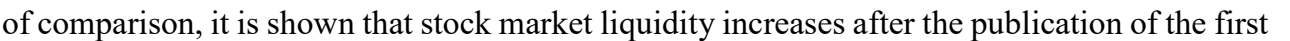




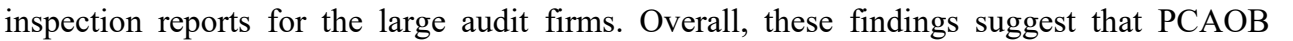
inspection reports change investors' perceptions of future audit quality and that there is a

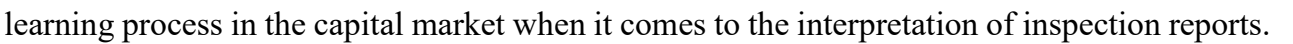

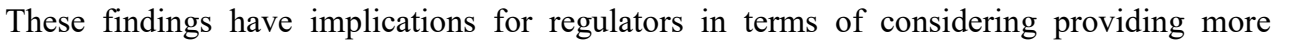

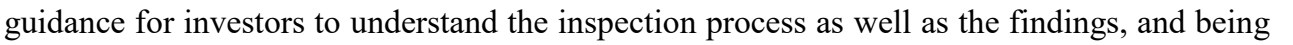

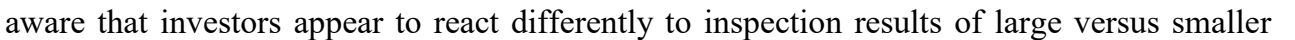

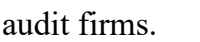

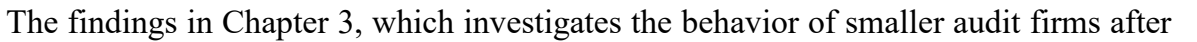

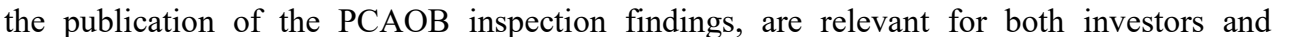
regulatory bodies. For investors, the results suggest that the audit firms' reactions to the quality

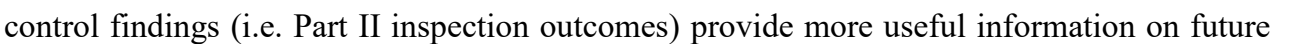

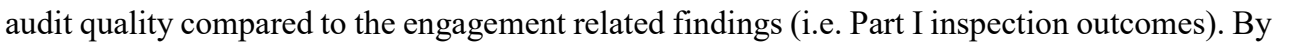

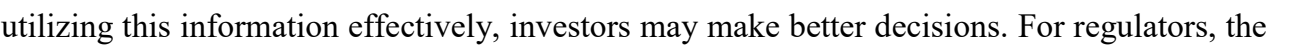

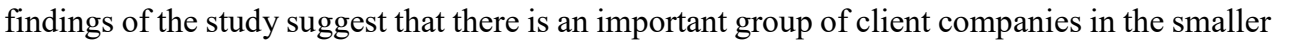

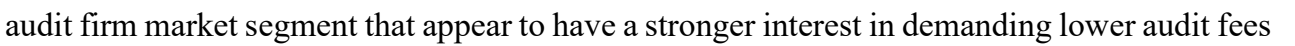
rather than audit quality. As regulators are using a "one size fits all" approach in implementing

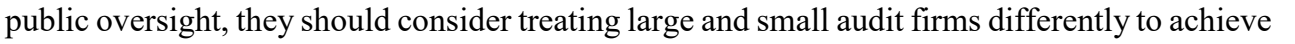

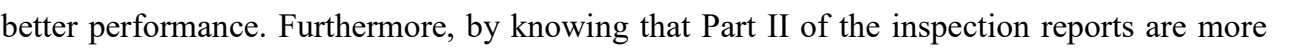
ए

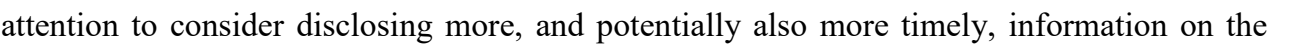

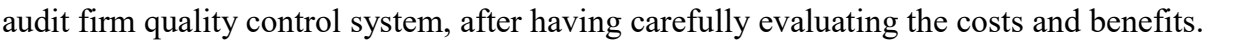

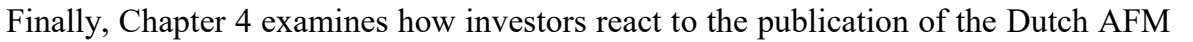

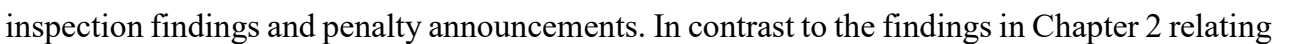

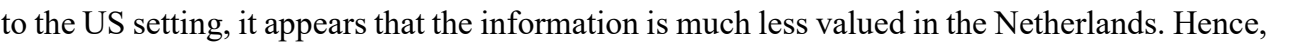
प

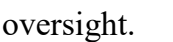

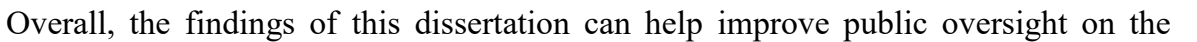

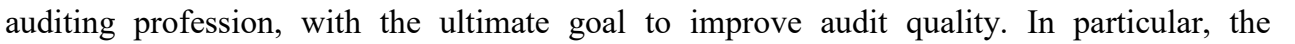

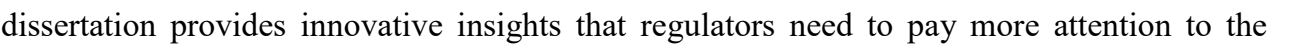

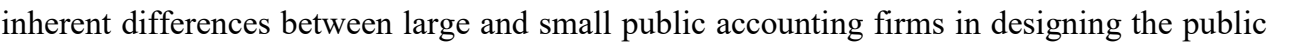

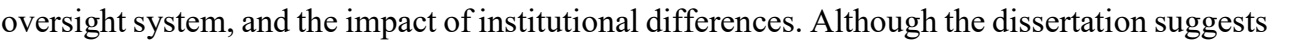

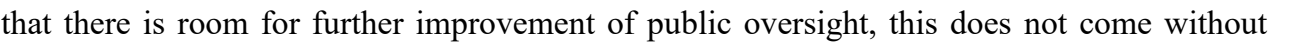

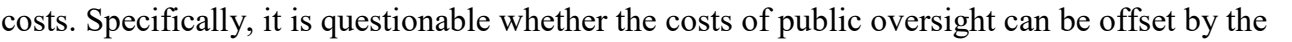

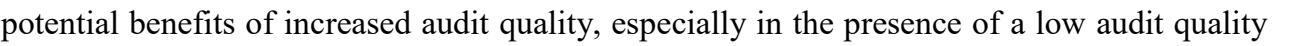

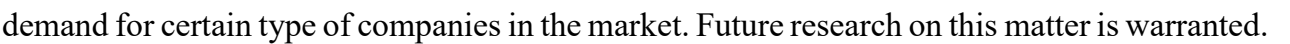




\section{Curriculum Vitae}

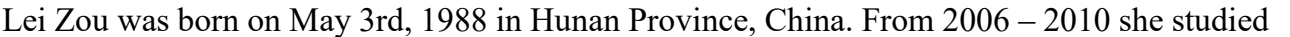

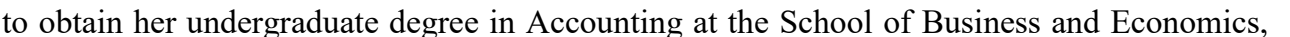

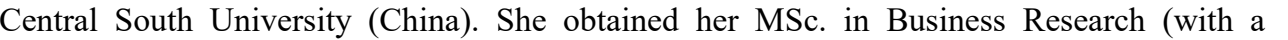

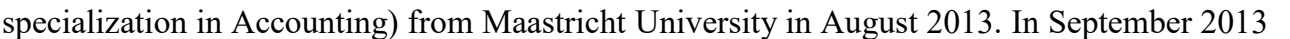

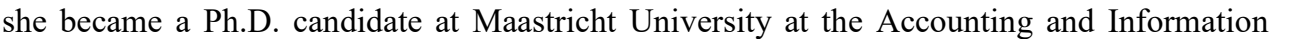

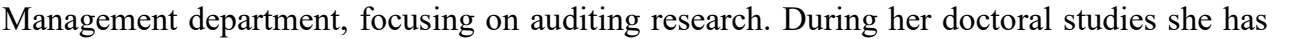

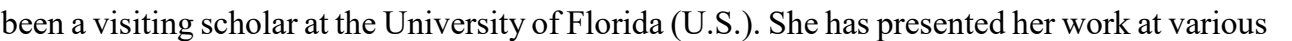

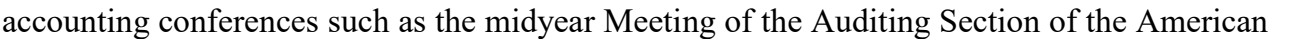

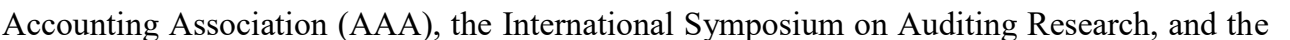

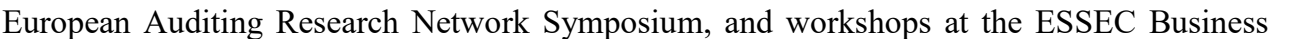

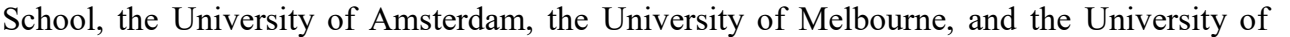

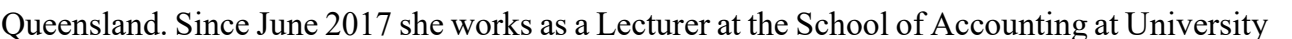

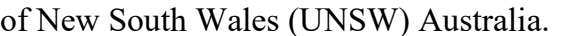

